\title{
ABSTRACTS OF WORKING PAPERS IN ECONOMICS
}

This section contains abstracts and complete bibliographic information for current working papers, listed alphabetically by primary author. Brief entries appear for secondary authors, cross-referenced to the primary author. For more recent as well as historical information, consult the AWPE DATABASE, available on magnetic media from Cambridge University Press.

(Call 212-924-3900)

\section{Abzug, Rikki}

TI Spouse Selection and Marital Instability. AU Bennett, Neil G.; Goldstein, Heidi; Abzug, Rikki.

\begin{abstract}
Ahearne, John F.
PD May 1989. TI Will Nuclear Power Recover in a Greenhouse? AA Resources for the Future. SR Resources for the Future Energy and Natural Resources Division Discussion Paper: ENR89-06; Energy and Natural Resources Division, Resources for the Future, 1616 P Street, NW., Washington, DC 20036, USA. PG 79. PR $\$ 5.00$ prepaid (U.S. funds only). JE Q42, Q43, Q48. KW Nuclear Power. Global Warming. Climate Change. Greenhouse Effect.

AB Commercial nuclear power is an important source of electricity worldwide, although the growth of nuclear power stagnated in the United States in the 1970's. Concerns about carbon dioxide emission from fossil fuel plants may lead to a reconsideration of nuclear power. The major problems in the United States which led to removing nuclear power as a choice for new generating capacity were lack of growing demand for electricity, rising costs per plant, and bad management, as well as growing public opposition. Unless these issues are recognized and addressed, greenhouse warming will not lead to nuclear power being chosen when utility executives select technologies to pursue for meeting new demands. Actions by Congress, the public. and the industry are needed.
\end{abstract}

\section{Ahmed, Shaghil}

PD January 1990. TI The Welfare Effects of Distortionary Taxation and Government Spending: Some New Results. AU Ahmed, Shaghil; Croushore, Dean D. AA Ahmed: Pennsylvania State University. Croushore; Federal Reserve Bank of Philadelphia. SR Federal Reserve Bank of Philadelphia Research Working Paper: 90-9; Working Papers, Department of Research, Federal Reserve Bank of Philadelphia, 10 Independence Mall, Philadelphia, PA 19106. PG 31. PR no charge (except overseas airmail, \$2.00; checks/money orders in U.S. funds payable to Federal Reserve Bank of Philadelphia.). JE H21, H50, E21. KW Welfare Cost. Excess Burden. Taxes. Government Spending. Taxation. AB This paper provides new calculations of the welfare effects of fiscal changes when government purchases of goods and services substitute for private consumption and act as an input into production. Using a general equilibrium model, we calculate, using U.S. data, the marginal cost of funds (MCF) for government purchases and the excess burden (EXB) from not using lump-sum taxes. The main results are; (1) The benchmark $\mathrm{MCF}$ is about 33 percent of revenue raised, indicating that the separable effects on utility would have to be large for an increase in aggregate government purchases to be welfare enhancing; (2) the MCF is sensitive to the degree of substitutability and productivity of government purchases, indicating that it is project specific; and (3) the EXB or distortionary effect of taxation is substantial.

\section{Akhtar, M. A.}

PD July 1990. TI The U.S. Financial System: A Status Report and a Structural Perspective. AU Akhtar, M. A.; White, Betsy Buttrill. AA Federal Reserve Bank of New York. SR Federal Reserve Bank of New York Research Paper: 9018; Federal Reserve Bank of New York, 33 Liberty St., Rm. 901, New York City, New York 10045. PG 41. PR no charge. JE E44, O16, O51, O11. KW Financial System. Financial Markets. Economic Development.

AB The primary focus of this paper is on structural aspects of the U.S. financial system. The first part of the paper provides a sketch of the current regulatory structure of the financial industry, and presents an overview of recent developments in the financial sector. The remainder of the paper is devoted to a discussion of several major problems facing the U.S. financial system. An underlying theme in this discussion is that the conflict and interactions between the continued fragmentation of the financial structure and rapid changes in the intermediation process have contributed to problems of the U.S. financial system.

PD March 1991. TI The Political and Institutional Independence of U.S. Monetary Policy. AU Akhtar, M. A.; Howe, Howard. AA Federal Reserve Bank of New York. SR Federal Reserve Bank of New York Research Paper: 9110; Federal Reserve Bank of New York, 33 Liberty St., Rm. 901, New York City, New York 10045. PG 51. PR no charge. JE E58, E52. KW Federal Reserve. Monetary Policy.

AB The structure of the Federal Reserve System allows significant political and institutional autonomy for U.S. monetary policy. A system of checks and balances around that structure constrains, however, the political and institutional independence of policy in important respects. The multiplicity of final economic goals, the lack of priority among those goals, and an elaborate accountability process impose significant limits on the process of establishing and pursuing policy objectives. Following a review of the institutional framework and accountability for monetary policy, this paper examines the legislative proposals, advanced since 1979, to reform or alter various aspects of the Federal Reserve. These proposals, collectively, highlight the limits on the political and institutional independence of the Federal Reserve. 
Alexander, Arthur J.

PD June 1989. TI The Development and Structure of Consumer Credit in Japan. AU Alexander, Arthur J.; Oh, Kong Dan. AA Rand Corporation. SR Rand Note: N2902; The Rand Corporation, 1700 Main Street, P.O. Box 2138, Santa Monica, CA 90406-2138. PG 60. PR not available. JE O53, O16, G21. KW Consumer Credit. Credit Rationing. Japan. Credit Markets. Savings.

AB This note describes and analyzes the development, structure, and regulation of consumer credit in Japan, and identifies significant laws, regulations, or ministerial guidance that may restrict consumer credit markets and constrain the behavior of Japanese households. It also assesses the links between household credit and saving. The authors conclude that the development of Japanese consumer credit is one of the results of the transformation of the Japanese economy, which became evident in the mid-1970s. The past decade has set the stage for a structural reconfiguration of credit markets in which the banking sector is the key player. Both the growth of the market and its broad structural development are occurring independently of government policy, although government regulation has influenced the detailed shape of the credit market.

\begin{abstract}
Allen, Beth
PD December 1990. TI Chosing R\&D Projects: An Informational Approach. AA University of Pennsylvania. SR University of Pennsylvania Center for Analytic Research in Economics and the Social Sciences (CARESS) Working Paper: 90-20; University of Pennsylvania, Center for Analytic Research in Economics and the Social Sciences, McNeil Building, 3718 Locust Walk, Philadelphia, PA 19104-6297. PG 12. PR no charge. JE O33, G31, D24. KW Investment. Innovation. Technological Change.

AB This paper develops a theoretical macroeconomic analysis of firms' decisions to pursue one or more research projects and firms' specific choice among many competing projects. The big advantage of this approach is that $R \& D$ is not considered to be a single homogeneous activity but rather alternative projects or even the phenomenon of several teams competing within a firm by performing the same experiments independently can be considered. Different levels of investment in the same research strategy are considered to be different projects as they yield different probabilities of success or different (possibly stochastic) return streams. A single firm simultaneously decides whether to undertake research and development activities and, if so, which particular such activity or activities will be performed.
\end{abstract}

\section{Allen, Franklin}

PD May 1991. TI Rational Finite Bubbles. AU Allen, Franklin; Gorton, Gary. AA Allen: University of Pennsylvania. Gorton: University of Pennsylvania and National Bureau of Economic Research. SR National Bureau of Economic Research Working Paper: 3707; National Bureau of Economic Research, 1050 Massachusetts Avenue, Cambridge, MA 02138. PG not available. PR \$2.00. JE G12, G10. KW Stock Market. Asset Pricing.

AB There has been a long-running debate about whether stock market prices are determined by fundamentals. To date no consensus has been reached. An important issue in this debate concerns the circumstances in which deviations from fundamentals are consistent with rational behavior. A continuous time example where there are a finite number of rational traders with finite wealth is presented. It is shown that a finitely lived security can trade above its fundamental.

\section{Allen, Polly Reynolds}

PD August 1990. TI The Dynamics of the Real Exchange Rate, Foreign Debt and Capital Intensity. AU Allen, Polly Reynolds; Stein, Jerome L. AA Brown University. SR Brown University Department of Economics Working Paper: 90-22; Department of Economics, Brown University, Providence, RI 02912. PG 28. PR no charge. JE F31, F34, F11, F41. KW Exchange Rates. Foreign Debt. Capital Intensity. Capital Mobility.

AB In a neoclassical optimizing model that focuses on the medium to long-run, we analyze the trajectories of the fundamental real exchange rate, the capital intensity and foreign debt intensity resulting from two fundamental disturbances: a change in social saving and a change in the productivity of capital. While both disturbances in a world of perfect capital mobility initially appreciate the fundamental real exchange rate, the subsequent paths of the exchange rate differ because the capital stock and debt to foreigners follow different trajectories, depending on the purpose of the borrowing. We identify the key parameters of the structural model that determine the different trajectories and steady-state values of the endogenous variables.

\section{Altonji, Joseph G.}

PD May 1991. TI The Demand for and Return to Education when Education Outcomes are Uncertain. AA Northwestern University and National Bureau of Economic Research. SR National Bureau of Economic Research Working Paper: 3714; National Bureau of Economic Research, 1050 Massachusetts Avenue, Cambridge, MA 02138.

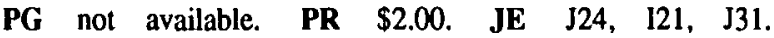
KW Human Capital. Education. Wages.

AB The vast literature on human capital and earnings assumes that individuals know in advance that they will complete a particular program of schooling. This paper treats education as a sequential choice that is made under uncertainty. A simple two period structural model is used to explore the effects of ability, high school preparation, preferences for schooling, the borrowing rate, and ex post payoffs to college on the probability of various post secondary college outcomes and the ex ante return to starting college. The model provides the basis for a simple empirical method of accounting for uncertainty about educational outcomes and for nonlinearity in the relationship between years of education and earnings when estimating the expected return to the first year of college.

\section{Angrist, Joshua D.}

PD October 1990. TI The Effect of Age at School Entry on Educational Attainment: An Application of Instrumental Variables with Moments from Two Samples. AU Angrist, Joshua D.; Krueger, Alan B. AA Angrist: Harvard University and National Bureau of Economic Research. Krueger. Princeton University and National Bureau of Economic Research. SR Princeton Industrial Relations Section Working Paper: 274; Industrial Relations Section, Department of Economics, Princeton University, Princeton, NJ 08544-2098. PG 37. PR \$1.50. JE J24. KW Compulsory Schooling. Education. Human Capital.

AB This paper tests the hypothesis that compulsory school 
attendance laws, which typically require school attendance until a specified birthday, induce a relationship between years of schooling and age at school entry. Variation in school start age created by children's date of birth provides a natural experiment for estimation of the effect of age at school entry. Because no large data set contains information on both age at school entry and educational attainment, we use an Instrumental Variables (IV) estimator with data derived from the 1960 and 1980 Censuses to test the age-at-entry/compulsory schooling model. In most IV applications, the two covariance matrices that form the estimator are constructed from the same sample. We use a method of moments framework to discuss IV estimators that combine moments from different data sets.

\section{Applegate, David}

PD July 1990. TI A Computational Study of the JobShop Scheduling Problem. AU Applegate, David; Cook, William. AA Applegate: Carnegie Mellon University. Cook: Bell Communications Research. SR Universitat Bonn Sonderforschungsbereich 303 - Discussion Paper: 90654-OR; Sonderforschungsbereich 303 an der Universitat Bonn, Adenauerallee 24-42, D-5300 Bonn 1, DEUTSCHLAND. PG 22. PR no charge. JE C44, C61, C63. KW Combinatorial Optimization. Scheduling Froblem. Computer Algorithm.

AB The job-shop scheduling problem is a notoriously difficult problem in combinatorial optimization. Although even modest sized instances remain computationally intractable, a number of important algorithmic advances have been made in recent years by Adams, Balas, and Zawack; Carlier and Pinson; Lageweg, Lenstra, and Rinnooy Kan; and others. Making use of a number of these advances, we have designed and implemented a new heuristic procedure for finding schedules, a cutting-plane method for obtaining lower bounds, and a combinatorial branch and bound algorithm. Our optimization procedure, combining the heuristic method and the combinatorial branch and bound algorithm, solved the wellknown $10 \times 10$ problem of Muth and Thompson in under 7 minutes of computation time on a Sun Sparcstation 1.

\section{Arnault, E. Jane}

PD December 1989. TI An Experimental Study of Comparable Worth. AU Arnault, E. Jane; Gordon, Louis; Joines, Douglas H.; Phillips, G. Michael. AA Amault: JurEcon, Inc. Gordon and Joines: University of Southern Califomia. Phillips: California State University, Northridge and JurEcon, Inc. SR Federal Reserve Bank of Kansas City Research Working Paper: 89-11; Research Division, Federal Reserve Bank of Kansas City, 925 Grand Ave., Kansas City, MO 64198. PG 18. PR no charge. JE J31, J41. KW Comparable Worth. Wages. Wage Contracts.

AB Proponents of comparable worth argue that each job possesses an inherent worth independent of the market forces of supply and demand. They further contend that inherent job worth can be measured with reasonable accuracy. This paper reports the results of an experimental study of comparable worth. Three commercial job evaluation firms rated the same set of 27 jobs in an actual company. Statistical analysis of the experimental data indicates that the three evaluators did not measure the same trait, implying that at least some of them failed to measure inherent job worth. These results suggest that any attempt to implement comparable worth may be quite sensitive to the evaluator chosen to measure job worth.

\section{Arnott, Richard}

PD March 1991. TI Price Equilibrium, Efficiency, and Decentralizability in Insurance Markets. AU Amott, Richard; Stiglitz, Joseph E. AA Amott: Boston College. Stiglitz: Stanford University. SR National Bureau of Economic Research Working Paper: 3642; National Bureau of Economic Research, 1050 Massachusetts Avenue, Cambridge, MA 02138. PG not available. PR \$2.00. JE D41, D82, D81. KW Moral Hazard. Prices. Market Equilibrium. Competitive Equilibrium. Insurance.

AB In this paper, we investigate the descriptive and normative properties of competitive equilibrium with moral hazard when firms offer "price contracts" which allow clients to purchase as much insurance as they wish at the quoted prices. We show that a price equilibrium always exists and is one of the three types: i) zero profit price equilibrium - zero profit, zero effort, full insurance; ii) positive profit price equilibrium positive profit, positive effort, partial insurance; and iii) zero insurance price equilibrium - zero insurance, zero profit, positive effort.

\section{Aron, Debra J.}

PD May 1991. TI Bonuses and Penalties as Equilibrium Incentive Devices, with Application to Manufacturing Systems. AU Aron, Debra J.; Olivella, Pau. AA Aron: Northwestern University. Olivella: Universitat Autonoma de Barcelona, Spain. SR Northwestem Center for Mathematical Studies in Economics and Management Science Working Paper: 932; Northwestern University, 2001 Sheridan Road, 3-014 Leverone Hall, Evanston, IL 60208-2014. PG not available. PR $\$ 3.00$ in the U.S. or Canada; $\$ 5.00$ via international mail. Make check payable to Northwestern University. JE J33, L23, L60. KW Incentives. Monitoring. Performance Appraisal. Compensation Packages.

AB No abstract.

\section{Ashenfelter, Orley}

PD July 1990. TI An Experimental Comparison of Dispute Rates in Altemative Arbitration Systems. AU Ashenfelter, Orley; Currie, Janet; Farber, Henry S.; Spiegel, Matthew. AA Ashenfelter: Princeton University. Currie: University of California, Los Angeles. Farber: Massachusetts Institute of Technology. Spiegel: Columbia University. SR Massachusetts Institute of Technology Department of Economics Working Paper: 562; Department of Economics, Massachusetts Institute of Technology, Cambridge, MA 02139. PG 40. PR \$6.00 Domestic, $\$ 8.00$ Overseas, $\$ 2.00$ Student. JE J52, C92. KW Arbitration. Bargaining. Experimental Economics. Dispute Rates.

AB This paper reports the results of a systematic experimental comparison of the effect of altemative arbitration systems on dispute rates. The key to our experimental design is the use of a common underlying distribution of arbitrator "fair" awards in the different arbitration systems. This allows us to compare dispute rates across different arbitration procedures where we hold fixed the amount of objective underlying uncertainty about the arbitration awards.

\section{Atack, Jeremy}

PD May 1991. TI Louis Brandeis, Work and Fatigue at the Start of the Twentieth Century: Prelude to Oregon's Hours Limitation Law. AU Atack, Jeremy; Bateman, Fred. AA Atack: University of Illinois and National Bureau of 
Economic Research. Bateman: Indiana University. SR National Bureau of Economic Research Working Paper Series on Historical Factors and Long-Run Growth: 25; National Bureau of Economic Research, 1050 Massachusetts Avenue, Cambridge, MA 02138. PG not available. PR \$2.00. JE J26, 118. KW Public Health. Hours of Work.

AB In this paper, we analyze the data from an 1892 California Bureau of Labor Statistics survey of 3,493 wageeamers that provides some evidence on the relationship between hours of work and time in a job and worsening health or days of absence from work as a result of ill-health. We conclude that these data support the hypothesis that long hours of work each day in hot and poorly ventilated workshops performing physically or mentally exhausting work at a pace set by inanimate machines was bad for employee health. However, it is hard to make a convincing case for the public regulation of hours and conditions in the workplace as a public, as opposed to a private, health question, except in the case of children, including children in utero, or communicable diseases such as tuberculosis.

\section{Atkeson, Andrew}

PD September 1990. TI Engel's Law and Saving. AU Atkeson, Andrew; Ogaki, Masao. AA Atkeson: University of Chicago. Ogaki: University of Rochester. SR University of Rochester Center for Economic Research Working Paper: 240; Department of Economics, University of Rochester, Rochester, NY 14627. PG 29. PR no charge. JE E21, D11, D12, O11. KW Engel's Law. Saving. Consumption. Consumer Expenditures. Consumer Economics.

AB It is well known that poor people spend a larger portion of their budget on food than rich people do. It has also been frequently observed that poor people allocate their consumption expenditure over time differently than rich people do. Kuznets, for instance, points out that saving rates increase over time as a country grows from the early stages to the late stages of development. In this paper, we ask the question: Under what conditions will the differences in saving behavior between rich and poor consumers be systematically related to the non-homotheticity of consumers' intratemporal demand for food?.

\footnotetext{
Attanasio, Orazio P.

PD September 1989. TI Consumer Expenditure Survey Database. AU Attanasio, Orazio P.; Koujianou, Penny; Weber, Guglielmo. AA Attanasio and Koujianou: Stanford University. Weber: University College London. SR Stanford Center for Economic Policy Research Discussion Paper Series: 177; 100 Encina Commons, Stanford University, Stanford CA 94305. PG 20. PR no charge for members of non-profit institutions, $\$ 3.00$ otherwise. JE C81. KW Consumer Expenditure Survey. Interview Survey. Diary Survey. Surveys. AB This document describes the CES data bank set up at the Center for Economic Policy Research at Stanford University. The data are on tape and can be accessed from the Watson mainframe computer by running SAS jobs. The data bank contains only a part of the information available in the original CES tapes (11 overall). The CES has been run on a regular basis since 1980 . The original tapes contain information on two independent samples of the U.S. population. About 4,500 households are interviewed every quarter and asked to answer questions on family characteristics, income, employment and
}

purchases - $80 \%$ of these are then reinterviewed the next quarter, while the remaining $20 \%$ are replaced by a new random group. This means that each household in the survey is interviewed 4 times. A slightly larger number of households (around 5,500) fill in a detailed diary on purchases of goods, while still providing information on income, employment and demographics. This latter group participates only once in the survey.

\section{Baas, S. M.}

TI Minimum Loss Scheduling. AU Nawijn, W. M.; Kern, W.; Baas, S. M.

PD March 1990. TI Scheduling Jobs on Parallel Machines, Each with a Unit-Capacity Buffer. AU Baas, $\mathbf{S}$. M.; Kem, W.; Nawijn, W. M. AA Kem: University of Cologne. Baas and Nawijn: University of Twente. SR Universitat Bonn Sonderforschungsbereich 303 Discussion Paper: 90.85; Sonderforschungsbereich 303 an der Universitat Bonn, Adenauerallee 24-42, D-5300 Bonn 1, DEUTSCHLAND. PG 15. PR no charge. JE C61, C67. KW Dynamic Programming. Scheduling Problem.

AB Given are a set of $\mathbf{k}$ parallel machines and a set of $\mathbf{n}$ jobs which arrive at fixed times. Each job has a fixed, but machinedependent processing time and value. Each machine can process one job at a time. A job is processed either immediately after its time of arrival or after having spent some time in a buffer, or it is rejected. It is shown that under certain weak conditions the problem of finding a minimum weight schedule can be solved in polynomial time, but that it becomes NP. complete if such conditions do not hold.

\section{Balduzzi, Pierluigi}

PD July 1990. TI Asset Prices in Monetary Economies. AU Balduzzi, Pierluigi; Foresi, Silverio. AA Balduzzi: University of California, Los Angeles. Foresi: University of Califomia, Los Angeles and New York University. SR New York University Salomon Brothers Center Working Paper: S. 90-21; Salomon Brothers Center for the Study of Financial Institutions, Graduate School of Business Administration, New York University, 90 Trinity Place, New York, NY 10006. PG 22. PR $\$ 5.00$. JE G11, G12, E44. KW Portfolio Choice. Money. Asset Pricing. Monetary Economy.

AB From the standpoint of the individual investor, we characterize the optimal portfolio choices in situations in which real cash balances provide valuable liquidity services. We show how the portfolio decisions and the decisions to consume and hold money for liquidity purposes can be effectively separated. This separation leads to general pricing results which hold for any monetary economy. From a general equilibrium perspective, all the sources of uncertainty can be reduced to a vector of economywide state variables to which the relevant risk premia are associated. The effects of these fundamental sources of risk on the asset values are studied in the context of a specific CAC economy.

\section{Baldwin, John R.}

PD June 1990. TI Market Structure and the Intensity of the Competitive Process in the Canadian Manufacturing Sector. AU Baldwin, John R.; Gorecki, Paul K. AA Baldwin: Queen's University and Business and Labor Markets Analysis Group, Statistics Canada. Gorecki: Economic Council Canada and Business and Labor Markets Analysis Group, Statistics Canada. SR Queen's Institute for Economic Research 
Discussion Paper: 780; Department of Economics, Queen's University, Kingston, Ontario, CANADA K7L 3N6. PG 70. PR \$3.00 Canada and U.S.; \$3.50 Foreign. JE L11, L22. KW Concentration Ratio. Competition. Firm Mobility. Market Structure.

AB Mobility statistics are direct measures of the intensity of competition; market structure indicators are indirect measures. In this regard the most widely employed measure of market structure is the concentration ratio. Despite the fact that structural measures provide only proxies for the extent of competition, they are widely used by professional economic staff during the formulation and administration of competition policy. This paper investigates the appropriateness of this approach. The paper then investigates the relationship between the main dimensions of concentration and mobility using principal component, canonical correlation, and regression analysis. The main dimension of concentration is related closely to the intensity of greenfield entry and close down exit.

PD August 1990. TI Industry Efficiency and Plant Turnover in the Canadian Manufacturing Sector. AA Queen's University and the Economic Council of Canada. SR Queen's Institute for Economic Research Discussion Paper: 791; Department of Economics, Queen's University, Kingston, Ontario, CANADA K7L 3N6. PG 33. PR \$3.00 Canada and U.S.; \$3.50 Foreign. JE L60, LA1, L22. KW Market Share. Firm Turnover. Market Structure. Manufacturing.

AB This paper examines the degree of industry efficiency in the Canadian manufacturing sector and its determinants in the 1970s. In addition, it shows the extent to which plant entry and exit, growth and decline contribute to changes in efficiency. The determinants of turnover are shown to be related to some of the same characteristics that are related to industry efficiency levels.

\section{Ball, Laurence}

PD May 1991. TI Externalities from Labor Mobility. AA National Bureau of Economic Research and Princeton University. SR National Bureau of Economic Research Working Paper: 3720; National Bureau of Economic Research, 1050 Massachusetts Avenue, Cambridge, MA 02138. PG not available. PR \$2.00. JE J61, J64. KW Labor Mobility. Unemployment.

AB This paper assumes that workers can move from a market with high unemployment to one with low unemployment at a cost. In principle, equilibrium mobility can be greater or less than the social optimum. For most plausible parameter values, however, mobility is too low. Intuitively, mobility has a beneficial externality: it helps workers remaining in the highunemployment market by reducing competition for jobs. Mobility hurts workers in the market that movers join, but this effect is usually smaller.

\section{Bar-Ilan, Avner}

PD August 1990. TI Monopolistic Competition and the Benefit of Inflation over Deflation. AA Tel Aviv University. SR Tel Aviv Foerder Institute for Economic Research Working Paper: 17-90; Department of Economics, Tel Aviv University, Ramat Aviv 69978, Tel Aviv, ISRAEL. PG 21. PR no charge. JE E31, D43, D58. KW Welfare Analysis. Inflation. Deflation. Monopolistic Competition.

AB This paper analyzes the welfare implications of inflation and deflation in a general equilibrium model with monopolistic firms that incur costs of price adjustment. It is shown that both inflation and deflation erode monopoly power and reduce profits by similar amounts. However, the social welfare implications of inflation and deflation are significantly different. Moderate inflation shifts prices from the monopolistic toward the competitive level and therefore enhances welfare; deflation, on the other hand, tends to raise prices and lower welfare. A transition from low inflation to deflation can yield a substantial welfare loss, and this might explain why we observe mild inflation far more often than we do deflation.

PD November 1990. TI An Impulse Control Method for Investment Decisions in Dynamic Technology. AU Bar-Ilan, Avner; Maimon, Oded. AA Tel Aviv University. SR Tel Aviv Foerder Institute for Economic Research Working Paper: 32-90; Department of Economics, Tel Aviv University, Ramat Aviv 69978, Tel Aviv, ISRAEL. PG 15. PR no charge. JE G31, M21, O32, M11. KW Business Investment. Present Value. Technological Progress.

AB This paper presents a new framework which can augment standard methods in evaluating profitability of investments, especially those involved in dynamic technology. In this case there is a possibility that although a certain investment is profitable using standard methods, it should not be undertaken because it precludes a more profitable investment later on, when more advanced equipment will be available. The investment decision faced by a firm is presented here as an impulse control problem, where the process of technological progress is modeled explicitly. The outcome of the optimization yields, in addition to investment expenditures, the expected time period between consecutive investments. A simple example demonstrates the use of the technique to actual investment decisions.

\section{Barbosa, Mariza M. T. I.}

TI Modelling the Use and Adoption of Technologies by Upland Rice and Soybean Farmers in Central-West Brazil. AU Strauss, John; Barbosa, Mariza M. T. I.; Teixeira, Sonia M.; Thomas, Duncan; Gomes, Raimundo A. Q., Jr.

TI Estimating the Impact of Income and Price Changes on Consumption in Brazil. AU Thomas, Duncan; Strauss, John; Barbosa, Mariza M. T. I.

\section{Barthold, Thomas A.}

PD May 1991. TI Bequest Taxes and Accumulation of Household Wealth: U.S. - Japan Comparison. AU Barthold, Thomas A.; Ito, Takatoshi. AA Barthold: Congress of the United States. Ito: Hitotsubashi University. SR National Bureau of Economic Research Working Paper: 3692; National Bureau of Economic Research, 1050 Massachusetts Avenue, Cambridge, MA 02138. PG not available. PR \$2.00. JE H24, D31, D91, O57. KW Tax System. Taxes. Intergenerational Transfers. Bequests.

AB The objective of this paper is two-fold. First, we describe and compare the gift and bequest (estate) tax systems in the United States and Japan. Second, we use tax data to estimate the magnitude of intergenerational transfers. The magnitude of intergenerational transfers provides aid in determining how much outstanding wealth is obtained through intergenerational transfers, an issue of current controversy. In both Japan and the United States, a substantial portion of wealth, and especially of land in Japan, is bequeathed from one generation to the next. 


\section{Batchelder, Ronald W.}

PD February 1991. TI Debt, Deflation, the Great Depression, and the Gold Standard. AU Batchelder, Ronald W.; Glasner, David. AA Batchelder. Pepperdine University and University of California, Los Angeles. Glasner: Federal Trade Commission. SR University of California at Los Angeles Department of Economics Working Paper: 611; Department of Economics, University of California, Los Angeles, 2263 Bunche, Los Angeles, CA 90024. PG 47. PR \$2.50. JE N22, E42. KW Great Depression. Federal Reserve. Gold Standard. Money Supply. Financial Markets.

AB This paper proposes a revised interpretation of the prolonged deflation and monetary contraction in the United States and most of the world during the Great Depression. Contrary to modem monetarist explanations, we argue that the monetary contraction of 1929-33 was the consequence of U.S. adherence to the gold standard; and that the sequential return to convertibility by gold standard countries during the 1920s increased the world's monetary demand for gold which induced a worldwide deflation. Further, we believe the U.S. maintained its commitment to a fixed dollar parity of gold over a longer period than most other countries did because America's politically powerful, domestic creditor interests successfully opposed increasing the dollar parity of gold.

\section{Bateman, Fred}

TI Louis Brandeis, Work and Fatigue at the Start of the Twentieth Century: Prelude to Oregon's Hours Limitation Law. AU Atack, Jeremy; Bateman, Fred.

\section{Bebchuk, Lucian Arye}

PD September 1990. TI The Effect of Insider Trading on Insiders' Choice among Risky Investment Projects. AU Bebchuk, Lucian Arye; Fershtman, Chaim. AA Bebchuk: Harvard University and National Bureau of Economic Research. Fershtman: Tel Aviv University and Northwestern University. SR Tel Aviv Foerder Institute for Economic Research Working Paper: 23-90; Department of Economics, Tel Aviv University, Ramat Aviv 69978, Tel Aviv, ISRAEL. PG 40. PR no charge. JE G31, M21. KW Managerial Economics. Business Investment. Insider Trading. Incentives. Corporations.

AB This paper studies certain effects of insider trading on the principal-agent problem in corporations. Specifically, we focus on insiders' choice among investment projects. Other things equal, insider trading leads insiders to choose riskier investment projects, because increased volatility of results enables insiders to make greater trading profits if they leam these results in advance of the market. This effect might or might not be beneficial, however, because insiders' riskaversion pulls them toward a conservative investment policy. We identify and compare insiders' choices of projects with insider trading and those without such trading. We also study the optimal contract design with insider trading and without such trading, thus identifying the effects that allowing such trading has on other elements of insiders' compensation.

PD September 1990. TI The Effect of Insider Trading on Insiders' Reaction to Opportunities to "Waste" Corporate Value. AU Bebchuk, Lucian Arye; Fershtman, Chaim. AA Bebchuk: Harvard University and National Bureau of Economic Research. Fershtman: Tel Aviv University and Northwestem University. SR Tel Aviv Foerder Institute for Economic Research Working Paper: 22-90; Department of
Economics, Tel Aviv University, Ramat Aviv 69978, Tel Aviv, ISRAEL. PG 33. PR no charge. JE M21, G32, G31. KW Corporations. Managerial Economics. Management. Insider Trading. Incentives.

AB This paper analyzes certain effects of insider trading on the principal-agent problem in corporations. Specifically, we focus on those managerial choices that confront managers with the need to decide between options that produce different corporate value but do not differ in the managerial effort involved. In the absence of insider trading, and as long as managers' salaries are positively correlated with their firm's results, managers will make such choices efficiently, and consequently such choices have previously received little attention. We show that, in the presence of insider trading, managers may make such choices inefficiently. With such trading, managers might elect to have a lower corporate value -- that is, they "waste" corporate value -- because having such a value might enable them to make greater trading profits.

\section{Becketti, Sean}

PD July 1990. TI The Prepayment Experience of FNMA Mortgage-Backed Securities. AU Becketti, Sean; Morris, Charles S. AA Federal Reserve Bank of Kansas City. SR Federal Reserve Bank of Kansas City Research Working Paper: 90-01; Research Division, Federal Reserve Bank of Kansas City, 925 Grand Ave., Kansas City, MO 64198. PG 69. PR no charge. JE G21. KW Mortgages.

AB This paper examines the prepayment experience of mortgage pass-throughs issued by the Federal National Mortgage Association (FNMA). We analyze a virtually complete record of the paydown of all FNMA mortgage pools. To the best of our knowledge, this data set has not previously been analyzed in the academic literature and relatively few practitioner publications present detailed information on the behavior of FNMA pools. One of the principal contributions of this paper is a careful description of the key features of the FNMA pools. The second contribution of this paper is a summary of the prepayment experience of the FNMA pools. This summary suggests ways in which the prepayment behavior of these pools might be modeled more formally.

\section{Beenstock, Michael}

PD May 1989. TI The Fiscal and Monetary Dynamics of Israeli Inflation: A Cointegrated Analysis of 1970-1987. AU Beenstock, Michael; Ben-Gad, Michael. AA Hebrew University, Jerusalem. SR Centre for Economic Policy Research Discussion Paper: 290; Centre for Economic Policy Research, 6 Duke of York Street, London SWIY 6LA, UNITED KINGDOM. PG 49. PR 2.00 pounds (\$4.00). JE O53, E51, E52, H62, E31. KW Inflation. Israel. Money Supply. Monetary Policy. Fiscal Deficit. Government Spending.

AB Using quarterly data from 1970-1987 we estimate a simple econometric model in which inflation and money supply are jointly determined and in which expectations of inflation are rational, or forward-looking. The model is estimated using the recently developed "co-integration" principle in econometrics. The main findings are that Israeli inflation reflected monetary growth which in turn reflected the fiscal deficit, and that the authorities have systematically accommodated inflationary shocks in the execution of monetary policy. 


\section{Ben-David, Dan}

PD May 1991. TI Equalizing Exchange: A Study of the Effects of Trade Liberalization. AA University of Houston. SR National Bureau of Economic Research Working Paper: 3706; National Bureau of Economic Research, 1050 Massachusetts Avenue, Cambridge, MA 02138. PG not available. PR \$2.00. JE F13, F14, O57, J31. KW Wage Differentials. Trade Barriers. Economic Integration.

AB It has been quite broadly documented that, historically, there has not been widespread convergence in levels of income across countries. This paper addresses the question of whether the behavior of cross-country income differentials over time, within a specified groups of countries, might be affected by the removal of trade barriers. The analysis focuses on the evolutionary period of the European Economic Community, which is characterized by a specific timetable for the removal of trade barriers. This liberalization is shown to be strongly related to a significant income convergence that took place between the members of the Community.

\section{Ben-Gad, Michael}

TI The Fiscal and Monetary Dynamics of Israeli Inflation: A Cointegrated Analysis of 1970-1987. AU Beenstock, Michael; Ben-Gad, Michael.

\section{Benhabib, Jess}

PD May 1991. TI Social Conflict, Growth and Income Distribution. AU Benhabib, Jess; Rustichini, Aldo. AA Benhabib: New York Univerity. Rustichini: Northwestern University. SR Northwestern Center for Mathematical Studies in Economics and Management Science Working Paper: 937; Northwestern University, 2001 Sheridan Road, 3-014 Leverone Hall, Evanston, IL 60208-2014. PG 67. PR $\$ 3.00$ in the U.S. or Canada; $\$ 5.00$ via international mail. Make check payable to Northwestern University. JE 041, D31. KW Income Distribution. Dynamic Game. Property Rights. Growth Model.

AB In this paper we study the relationship between wealth, income distribution and growth in a game-theoretic context in which property rights are not completely enforceable. We consider equilibrium paths of accumulation which yield players utilities that are at least as high as those that they could obtain by appropriating higher consumption at the present and suffering retaliation later on. We focus on those subgame perfect equilibria which are constrained Pareto-efficient (second best). In this set of equilibria we study how the level of wealth affects growth. In particular, we consider cases which produce classical traps (with standard concave technologies): growth may not be possible from low levels of wealth because of incentive constraints while policies (sometimes even firstbest policies) that lead to growth are sustainable as equilibria from high levels of wealth.

\section{Bennett, Charles L.}

TI The Costs and Financing of Care for AIDS Patients: Results of a Cohort Study in Los Angeles. AU Pascal, Anthony; Bennett, Charles L.; Cvitanic, Marilyn; Gorman, Michael; Serrato, Carl.

\section{Bennett, Neil G.}

PD September 1989. TI Spouse Selection and Marital Instability. AU Bennetı, Neil G.; Goldstein, Heidi; Abzug, Rikki. AA Yale University. SR Yale Economic Growth
Center Discussion Paper: 582; Economic Growth Center, Yale University, 27 Hillhouse Avenue, New Haven, CT 06520. PG 38. PR $\$ 2.00+$ Postage. JE J12. KW Marriage. Divorce.

AB In this paper we test several hypotheses regarding the relationship between spouse selection and marital instability. The divergent world views, values, and expectations that differences in age, religion, and education bring to bear on a marriage appear to significantly undermine the viability of the relationship. Specifically, a woman who marries a man of a different religion, of lower educational achievement, or of a younger age is subject to a considerably higher likelihood of marital dissolution than her homologous married counterpart. It is important to note that those who are part of heterogeneous unions are a select group of relatively nontraditional individuals who may hold non-traditional views about the dominion of legal marriage. Therefore, they may be more apt to end such a traditional arrangement if it is unsatisfying to them.

PD September 1989. TI The Divergence of Black and White Marriage Patterns. AU Bennett, Neil G.; Bloom, David E.; Craig, Patricia H. AA Yale University. SR Yale Economic Growth Center Discussion Paper: 583; Economic Growth Center, Yale University, 27 Hillhouse Avenue, New Haven, CT 06520. PG 37. PR \$2.00 + Postage. JE J12, J11. KW Marriage. Minorities. Education. Women.

AB Our purpose in this paper is first, to examine patterns of first marriage among black and white women in the United States, and then, to assess the various factors that underlie these patterns. Three major differences exist between the first marriage patterns of black and white women; lower proportions of blacks marry than whites, the proportion of women who ever marry has declined substantially across cohorts of black women but comparatively modestly across cohorts of white women, and increased education is associated negatively, if only slightly, with the probability of ever marrying among white women, but is associated positively among black women. The observed racial divergence of marriage patterns is demonstrated to be consistent with three factors differentially experienced by blacks and whites: the marriage squeeze, labor market success, and out-of-wedlock childbearing.

TI Modeling American Marriage Patterns. AU Bloom, David E.; Bennett, Neil G.

\section{Bennett, Paul}

PD May 1990. TI Evidence on the Influence of Financial Changes on Interest Rates and Monetary Policy. AA Federal Reserve Bank of New York. SR Federal Reserve Bank of New York Research Paper: 9007; Federal Reserve Bank of New York, 33 Liberty St., Rm. 901, New York City, New York 10045. PG 43. PR no charge. JE E44, E52, E43. KW Interest Rates. Monetary Policy. Financial Markets. Credit.

AB This paper reviews a number of recent studies that directly or indirectly bear on how financial changes have influenced the behavior of interest rates and the transmission of monetary policy. One conclusion is that the financial changes have made credit more available, thus raising the equilibrium level of interest rates. In addition, there is at least some support for the assertion that the interest elasticity of aggregate demand has fallen during the past decade or two. However, increased sensitivities associated with greater financial leverage and the 
heightened role of exchange rates have made the second of these propositions less secure.

\section{Bental, Benjamin \\ PD December 1990. TI Competitive Banking with Confidence Crisis and Intemational Borrowing. AU Bental, Benjamin; Eckstein, Zvi; Peled, Dan. AA Bental and Peled: Israel Institute of Technology. Eckstein: Tel Aviv University and Boston University. SR Tel Aviv Foerder Institute for Economic Research Working Paper: 37-90; Department of Economics, Tel Aviv University, Ramat Aviv 69978, Tel Aviv, ISRAEL. PG 33. PR no charge. JE G21, F34. KW International Borrowing. Banking Crisis. Commercial Banks. International Lending. Banking. \\ AB This paper describes a model with banks which provide risk sharing services among local depositors and improved terms on intemational loans of capital. However, the operation of banks is subject to "confidence crises" which take the form of self-fulfilling concerns of depositors about the banks' future viability. In a banking equilibrium all parties involved - local depositors, a competitive banking sector, and foreign lenders - are making their decisions while being aware of the risk inherent in the banking system. Banks' choices include the level of foreign loans and the term structure of state contingent returns on deposits. It is shown that in an equilibrium in which banks seek to maximize the expected utility of their depositors - returns on deposits are chosen so as to deter a "run on the banks" even when a confidence crisis occurs.}

\section{Berg, Sanford V.}

PD July 1990. TI An Evaluation of Incentive Regulations for Electric Utilities. AU Berg, Sanford V.; Jeong, Jinook. AA University of Florida. SR University of Florida Working Paper in Economics: 90-4; Department of Economics, University of Florida, Gainesville, FL 32611. PG not available. PR no charge. JE Q48, Q41. KW Regulations. Utilities. Energy. Government Policy.

AB This empirical study examines the determinants and impacts of incentive regulations introduced by utility commissions in the late 1970 s and early 1980s. Rewards for generating plant utilization and low heat rates were introduced in states whose firm's exhibited relatively high managerial slack (or relatively higher costs). However, the empirical results did not find that the introduction of specific cost component incentives improved overall operating cost performance.

\section{Bergman, Yaacov Z.}

PD July 1990. TI Opportunistic Behavior in Debt Renegotiations and the Capital Structure of the Firm. AU Bergman, Yaacov Z.; Callen, Jeffrey L. AA Bergman: Brown University. Callen: The Hebrew University. SR Brown University Department of Economics Working Paper: 90-24; Department of Economics, Brown University, Providence, RI 02912. PG 50. PR no charge. JE G32, G33, D92. KW Renegotiation. Bargaining. Debt. Corporations. Bankruptcy. Capital Structure.

AB This paper models debt renegotiations as a bargaining game between shareholder-oriented management and debtholders, in which the former credibly threatens to run down firm assets, thereby forcing concessions from the latter. In equilibrium, this implies an upper bound on debt issued, which is less than the value of the firm. If there is also an incentive to issue debt, such as the tax deductibility of interest expense, an interior equilibrium capital structure obtains, without recourse to bankruptcy deadweight costs. Inter alia, the model explains variations in debt-equity ratios and the use of certain puzzling debt covenants.

\section{Berlin, Mitchell}

PD September 1990. TI Debt Covenants and Renegotiations. AU Berlin, Mitchell; Mester, Loretta J. AA Berlin: New York University. Mester: Federal Reserve Bank of Philadelphia. SR New York University Salomon Brothers Center Working Paper: S-90-23; Salomon Brothers Center for the Study of Financial Institutions, Graduate School of Business Administration, New York University, 90 Trinity Place, New York, NY 10006. PG 45. PR $\$ 5.00$. JE G21. KW Debt Contracts. Debt. Credit. Negotiations. AB This paper analyzed the optimal design of restrictive covenants for debt contracts both when contract renegotiation is possible and when it is not. Although restrictive covenants control agency problems, they reduce the borrowing firm's flexibility to pursue profitable opportunities. When contracts can be renegotiated covenants will be more severe, because they can be relaxed selectively when the borrower can convince the lender that they pose an inefficient constraint. We also analyze the value of the option to renegotiate as the firm's ex ante creditworthiness varies and find that firms with high credit risk will find the option to renegotiate most valuable. The model is used to explain why bank loans and privately placed debt will typically have more stringent covenants than public debt, and to predict the types of firms that will borrow using closely held debt.

\section{Bernard, Andrew B.}

PD May 1991. TI Convergence of International Output Movements. AU Bernard, Andrew B.; Durlauf, Steven N. AA Durlauf: Stanford University and National Bureau of Economic Research. Bernard: Stanford University. SR National Bureau of Economic Research Working Paper: 3717; National Bureau of Economic Research, 1050 Massachusetts Avenue, Cambridge, MA 02138. PG not available. PR \$2.00. JE F43, 034, F41. KW Developed Countries. Technology. Output.

AB This paper explores the convergence of real per capita output in advanced industrialized economies. We start by observing that in a stochastic environment, convergence in per capita GDP requires that permanent shocks to one economy be associated with permanent shocks to other economies. Convergence is a natural outcome of models where exogenous technical change migrates across countries with similar microeconomic specifications. Conversely, in a world where some component of permanent output movements is due to technical change whereas other components are due to domestic factors, national economies may diverge over time. We formalize a general definition of convergence using the notions of unit roots and co-integration developed in the time series literature.

\section{Bernheim, B. Douglas}

PD September 1989. TI Comparison of the Cost of Capital in the U.S. and Japan: The Roles of Risk and Taxes. AU Bernheim, B. Douglas; Shoven, John B. AA Bernheim: Northwestem University. Shoven: Stanford University and National Bureau of Economic Research. 
SR Stanford Center for Economic Policy Research Discussion Paper Series: 179; 100 Encina Commons, Stanford University, Stanford CA 94305. PG 54. PR no charge for members of non-profit institutions, $\$ 3.00$ otherwise. JE G31, H25, O57. KW Cost of Capital. Taxes. United States. Japan. Risk Premium.

AB This paper argues that conventional measures of the cost of capital are flawed primarily because they do not simultaneously account for the effects of taxes, risk premia, and interest rates. The handling of risk premia in the existing literature is particularly inadequate. Thus, the paper develops a theoretical measure of the cost of capital including both risk and tax considerations. It also numerically assesses the risk premia in the U.S. and Japan in 1980 and 1988. Finally, the paper computes cost of capital figures for plant and automobile investments in both countries for both years.

\section{Bernstein, Alvin $\mathbf{H}$.}

PD October 1989. TI Soviet Defense Spending: The Spartan Analogy. AA Rand Corporation. SR Rand Note: N-2817; The Rand Corporation, 1700 Main Street, P.O. Box 2138, Santa Monica, CA 90406-2138. PG 44. PR not available. JE O53, P26, P51. KW Soviet Union. Political Economics. Military State. Soviet Economy.

AB This note attempts to provide the means for evaluating the frequently made comparison between the Soviet Union and ancient Sparta as states where politics takes precedence over economics. It marshals and explicates both the ancient evidence and modem scholarship on the issues that a student of the contemporary Soviet economy must understand in order to judge to what extent ancient Spartan society sheds light on the way the Soviet Union does business today. The author describes the origins, developments, and ultimate failure of Sparta's political economy, and analyzes that economy's strengths and vulnerabilities. He points out that the striking similarities that many scholars have noted between the two societies come principally from the fact that they are both militaristic states. He also cautions that the Spartan analogy may be useful for acquiring insights into the Soviet economy, but it has no predictive value.

\section{Bernstein, Jeffrey I.}

PD December 1990. TI A Dynamic Model of Product Demand, Cost of Production and Interindustry R\&D Spillovers. AU Bernstein, Jeffrey I.; Nadiri, M. Ishaq. AA Bernstein: Carleton University. Nadiri: New York University. SR New York University Economic Research Reports: 90-53; New York University, Faculty of Arts and Science, Department of Economics, Washington Square, New York, N.Y. 10003. PG 47. PR no charge. JE O32, O33, L11, D24. KW Product Demand. Production. Technological Change. R\&D. Spillovers.

AB The purpose of this paper is to develop and estimate a model of production with endogenous technological change. Technological change arises from R\&D capital accumulation decisions. These decisions respond to market and government incentives and generate $R \& D$ capital spillovers. A spillover network of senders and receivers is estimated. The network shows that each receiving industry is affected by a distinct set of R\&D sources and each sending industry affects a unique set of receivers. For the receivers, spillovers generally expand product markets, lower product prices, increase production costs and input demands. For the sources, significant R\&D spillovers cause the social rates of return to R\&D capital to be substantially above the private returns.

\section{Bertocchi, Graziella}

PD May 1990. TI Efficiency and Optimality in Stochastic Models with Production. AU Bertocchi, Graziella; Kehagias, Athanasios. AA Brown University. SR Brown University Department of Economics Working Paper: 90-18; Department of Economics, Brown University, Providence, RI 02912. PG 28. PR no charge. JE O41, P21, E11. KW Stochastic Model. Growth Model. Central Planner.

AB We consider a discrete-time, infinite-horizon, one-good stochastic growth model, and we solve the central planner's optimization problem by applying a stochastic version of Pontryagin's maximum principle for Markov controls. An approximation method is used in order to extend to an infinite horizon a stochastic maximum principle derived by Arkin and Evstigneev (1987) for the finite-horizon case. We obtain efficiency conditions which are expressed in terms of stochastic multipliers, i.e., "shadow" price functions, and a transversality condition. We interpret these conditions by treating uncertainty as a source of heterogeneity, i.e., by considering different realizations of the capital stock as different types of capital. A connection can then be established between the stochastic onegood model and a deterministic model with heterogeneous capital goods, where the dimension of the state space increases over time reflecting the history of the stochastic shock.

PD September 1990. TI Safe Debt, Risky Capital. AA Brown University. SR Brown University Department of Economics Working Paper: 90-25; Department of Economics, Brown University, Providence, RI 02912. PG 26. PR no charge. JE H63, G11, G31, E22. KW Public Debt. National Debt. Investment. Portfolio Choice. Savings.

AB We explore the role of national debt in a dynamic economy where claims on physical capital are risky. We first analyze the positive implications of debt issuance: portfolio diversification dictates an asset valuation equation relating the return on safe national debt to the risky return on capital; the introduction of a second investment opportunity complicates the dynamic behavior of the economy, posing problems of financial instability; debt-capital substitution reduces both the riskiness and the level of aggregate income, introducing a potential trade-off between the insurance role of public debt and the productive loss associated with it. Welfare considerations show that national debt can still cure oversaving, but provides only partial protection against aggregate uncertainty; the achievement of Pareto optimality is therefore not guaranteed by the public provision of an additional financial instrument.

\section{Betancourt, Roger R.}

PD September 1990. TI The Outputs of Retail Activities: Concepts, Measurement, and Evidence. AU Betancourt, Roger R.; Gautschi, David A. AA Betancourt: University of Maryland, College Park. Gautschi: Yale University. SR University of Maryland Department of Economics Working Paper Series: 90-17; Department of Economics, University of Maryland, College Park, MD 20742. PG 39. PR no charge. JE L81, L11, M21. KW Distribution Services. Prices. Retail Trade.

AB In this paper we develop a new economic framework for the empirical analysis of retail margins. This framework departs 
from the definition of profits and incorporates recent theoretical developments formalizing the role of distribution services as outputs of retail activities. Since the theory implies a nonlinear functional form, nonlinear least squares is the main estimation method. Our main results are: the measures of outputs of retail activities identified in the data perform as important and robust determinants of retail margins; variables that capture oligopolistic features of market structure play a limited or no role in determining retail margins; the hypothesis of quantity setting behavior is categorically rejected by the data; retail firms will evolve to provide lower accessibility of location for the typical consumer in terms of distance but they will provide him or her with broader assortments and more information.

\section{Bixby, Robert E.}

PD September 1990. TI Matroid Optimization and Algorithms. AU Bixby, Robert E.; Cunningham, William H. AA Bixby: Rice University. Cunningham: Carleton University. SR Universitat Bonn Sonderforschungsbereich 303 - Discussion Paper: 90658-OR; Sonderforschungsbereich 303 an der Universitat Bonn, Adenauerallee 24-42, D-5300 Bonn 1, DEUTSCHLAND. PG 66. PR no charge. JE C61, C63. KW Matroid Optimization. Matroid Intersection. Submodular Functions. Connectivity Algorithms. Linear Programming.

AB This chapter considers matroid theory from a constructive and algorithmic viewpoint. A substantial part of the developments in this direction have been motivated by optimization. Matroid theory has led to a unification of fundamental ideas of combinatorial optimization as well as to the solution of significant open problems in the subject. In addition to its influence on this larger subject, matroid optimization is itself a beautiful part of matroid theory.

\section{Blackorby, Charles}

PD October 1989. TI Adult-Equivalence Scales, Interpersonal Comparisons of Well-Being, and Applied Welfare Economics. AU Blackorby, Charles; Donaldson, David. AA University of British Columbia. SR University of British Columbia Department of Economics Discussion Paper: 89-24; University of British Columbia, \#997-1873 East Mall, Vancouver, BC V6T 1W5, CANADA. PG not available. PR $\$ .20$ per page Canadian to other than educational institutions. JE 131, D63, D11. KW Adult Equivalence. Well-Being. Households. Welfare Economics.

AB Adult-equivalence scales may be interpreted as providing comparisons of levels of well-being between individual members of different households. In this paper, we investigate the potential of these scales for social evaluations (applied welfare economics) that: (i) take account of the fact that behavior rests on household decisions while individual household members experience well-being or utility, (ii) are based on individual (rather than "household") levels of wellbeing, and (iii) take account of inequality of well-being and, therefore, of incomes.

\section{Blanchard, Olivier Jean}

PD January 1990. TI Ranking, Unemployment Duration, and Wages. AU Blanchard, Olivier Jean; Diamond, Peter. AA Massachusetts Institute of Technology. SR Massachusetts Institute of Technology Department of Economics Working Paper: 546; Department of Economics, Massachusetts Institute of Technology, Cambridge, MA 02139.
PG not available. PR $\$ 6.00$ Domestic, $\$ 8.00$ Overseas, $\$ 2.00$ Student. JE J41, J64, J31. KW Unemployment. Wages. Job Vacancies.

AB Firms often receive multiple acceptable applications for vacancies, requiring a choice among candidates. This paper contrasts equilibria when firms select workers at random and when firms select the worker with the shortest spell of unemployment, called ranking. With the filling of vacancies unaffected by the selection rule, both equilibria have the same aggregate dynamics, but different distributions of unemployment durations. With the threat point for the Nash bargained wage being a worker with zero unemployment duration, the wage with ranking is much more sensitive to changes in the tightness of the labor market. The same holds for efficiency wages.

\section{Bliss, Christopher}

PD February 1990. TI The Optimal External Tariff in an Enlarging Customs Union. AA Nuffield College. SR Centre for Economic Policy Research Discussion Paper: 368; Centre for Economic Policy Research, 6 Duke of York Street, London SW1Y 6LA, UNITED KINGDOM. PG 46. PR 2.00 pounds $(\$ 4.00)$. JE F15, F13. KW Customs Union. Tariffs. Economic Integration. Trade Model.

AB A customs union is enlarged by the addition of one or more new countries. What should be the consequential change in its common external tariff (CET)? The paper attempts to make this question precise and to apply it to the enlargement of the EC. In many simple trade models the optimal CET is always zero, which makes the question trivial. Various cases can be developed, however, in which a positive CET is optimal. Some of these are reviewed and their implications for customs union enlargement elucidated. A neutral enlargement, under which trade with the outside world is held constant, proves to be an important and enlightening reference case.

\section{Bloom, David E.}

TI The Divergence of Black and White Marriage Patterns. AU Bennett, Neil G.; Bloom, David E.; Craig, Patricia H.

PD September 1989. TI Modeling American Marriage Patterns. AU Bloom, David E.; Bennett, Neil G. AA Yale University. SR Yale Economic Growth Center Discussion Paper: 584; Economic Growth Center, Yale University, 27 Hillhouse Avenue, New Haven, CT 06520. PG 21. PR $\$ 2.00+$ Postage. JE J12, J11. KW Marriage. Marital Status. Race. Education.

AB This paper analyzes cohort marriage patterns in the United States in order to determine whether declining rates of first marriage are due to changes in the timing of marriage, changes in the incidence of marriage, or both. A parametric model that is well suited to the analysis of censored data is fit to information on marital status and age at first marriage derived from three independent data sets. An extended version of the model is also estimated in which its parameters are allowed to depend on social and economic variables. The results provide evidence that the incidence of first marriage is declining across cohorts and that the mean age at first marriage is increasing among those who do marry. In addition, education is the most powerful correlate of marriage timing, whereas race is the most powerful correlate of marriage incidence.

Boldin, Michael D.

PD September 1990. TI Sunspots, Asset Bubbles, and the 
Store of Value Motive in Overlapping Generations Models. AA Federal Reserve Bank of New York. SR Federal Reserve Bank of New York Research Paper: 9031; Federal Reserve Bank of New York, 33 Liberty St., Rm. 901, New York City, New York 10045. PG 32. PR no charge. JE G12, G14, E44, E21. KW Stock Market. Financial Markets. Savings.

AB Sunspot Equilibria (SSE) are studied where only the realized returns of purely financial assets are affected by "self fulfilling" beliefs. It is shown that SSE will generally exist even when agents have access to other means of savings (storage) that are immune to these extraneous factors. Also the model shows a connection between large "sunspot" fluctuations and high equity premiums in financial markets. The results provide a theoretical background for empirical research that pursues a "sunspot" explanation for stock market volatility that is independent of real factors in the economy.

PD December 1990. TI Characterizing Business Cycles with a Markov Switching Model: Evidence of Multiple Equilibria. AA Federal Reserve Bank of New York. SR Federal Reserve Bank of New York Research Paper: 9037; Federal Reserve Bank of New York, 33 Liberty St., Rm. 901. New York City, New York 10045. PG 48. PR no charge. JE E32, E37, E24. KW Business Cycle. Unemployment. Search Model.

AB To determine the extent of asymmetries in business cycles, a Markov Switching Model is applied to GNP growth and unemployment. Two equilibria, defined by distinct converging rates of unemployment, are found. The estimates are consistent with Diamond's (1984) two sided search models and the extension of Howitt and McAfee (1988) that allows exogenous factors ("animal spirits") to drive business cycle fluctuations. Comparisons are also made to other theories, especially real business cycle models. The results suggest that due to specification problems, many previous tests of the natural rate hypothesis should be cast in doubt.

\section{Bordo, Michael D.}

PD April 1991. TI Money Versus Credit Rationing: Evidence for the National Banking Era, 1880-1914. AU Bordo, Michael D.; Rappoport, Peter, Schwartz, Anna J. AA Bordo and Rappoport: Rutgers University. Schwartz: National Bureau of Economic Research. SR National Bureau of Economic Research Working Paper: 3689; National Bureau of Economic Research, 1050 Massachusetts Avenue, Cambridge, MA 02138. PG not available. PR $\$ 2.00$. JE N21, E44, E32. KW National Banking Act. Banking System. Business Cycle. Credit Rationing. Business Fluctuations.

AB In this paper we examine the evidence for two competing views of how monetary and financial disturbances influenced the real economy during the national banking era, 1880-1914. According to the monetarist view, monetary disturbances affected the real economy through changes on the liability side of the banking system's balance sheet independent of the composition of bank portfolios. According to the credit rationing view, equilibrium credit rationing in a world of asymmetric information can explain short-run fluctuations in real output. Using structural VARs we incorporate monetary variables in credit models and credit variables in monetarist models, with inconclusive results. To resolve this ambiguity, we invoke the institutional features of the national banking era. Most of the variation in bank loans is accounted for by loans secured by stock, which in turn reflect volatility in the stock market.

\section{Bose, Gautam}

PD October 1989. TI Consumption-Loans, Insurance and Debt-Traps in Subsistence Agriculture. AA University of Southern California. SR University of Southern California Modelling Research Group Working Paper: M8924; Department of Economics, University of Southern Califomia, University Park, Los Angeles, CA 90089-0152. PG 12. PR no charge. JE Q14, L12, O13. KW Consumption Loans. Insurance. Agriculture. Monopoly. Private Debt.

AB Steady-state equilibria with consumption loans are compared with explicit insurance arrangements, in the context of subsistence agriculture. The case where the lender is an absolute monopolist is considered first. The consequences of competition entering in the insurance and credit markets are then analyzed. It is seen that the monopolist's profits are more easily eroded by competition if he was initially providing insurance explicitly. With an initial consumption loan agreement, his monopoly profits are unaffected by the presence of competition, if a simple condition holds on the productivity of the borrower.

\section{Bossert, Walter}

PD October 1989. TI On Intra- and Interpersonal Utility Comparisons. AA University of British Columbia and Universitat Karlsruhe. SR University of British Columbia Department of Economics Discussion Paper: 89-25; University of British Columbia, \#997-1873 East Mall, Vancouver, BC V6T IW5, CANADA. PG 19. PR $\$ .20$ per page Canadian to other than educational institutions. JE D71, D63, D11. KW Utility. Social Choice. Social Welfare Function.

AB In this paper, it is suggested to formulate assumptions on the comparability of individual utilities in terns of meaningful statements rather than using the usual way of defining such assumptions by means of certain sets of admissible transformations. Various assumptions involving (intra and interpersonal) comparisons of utility levels, utility differences, and utility ratios are introduced in terms of meaningful statements and compared to their "traditional" counterparts. It is shown that these two approaches are, in general, not equivalent. In a social choice framework, it is demonstrated that the difference between these approaches can be quite substantial: replacing the usual cardinal unit comparability assumption by a condition involving comparisons of utility differences which is similar in spirit turns a well-known characterization of utilitarian social welfare functionals into an impossibility theorem.

PD April 1990. TI Disagreement Point Monotonicity, Transfer Responsiveness, and the Egalitarian Bargaining Solution. AA University of British Columbia and Universitat Karlsruhe. SR University of British Columbia Department of Economics Discussion Paper: 90-07; University of British Columbia, \#997-1873 East Mall, Vancouver, BC V6T IW5, CANADA. PG 9. PR $\$ .20$ per page Canadian to other than educational institutions. JE C78, D74. KW Bargaining. Egalitarianism. Game Theory.

AB This paper provides an axiomatization of the egalitarian bargaining solution. The central axiom used (together with some standard properties of bargaining solutions) in this characterization is a transfer responsiveness condition. First, it ensures that no transfer paradox can occur if bargaining power 
is transferred from one agent to another by decreasing one agent's and increasing the other agent's component of the disagreement point. Second, the extent of external effects of such a transfer is limited by requiring that agents not involved in the transfer neither gain more than the "winner" nor lose more than the "loser" of the transfer.

\section{Bound, John}

PD May 1991. TI Industrial Shifts, Skills Levels, and the Labor Market for White and Black Males. AU Bound, John; Holzer, Harry J. AA Bound: University of Michigan and National Bureau of Economic Research. Holzer: Michigan State University. SR National Bureau of Economic Research Working Paper: 3715; National Bureau of Economic Research, 1050 Massachusetts Avenue, Cambridge, MA 02138. PG not available. PR \$2.00. JE J23, J15, E24. KW Wages. Minorities. Employment.

AB In this paper we estimate the effects of industrial shifts in the 1970s and 1980s on the wages and employment of black and white males. We use micro Census data for 52 MSAs, and estimate effects separately by age and education group. The results show that industrial shifts did reduce demand for blacks and less skilled males in 1970s and 1980s. Demand shifts away from manufacturing, in particular, reduced employment and wages for black and white males. While the magnitudes of these effects are fairly small for many groups, they can account for one-third to one-half of the employment decline for lesseducated young blacks in the 1970 s. These results imply fairly large effects on the earnings of less-skilled males in the 1980 s as well.

\section{Bovenberg, A. Lans}

PD September 1989. TI Promoting Investment Under International Capital Mobility: An Intertemporal General Equilibrium Analysis. AU Bovenberg, A. Lans; Goulder, Lawrence H. AA Bovenberg: International Monetary Fund. Goulder: Stanford University and National Bureau of Economic Research. SR Stanford Center for Economic Policy Research Discussion Paper Series: 178; 100 Encina Commons, Stanford University, Stanford CA 94305. PG 53. PR no charge for members of non-profit institutions, $\$ 3.00$ otherwise. JE F21, F43, F41, H32. KW Subsidies. Capital Mobility. Open Economy. Capital Flows. International Investment.

AB This paper uses a dynamic computable general equilibrium model to compare, in an economy open to international capital flows, the effects of two U.S. policies -the introduction of an investment tax credit and a reduction in the statutory corporate income tax rate -- differ in their treatment of old (existing) and new capital. The model features adjustment dynamics, intertemporal optimization by U.S. and foreign households and firms endowed with model-consistent expectations, imperfect substitution between domestic and foreign assets in portfolios, an integrated treatment of the current and capital accounts of the balance of payments, and industry disaggregation in the United States.

\section{Brauer, David A.}

PD September 1990. TI The Effect of Import Competition on Manufacturing Wages. AA Federal Reserve Bank of New York. SR Federal Reserve Bank of New York Research Paper: 9030; Federal Reserve Bank of New York, 33 Liberty St., Rm. 901, New York City, New York 10045.
PG 41. PR no charge. JE J31, L60. KW Wages. Imports. Manufacturing.

AB This paper investigates the impact of increasing imports on compensation in U.S. manufacturing. Using regression analysis, I find that increased import penetration ratios are associated with a small but significant reduction in real earnings. By concentrating on the period 1975-1985, I find that the direct effect of imports on earnings was much greater in relatively low-wage industries producing nondurable goods (i.e. shoes, apparel) than in high-wage durable-goodsproducing industries (i.e. autos, steel). In addition there is an indirect effect through the elimination of jobs in high-wage industries. However the impact of imports on aggregate manufacturing wages is found to be small.

\section{Brenton, L. Alan}

TI Non-Tariff Barriers and Rationing: U.K. Footwear Imports. AU Winters, P. A.; Brenton, L. Alan.

\section{Bresnahan, Timothy}

TI Measurement, Coordination, and Learning in a Multiplant Network. AU Chew, W. Bruce; Clark, Kim B.; Bresnahan, Timothy.

\section{Broll, Udo}

PD June 1990. TI Two-Country Firm: Exchange Rate Uncertainty and Futures Markets. AU Broll, Udo; Zilcha, Itzhak. AA Broll: University of Konstanz. Zilcha: Tel Aviv University. SR Tel Aviv Foerder Institute for Economic Research Working Paper: 13-90; Department of Economics, Tel Aviv University, Ramat Aviv 69978, Tel Aviv, ISRAEL. PG 23. PR no charge. JE F41, F23, F31, F21. KW Currency. Foreign Investment. Multinational Firms. Exchange Rate. Futures Markets.

AB In this paper we consider a monopolistic, risk averse two-country firm which sells and produces at home and abroad under exchange rate uncertainty. We analyze the impact of currency futures markets, the impact of direct investments and the effects of the fluctuating exchange rate when no risk sharing mechanism is available. First, we investigate the effects of uncertainty without any futures markets. It is shown that the firm internalizes such missing insurance devices by increasing foreign production and lowering foreign sales. Second, the implications of futures markets for production, sales, and foreign investments are discussed. In a long-run analysis it is shown that establishing currency futures markets results in a lower labor intensity and that the level of firm specific capital increases. Provided that the risk premium is not too high foreign investments are higher with futures markets.

\section{Bronsard, C.}

PD September 1990. TI From a Hicks-Grandmont Temporary Equilibrium to a Rational Expectation Equilibrium and Conversely. AU Bronsard, C.; Salvas-Bronsard, L.; Trognon, A. AA Bronsard: University of Montreal and CEPREMAP. Salvas-Bronsard: University of Montreal and INSEE. Trognon: INSEE. SR Unite de Recherche Document de Travail ENSAE/INSEE: 9017; INSEE, Unite de Recherche, 18 Bd. Adolphe Pinard, 75675 Paris cedex 14, FRANCE. PG 28. PR no charge. JE D51, D45. KW Rational Expectations. Rationing.

AB A condition is given under which a Hicks-Grandmont equilibrium is a rational expectations equilibrium. A generic 
converse holds: the condition is recovered when a rational expectations equilibrium is a Hicks-Grandmont equilibrium. Finally, the condition can be used to decompose the price-effect and scrutinize the "interior" of the REH. A "law of demand" supposes a further axiomatization of the Roy-consistency type.

PD October 1990. TI The Producer and the Real Balance Effect. AU Bronsard, C.; Ouellette, P.; Salvas-Bronsard, L. AA Bronsard: University of Montreal and CEPREMAP. Ouellette: University of Montreal. Salvas-Bronsard: University of Montreal and INSEE. SR Unite de Recherche Document de Travail ENSAE/INSEE: 9016; INSEE, Unite de Recherche, 18 Bd. Adolphe Pinard, 75675 Paris cedex 14, FRANCE. PG 31. PR no charge. JE D51, D21, E23. KW Production. Hotelling Lemma. Expectations. Factor Demand. Shephard Lemma.

AB In this paper, an axiomatization of expectation functions is presented such that a generalized Hotelling lemma can be stated in a temporary context (an economy where exchange occurs sequentially). The Modigliani-Miller theorem is recovered when this lemma is reduced to the classical Hotelling's lemma through further restrictions on expectations. A complete system of conditional factor demand functions is characterized when the generalized Hotelling lemma is transformed into a generalized Shephard lemma. The Modigliani-Miller theory is directly testable via the structure of real balance effects.

\section{Bruce, Neil}

PD June 1990. TI The Efficiency Effects of Discrete Tax Rate Changes without Lump-Sum Taxes and Transfers. AA Queen's University. SR Queen's Institute for Economic Research Discussion Paper: 782; Department of Economics, Queen's University, Kingston, Ontario, CANADA K7L 3N6. PG 26. PR $\$ 3.00$ Canada and U.S.; $\$ 3.50$ Foreign. JE H21, 138. KW Tax Policy. Taxes.

AB An exact expression for the normalized change in utility resulting from discrete changes in tax rates on economic activities is derived using centain linearity assumptions in preferences. This expression is used to consider alternative ways of identifying the resulting efficiency cost (or excess burden) when lump-sum taxes and transfers are assumed to be unavailable to compensate for revenue changes. Benchmark tax structures other than lump-sum taxation, specifically Ramsey optimal and uniform tax structures, are used to identify the efficiency cost of revenue neutral tax changes. The results are used to explain and extend various known results on the efficiency effects of such tax changes as well as to make an efficiency case for avoiding arbitrary departures from uniformity even when lump-sum taxes are infeasible.

\section{Bryson, John}

TI Small Firms, Business Services Growth and Regional Development in the U.K.: Some Empirical Findings. AU Keeble, David; Bryson, John; Wood, Peter.

\section{Budd, John W.}

PD October 1990. TI Pattern Bargaining and UAW Wage Determination: An Empirical Examination. AA Princeton University. SR Princeton Industrial Relations Section Working Paper: 275; Industrial Relations Section, Department of Economics, Princeton University, Princeton, NJ 08544-2098. PG 46. PR \$1.50. JE J51, J53, L62. KW United Auto Workers. Unions. Collective Bargaining. Negotiations.
Automobiles. Manufacturing.

AB The bargaining behavior of the UAW is well-known: the pattern set by a target settlement in the automobile industry serves as the union's goal in subsequent UAW contracts in many industries. Two new data sets covering UAW contract outcomes are constructed to estimate the empirical importance of the target outcome for subsequent negotiations in the postwar period up to 1979. Conditions determining variations in the amount of uniformity achieved by pattern following in both wage levels and percent increases are analyzed. Bargaining unit size and industry are found to have important influences on pattern following while measures of firm profitability do not.

\section{Buddin, Richard}

PD June 1989. TI Weight Problems and Attrition of High-Quality Military Recruits. AA Rand Corporation. SR Rand Note: N-2847; The Rand Corporation, 1700 Main Street, P.O. Box 2138, Santa Monica, CA 90406-2138. PG 35. PR not available. JE J45, H56. KW Armed Forces. Military Personnel.

AB Despite recent interest in the physical standards for screening recruits in the Armed Services, few studies have been done on the relationship between recruit weight problems and military personnel attrition. This note examines the implications of physical standards for restricting the accession of recruits with weight problems and considers whether potentially overweight recruits who are allowed to enlist have higher rates of premature separation form the military than recruits from average weight categories. It presents separate analyses of the relationship between attrition and weight, by Service, gender, and training phase of the enlisted term.

\section{Buiter, Willem $\mathbf{H}$.}

PD December 1989. TI The "Gold Standard Paradox" and Its Resolution. AU Buiter, Willem H.; Grilli, Vittorio U. AA Buiter: Yale University and Center for Economic Policy Research. Grilli: Yale University. SR Centre for Economic Policy Research Discussion Paper: 361; Centre for Economic Policy Research, 6 Duke of York Street, London SWIY 6LA, UNITED KINGDOM. PG 53. PR 2.00 pounds (\$4.00). JE F31, E42, E52. KW Exchange Rates. Speculation. Foreign Exchange. Monetary Regimes.

AB This paper analyzes Krugman's contention that there is a "gold standard paradox" in the speculative attack literature. The paradox occurs if a country's currency appreciates after it runs out of gold or equivalently if a speculative attack can happen only after the country "naturally" runs out of reserves. We first show that Krugman's paradox is a very general phenomenon, which does not require mean-reverting processes for the fundamentals, and which can be present in discrete time models as well as in continuous time models. We present several specific cases in which the paradox occurs, i.e., environments which do not support an equilibrium. Next we show that, contrary to Krugman's conjecture, it is not necessary to abandon the assumption of a perfectly fixed exchange rate in favor of a band system in order to recover a well-defined equilibrium. We propose two alternative ways of amending the model which produce an equilibrium and preserve the fixed exchange rate assumption.

PD February 1990. TI Debt, Deficits and Inflation: An Application to the Public Finances of India. AU Buiter, Willem H.; Patel, Urjit R. AA Yale University. SR Yale Economic Growth Center Discussion Paper: 593; Economic 
Growth Center, Yale University, 27 Hillhouse Avenue, New Haven, CT 06520. PG 58. PR \$2.00 + Postage. JE O11, O53, H60. KW Public Sector. India. Public Debt. Seigniorage.

AB The paper studies the solvency of the Indian public sector and the eventual monetization and inflation implied by stabilization of the debt-GNP ratio without any changes in the primary deficit. The nonstationarity of the discounted public debt suggests that indefinite continuation of the pattern of behavior reflected in the historical discounted debt process is inconsistent with the maintenance of solvency. This message is reinforced by the recent behavior of the debt-GNP ratio and the ratio of primary surplus plus seigniorage to GNP. Our estimates of the base money demand function suggest that even maximal use of seigniorage will not be sufficient to restore solvency.

TI Persistent Differences in National Productivity Growth Rates with a Common Technology and Free Capital Mobility. AU Kletzer, Kenneth M.; Buiter, Willem $\mathrm{H}$.

\section{Burda, Michael C.}

PD March 1990. TI Intertemporal Prices and the U.S. Trade Balance in Durable Goods. AU Burda, Michael C.; Gerlach, Stefan. AA Burda: INSEAD. Gerlach: Brandeis University. SR Centre for Economic Policy Research Discussion Paper: 379; Centre for Economic Policy Research, 6 Duke of York Street, London SWIY 6LA, UNITED KINGDOM. PG 30. PR 2.00 pounds $(\$ 4.00)$. JE F32, F31. KW Durable Goods. Trade Balance. Current Account. AB This paper shows that virtually all of the rapid worsening of the U.S. trade deficit since 1982 can be attributed to the balance on durable goods. Moreover, this deterioration has been concentrated in capital goods rather than consumer durables or automobiles. In the context of a simple model, we show that the key distinction between the trade balance in nondurables and durables is the role of intertemporal prices in the latter. This result suggests that the deficit on durables may be due to a reduction of their intertemporal prices associated with, among other things, the temporary appreciation of the dollar in the early 1980s. The key role of intertemporal prices is confirmed by our econometric findings.

\section{Caillaud, Bernard}

PD 1989. TI Noisy Observation in Adverse Selection Models. AU Caillaud, Bernard; Guesnerie, Roger; Rey, Patrick. AA Caillaud: CEPREMAP. Guesnerie: DELTA, Paris. Rey: ENSAE, Paris. SR CEPREMAP Discussion Paper: 8921; CEPREMAP, 142 rue du Chevaleret, 75013 Paris, FRANCE. PG 32. PR 20 ff. JE C78, D82. KW Principal-Agent Model . Bargaining. Contracts. Incomplete Information.

AB We consider a principal-agent contracting problem under incomplete information where some of the agent's actions are imperfectly observable. Contracts take the form of noisy reward schedules, where transfers depend on the observable signals. We first review situations where an optimal noisy reward schedule allows the principal to reach his pure adverse selection utility despite the imperfection of observation. Among all possible schedules, those linear with respect to the imperfectly observed variables implement a given adverse selection mechanism independently of the specification of the noise and are thus desirable. We exhibit sufficient conditions under which linear reward schedules implement a given mechanism. Finally, we characterize necessary conditions for a mechanism to be implementable under noisy observation by a linear schedule, and by quadratic schedules. We give the geometric intuition behind all results.

PD 1989. TI The Role of Outside Considerations in the Design of Compensation Schemes. AU Caillaud, Bernard; Hermalin, Benjamin. AA Caillaud: CEPREMAP. Hermalin: University of California, Berkeley. SR CEPREMAP Discussion Paper: 8922; CEPREMAP, 142 rue du Chevaleret, 75013 Paris, FRANCE. PG 49. PR 20 ff. JE C78, D82, L22. KW Principal-Agent Model. Asymmetric Information. Bargaining Theory.

AB In this paper, we analyze a principal-agent relationship under incomplete information, where the principal foresees a future interaction with a third party. As the parameter of asymmetric information also plays a role in the interaction with the third party, the principal may alter both the output targets assigned to the agent and the agent's compensation schedule relative to the no-third-party situation, in order to manipulate what information is revealed through the contract to the third party. The form of the optimal contract is shown to depend heavily on the observability of the contracting game by the third party, as well as on the importance of revealing or concealing information. We also present applications to models of entry deterrence when the firm is viewed as a ownermanager hierarchy, and empirical implications on the pattern of managerial compensation schemes.

\section{Callen, Jeffrey $L$.}

TI Opportunistic Behavior in Debt Renegotiations and the Capital Structure of the Firm. AU Bergman, Yaacov Z.; Callen, Jeffrey L.

\section{Calvo, Guillermo A.}

PD October 1990. TI Optimal Maturity of Nominal Government Debt: The First Tests. AU Calvo, Guillermo A.; Guidotti, Pablo E.; Leiderman, Leonardo. AA Calvo and Guidotti: International Monetary Fund. Leiderman: Tel Aviv University. SR Tel Aviv Foerder Institute for Economic Research Working Paper: 29-90; Department of Economics, Tel Aviv University, Ramat Aviv 69978, Tel Aviv, ISRAEL. PG 14. PR no charge. JE H63. KW Taxes. Government Revenue. Government Bonds. Government Debt. AB We report a first set of empirical results obtained from estimating, on U.S. data, a model of the optimal maturity structure of nominal government debt in a context where there is no full policy precommitment and markets are incomplete.

PD May 1991. TI From Centrally-Planned to Market Economies: The Road from CPE to PCPE. AU Calvo, Guillermo A.; Frenkel, Jacob A. AA Calvo: Intemational Monetary Fund. Frenkel: International Monetary Fund and National Bureau of Economic Research. SR National Bureau of Economic Research Working Paper: 3698; National Bureau of Economic Research, 1050 Massachusetts Avenue, Cambridge, MA 02138. PG not available. PR \$2.00. JE P22, P23, P51, E44. KW Credit Markets. Prices. Market Economy. Capitalism. Socialism. Political Science.

AB This paper deals with the early stages of transformation of centrally-planned economies (CPEs) into market economies during which expectations play a key role. It focuses on the transitional phase during which the economy is not any more a CPE but has not yet become a market economy. During this phase the economy is referred to as a "previously centrally- 
planned economy" (PCPE). A simple model is developed to analyze the consequences of expected price liberalization. The model highlights the anticipatory character of economic behavior during the early stages of the transformation process. A major focus is given to credit markets.

\section{Canova, Fabio}

PD April 1990. TI Are Exchange Rates Really Random Walks? AA Brown University. SR Brown University Department of Economics Working Paper: 90-16; Department of Economics, Brown University, Providence, RI 02912. PG 34. PR no charge. JE F31, F32, E37. KW Exchange Rates. Bayesian Analysis. Forecasting. Economic Fluctuations.

AB This paper employs a multivariate Bayesian time varying coefficients (TVC) approach to model and forecast exchange rate data. It is shown that, if used as a data generating mechanism, a TVC model induces nonlinearities in the conditional moments and leptokurtosis in the unconditional distribution of the series. It is also shown that leptokurtic behavior disappears under time aggregation. Several studies have demonstrated that the empirical distribution of exchange rate data displays these features. As a forecasting device, a Bayesian TVC model produces significant improvements over a random walk model. The improvements are robust to various changes in the forecasting environment.

PD June 1990. TI Forecasting a Multitude of Time Series with Common Seasonal Patterns. AA Brown University. SR Brown University Department of Economics Working Paper: 90-21; Department of Economics, Brown University, Providence, RI 02912. PG 35. PR no charge. JE E32, E37, C11. KW Seasonality. Common Factors. Autoregressive Models. Forecasting.

AB This paper proposes a methodology for modeling and forecasting series which possess common patterns at seasonal and/or other frequencies. The approach is in the Bayesian autoregression tradition originally developed by Litterman (1980); Doan, Litterman and Sims (1984); and Sims (1989) and builds common patterns directly into the prior of the coefficients of the model by means of a set of uncertain linear restrictions. To gauge the usefulness of the approach, the procedure is applied to a problem of forecasting a small vector of national industrial production indices.

\section{Card, David}

PD December 1990. TI The Effects of Minimum Wage Legislation: A Case Study of California, 1987-89. AA Princeton University. SR Princeton Industrial Relations Section Working Paper: 278; Industrial Relations Section, Department of Economics, Princeton University, Princeton, NJ 08544-2098. PG 46. PR \$1.50. JE J21, J22, J31, J38. KW Minimum Wage. Legislation. Public Policy. Labor Force. Wages. Employment.

AB In July 1988 California's minimum wage rose from $\$ 3.35$ to $\$ 4.25$. During the previous year, 11 percent of California workers and fully one-half of its teenage workers earned less than the new state minimum. The state-specific nature of the California increase provides a valuable opportunity to study the effects of minimum wage legislation. As in a conventional non-experimental program evaluation, labor market trends in other states can be used to infer what should have happened in California in the absence of the law. Drawing on published labor market statistics and microdata samples from the Current
Population Survey, I apply this strategy to estimate the effects of the rise in the minimum wage on various groups and industries in the state. Special attention is paid to teenage workers and employees in retail trade.

PD May 1991. TI School Quality and Black-White Relative Earnings: A Direct Assessment. AU Card, David; Krueger, Alan B. AA Princeton University and National Bureau of Economic Research. SR National Bureau of Economic Research Working Paper: 3713; National Bureau of Economic Research, 1050 Massachusetts Avenue, Cambridge, MA 02138. PG not available. PR \$2.00. JE N32, J31, J24, I21. KW Wage Differential. Education. Human Capital.

AB The average wage differential between black and white men fell from 40 percent in 1960 to 25 percent in 1980. Much of this convergence is attributable to a relative increase in the rate of return to schooling among black workers. It is widely argued that the growth in the relative return to black education reflects the dramatic improvements in the quality of black schooling over the past century. To test this hypothesis we have assembled data on three aspects of school quality -- pupilteacher ratios, annual teacher pay, and term length -- for black and white schools in 18 segregated states from 1915 to 1966.

PD May 1991. TI Do Minimum Wages Reduce Employment? A Case Study of California, 1987-1989. AA Princeton University and National Bureau of Economic Research. SR National Bureau of Economic Research Working Paper: 3710; National Bureau of Economic Research, 1050 Massachusetts Avenue, Cambridge, MA 02138. PG not available. PR \$2.00. JE J38, J23. KW Minimum Wage Law. Labor Demand. Employment.

AB In July 1988 California's minimum wage rose from $\$ 3.35$ to $\$ 4.25$. In the previous year, 11 percent of California workers and fully one-half of its teenage workers earned less than the new state minimum. The state-specific nature of the California increase provides a valuable opportunity to study the effects of minimum wage legislation. As in a conventional nonexperimental program evaluation, labor market trends in other states can be used to infer what would have happened in California in the absence of the law. Drawing on published labor market statistics and microdata samples from the Current Population Survey, I apply this strategy to estimate the effects of the rise in the minimum wage on various groups and industries in the state.

\section{Case, Anne C.}

PD May 1991. TI The Company You Keep: The Effects of Family and Neighborhood on Disadvantaged Youths. AU Case, Anne C.; Katz, Lawrence F. AA Case: Princeton University and National Bureau of Economic Research. Katz: Harvard University and National Bureau of Economic Research. SR National Bureau of Economic Research Working Paper: 3705; National Bureau of Economic Research, 1050 Massachusetts Avenue, Cambridge, MA 02138. PG not available. PR \$2.00. JE J11, J13, A14. KW Children Poverty. Human Capital. Peer Groups. Family. Neighborhoods. AB We examine the effects of family background variables and neighborhood peers on the behaviors of inner-city youths in a tight labor market using data from the 1989 NBER survey of youths living in low-income Boston neighborhoods. We find that family adult behaviors are strongly related to analogous youth behaviors. The links between the behavior of older family members and youths are important for criminal activity, 
drug and alcohol use, childbearing out of wedlock, schooling, and church attendance. We also find that the behaviors of neighborhood peers appear to substantially affect youth behaviors in a manner suggestive of contagion models of neighborhood effects.

\section{Caskey, John P.}

PD July 1988. TI The IMF and Concerted Lending in Latin American Debt Restructurings: A Formal Analysis. AA Federal Reserve Bank of Kansas City and Swarthmore College. SR Federal Reserve Bank of Kansas City Research Working Paper: 88-03; Research Division, Federal Reserve Bank of Kansas City, 925 Grand Ave., Kansas City, MO 64198. PG 24. PR no charge. JE F33, G21, F34. KW International Monetary Fund. Latin America. Debt Restructuring. Sovereign Debt.

AB This paper models the IMF's policy of making its participation in an adjustment program contingent on a commitment by banks to finance the associated debt restructuring. The analysis shows that the tactic pressures smaller banks, tempted not to participate in sovereign debt restructurings, to participate. However, it is also shown that the bank participation rate falls as required new lending rises. Furthermore, the incentive for banks to choose not to participate rises as the probability of a future default rises and as bank capital increases.

PD March 1989. TI Price Flexibility and Macroeconomic Stability: An Empirical Simulation Analysis. AU Caskey, John P.; Fazzari, Steven. AA Caskey: Swarthmore College. Fazzari: Washington University. SR Federal Reserve Bank of Kansas City Research Working Paper: 89-02; Research Division, Federal Reserve Bank of Kansas City, 925 Grand Ave, Kansas City, MO 64198. PG 31. PR no charge. JE E31, E32, E37. KW Prices. Inflation. Business Cycle. Macroeconomic Model.

AB In standard theoretical macroeconomic models, price flexibility stabilizes the economy. The more quickly prices fall (or inflation decreases) in a recession, the faster output returns to its full employment level. Recent theoretical work, however, casts doubt on this notion. Some theorists argue that falling prices can raise real interest rates and dampen aggregate demand. Others see contractionary effects from widespread financial distress caused by unexpected deflation. In this paper, we present findings from empirically based simulations of a small dynamic macro model designed to examine these issues. Our results show that, for a number of credible specifications and parameter values, greater price flexibility following a negative demand shock magnifies the severity of the subsequent contraction.

PD December 1989. TI Pawnbroking in America: The Economics of a Forgotten Credit Market. AA Swarthmore College. SR Federal Reserve Bank of Kansas City Research Working Paper: 89-17; Research Division, Federal Reserve Bank of Kansas City, 925 Grand Ave., Kansas City, MO 64198. PG 26. PR no charge. JE G21, 131. KW Credit Market. Poverty. Credit Rationing.

AB Drawing on data from state regulatory agencies and interviews with pawnbrokers, this paper examines the role of pawnbroking in U.S. credit markets. Among the findings presented are the following: Pawn shops serve as a source of credit to millions of low income Americans, providing average secured loans of about $\$ 50$ with one and two month maturity periods. Most states regulate pawn shop interest rates, with ceiling APR interest rates varying across the states from 36 percent to 300 percent. Given this variation, pawn shops are highly unequally distributed across the U.S., with the vast majority in Southern and Central mountain states which tend to have the most generous usury ceilings. Pawn shop default rates average about 20 percent. Pawn shop credit is somewhat cyclical; the average loan size increases when the economy is doing well.

\section{Cass, David}

PD December 1990. TI Incomplete Financial Markets and Indeterminacy of Competitive Equilibrium. AA University of Pennsylvania. SR University of Pennsylvania Center for Analytic Research in Economics and the Social Sciences (CARESS) Working Paper: 90-23; University of Pennsylvania, Center for Analytic Research in Economics and the Social Sciences, McNeil Building, 3718 Locust Walk, Philadelphia, PA 19104-6297. PG 45. PR no charge. JE D52, D58, C62. KW Competitive Equilibrium. Incomplete Markets.

AB The general conception of this line of inquiry is to broaden the canonical Walrasian or competitive equilibrium paradigm -- a la Arrow-Debreu -- to encompass (with regard to the economy's financial sector) richer institutional structure and various market failures. As one might have predicted, this research has focused on the three classical issues in general equilibrium theory, existence, optimality and uniqueness or, better, determinacy.

\section{Chae, Suchan}

PD December 1989. TI An N-Person Pure Bargaining Solution. AU Chae, Suchan; Yang, Jeong-Ae. AA Chae: University of British Columbia and Rice University. Yang: Rice University. SR University of British Columbia Department of Economics Discussion Paper: 89-28; University of British Columbia, \#997-1873 East Mall, Vancouver, BC V6T IW5, CANADA. PG 26. PR $\$ .20$ per page Canadian to other than educational institutions. JE C78, C72. KW Perfect Equilibrium. Game Theory. Bargaining. Nash Equilibrium.

AB We propose an n-person bargaining solution which is parameterized by the costs of bargaining, generalizing Rubinstein's two-person solution. This solution approaches a weighted Nash solution as the costs of bargaining become negligible. We also present an n-person bargaining process which yields the solution as the unique perfect equilibrium outcome.

\section{Chan, Anthony}

PD June 1990. TI A Cross-Sectional Analysis of Mutual Funds' Market Timing and Security Selection Skill. AU Chan, Anthony; Chen, Carl R.; Lee, Cheng F.; Rahman, Shafigur. AA Federal Reserve Bank of New York. SR Federal Reserve Bank of New York Research Paper: 9014; Federal Reserve Bank of New York, 33 Liberty St., Rm. 901, New York City, New York 10045. PG 30. PR no charge. JE G11, G14. KW Mutual Funds. Portfolio Choice.

AB This paper analyzes security selection and market timing abilities of a sample of mutual fund managers. The factors which may have an impact on disaggregated performance measures are investigated. The results indicate weak asset 
selection and negative market timing skills for average portfolio managers. It was also found that expense ratio, size, load fee and stated objective contribute to cross-sectional variations in selectivity and market timing activity of mutual funds. Nonetheless, direction and magnitude of these impacts tend to vary across different objective groups of funds.

PD July 1990. TI An Empirical Examination of Government Expenditures and the Ex-Ante Crowding Out Effect for the British Economy. AU Chan, Anthony; Gustafson, Elizabeth. AA Federal Reserve Bank of New York. SR Federal Reserve Bank of New York Research Paper: 9017; Federal Reserve Bank of New York, 33 Liberty St., Rm. 901, New York City, New York 10045. PG 16. PR no charge. JE E62, E13, E21, H31. KW Consumption. Government Expenditures. Fiscal Policy. Government Spending.

AB The conventional macroeconomic view that consumers make their consumption decisions without regard for goods provided by the government has been examined in the literature. Moreover, the line of research that questions this conventional view argues that this separation does not have a firm theoretical backing. If consumers take government expenditures into account when maximizing their utility functions then the effects of fiscal policy actions will tend to appear weaker than those suggested by most conventional analyses. This paper will empirically examine the ex ante crowding-out effect of government expenditures upon private consumption expenditures for the British economy.

PD September 1990. TI How Well do Asset Allocation Managers Allocate Assets? AU Chan, Anthony; Chen, Carl R. AA Federal Reserve Bank of New York. SR Federal Reserve Bank of New York Research Paper: 9021; Federal Reserve Bank of New York, 33 Liberty St., Rm. 901, New York City, New York 10045. PG 25. PR no charge. JE G11, G14. KW Market Efficiency. Mutual Funds. Portfolio Choice. AB This paper analyzes the total and disaggregated performances of a specialized type of mutual fund named asset allocation funds. These funds reportedly move assets in and out of the market among different market sectors based upon the signals emitted by various market indicators. Weekly data results for individual funds find some stock selection ability. However, this result is not observed when monthly data is employed and is not found when the funds are grouped into portfolios. Moreover, this study finds no evidence that may support the notion that these types of funds excel in the timing of market movements. Finally, the Sharpe and Treynor conventional performance measures demonstrate that the total performance of these funds was inferior when compared to the market portfolio.

PD November 1990. TI Are the Preliminary Announcements of Some Macroeconomic Variables Rational? AU Chan, Anthony; Dhawale, Hareesh. AA Federal Reserve Bank of New York. SR Federal Reserve Bank of New York Research Paper: 9035; Federal Reserve Bank of New York, 33 Liberty St., Rm. 901, New York City, New York 10045. PG 17. PR no charge. JE E27, C82, D33. KW Forecasting. National Income Accounts.

AB This study examines whether (nominal) preliminary estimates of gross national product, wages and salaries, total personal consumption and disposable personal income are rational forecasts of the final estimates. Data is analyzed from 1966:1 to 1990:1 and for two subsamples i.e., 1966:1 to 1978:1 and 1978:2 to 1990:1. Unbiasedness and efficiency tests surprisingly reveal that data for these variables has actually improved over time. These results run counter to the literature which contends that economic data has recently become less reliable.

\section{Chang, Roberto}

PD January 1991. TI Bargaining a Monetary Union. AA New York University. SR New York University Economic Research Reports: 91-02; New York University, Faculty of Arts and Science, Department of Economics, Washington Square, New York, N.Y. 10003. PG 54. PR no charge. JE F11, F15, F33, C78, F41. KW Bargaining. Monetary Union.

AB Two governments bargain over the distribution of the benefits of a monetary union in a cash-in-advance world. Because households trade every period, private expectations about the bargaining outcome affect and are affected by the game played by the governments. I introduce the concept of sustainable bargaining equilibrium (SBE) to characterize the solutions of this problem. All agents are perfectly informed and act rationally. However, there is a continuum of SBE payoff partitions indexed by private expectations. Some SBEs imply delay for an arbitrary number of periods. The determinants of the negotiated agreement in each SBE are discussed.

\section{Che, Yeon Koo}

PD August 1989. TI Design Competition Through Multi-Dimensional Biddings. AA Stanford University. SR Stanford Center for Economic Policy Research Discussion Paper Series: 183; 100 Encina Commons, Stanford University, Stanford CA 94305. PG 49. PR no charge for members of non-profit institutions, $\$ 3.00$ otherwise. JE D44, C78. KW Bidding. Value Equivalence. Quality Bias. Auctions. Price Competition.

AB Traditional auction theory, by focusing only on the price competition, fails to recognize the distinctive feature of the DoD source selection: the design competition. To study the feature, we present a general model of two-dimensional auctions, where bidders bid on both price and quality. The model is general in that it encompasses the single dimensional and other restrictive forms of two-dimensional auctions as special, sub-optimal cases. As implementable and somewhat realistic schemes, we consider three different two-dimensional auctions: (1) first value, (2) second value, (3) second preferred offer.

PD April 1990. TI The Role of Precedent in Repeated Litigations. AU Che, Yeon Koo; Yi, Jong Goo. AA Stanford University. SR Stanford Center for Economic Policy Research Discussion Paper Series: 201; 100 Encina Commons, Stanford University, Stanford, CA 94305. PG 28. PR no charge for members of non-profit institutions, $\$ 3.00$ otherwise. JE K41, K10. KW Litigation. Common Law. Law. Legal System.

AB We apply the two period litigation model with asymmetric information, developed by Che and Yi (1990), to examine the roles of precedent, an important aspect of the common law system. We postulate that precedent creates two different forms of decision inertia in successive trials: (1) correlated decisions (winning probabilities); and (2) correlated damages. With this framework, we find: (i) the defendant is more willing to settle out of the court when an unfavorable precedent is more likely to be set, resulting in a high settlement 
rate; (ii) precedent tends to create so called "landmark' cases, in which an initial decision matters a lot and the involved parties engage in pre-emptive campaigns to turn the precedent in their favor, which could be socially wasteful; and (iii) correlated decisions tend to penalize the plaintiff with low winning probability and discourage the nuisance suits.

PD April 1990. TI Litigations with Multiple Plaintiffs: The Case of Effort Externality. AU Che, Yeon Koo; Yi, Jong Goo. AA Stanford University. SR Stanford Center for Economic Policy Research Discussion Paper Series: 200; 100 Encina Commons, Stanford University, Stanford, CA 94305. PG 37. PR no charge for members of non-profit institutions, $\$ 3.00$ otherwise. JE K41, K10. KW Litigation. Class Action Suits. Legal System. Law. Settlement.

AB In this paper, we analyze the disputing parties' litigation behavior in a sequential/multiple plaintiff context, focusing on "effort externality". Effort externality arises when the first plaintiff's investigative effort uncovers a critical information which can be shared and used by subsequent plaintiffs in launching a successful trial case against the same defendant. Postulating that the information transmission is greater through trials than through settlements, we find that the defendant is more willing to settle with the initial plaintiff than would be suggested by the single plaintiff model. Thus, the external effect spills back over to the first plaintiff. However, if the externality is substantial, there may be a significant second-mover advantage on the part of the plaintiffs, which might result in delays in bringing suits. Finally, this informational/effort externality is shown to lead to plaintiffs opting-out of coordinated class actions.

PD May 1990. TI Eliciting Multi-Dimensional Care through Liability and Regulation. AA Stanford University. SR Stanford Center for Economic Policy Research Discussion Paper Series: 199; 100 Encina Commons, Stanford University, Stanford, CA 94305. PG 30. PR no charge for members of non-profit institutions, $\$ 3.00$ otherwise. JE K32, K13. KW Liability. Legal Standards. Safety Regulation. Legal System. Negligence.

AB This paper examines the incentive performance of liability and regulation when a potential injurer can take two types of preventative care, one of which is observed and one of which is not. The problem is studied in a general asymmetric information model, where settlement behavior is endogenous and which incorporates an uncertain legal standard. Contrary to existing literature, we find: (1) a shift to a negligence rule may have a perverse effect on unobserved care; (2) uncertainty in legal standards may be socially beneficial as it provides a relatively good incentive for unobserved care; (3) a regulation may not be effective if preventative care efforts are substitutes but is effective if they are complements; (4) an increase in the settlement rate may or may not increase in the level of care, depending on the cause of the increase; (5) a "decouping" arrangement with a feature that the defendant pays more than the plaintiff recovers, reduces legal costs and is therefore socially beneficial.

\section{Chen, Carl R.}

TI A Cross-Sectional Analysis of Mutual Funds' Market Timing and Security Selection Skill. AU Chan, Anthony; Chen, Carl R.; Lee, Cheng F.; Rahman, Shafigur.

TI How Well do Asset Allocation Managers Allocate
Assets? AU Chan, Anthony; Chen, Carl R.

\section{Cheng, Leonard $\mathrm{K}$}

PD October 1990. TI A Schumpeterian Model of Economic Growth and Fluctuations. AU Cheng, Leonard K; Dinopoulos, Elias. AA University of Florida. SR University of Florida Working Paper in Economics: 9010; Department of Economics, University of Florida, Gainesville, FL 32611. PG 54. PR no charge. JE O41, O32, E32. KW Endogenous Growth. Business Fluctuations. R\&D. Technology.

AB We develop a dynamic general equilibrium, multisectoral model of endogenous economic growth and fluctuations. Economic agents optimize intertemporally under rational expectations and full employment. The Schumpeterian process of creative destruction is modeled by a sequence of $R \& D$ races to discover superior quality products. The winner of each R\&D race enjoys temporary monopoly power for a period which is equal to an exogenously given imitation lag. We show that there is no steady-state growth equilibrium. Economic fluctuations are caused by the introduction of diminishing returns to quality improvements coupled with the possibility of replenishing the opportunities of improvements with new breakthroughs.

\section{Chew, W. Bruce}

PD August 1989. TI Measurement, Coordination, and Learning in a Multiplant Network. AU Chew, W. Bruce; Clark, Kim B.; Bresnahan, Timothy. AA Chew and Clark: Harvard Business School. Bresnahan: Stanford University. SR Stanford Center for Economic Policy Research Discussion Paper Series: 174; 100 Encina Commons, Stanford University, Stanford CA 94305. PG 37. PR no charge for members of non-profit institutions, $\$ 3.00$ otherwise. JE D21, D24, L23, O32. KW Productivity. Learning. Technology. Industrial Organization.

AB Large differences in productivity among plants in the same firm making the same products pose parallel problems for economists and managers. Why have the techniques and practices used at the more productive plants not spread to the rest of the firm? How can the firm's central mangement encourage this spread? We study differences in productivity across the plants of a firm operating many commercial kitchens. As in other industries, even after controlling for product mix, local labor market, and the level of investment, we find large differences in productivity. We analyze the organizational, informational, and incentive issues that inhibit the spread of technology within the particular firm. These lead to general observations about the role of quantitative plant performance measures in organizational design.

\section{Chiswick, Barry R.}

PD July 1990. TI Language in the Labor Market: The Immigrant Experience in Canada and the United States. AU Chiswick, Barry R.; Miller, Paul W. AA Chiswick: University of Illinois at Chicago. Miller: Queen's University. SR Queen's Institute for Economic Research Discussion Paper: 784; Department of Economics, Queen's University, Kingston, Ontario, CANADA K7L 3N6. PG 88. PR $\$ 3.00$ Canada and U.S.; $\$ 3.50$ Foreign. JE J61, J21. KW Language. Immigrants. Wages.

AB This paper explores the determinants and labor market consequences for immigrants of proficiency in speaking the 
dominate language (English in the U.S., English or French in Canada). The statistical analysis is for adult men using the self-reported data, including data on language skills, available in the 1980 and 1981 censuses of the U.S. and Canada, respectively. Fluency in the dominant language in the two countries is shown to vary systematically with the immigrant's skills, demographic characteristics, country of origin and economic incentives.

\section{Cho, Jang-Ok}

PD March 1990. TI Ex Post Heterogeneity and the Business Cycle. AA Queen's University. SR Queen's Institute for Economic Research Discussion Paper: 788; Department of Economics, Queen's University, Kingston, Ontario, CANADA K7L 3N6. PG 47. PR \$3.00 Canada and U.S.; \$3.50 Foreign. JE E13, E32, E24, E37. KW Business Cycle. Economic Fluctuations. Heterogeneity. Productivity.

AB The reason why the assumption of a representative agent is so popular in the equilibrium business cycle literature is mainly that equilibrium allocations are derived by solving a concave programming problem, whereas once heterogeneity is introduced it is necessary to solve for weights on individual utilities and this generally involves solving a complicated fixed point problem. The representative agent framework is extended in a way that permits workers to have different skills. The key feature is that each agent faces a stochastic productivity ex ante but a different realized productivity ex post from others'. This means that there is no ex ante heterogeneity but ex post heterogeneity, and hence an equal weight is applied to the utilities of all agents. The results show how serious the aggregation problem is in aggregate fluctuations.

PD May 1990. TI Market Structure and the Business Cycle. AA Queen's University. SR Queen's Institute for Economic Research Discussion Paper: 789; Department of Economics, Queen's University, Kingston, Ontario, CANADA K7L 3N6. PG 48. PR $\$ 3.00$ Canada and U.S.; $\$ 3.50$ Foreign. JE E13, E32, E23. KW Business Cycle. Oligopoly. Economic Fluctuations.

AB The key ingredients of real business cycle models are common. The market structure is perfectly competitive, the forcing process is a technology shock, and in most cases agents are identical. Textbook market structures are introduced in a real business cycle model. The market structures studied are perfect competition, monopoly, oligopoly, and monopolistic competition. The results show that economy wide monopoly or two-firm oligopoly with the lechnology shock of the size estimated by Prescott (1986) cannot produce the output volatility observed in the U.S. economy. However, ten-firm oligopoly can mimic the output volatility with the technology shock of the same size.

PD May 1990. TI Money, Nominal Contracts, and the Business Cycle: I. One-Period Contract Case. AA Queen's University. SR Queen's Institute for Economic Research Discussion Paper: 790; Department of Economics, Queen's University, Kingston, Ontario, CANADA K7L 3N6. PG 52. PR \$3.00 Canada and U.S.; \$3.50 Foreign. JE E32, E13, E31, E37. KW Business Cycle. Contracts. General Equilibrium Model.

AB A modified aversion of the nominal contract developed by Gray (1976) and Fischer (1977) is introduced in a general equilibrium model with money which has been used in the real business cycle literature. Money is introduced in the model through cash-in-advance constraint. The contract studied is more efficient than that studied by Gray-Fischer in the sense that the processes involved in the calculation of the nominal contract are not from any other model but from the contract model itself. Two kinds of contract are examined, namely a nominal wage contract and a nominal price contract. A nominal wage contract improves the fit of the model in every respect. In other words, a nominal wage contract resolves almost all the controversies related to the real business cycle approach.

PD August 1990. TI Risk Sharing, Indivisible Labor and Aggregate Fluctuations. AU Cho, Jang-Ok; Rogerson, Richard. AA Cho: Queen's University. Rogerson: Stanford University. SR Queen's Institute for Economic Research Discussion Paper: 787; Department of Economics, Queen's University, Kingston, Ontario, CANADA K7L 3N6. PG 26. PR \$3.00 Canada and U.S.; \$3.50 Foreign. JE E32, E13, E37. KW Economic Fluctuations. Business Cycle.

AB This paper studies fluctuations in a real business cycle model when there is a risk neutral agent present to offer insurance to workers. This economy is compared with one in which there is no risk neutral agent but labor is indivisible. In static models it is difficult to distinguish the risk sharing and indivisible labor economies, but in dynamic models with capital accumulation the indivisible labor model appears to perform better.

\section{Chou, Chien-Fu}

PD November 1990. TI Partially Compatible Brands and Consumer Welfare. AU Chou, Chien-Fu; Shy, Oz. AA Chou: State University of New York at Albany. Shy: Tel Aviv University. SR Tel Aviv Foerder Institute for Economic Research Working Paper: 34-90; Department of Economics, Tel Aviv University, Ramat Aviv 69978, Tel Aviv, ISRAEL. PG 15. PR no charge. JE L63, L52, L22. KW Computer Software. Differentiated Products. Market Power. Computer Industry.

AB We propose an environment for modeling an industry producing differentiated brands which are partially compatible with each other. We show that when each brand is supported by its brand specific supporting services, a firm may increase the variety of its supporting services and its market share by reducing the degree of compatibility of its machine with other machines' supporting services. However, when a firm is not supported by its brand specific supporting services, it can only gain additional market share when it increases the compatibility of its machine. We also show that consumers benefit when machines become more compatible. However, consumers may become worse off and producers become better off when the products become one hundred percent compatible.

PD December 1990. TI Do Consumers Always Gain When More People Buy the Same Brand? AU Chou, ChienFu; Shy, Oz. AA Chou: State University of New York at Albany. Shy: Tel Aviv University and State University of New York at Albany. SR Tel Aviv Foerder Institute for Economic Research Working Paper: 40-90; Department of Economics, Tel Aviv University, Ramat Aviv 69978, Tel Aviv, ISRAEL. PG 21. PR no charge. JE L63, L52, D10. KW Consumers. Computer Industry. Computer Software.

AB We analyze markets for goods in which the consumer's value for a specific brand increases with an increase in the variety of the brand's specific supporting services. We 
demonstrate that consumers are not always better off with an increase in the number of consumers purchasing the same brand even though the variety of the brand specific supporting services may increase. The paper also analyzes the effects of changing the distribution of consumer tastes on the market shares of brand producing firms and the variety of services supporting each brand. Then, we ask whether consumers and firms benefit from having supporting services that are compatible with all brands.

\section{Chung, Alan H.}

TI Globalization, Convergence, and the Prospects for Economic Growth. AU Helliwell, John F.; Chung, Alan H.

\section{Chvatal, Vasek}

PD February 1990. TI Dealing with Hard Problems (Lecture Notes on Approximation Algorithms and Randomized Algorithms). AA University of Bonn. SR Universitat Bonn Sonderforschungsbereich 303 - Discussion Paper: 90646-OR; Sonderforschungsbereich 303 an der Universitat Bonn, Adenauerallee 24-42, D-5300 Bonn 1, DEUTSCHLAND. PG 46. PR no charge. JE C44, C67, C63. KW Approximation Algorithm. Randomized Algorithm. Multiprocessor Systems. Knapsack Problem. Random Graphs. Scheduling Problem.

AB Complex operations often split into simple tasks; there may be precedence constraints specifying that certain tasks must be completed before the execution of others can begin; these precedence constraints form a partial order on the set of all tasks (or else the operation cannot be carried out). Assuming that the execution time $t(x)$ of each task $x$ is known in advance, it is natural to ask how soon can the entire operation be completed. In general, finding an optimal schedule may be very difficult, even when there are no precedence constraints at all and precisely two processors are available. In this case, the problem reduces to splitting a set of numbers into two subsets with subtotals as close to each other as possible; deciding whether this can be done so that the two subtotals match is a well-known NP-complete problem. Hence prospects of finding a fast algorithm to solve the multiprocessor scheduling problem are not very good. A more modest objective is finding a fast algorithm that will always deliver a schedule whose finishing time does not exceed the optimal value by too much.

PD August 1990. TI Which Claw-Free Graphs are Perfectly Orderable? AA University of Bonn. SR Universitat Bonn Sonderforschungsbereich 303 Discussion Paper: 90653-OR; Sonderforschungsbereich 303 an der Universitat Bonn, Adenauerallee 24-42, D-5300 Bonn 1, DEUTSCHLAND. PG 30. PR no charge. JE C61, C60. KW Graph Theory. Matrix Operations. Linear Algebra. AB Lovasz (1979, p. 528) proposed to call a zero-one matrix totally balanced if it does not contain as a submatrix an (edgevertex) incidence matrix of any cycle of length at least three. The purpose of the present paper is to generalize this characterization of totally balanced matrices.

PD September 1990. TI Small Transversals in Hypergraphs. AU Chvatal, Vasek; McDiarmid, C. AA Chvatal: University of Bonn. McDiarmid: Corpus Christi College, Oxford. SR Universitat Bonn Sonderforschungsbereich 303 - Discussion Paper: 90649-OR; Sonderforschungsbereich 303 an der Universitat Bonn, Adenauerallee 24-42, D-5300 Bonn 1, DEUTSCHLAND.
PG 10. PR no charge. JE C60. KW Graph Theory. AB For each positive integer $k$, we consider the set $A(k)$ of all ordered pairs $[a, b]$ such that in every k-graph with $n$ vertices and $m$ edges some set of at most $a m+b n$ vertices meets all the edges. We show that each $A(k)$ with $k$ greater than or equal to 2 has infinitely many extreme points and conjecture that, for every positive epsilon, it has only finitely many extreme points $[a, b]$ with a greater than or equal to epsilon. With the extreme points ordered by the first coordinate, we identify the last two extreme points of every $A(k)$, identify the last three extreme points of $A(3)$, and describe $A(2)$ completely. A by-product of our arguments is a new algorithmic proof of Turan's theorem.

\section{Clark, Jeffrey A.}

PD December 1988. TI Entry Barriers, Market Concentration and Bank Profitability: A Switching Regression Approach. AA Florida State University. SR Federal Reserve Bank of Kansas City Research Working Paper: 88-12; Research Division, Federal Reserve Bank of Kansas City, 925 Grand Ave., Kansas City, MO 64198. PG 29. PR no charge. JE G21, L16, L10. KW Commercial Banks. Banking.

AB The structure-performance paradigm theorizes that in the presence of substantial barriers to entry, the concentration of resources in a small number of firms will produce noncompetitive pricing behaviors that result in monopoly profits. In the absence of substantial entry barriers, noncompetitive pricing and monopoly profits cannot be sustained even when the market is highly concentrated. Most previous empirical tests of this paradigm either do not attempt to assess the extent of entry barriers, or rely on the subjective judgment of the researcher. In this paper, a switching regression methodology is employed to test the hypothesis that the impact of market concentration on the profitability of commercial banks depends upon the overall entry barriers in local banking markets.

\section{Clark, Kim B.}

TI Measurement, Coordination, and Learning in a Multiplant Network. AU Chew, W. Bruce; Clark, Kim B.; Bresnahan, Timothy.

\section{Coate, Malcolm B.}

PD October 1990. TI Exclusion, Collusion and Confusion: The Limits of Raising Rival's Costs. AU Coate, Malcolm B.; Kleit, Andrew N. AA Federal Trade Commission. SR Federal Trade Commission Bureau of Economics Working Paper: 179; Bureau of Economics, Federal Trade Commission, 6th and Pennsylvania Ave. NW, Washington, D.C. 20580. PG 29. PR no charge. JE L22, L42, L12, D42. KW Predation. Monopoly. Vertical Integration. Antitrust Policy. Competition.

AB The 1980's saw the evolution of a vertical antitust theory often referred to as "Raising Rivals' Costs." Our analysis examines this theory and its robustness with respect to a number of assumptions. In addition, the applicability of the theory to two well known cases is evaluated. In these cases, the facts are shown to be inconsistent with the requirements of the theory. It appears that while "Raising Rivals' Costs" is a theoretically valid method of achieving an anticompetitive effect on price, its practical uses are extremely limited. 


\section{Cook, William}

TI A Computational Study of the Job-Shop Scheduling Problem. AU Applegate, David; Cook, William.

\section{Cooper, Russell}

PD November 1990. TI The Aggregate Implications of Machine Replacement Theory and Evidence. AU Cooper, Russell; Haltiwanger, John. AA Cooper: Boston University. Haltiwanger: University of Maryland, College Park. SR University of Maryland Department of Economics Working Paper Series: 90-23; Department of Economics, University of Maryland, College Park, MD 20742. PG 40. PR no charge. JE E22, E23, E32. KW Depreciation. Production. Economic Fluctuations. Investment.

AB This paper studies an economy in which producers must incur resource costs to replace depreciated machines. The process of costly replacement and depreciation creates endogenous fluctuations in productivity, employment and output of a single producer. We also explore the spillover effects of machine replacement on other sectors of the economy and provide conditions for synchronized machine replacement by multiple, independent producers. The implications of our model are generally consistent with observed monthly output and productivity fluctuations in automobile plants and with monthly variations in employment and production in the manufacturing sector.

\section{Copeland, Brian R.}

PD January 1990. TI International Trade in Waste Products in the Presence of Illegal Disposal. AA University of British Columbia. SR University of British Columbia Department of Economics Discussion Paper: 90-01; University of British Columbia, \#997-1873 East Mall, Vancouver, BC V6T IW5, CANADA. PG 19. PR \$.20 per page Canadian to other than educational institutions. JE F14, D62. KW International Trade. Waste Products.

AB This paper develops a simple model of international trade in waste disposal services and investigates the welfare effects of restricting such trade. While the first best policy is to allow free trade in all goods and services and to use internal taxes and regulation to control the externalities associated with waste disposal, such a policy increases the incentives for firms to evade taxes and regulations and dispose of their wastes illegally. In this case, the optimal tax can be lower than it would be in the absence of illegal activity, and trade restrictions on waste disposal can be welfare-improving.

\section{Corsetti, Giancarlo}

PD September 1990. TI Testing for Solvency of the Public Sector. An Application to Italy. AA Yale University. SR Yale Economic Growth Center Discussion Paper: 617; Economic Growth Center, Yale University, 27 Hillhouse Avenue, New Haven, CT 06520. PG 34. PR $\$ 2.00+$ Postage. JE H60, F15, E63. KW Public Debt. Italy. Fiscal Policy. Monetary Policy.

AB Credible participation in the European Monetary Union requires that member countries pursue sustainable fiscal and monetary policies - and solvency is a weak prerequisite for sustainability. Solvency tests develop from the idea of verifying whether the public sector intertemporal budget constraint in a dynamically efficient economy would be met, were both the current fiscal and monetary policy and the macroeconomic environment stable over time. This has an empirical counterpart in a zero unconditional expectation for the series of discounted net public debt, which is the null hypothesis for the time series based tests. The empirical application rejects the null hypothesis of solvency for the general government in Italy, with a caveat suggested by the absence of a consolidated public sector accounts including the vast Italian public holding companies.

\section{Cosh, Andy}

PD August 1990. TI Predicting Success: Pre-Merger Characteristics and Post-Merger Performance. AU Cosh, Andy; Hughes, Alan; Lee, Kevin; Singh, Ajit. AA University of Cambridge. SR University of Cambridge Small Business Research Centre Working Paper: 6; Department of Applied Economics, University of Cambridge, Sidgwick Avenue, Cambridge CB3 9DE, UNITED KINGDOM. PG 24. PR $\$ 5.00$ (2.50 pounds); checks payable to University of Cambridge. JE G34, L22. KW Mergers. Corporations. Takeovers.

AB There is a large body of literature which examines the impact of merger upon corporate performance. With few exceptions studies focus on average outcomes in samples of mergers and ignore the wide dispersion of results around the mean. This paper breaks with the past by asking whether those mergers which do better than average can be distinguished from the rest in terms of their premerger characteristics, including their size, financial performance and shareownership variables. It is shown that it is possible to successfully discriminate between those that succeed and those that fail. The least successful mergers are those which involve the most profitable companies prior to merger. The regression towards the mean which this implies is greater for merging than for non-merging companies. A number of alternative theoretical explanations are considered in interpreting these results.

\section{Costello, Donna M.}

PD October 1990. TI The Dynamic Adjustment of Productivity Growth Across Countries: Implications for Models of Endogenous Economic Growth. AA University of Florida. SR University of Florida Working Paper in Economics: 9012; Department of Economics, University of Florida, Gainesville, FL 32611. PG 49. PR no charge. JE D24, O30, 057. KW Economic Growth. International Trade. Business Cycles. Technology. Productivity. Growth Model.

AB In this paper, I analyze the long-run relationship and short-run dynamics of productivity growth across countries. I employ co-integration to determine if different countries and industries share a common stochastic trend in productivity. I explore the consistency of these results with alternative explanations of the international transmission of macroeconomic disturbances and models of economic growth. There is strong support for the idea that an economic relation among countries' growth arises from the transition of technology. The results are consistent with recent models of endogenous growth.

\section{Cragg, John G.}

PD October 1989. TI Testing Identifiability of Simultaneous Equation Coefficients. AU Cragg, John G.; Donald, Stephen G. AA University of British Columbia. SR University of British Columbia Department of Economics Discussion Paper: 89-23; University of British Columbia, \#997-1873 East Mall, Vancouver, BC V6T 1W5, 
CANADA. PG 36. PR $\$ .20$ per page Canadian to other than educational institutions. JE C $31, \mathrm{C} 13, \mathrm{C} 51$. KW Identification Tests. Simultaneous Equations. Characteristic Roots. Asymptotic Theory.

AB A test based on generalized method of moments considerations, which turns out to be virtually identical to one arising from maximum likelihood for the rank condition for the identifiability of the structural parameters of one of a set of linear simultaneous equations, is explored. An asymptotic expansion suggests a correction to the asymptotic distribution and in addition a jackknife version of the test is explored. A small sampling experiment indicates that the tests are of use.

\section{Craig, Patricia H.}

TI The Divergence of Black and White Marriage Patterns. AU Bennett, Neil G.; Bloom, David E.; Craig, Patricia $H$.

\section{Crane, Keith}

PD May 1988. TI An Assessment of the Economic Reform in Poland's State-Owned Industry. AA Rand Corporation. SR Rand Note: N-2710; The Rand Corporation, 1700 Main Street, P.O. Box 2138, Santa Monica, CA 90406-2138. PG 39. PR not available. JE O52, O11, P21, P26. KW Economic Reform. Poland. Socialism. Government Policy.

AB This note assesses the economic reform in Polish stateowned industry begun in 1982. It describes the system and traces out how the competing policy goals of the Polish government have served to generate a plethora of contradictory regulations that have greatly reduced the potential effectiveness of the reform. Using survey data from interviews with Polish managers, the note finds that administrative constraints on the procurement of inputs, coupled with a distorted price and incentive system, not the psychological attitude of enterprise managers, have limited economic efficiency. Data on investment, employment, and productivity show that resource flows have been the reverse of what one would expect based on enterprise profitability, indication that administrative decisions, not markets, continue to determine the allocation of goods and services in Poland.

\section{Crosson, Pierre}

TI Policy Options for Adaptation to Climate Change. AU Rosenberg, Norman J.; Crosson, Pierre; Easterling, William E., III; Frederick, Kenneth; Sedjo, Roger.

\section{Croushore, Dean D.}

PD September 1989. TI Money in the Utility Function: An Adequate Microfoundation of Money? AA Federal Reserve Bank of Philadelphia. SR Federal Reserve Bank of Philadelphia Research Working Paper: 89-25; Working Papers, Department of Research, Federal Reserve Bank of Philadelphia, 10 Independence Mall, Philadelphia, PA 19106. PG 16. PR no charge (except overseas airmail, \$2.00; checks/money orders in U.S. funds payable to Federal Reserve Bank of Philadelphia.). JE E13, E31. KW Money. Microfoundations. Inflation. Monetary Theory.

AB Does the money-in-the-utility-function (MUF) model provide an adequate microfoundation for monetary theory? Feenstra (1986) argues that it does, by showing an equivalence between the MUF model and other microfoundations-of-money models. This paper raises two difficulties with Feenstra's approach. It then uses his analysis to show that a shopping-time model of money is equivalent to an MUF model and overcomes these two objections. The results are applied to the analysis of optimal inflation.

TI The Welfare Effects of Distortionary Taxation and Government Spending: Some New Results. AU Ahmed, Shaghil; Croushore, Dean D.

PD July 1990. TI Taxation as Insurance Against Income Uncertainty. AA Federal Reserve Bank of Philadelphia. SR Federal Reserve Bank of Philadelphia Research Working Paper: 90-15; Working Papers, Department of Research, Federal Reserve Bank of Philadelphia, 10 Independence Mall, Philadelphia, PA 19106. PG 29. PR no charge (except overseas airmail, \$2.00; checks/money orders in U.S. funds payable to Federal Reserve Bank of Philadelphia.). JE E21, E13, H21. KW Ricardian Equivalence. Taxes. Government Debt. Income Uncertainty.

AB When the wage rate is stochastic and labor supply is elastic, does Ricardian equivalence hold? It does for changes in the timing of lump-sum taxes. But lump-sum taxes are not optimal, because distortionary taxes provide insurance against income uncertainty. In this paper, I calculate the marginal tax rate that maximizes expected utility when the wage rate is uncertain. At this optimum, the marginal propensity to consume from a tax cut (MPCT) varies with the fiscal experiment: (1) with all lump-sum taxes, MPCT=0; (2) cutting a lump-sum tax and increasing a distortionary tax yields MPCT less than 0 (unless labor supply is very inelastic); and (3) reducing a distortionary tax today and increasing one in the future gives MPCT negative but close to zero.

PD January 1991. TI A Measure of Federal Reserve Credibility. AU Croushore, Dean D.; Koot, Ronald S. AA Croushore: Federal Reserve Bank of Philadelphia. Koot: Pennsylvania State University. SR Federal Reserve Bank of Philadelphia Research Working Paper: 91-1; Working Papers, Department of Research, Federal Reserve Bank of Philadelphia, 10 Independence Mall, Philadelphia, PA 19106. PG 22. PR no charge (except overseas airmail, \$2.00; checks/money orders in U.S. funds payable to Federal Reserve Bank of Philadelphia.). JE E31, E37, E58. KW Credibility. Phillips Curve. Inflation. Forecasting. Federal Reserve.

AB We create two credibility variables, one depending on the correspondence between the Fed forecast of inflation and the private sector's forecast, the other between the Fed forecast and actual inflation. These are measures of credibility in terms of whether the public believes that the Fed will carry out its announced policy and whether the policy will have the effect claimed by the Fed. We find that credibility was surprisingly high in the late 1970s. The Fed's change in regime led to little change in credibility. The credibility variables help reduce the forecast errors of the Phillips curve in the early 1980s.

\section{Cunningham, William H.}

TI Matroid Optimization and Algorithms. AU Bixby, Robert E.; Cunningham, William $\mathrm{H}$.

\section{Currie, Janet}

TI An Experimental Comparison of Dispute Rates in Alternative Arbitration Systems. AU Ashenfelter, Orley; Currie, Janet; Farber, Henry S.; Spiegel, Matthew. 


\section{Cutler, David M.}

PD January 1990. TI Speculative Dynamics and the Role of Feedback Traders. AU Cutler, David M.; Poterba, James M.: Summers, Lawrence $H$. AA Poterba: Massachusetts Institute of Technology and National Bureau of Economics. Cutler: Massachusetts Institute of Technology. Summers: Harvard University and National Bureau of Economic Research. SR Massachusetts Institute of Technology Department of Economics Working Paper: 545; Department of Economics, Massachusetts Institute of Technology, Cambridge, MA 02139. PG not available. PR $\$ 6.00$ Domestic, $\$ 8.00$ Overseas, \$2.00 Student. JE G12, G14. KW Asset Pricing. Stock Market. Efficient Market Hypothesis. Asset Markets. Speculation.

AB This paper summarizes our earlier research documenting the characteristic speculative dynamics of many asset markets and suggests a framework for understanding them. Our model incorporates "feedback traders," traders whose demand is based on the history of past returns rather than the expectation of future fundamentals. We use this framework to describe ways in which the characteristic return patterns might be generated, and also to address the long-standing question of whether profitable speculation stabilizes asset markets.

PD January 1990. TI Syeculative Dynamics. AU Cutler, David M.; Poterba, James M.; Summers, Lawrence $H$. AA Poterba: Massachusetts Institute of Technology and National Bureau of Economic Research. Cutler: Massachusetts Institute of Technology. Summers: Harvard University and National Bureau of Economic Research. SR Massachusetts Institute of Technology Department of Economics Working Paper: 544; Department of Economics, Massachusetts Institute of Technology, Cambridge, MA 02139. PG not available. PR $\$ 6.00$ Domestic, $\$ 8.00$ Overseas, \$2.00 Student. JE G12, G14. KW Asset Pricing. Stock Market. Efficient Market Hypothesis. Asset Returns. Speculation.

AB This paper presents evidence on the characteristic speculative dynamics of a wide rage of asset returns. It highlights three stylized facts. First, returns tend to be positively serially correlated at high frequency. Second, returns tend to be negatively serially correlated over long horizons. Third, deviations of asset values from proxies for fundamental value have predictive power for returns. These patterns emerge repeatedly in our analyses of stocks, bonds, foreign exchange, real estate, collectibles, and precious metals, and they appear too strong to be attributed only to small sample biases. The pervasive nature of these patterns suggests that they may be due to inherent features of the speculative process, rather than to variation in risk factors which affect particular markets.

\section{Cvitanic, Marilyn}

TI The Costs and Financing of Care for AIDS Patients: Results of a Cohort Study in Los Angeles. AU Pascal, Anthony; Bennett, Charles L.; Cvitanic, Marilyn; Gorman, Michael; Serrato, Carl.

\section{da Cruz, EImar R.}

TI The Economic Impacts of the PROCISUR Program: An International Study. AU Evenson, Robert E.; da Cruz. Elmar R.

\section{DaVanzo, Julie}

PD January 1990. TI Household Production of Health: A Microeconomic Perspective on Health Transitions. AU DaVanzo, Julie; Gertler, Paul. AA Rand Corporation. SR Rand Note: N-3014; The Rand Corporation, 1700 Main Street, P.O. Box 2138, Santa Monica, CA 90406-2138. PG 26. PR not available. JE I12, I11. KW Health Care. Medical Technology. Health Production.

AB Over the past 20 years, advances in medical technology have not led to desired health improvements in the Third World. Governments may import and distribute medical technologies widely, but the effectiveness of these technologies will depend on how people respond to them. If such programs are to be effective, planners and practitioners must know what governs families' decisions to seek care and engage in healthimproving behaviors. This note argues that behavioral research can inform health policy on three dimensions: (1) how behavioral choices affect health status, (2) what determines these choices, and (3) how policy-makers can influence these choices. It shows that economic theory -- especially the theory of the household production of health -- provides a useful framework for analyzing these three dimensions.

\section{Davidson, Russell}

PD May 1990. TI Regression-Based Methods for Using Control and Antithetic Variates in Monte Carlo Experiments. AU Davidson, Russell; MacKinnon, James G. AA Davidson: Queen's University and GREQE, France. MacKinnon: Queen's University. SR Queen's Institute for Economic Research Discussion Paper: 781; Department of Economics, Queen's University, Kingston, Ontario, CANADA K7L 3N6. PG 30. PR \$3.00 Canada and U.S.; $\$ 3.50$ Foreign. JE C15, C13. KW Distribution Theory. Monte Carlo. Simulation Model. Quantiles. Linear Regression Model. AB Methods based on linear regression provide a very easy way to use the information in control and antithetic variates to improve the efficiency with which certain features of the distributions of estimators and test statistics are estimated in Monte Carlo experiments. We propose a new technique that allows these methods to be used when the quantities of interest are quantiles. Ways to obtain approximately optimal control variates in many cases of interest are also proposed. These methods seem to work well in practice, and can greatly reduce the number of replications required to obtain a given level of accuracy.

PD December 1990. TI The Geometry of the Wald Test. AA Queen's University. SR Queen's Institute for Economic Research Discussion Paper: 800; Department of Economics, Queen's University, Kingston, Ontario, CANADA K7L 3N6. PG 34. PR \$3.00 Canada and U.S.; $\$ 3.50$ Foreign. JE C12. KW Wald Test. Geometry. Hypothesis Testing.

AB The issue of the non-invariance of the Wald test under nonlinear reparametrizations of the restrictions under test is studied from a differential geometric viewpoint. Quantities that can be defined in purely geometrical terms are by construction invariant under reparametrization, and various attempts are made to construct a Wald test out of such invariant quantities only. Despite the existence of a wide variety of possibilities, no computationally convenient invariant test statistic emerges from the analysis, since all the statistics considered need calculations equivalent in difficulty to the estimation of the restricted model, contrary to the spirit of the Wald test. 
Davis, Steve J.

PD November 1990. TI Published Versus Sample Statistics from the ASM; Implications for the LRD. AU Davis, Steve J.; Haltiwanger, John; Schuh, Scott. AA Davis: University of Chicago. Haltiwanger: University of Maryland, College Park. Schuh: Johns Hopkins University. SR University of Maryland Department of Economics Working Paper Series: 90-24; Department of Economics, University of Maryland, College Park, MD 20742. PG 10. PR no charge. JE C81, L60. KW Manufacturing. Sample Selection Bias. Micro Data. Data Collection.

AB This paper documents cross-sectional and time series differences between ASM and LRD estimates of levels and growth rates of total employment, and compares the with employment estimates provided by Bureau of Labor statistics and County Business Patterns data. For total manufacturing. employment level and growth rate estimates display a high degree of similarity across all four data sources.

PD January 1991. TI Published Versus Sample Statistics from the ASM: Implications for the LRD. AU Davis, Steve J.; Haltiwanger, John; Schuh, Scott. AA Davis; University of Chicago. Haltiwanger: University of Maryland. Schuh: Johns Hopkins University and Bureau of the Census. SR Bureau of the Census Center for Economic Studies Discussion Paper: 911; Center for Economic Studies, Bureau of the Census, Washington, DC 20233. PG 38. PR no charge. JE C81, C82. KW Longitudinal Data. Micro Data. Aggregation. Macro Data. Sample Selection.

AB In principle, the Longitudinal Research Database (LRD) which links the establishments in the Annual Survey of Manufactures (ASM) is ideal for examining the dynamics of firm and aggregate behavior. However, the published ASM aggregates are not simply the appropriately weighted sums of establishment data in the LRD. Instead, the published data equal the sum of LRD-based sample estimates and nonsample estimates. The latter reflect adjustments related to sampling error and the imputation of small establishment data. Differences between the LRD and the ASM raise questions for users of both data sets. For ASM users, time series variation in the difference indicates potential problems in consistently and reliably estimating the nonsample portion of the ASM. For LRD users, potential sample selection problems arise due to the systematic exclusion of data from small establishments.

PD May 1991. TI Wage Dispersion Between and Within U.S. Manufacturing Plants, 1963-1986. AU Davis, Steve J.; Haltiwanger, John. AA Davis: University of Chicago and National Bureau of Economic Research. Haltiwanger: University of Maryland. SR National Bureau of Economic Research Working Paper: 3722; National Bureau of Economic Research, 1050 Massachusetts Avenue, Cambridge, MA 02138. PG not available. PR $\$ 2.00$. JE J31, L60. KW Wade Differentials. Manufacturing.

AB This paper exploits a rich and largely untapped source of information on the wages and other characteristics of individual manufacturing plants to cast new light on recent changes in the United States wage structure. Our primary data source, the Longitudinal Research Datafile (LRD), contains observations on more than 300,000 manufacturing plants during Census years $(1963,1967,1972,1977,1982)$ and 50,000-70,000 plants during intercensus years since 1972 . We use the information in the LRD to investigate changes in the plant-wage structure over the past three decades. We also combine plant-level wage observations in the LRD with wage observations on individual workers in the Current Population Survey (CPS) to estimate the between-plant and within-plant components of overall wage dispersion.

\section{Day, Richard H.}

TI Chaotically Switching Bear and Bull Markets: The Derivation of Stock Price Distribution from Behavioral Rules. AU Huang, Weihong; Day, Richard $\mathrm{H}$.

\section{De Grauwe, Paul}

PD January 1990. TI Deterministic Chaos in the Foreign Exchange Market. AU De Grauwe, Paul; Vansanten, Kris. AA Katholieke Universiteit Leuven. SR Centre for Economic Policy Research Discussion Paper: 370; Centre for Economic Policy Research. 6 Duke of York Street, London SWIY 6LA, UNITED KINGDOM. PG 49. PR 2.00 pounds (\$4.00). JE F31, F41, F47. KW Exchange Rates. Deterministic Model. Trade Balance.

AB Linear models in which exchange rates are driven by stochastic "news" are subject to a number of failings. In this paper we present a nonlinear deterministic model, incorporating concepts from chaos theory, which is capable of producing unpredictable exchange rate movements without "news". Two non-linearities arise from a J-curve effect in the trade balance and the modeling of both "chartist" and "fundamental" influence in expectations formation. The model displays extreme sensitivity to only small changes in its initial conditions and its parameter values. Only a few periods after such changes, the time path of the exchange rate appears to have been generated from a totally different model. This implies that forecasts based on exchange rate models are effectively impossible, because the tiniest errors generate totally different paths for the exchange rate.

\section{de Macedo, Jorge Braga}

PD February 1990. TI External Liberalization with Ambiguous Public Response: The Experience of Portugal. AA Commission of the European Communities. SR Centre for Economic Policy Research Discussion Paper: 378; Centre for Economic Policy Research, 6 Duke of York Street, London SWIY 6LA, UNITED KINGDOM. PG 44. PR 2.00 pounds (\$4.00). JE O52, E63, O11, F15. KW Portugal. Economic Integration.

AB This paper reviews the traditional ambiguity of Portuguese policy towards external liberalization. Production and labor markets have become segmented as a result of the soft budget constraint faced by large corporations and job protection in the public sector. Relaxation of entry requirements into banking since 1985 has made it more difficult for the government to use the banks as implicit tax collectors. But the frozen state of banking and a disguised fiscal policy still constrain monetary and exchange rate policy. Until a credible Multi-Annual Fiscal Adjustment Strategy is established, the necessary disinflation to allow active monetary policy and entry into the EMS will not be achieved.

\section{Deaton, Angus}

PD November 1989. TI Saving and Liquidity Constraints. AA Princeton University. SR Princeton Woodrow Wilson School Discussion Paper in Economics: 153; Woodrow Wilson School, Princeton University, Princeton, NJ 08544. PG 51. PR no charge. JE E21, D91. 
KW Saving. Borrowing. Consumption. Life Cycle Models. Credit Rationing.

AB This paper is concerned with the theory of saving when consumers are not permitted to borrow, and with the ability of such a theory to account for some of the stylized facts of saving behavior. When consumers are relatively impatient, and when labor income is independently and identically distributed over time, assets act like a buffer stock, protecting consumption against bad draws of income. The precautionary demand for saving interacts with borrowing constraints to provide a motive for holding assets. If the income process is positively autocorrelated, but stationary, assets are still used to buffer consumption, but do so less effectively, and at a greater cost in terms of foregone consumption. In the limit, when labor income is a random walk, it is optimal for impatient liquidity constrained consumers simply to consume their incomes.

\section{Delgado, Miguel A.}

PD June 1990. TI Semiparametric Specification Testing of Nonlinear Models. AU Delgado, Miguel A.; Stengos, Thanasis. AA Delgado: Indiana University. Stengos: University of Guelph. SR Queen's Institute for Economic Research Discussion Paper: 783; Department of Economics, Queen's University, Kingston, Ontario, CANADA K7L 3N6. PG 28. PR $\$ 3.00$ Canada and U.S.; $\$ 3.50$ Foreign. JE C12, C14, C52, C21. KW Artificial Nesting. Nonnested Hypothesis. Specification Test. Hypothesis Testing. Nonlinear Model.

AB We propose a specification test of a parametrically specified nonlinear model against a weakly specified alternative. We generalize a similar test procedure proposed by Delgado and Stengos (1990) to test the specification of a linear model. We estimate the alternative model by using $k$ nonparametric nearest neighbors in the context of an artificial regression. We derive the asymptotic distribution of the test statistic under the null hypothesis and under a series of local alternatives. Monte Carlo simulations suggest that the test has good power and size characteristics.

\section{Demski, Joel S.}

PD June 1990. TI Resolving Double Moral Hazard Problems with Buyout Agreements. AU Demski, Joel S.; Sappington, David E. M. AA Demski: Yale University. Sappington: University of Florida. SR University of Florida Working Paper in Economics: 90-9; Department of Economics, University of Florida, Gainesville, FL 32611. PG 19. PR no charge. JE M21, D21, D80. KW Moral Hazard. Buyout. Incentives.

AB We consider a double moral hazard problem in which the efforts of two parties, e.g., the owner of a firm and a risk averse worker in the firm, are not verifiable. The realized value of the firm's random profit stream is also unverifiable. Furthermore, there is no third party to break a "balanced budget" requirement. We show that the double moral hazard problem can be resolved completely and costlessly when the owner, who can observe the worker's actions, has the option of requiring the worker to purchase the firm at a prenegotiated price.

\section{Devereux, Michael B.}

PD July 1990. TI Growth, Specialization, and Trade Liberalization. AA Queen's University. SR Queen's Institute for Economic Research Discussion Paper: 786; Department of Economics, Queen's University, Kingston,
Ontario, CANADA K7L 3N6. PG 48. PR $\$ 3.00$ Canada and U.S.; \$3.50 Foreign. JE F11, F13, F43, 019 . KW Economic Growth. Tariffs. Trade Policy. International Trade.

AB This paper examines a two-way interaction between trade liberalization and economic growth. Through dynamic increasing returns to specialization, international trade can increase world growth rates. But growth, through specialization, alters patterns of comparative advantage, changing the incentives to levy tariffs in a dynamic tariff game between governments. Two types of equilibria are analyzed. In one, average growth rates are low, tariffs are high and rising, the ratio of exports to income (the trade ratio) is low, and falls to zero asymptotically. In the other, growth rates are high, tariffs are low and falling, the trade ratio is higher, and rises over time. The conditions under which each type of equilibrium will be observed are investigated.

\section{Deza, Michel}

PD July 1990. TI The Cut Cone III: On the Role of Triangle Facets. AU Deza, Michel; Larent, Monique; Poljak, Svatopluk. AA Deza: University of Paris VIl and Tokyo Institute of Technology. Laurent: University of Paris, Dauphine. Poljak: Charles University, Prague. SR Universitat Bonn Sonderforschungsbereich 303 Discussion Paper: 90655-OR; Sonderforschungsbereich 303 an der Universitat Bonn, Adenauerallee 24-42, D-5300 Bonn 1, DEUTSCHLAND. PG 25. PR no charge. JE C60. KW Graph Theory. Cut Polytope.

AB The cut polytope $P(n)$ is the convex hull of the incidence vectors of the cuts (i.e. complete bipartite subgraphs) of the complete graph on $\mathbf{n}$ nodes. A well known class of facets of $P(n)$ arises from the triangle inequalities; $x(i j)+x(i k)+x(j k)$ less than or equal to 2 and $x(i j)-x(i k)-x(j k)$ less than or equal to 0 for 1 less than or equal to $i, j, k$, less than or equal to $n$. Hence, the metric polytope $M(n)$ defined as the solution set of the triangle inequalities, is a relaxation of $P(n)$. We consider several properties of geometric type for $P(n)$, in particular, concerning its position within $M(n)$. Strengthening the known fact that $P(n)$ has diameter 1 , we show that any set of $k$ cuts, $k$ less than or equal to $\log n$ to the base 2 , satisfying some additional assumption, determines a simplicial face of $M(n)$ and thus, also, of $P(n)$. In particular, the collection of low dimension faces of $P(n)$ is contained in that of $M(n)$.

PD September 1990. TI Bouquets of Matroids and FSquashed Geometries. AU Deza, Michel; Laurent, Monique; Pasini, Antonio. AA Deza: University of Paris VII. Laurent: University of Paris, Dauphine. Pasini: University of Naples. SR Universitat Bonn Sonderforschungsbereich 303 . Discussion Paper: 90661-OR; Sonderforschungsbereich 303 an der Universitat Bonn, Adenauerallee 24-42, D-5300 Bonn 1, DEUTSCHLAND. PG 113. PR no charge. JE C60. KW Matroids.

AB Bouquets of matroids and F-squashed geometries were introduced as an extension of the notion of matroid as part of a general trend in the last decades to find a good degree of generality which still preserves the validity of deep results known for matroids. Bouquets of matroids are a natural generalization of matroids; namely, a bouquet of matroids is a union (in set theoretic sense) (of the flat families) of matroids which is stable under intersection. The basic idea of F-squashed geometries was to define an analogue of matroids in which the flats, in addition to satisfying some axioms of matroidal type, 
have to be contained in a given universe (hereditary set family) defined by a clutter $F$. The problems and properties we consider for F-squashed geometries come mainly from the specification of the universe.

\section{Dhawale, Hareesh}

TI Are the Preliminary Announcements of Some Macroeconomic Variables Rational? AU Chan, Anthony; Dhawale, Hareesh.

\section{Diamond, Peter}

TI Ranking, Unemployment Duration, and Wages. AU Blanchard, Olivier Jean; Diamond, Peter.

PD October 1990. TI Integrating Allocation and Stabilization Budgets. AA Massachusetts Institute of Technology. SR Massachusetts Institute of Technology Department of Economics Working Paper: 565; Department of Economics, Massachusetts Institute of Technology, Cambridge, MA 02139. PG 28. PR \$6.00 Domestic, $\$ 8.00$ Overseas, $\$ 2.00$ Student. JE H21, E63, H77. KW Public Finance. Taxation. Public Policy.

AB From the perspective underlying the use of three separable budgets, there is no trade-off between equity and efficiency; the government has sufficient powers to set the distribution of income as desired, without distorting any private decisions. This conclusion is obviously wrong. The problem for an analyst is to formulate a model which can generate insights into how the balance between equity and efficiency should be struck. This requires several ingredients. The model should have the property, either as an assumption or an implication of more basic assumptions, that it is impossible to change income distribution without affecting marginal decisions. The model needs to be a general equilibrium model. The model needs to be analytically tractable.

\section{Dick, Andrew R.}

PD October 1990. TI An Efficiency Explanation for Why Firms Second Source. AA University of California, Los Angeles. SR University of California at Los Angeles Department of Economics Working Paper: 602; Department of Economics, University of California, Los Angeles, 2263 Bunche, Los Angeles, CA 90024. PG 33. PR \$2.50. JE L23, L22, L63, M21, O32. KW Second-Source. Semiconductor Industry. Subcontracting. Technology.

AB This paper scrutinizes the practice of second-sourcing, or contracting-out of production to competitors, by firms facing technological and demand uncertainty. In contrast to the existing literature which focuses on precluding opportunistic behavior by monopoly suppliers, I show how sellers and buyers can both benefit from the practice. Second-sourcing allows producers to avoid firm-specific uncertainty (eg., R\&D risk), and to increase their flexibility in responding to industry-wide uncertainty (eg., demand risk). Buyers benefit through a reduced probability of stock-outs and a lower average cost for their inputs. The semiconductor industry serves as an illustrative example throughout.

Diewert, W. E.

PD November 1989. TI Exact and Superlative Welfare Change Indicators. AA University of British Columbia. SR University of British Columbia Department of Economics Discussion Paper: 89-27; University of British
Columbia, \#997-1873 East Mall, Vancouver, BC V6T IW5, CANADA. PG 31. PR $\$ .20$ per page Canadian to other than educational institutions. JE D11, D63. KW Welfare Theory. Functional Forms. Equivalent Variation. Expenditure Functions.

AB An exact welfare change indicator is defined to be a known function of the price and quantity data for two periods (which pertains to a utility maximizing consumer) which is exactly equal to the Hicksian equivalent variation. A welfare change indicator is termed superlative if it is exactly equal to the equivalent variation for an expenditure function which has a second order approximation property. The paper exhibits a number of superlative welfare change indicators, including one which uses the Fisher ideal quantity index as a basic building block. The paper also reviews the earlier attempts of Hicks and Weitzman to obtain equivalent variation measures that had a second order approximation property.

PD May 1990. TI Quadratic Spline Models for Producer Supply and Demand Functions. AU Diewert, W. E.; Wales, T. J. AA University of British Columbia. SR University of British Columbia Department of Economics Discussion Paper: 90-08; University of British Columbia, \#997-1873 East Mall, Vancouver, BC V6T 1W5, CANADA. PG not available. PR $\$ .20$ per page Canadian to other than educational institutions. JE O33, D24. KW Technology. Profit. Profit Functions. Production.

AB In this paper we propose forms for profit functions that generalize the normalized quadratic forms first proposed by Diewert and Wales. The generalizations incorporate linear and quadratic splines in a time (technical change) variable, and retain the attractive property of providing a local second order approximation while maintaining the correct curvature globally. In addition, the generalizations have desirable approximation properties with respect to the splined variables. The new forms are estimated using aggregated Japanese producer data on nine goods (three outputs and six inputs) for the period 1955 through 1987 . The splined technical change effects are found to be highly significant.

\section{Dinopoulos, Elias}

TI A Schumpeterian Model of Economic Growth and Fluctuations. AU Cheng, Leonard K; Dinopoulos, Elias.

\section{Dominguez, Kathryn Mary}

PD December 1989. TI Market Responses to Coordinated Central Bank Intervention. AA Harvard University. SR Harvard John F. Kennedy School of Government Discussion Paper: 179D; J.F.K. School of Government, 79 J.F.K. Street, Cambridge, MA 02138. PG 47. PR no charge. JE F31, F42, E58. KW Foreign Exchange. Central Bank. Policy Coordination. Monetary Policy.

AB The scale of unilateral and coordinated intervention in the foreign exchange market by the G-5 countries has become considerably larger over the last few years, following a period in which official U.S. policy was opposed to intervention. This paper examines market responses to official sterilized central bank intervention policy over the period 1985 through 1987. The efficacy of sterilized intervention is hypothesized to depend on the market's belief that central banks both have "inside" information about future monetary policy and the incentive to reveal that information truthfully through intervention signals. Central banks may agree to coordinate their intervention 
operations in order to influence the market's perception of the relative importance and credibility of own signals.

\section{Donald, Stephen G.}

TI Testing Identifiability of Simultaneous Equation Coefficients. AU Cragg, John G.; Donald, Stephen G.

\section{Donaldson, David}

TI Adult-Equivalence Scales, Interpersonal Comparisons of Well-Being, and Applied Welfare Economics. AU Blackorby, Charles; Donaldson, David.

\section{Donaldson, R. Glen}

PD December 1989. TI Sources of Panics: Evidence from the Weekly Data. AA Princeton University. SR Princeton Woodrow Wilson School Discussion Paper in Economics: 149; Woodrow Wilson School, Princeton University, Princeton, NJ 08544. PG 40. PR no charge. JE N21, N22, E43, E51. KW Banking. Economic History. Money Supply. Banking. Business Cycle.

AB This paper uses weekly data (1867-1933) to investigate empirically the sources of banking and financial panics. Results produced reverse the conclusions of previous studies based on quarterly and monthly data by demonstrating (i) that the behavior of panic variables is governed by a (predictably) different structural relationship than that governing non-panic behavior and (ii) that a panic's occurrence can be predicted one week in advance by variables that measure "tightness" in the money market. These findings are used to reject the extreme claims that panics are either purely random events, or that they are systematically linked to the underlying business cycle, in favor of the hypothesis that panics are "special", but predictable, events caused by temporary shortages of cash.

PD December 1989. TI Panic, Liquidity and the Lender of Last Resort. AA Princeton University. SR Princeton Woodrow Wilson School Discussion Paper in Economics: 150; Woodrow Wilson School, Princeton University, Princeton, NJ 08544. PG 39. PR no charge. JE E58, E51, G21. KW Federal Reserve. Monopoly. Bank Runs. Money Supply. Banking Panics.

AB This paper develops a model in which banking and financial panics are the result of local monopolies, or "corners", on the supply of privately controlled cash reserves. Execution of a cash comer results in an abrupt decline in the cash value of non-cash assets which produces the dramatic decrease in security prices, increase in interest rates and wave of "contagious" bank runs that are characteristic of panics. A lender of last resort prevents panics by ensuring that the supply of cash is sufficiently elastic to prevent corners.

\section{Dowrick, Steve}

TI Wage Bargaining with Endogenous Profits, Overtime Working and Heterogeneous Labor. AU Mumford, Karen; Dowrick, Steve.

\section{Drees, Burkhard}

PD September 1990. TI Is the Price of a Riskier Asset More Volatile? AU Drees, Burkhard; Eckwert, Bernhard. AA Drees: George Washington University, Eckwert: University of Bonn. SR Universitat Bonn Sonderforschungsbereich 303 - Discussion Paper: A-320; Sonderforschungsbereich 303 an der Universitat Bonn,
Adenauerallee 24-42, D-5300 Bonn 1, DEUTSCHLAND. PG 14. PR no charge. JE G12. KW Stochastic Model. Financial Instruments. Asset Prices.

AB This paper studies the relationship between the risk of financial instruments and the volatility of their equilibrium prices in a two-period stochastic asset valuation model. It is shown that if individual preferences exhibit risk substitutability then the riskier asset has a more volatile price compared to the less risky asset. Agent's risk complementarity, on the other hand, implies an inverse relationship between the relative riskiness of assets and their price fluctuations. Assuming time separable preferences severs the link between risk and price variability.

PD September 1990. TI A Simple Resolution of the Excess Volatility Puzzle. AU Drees, Burkhard; Eckwert, Bernhard. AA Drees; George Washington University. Eckwert; University of Bonn. SR Universitat Bonn Sonderforschungsbereich 303 - Discussion Paper: A-318; Sonderforschungsbereich 303 an der Universital Bonn, Adenauerallee 24.42, D.5300 Bonn 1, DEUTSCHLAND. PG 6. PR no charge. JE G12, G11, G14. KW Asset Market. Stock Prices. Stock Market. Dividends.

AB If individual preferences exhibit risk complementarity, spillover effects between asset markets may account for significant stock price volatility even if the dividends of most assets are stable.

PD September 1990. TI The Price Volatility of Bubbly and Non-Bubbly Assets when Agents have Non-TimeSeparable Preferences. AU Drees, Burkhard; Eckwert, Bernhard. AA Drees: George Washington University. Eckwert: University of Bonn. SR Universitat Bonn Sonderforschungsbereich 303 - Discussion Paper: A-319; Sonderforschungsbereich 303 an der Universitat Bonn, Adenauerallee 24-42, D-5300 Bonn 1, DEUTSCHLAND. PG 17. PR no charge. JE G12, G11, G14. KW Asset Prices. Preferences. Financial Assets.

AB A bubbly asset should be expected riskier than stocks which represent claims to the real resources of an economy. Since empirical evidence suggests that fiat money, which is a bubbly asset if traded at a positive price, possesses a much less volatile real price than stocks, there is a question as to whether these two aspects can be reconciled within a general equilibrium framework. This paper shows that a reconciliation can be achieved if individuals are sufficiently risk averse (degree of relative risk aversion larger than one) and if their preferences exhibit risk complementarity.

PD September 1990. TI Price Level Fluctuations under the Real-Bills Doctrine and the Quantity Theory. AU Drees, Burkhard; Eckwert, Bernhard. AA Drees: Texas A\&M University. Eckwert: University of Bonn. SR Universitat Bonn Sonderforschungsbereich 303 - Discussion Paper: A-311; Sonderforschungsbereich 303 an der Universitat Bonn, Adenauerallee 24-42, D-5300 Bonn 1, DEUTSCHLAND. PG 18. PR no charge. JE E42, E52, E31, E32. KW Monetary Policy. Quantity Theory. Price Level. Business Cycle.

AB In an economy where a banking system creates inside money by making short-term production loans, a laissez-faire real bills policy can lead to smaller fiuctuations in the price level than a constant-money-supply quantity theory policy. 
Dubin, Jeffrey A.

PD February 1990. TI Subsidy to the Commercial Nuclear Power Industry Through the Price-Anderson Liability Limit. AU Dubin, Jeffrey A.; Rothwell, Geoffrey S. AA Dubin: California Institute of Technology. Rothwell: Stanford University. SR Stanford Center for Economic Policy Research Discussion Paper Series: 186; 100 Encina Commons, Stanford University, Stanford CA 94305. PG 9. PR no charge for members of non-profit institutions, $\$ 3.00$ otherwise. JE Q42, Q48 K13. KW Nuclear Power. Insurance. Federal Subsidies. Liability.

AB Between 1959 and 1982, the Price-Anderson Act limited the liability of nuclear power plant operators for accidental damages to $\$ 560$ million. This limit grew to $\$ 7$ billion with the 1988 amendments to the Act. Using insurance premiums charged for the first $\$ 160$ million of coverage and Nuclear Regulatory Commission's estimate of the probability of a worse-case loss, we model the distribution of damages with a log-logistic density function. We find that the value of the Price-Anderson subsidy was $\$ 60$ million per reactor year before 1982 , but dropped to $\$ 22$ million with the 1988 amendments.

PD February 1991. TI The Heterogeneous Logit Model. AU Dubin, Jeffrey A.; Zeng, Langche. AA California Institute of Technology. SR Caltech Social Science Working Paper: 759; Division of Humanities and Social Sciences, 22877, California Institute of Technology, Pasadena, CA 91125. PG not available. PR no charge. JE C25, C13, C51. KW Heteroskedasticity. Logit Model.

AB Probabilistic choice systems in the generalized extreme value (GEV) family embody two restrictions not shared by the covariance probit model. First, the unobserved components of random utility are homoskedastic across individuals and alternatives. Second, the degree of similarity among alternatives is also assumed to be constant across individuals. This paper considers extensions to models in the GEV class which relax these two restrictions. An empirical application concerning the demand for cameras is developed to demonstrate the potential significance of the heterogeneous logit model.

\section{Duca, John V.}

PD December 1989. TI Optimal Monetary Policy in a Multisector Economy with an Economy-Wide Money Market. AU Duca, John V.; VanHoose, David D. AA Duca: Board of Governors of the Federal Reserve System. VanHoose: Indiana University. SR Federal Reserve Bank of Kansas City Research Working Paper: 89-14; Research Division, Federal Reserve Bank of Kansas City, 925 Grand Ave., Kansas City, MO 64198. PG 18. PR no charge. JE E52, E12, E24, E23. KW Monetary Policy. Interest Rates. Wages.

AB This paper analyzes the implications for an optimal interest-rate-conditioned monetary policy of asymmetric wage behavior in a multisector, closed economy. The analysis incorporate a stylized Poole (1970)-type IS-LM structure into the two-sector macro model of Duca (1987), in which one sector has a contract-style labor market. A key implication is that, when sectors are linked through an aggregate money market and all goods are consumed by workers in each sector, the relative effect of an interest rate change on output across the two sectors is the same as the relative output effect of symmetric supply shocks. As a result, one optimal combination policy rule can stabilize output in every sector if there are symmetric supply and demand disturbances, but not if there are asymmetric shocks.

\section{Dunne, Paul}

PD September 1990. TI Age, Size, Growth and Survival: U.K. Companies in the 1980s. AU Dunne, Paul; Hughes, Alan. AA University of Cambridge. SR University of Cambridge Small Business Research Centre Working Paper: 4; Department of Applied Economics, University of Cambridge, Sidgwick Avenue, Cambridge CB3 9DE, UNITED KINGDOM. PG 18. PR $\$ 5.00$ (2.50 pounds); checks payable to University of Cambridge. JE G33, L11, L16, G32. KW Firm Size. Bankruptcy. Corporations.

AB This paper examines the growth and survival records of a large sample of quoted and unquoted U.K. companies in the period 1975-85. It is shown that smaller companies have grown faster than larger companies in the period as a whole and two subperiods. Careful attention is paid to problems of sample selection bias and other econometric issues involved in estimating the size growth relationship. Age is shown to have a significant independent effect of growth performance, and an examination of death rates by size of firm shows that in the early 1980s the largest and smallest companies were least vulnerable to takeover.

PD October 1990. TI Small Businesses: An Analysis of Recent Trends in their Relative Importance and Growth Performance in the U.K. with Some European Comparisons. AU Dunne, Paul; Hughes, Alan. AA University of Cambridge. SR University of Cambridge Small Business Research Centre Working Paper: 1; Department of Applied Economics, University of Cambridge, Sidgwick Avenue, Cambridge CB3 9DE, UNITED KINGDOM. PG 109. PR $\$ 5.00$ (2.50 pounds); checks payable to University of Cambridge. JE L11, L60, L16. KW Small Businesses. Employment. Manufacturing.

AB This paper examines the empirical evidence bearing on the changing role of small businesses in the U.K. economy in recent years. Comparisons are made with developments elsewhere in Europe. The analysis shows that in the 1980s relatively stable employment in small firms in the U.K. manufacturing sector accompanied by declining large firm employment has led to a significant shift in employment shares in favor of the former. A less marked shift has occurred in terms of output. Small companies have since the 1960s experienced somewhat faster growth than larger companies. Similar trends have been experienced in France and Italy and to a somewhat lesser extent in Germany. The U.K. still has a larger share of activity in the hands of larger businesses than all three of these countries.

\section{Durlauf, Steven N.}

PD May 1991. TI Nonergodic Economic Growth. AA Stanford University and National Bureau of Economic Research. SR National Bureau of Economic Research Working Paper: 3719; National Bureau of Economic Research, 1050 Massachusetts Avenue, Cambridge, MA 02138. PG not available. PR \$2.00. JE O32, O41. KW Technology. Growth Model. Coordination Failure.

AB This paper explores the role of complementarities and coordination failure in economic growth. We analyze the evolution composed of a countable set of infinitely-lived heterogeneous industries. Individual industries exhibit nonconvexities in production and are linked across time through localized technological complementarities. Each 
industry employs one of two production techniques. One technique is more efficient in using capital than the other, but requires the payment of a fixed capital cost. Both techniques exhibit technological complementarities in the sense that the productivity of capital invested in a technique is a function of the technique choices made by various industries the previous period. These complementarities, when strong enough, interact with incompleteness of markets to produce multiple Paretorankable equilibria in long-run economic activity.

PD May 1991. TI Path Dependence in Aggregate Output. AA Stanford University and National Bureau of Economic Research. SR National Bureau of Economic Research Working Paper: 3718; National Bureau of Economic Research, 1050 Massachusetts Avenue, Cambridge, MA 02138. PG not available. PR \$2.00. JE E32, D52, E23. KW Output. Business Fluctuations. Incomplete Markets.

AB This paper studies an economy in which incomplete markets and strong complementarities interact to generate path dependent aggregate output fluctuations. An economy is said to be path dependent when the effect of a shock on the level of aggregate output is permanent in the absence of future offsetting shocks. Extending the model developed in Durlauf [1991] we analyze the evolution of an economy which consists of a countable infinity of industries. The production functions of individual firms in each industry are nonconvex and are linked through localized technological complementarities.

TI Convergence of International Output Movements. AU Bernard, Andrew B.; Durlauf, Steven N.

\section{Easterling, William E., III}

TI Policy Options for Adaptation to Climate Change. AU Rosenberg, Norman J.; Crosson, Pierre; Easterling, William E., III; Frederick, Kenneth; Sedjo, Roger.

TI Policy Options for Adaptation to Climate Change. AU Rosenberg. Norman J.; Crosson, Pierre; Easterling, William E., III; Frederick, Kenneth; Sedjo, Roger.

\section{Eckstein, Zvi}

TI Competitive Banking with Confidence Crisis and International Borrowing. AU Bental, Benjamin; Eckstein, Zvi; Peled, Dan.

\section{Eckwert, Bernhard}

PD July 1990. TI Allocative Effects of Financial Assets and the Long Run Neutrality of Money when Markets are Incomplete. AA University of Bonn. SR Universitat Bonn Sonderforschungsbereich 303 - Discussion Paper: A-302; Sonderforschungsbereich 303 an der Universitat Bonn, Adenauerallee 24-42, D-5300 Bonn 1, DEUTSCHLAND. PG 21. PR no charge. JE D52, D51, E44. KW Incomplete Markets. Equilibrium Allocation. Money. Financial Markets.

AB We analyze the allocative role of money as a numeraire in an intertemporal general equilibrium model with incomplete financial markets and nominal financial instruments. It is shown that regardless of their return specification nominal assets in net supply increase the consumption risk and trigger an endogenous monetary process which diminishes the influence of these assets on the equilibrium allocation through time. The nonneutrality of money claimed in the recent literature is a temporary phenomenon only. Asymptotically, the traditional neutrality theorems are valid.
TI Is the Price of a Riskier Asset More Volatile? AU Drees, Burkhard; Eckwert, Bernhard.

TI A Simple Resolution of the Excess Volatility Puzzle. AU Drees, Burkhard; Eckwert, Bernhard.

TI The Price Volatility of Bubbly and Non-Bubbly Assets when Agents have Non-Time-Separable Preferences. AU Drees, Burkhard; Eckwert, Bernhard.

PD September 1990. TI Stochastic and Structural Fiscal Policy in a Monetary Stationary Economy. AA University of Bonn. SR Universitat Bonn Sonderforschungsbereich 303 Discussion Paper: A-312; Sonderforschungsbereich 303 an der Universitat Bonn, Adenauerallee 24-42, D-5300 Bonn 1, DEUTSCHLAND. PG 16. PR no charge. JE G12, E44, E63, E32. KW Asset Prices. Fiscal Policy. Portfolio Choice. Asset Pricing. Business Cycle.

AB In the framework of a monetary asset pricing model which is simple enough to generate closed form formulae for equilibrium price functions the interactions between output, fiscal policy, and asset markets is investigated. With money yielding liquidity services in the exchange process real stock prices are negatively correlated with anticipated (stochastic) fiscal policy changes, while the impact of unanticipated (structural) fiscal policy on the stock market depends qualitatively on the "business cycle" of the economy. It is shown that the monetary character of the economy, more precisely the role of money in the exchange process, is critical for the relationship between fiscal policy and real share prices. Moreover, while contingent fiscal policy measures may be successful in stabilizing the real interest rate on money they are incapable of achieving a stable term structure of the real rate on stocks. In contrast, uncontingently higher public expenditures generally promote the volatility of the real rates on financial assets.

TI Price Level Fluctuations under the Real-Bills Doctrine and the Quantity Theory. AU Drees, Burkhard; Eckwert, Bernhard.

\section{Economides, Nicholas}

PD April 1990. TI Compatibility and the Creation of Shared Networks. AA Stanford University and Columbia University. SR Stanford Center for Economic Policy Research Discussion Paper Series: 196; 100 Encina Commons, Stanford University, Stanford, CA 94305. PG 30. PR no charge for members of non-profit institutions, $\$ 3.00$ otherwise. JE L11, L22, L23, D23. KW Networks. Compatibility. Production. Industrial Organization.

AB This article discusses the incentives of private networks to adopt compatible specifications so that transactions across networks are feasible and at no extra cost due to incompatibilities. A private network can vary its degree of compatibility with another private network. In general, an adapter is required for transactions across networks, and each private network can add to the cost of the adapter through its choice of specifications. It is shown, that even in the absence of binding agreements, full compatibility (zero adapter's cost) will emerge at equilibrium provided that the demands for each of the potential transactions are of the same size. Various degrees of incompatibility and limitations of access across private networks will emerge when this condition does not hold. 


\section{Edwards, Sebastian}

PD May 1991. TI Political Instability, Political Weakness and Inflation: An Empirical Analysis. AU Edwards, Sebastian; Tabellini, Guido. AA University of California, Los Angeles and National Bureau of Economic Research. SR National Bureau of Economic Research Working Paper: 3721; National Bureau of Economic Research, 1050 Massachusetts Avenue, Cambridge, MA 02138. PG not available. PR \$2.00. JE E64, P52, P16, P26, D70. KW Political Science. Inflation. Government Policy.

AB In this paper we analyze empirically the most important implications of two family political economy models of inflation: the "myopic" government approach and the "weak" government approach. In myopic government models inflation is the deliberate outcome of politicians strategic behavior, while in the weak government models inflation is the unavoidable result of a political struggle between different factions. In testing the implications of these two models we use a new data set on political developments in 76 countries for the period 1971-1982. Using a number of altemative definitions of the inflation tax we find out that the data supports the implications of the myopic governments models.

PD May 1991. TI Trade Orientation, Distortions and Growth in Developing Countries. AA University of California, Los Angeles and National Bureau of Economic Research. SR National Bureau of Economic Research Working Paper: 3716; National Bureau of Economic Research, 1050 Massachusetts Avenue, Cambridge, MA 02138. PG not available. PR $\$ 2.00$ JE F14, F41, F43. KW Developing Countries. International Trade. Trade Model. AB In this paper I use a cross country data set to analyze the relationship between trade orientation, trade distortions and growth. I first develop a simple endogenous growth model that emphasizes the process of technological absorption in small developing countries. According to this model countries that liberalize their international trade and become more open will tend to grow faster. Whether this higher growth is permanent, or only a short-run result, will depend on the relative size of some key parameters. Using nine alternative indicators of trade orientation I find out that the data supports the view that more open economies tend to grow faster than economies with trade distortions.

\section{El-Gamal, Mahmoud A.}

PD February 1991. TI A Bayesian Sequential Experimental Study of Learning in Games. AU El-Gamal, Mahmoud A.; McKelvey, Richard D.; Palfrey, Thomas R. AA California Institute of Technology. SR Caltech Social Science Working Paper: 757; Division of Humanities and Social Sciences, 228-77, California Institute of Technology, Pasadena, CA 91125. PG 34. PR no charge. JE C92, C71, C11. KW Bayesian Analysis. Learning. Experimental Economics.

AB This paper applies a Bayesian sequential statistical procedure to the study of different types of leaming in economic laboratory experimental games. The sequential procedure starts with priors on the models in question and the nuisance parameters associated with them. After each data point is observed, we update our priors on the models and their parameters, and continue running experiments until a prespecified stopping rule is invoked. At the time the stopping rule is invoked, we stop collecting data, and decide in favor of one of the two models, or decide that the models cannot be distinguished within the current experimental framework. We study games in which there are two important sources of leaming. The first kind involves learning about a specific opponent, and the second kind involves leaming about parameters shared by a population of opponents.

\section{Emons, Winand}

PD August 1988. TI On the Effectiveness of Liability Rules When Agents are Not Identical. AU Emons, Winand; Sobel, Joel. AA Emons: University of Bonn and University of California, San Diego. Sobel: University of California, San Diego. SR University of California at San Diego Department of Economics Discussion Paper: 88-39; Department of Economics, 0508, University of California at San Diego, La Jolla, CA 92093. PG 16. PR \$2.00; Checks payable to UC Regents. JE K13, D60. KW Liability Law. Mechanism Design.

AB This paper is about accidents involving two risk-neutral parties. Both parties engage in actions that are profitable but affect the magnitude of possible bilateral accidents. We analyze how the action choices can be decentralized by liability rules that assign the accident costs to the two parties. If we allow for punitive damages, we can implement the first-best actions by a liability rule even if agents are not identical. Under this liability rule some individuals may be in expectation better off in the event of an accident than in the event of no accident. We provide conditions under which this problem does not arise.

\section{Englander, A. Steven}

PD August 1990. TI Optimal Monetary Policy Design: Rules vs. Discretion Again. AA Federal Reserve Bank of New York. SR Federal Reserve Bank of New York Research Paper: 9019; Federal Reserve Bank of New York, 33 Libenty St., Rm. 901, New York City, New York 10045. PG 51. PR no charge. JE E31, E52, E37. KW Monetary Policy. Inflation. Expectations.

AB This paper presents a nontechnical review of the time consistency literature as it applies to monetary policy. It argues that the policy relevance of the time consistency literature is overstated. The assumptions required to generate equilibrium inflation under rational expectations are unrealistic, requiring the policy-maker to have an exceptionally naive view of the public's expectations formation process. Moreover, many of the insights of this literature can be obtained from simpler models with adaptive expectations. Empirically there are very few instances in which disinflation is achieved at low output costs, and the presence of a policy rule does not appear significant in these cases.

\section{Erdos, Peter L.}

PD November 1990. TI Sharpening the Lym Inequality. AU Erdos, Peter L.; Frankl, P.; Kleitman, D. J.; Saks, M. E.; Szekely, L. A. AA Erdos: University of Bonn. Frankl: University of Paris. Kleitman: Massachusetts Institute of Technology. Saks: University of California, San Diego. Szekely: University of Budapest and University of New Mexico. SR Universitat Bonn Sonderforschungsbereich 303 - Discussion Paper: 90667-OR; Sonderforschungsbereich 303 an der Universitat Bonn, Adenauerallee 24-42, D-5300 Bonn 1, DEUTSCHLAND. PG 8. PR no charge. JE C61, C60. KW Sperner Family. LYM Inequality. Kruskal-Katona Theorem.

AB The level sequence of a Sperner family $\mathrm{F}$ is the sequence 
$f(F)=\{f(i)(F)\}$, where $f(i)(F)$ is the number of $i$ element sets of F. The LYM inequality gives a necessary condition for an integer sequence to be the level sequence of a Sperner family on an $n$ element set. Here we present an indexed family of inequalities that sharpen the LYM inequality.

PD November 1990. TI Counting Bichromatic Evolutionary Trees. AU Erdos, Peter L.; Szekely, L. A. AA Erdos: University of Bonn. Szekely: University of Budapest. SR Universitat Bonn Sonderforschungsbereich 303 - Discussion Paper: 90666-OR; Sonderforschungsbereich 303 an der Universitat Bonn, Adenauerallee 24-42, D-5300 Bonn 1, DEUTSCHLAND. PG 8. PR no charge. JE C63, C60. KW Tree Theorem. Evolutionary Trees.

AB We give a short and transparent bijective proof to the bichromatic binary tree theorem of Carter, Hendy, Penny, Szekely and Wormald on the number of bichromatic evolutionary trees. The proof simplifies M. A. Steel's proof.

\section{Ericson, Richard}

TI Empirical Implications of Alternative Models of Firm Dynamics. AU Pakes, Ariel; Ericson, Richard.

\section{Estrella, Arturo}

PD September 1990. TI Corporate Leverage and Taxes in the U.S. Economy. AA Federal Reserve Bank of New York. SR Federal Reserve Bank of New York Research Paper: 9023; Federal Reserve Bank of New York, 33 Liberty St., Rm. 901, New York City, New York 10045. PG 14. PR no charge. JE H25, M21, L52, L20. KW Corporate Leverage. Taxes. Taxation. Corporate Finance. Business Investment.

AB The results of this paper, as well as those of the other papers it surveys, have failed to demonstrate a clear link between tax factors and the increase of highly leveraged financing in the 1980s. Nevertheless, a role for taxes may not be conclusively ruled out, since there is some evidence that tax factors increased the attractiveness of debt in the 1981-86 period. While the timing is not quite right to explain the observed trends in corporate finance, the results are at the very least suggestive. The fact remains, however, that the economics profession has found quite a challenge in the modeling of the determinants of corporate capital structure in ways that are both conceptually sound and empirically verifiable.

\section{Evans, Martin D. D.}

PD August 1990. TI Do Risk Premia Explain It All? Evidence from the Term Structure. AU Evans, Martin D. D.; Lewis, Karen K. AA Evans: New York University. Lewis: New York University and National Bureau of Economic Research. SR New York University Salomon Brothers Center Working Paper: S-90-22; Salomon Brothers Center for the Study of Financial Institutions, Graduate School of Business Administration, New York University, 90 Trinity Place, New York, NY 10006. PG 29. PR \$5.00. JE G12, E43. KW Term Structure. Risk Premium. Asset Pricing.

AB Most studies of the expectations theory of the term structure reject the model. However, the significance of the rejections depend strongly upon the form of the test. In this paper, we use the pattern of rejections across maturities to back out the implied behavior of time-varying risk premia and/or market forecasts. We then use a new technique to test whether stationary risk premia alone can be responsible for these rejections. Surprisingly, this test is rejected for short maturities up to 6 months, suggesting that time-varying risk premia do not explain it all. We also describe how this method can be used to test other asset pricing relationships.

\section{Evenson, Robert E.}

PD November 1989. TI The Economic Impacts of the PROCISUR Program: An International Study. AU Evenson, Robert E.; da Cruz, Elmar R. AA Yale University. SR Yale Economic Growth Center Discussion Paper: 588; Economic Growth Center, Yale University, 27 Hillhouse Avenue, New Haven, CT 06520. PG 26. PR $\$ 2.00+$ Postage. JE O13, 019, O54. KW Latin America. Agriculture. Technology.

AB The PROCISUR program installed in several Latin American countries in 1988 is designed to facilitate the exchange of agricultural scientific findings between member countries. This paper reports a statistical evaluation of the program's economic impact. The model utilized specifies that the "spill-in" of technology from one country to another is enhanced by the program. Statistical estimates confirm that the program did enhance spill-in of technology in all three commodity programs evaluated (corn, wheat and soybeans). The economic return to program investment, calculated from the estimates, was extraordinarily high indicating that programs of this type can be quite effective.

PD January 1991. TI Patent Data by Industry: Evidence for Invention Potential Exhaustion? AA Yale University. SR Yale Economic Growth Center Discussion Paper: 620; Economic Growth Center, Yale University, Box 1987 Yale Station, New Haven, Connecticut 06520. PG 30. PR $\$ 2.00$ plus postage. JE O31. KW Technology. Inventions. Patents.

AB The ratio of patented inventions to real $R \& D$ expenditures (R\&D), or to the number of scientists and engineers engaged in $R \& D$, has declined in all countries for which data are available over the 1969 to 1987 period. Not only have declines in these ratios taken place, but these declines have been large. By 1985-6 patent/R\&D ratios were only 55 , $44,42,40$, and 75 percent of the 1972-3 levels for the U.S., U.K., Germany, France, and Japan respectively. This paper examines data for these ratios for twenty-three industries for the 1969 to 1987 period in the five leading invention producing countries. The objective is to determine how much of the decline in these ratios can be attributed to changes in the "propensity to patent" (i.e., to changes in the proportion of inventions that are patented) and how much can be attributed to "invention potential exhaustion" (i.e., to a real reduction in invention made per unit of inventive effort.).

\section{Ewen, R.}

PD June 1990. TI On Coverings of the Complete Graph with 4 Vertices. AU Ewen, R.; Hofmeister, M. AA University of Cologne. SR Universitat Bonn Sonderforschungsbereich 303 - Discussion Paper: 90.87; Sonderforschungsbereich 303 an der Universitat Bonn, Adenauerallee 24-42, D-5300 Bonn 1, DEUTSCHLAND. PG 10. PR no charge. JE C60. KW Graph Theory. Covering Projections. Isomorphism.

AB We present a permutation group whose orbits classify isomorphism of covering projections of the complete graph with 4 vertices. Two structure theorems concerning with this group are proved. 
Fackler, James S.

PD December 1988. TI Federal Credit, Private Credit, and Economic Activity. AA University of Kentucky. SR Federal Reserve Bank of Kansas City Research Working Paper: 88-13; Research Division, Federal Reserve Bank of Kansas City, 925 Grand Ave., Kansas City, MO 64198. PG 33. PR no charge. JE E58, E51, H63, G21. KW Private Debt. Public Debt. Credit Market.

AB The Federal Open Market Committee has been monitoring total domestic nonfinancial debt since early 1983 . The evidence reported in this paper shows that the Federal and non-Federal components of the debt have significantly different impacts on economic activity. Thus, monitoring total debt rather than its major subcomponents implies that the Committee is ignoring important information contained in a more disaggregated analysis.

\section{Faigle, Ulrich}

PD August 1989. TI A Greedy Pre-Processing Algorithm for Setup Optimization. AU Faigle, Ulrich; Schrader, Rainer. AA Faigle: University of Bonn. Schrader: University of Twente. SR Universitat Bonn Sonderforschungsbereich 303 - Discussion Paper: 89589-OR; Sonderforschungsbereich 303 an der Universitat Bonn, Adenauerallee 24-42, D-5300 Bonn 1, DEUTSCHLAND. PG 6. PR no charge. JE C60, C63. KW Pre-Processing Algorithm. Cycle-Free Orders. Algorithms. Ordered Sets.

AB A pre-processing algorithm for setup optimization in general ordered sets is proposed. Moreover, the class of weakly cycle-free orders is introduced. All orders in this class are Dilworth optimal. Cycle-free orders and bipartite Dilworth optimal orders are proper subclasses. The algorithm allows greedy setup optimization in cycle-free orders and coincides with the algorithm of Syslo et al. [1987] in the class of bipartite orders.

PD February 1990. TI Some Convergence Results for Probabilistic Tabu Search. AU Faigle, Ulrich; Kem, W. AA Faigle: University of Twente. Kern: University of Cologne. SR Universitat Bonn Sonderforschungsbereich 303 - Discussion Paper: 90.83; Sonderforschungsbereich 303 an der Universitat Bonn, Adenauerallee 24-42, D-5300 Bonn 1, DEUTSCHLAND. PG 16 . PR no charge. JE C61, C60. KW Simulated Annealing. Markov Process. Search Strategies. Optimization Problem. Long Term Memory.

AB During recent years, much work has gone into the exploration of general fundamental principles underlying local search strategies for combinatorial optimization. Many of these strategies can be subsumed under the general framework of so called "Tabu Search", which tries to incorporate strategic ideas into purely memoryless local search heuristics such as Simulated Annealing. We consider some examples of such "long-term memory" strategies for modifying both the generation and acceptance probabilities and investigate their impact on convergence results. It turns out that several "Tabu Search" ideas may be incorporated into the classical Simulated Annealing approach without affecting the theoretical convergence properties.

PD March 1990. TI Some Order Dimension Bounds for Communication Complexity Problems. AU Faigle, Ulrich; Kem, W. AA Faigle: University of Twente. Kern: University of Cologne. SR Universitat Bonn Sonderforschungsbereich 303 - Discussion Paper: 90.86; Sonderforschungsbereich 303 an der Universitat Bonn, Adenauerallee 24-42, D-5300 Bonn 1, DEUTSCHLAND. PG 13. PR no charge. JE C60, C62. KW Communication Complexity. Ordered Sets. Stable Set Problem. Cliques.

AB We associate with a general $(0,1)$-matrix $\mathrm{M}$ an ordered set $P(M)$ and derive lower and upper bounds for the deterministic communication complexity of $\mathrm{M}$ in terms of the order dimension of $\mathrm{P}(\mathrm{M})$. We furthermore consider the special class of communication matrices $\mathrm{M}$ obtained as cliques vs. stable sets incidence matrices of comparability graphs G. We bound their complexity by $O[(\log d)$ times $(\log n)]$, where $n$ is the number of nodes of $G$ and $d$ is the order dimension of an orientation of G. In this special case, our bound is shown to improve other well-known bounds obtained for the general cliques vs. stable set problem.

\section{Farber, Henry S.}

PD July 1990. TI Medical Malpractice: An Empirical Examination of the Litigation Process. AU Farber, Henry S.; White, Michelle J. AA Farber: Massachusetts Institute of Technology. White: University of Michigan, Ann Arbor. SR Massachusetts Institute of Technology Department of Economics Working Paper: 561; Department of Economics, Massachusetts Institute of Technology, Cambridge, MA 02139. PG 35. PR $\$ 6.00$ Domestic, $\$ 8.00$ Overseas, $\$ 2.00$ Student. JE K41, 141. KW Medical Malpractice. Dispute Settlement. Law. Litigation. Negligence.

AB New data on medical malpractice claims against a single hospital where a direct measure of the quality of medical care is available are used to address 1) the specific question of the role of the negligence rule in the dispute settlement process in medical malpractice, and 2) the general question of how the process of negotiation and dispute resolution in medical malpractice operates with regard to both the behavior of the parties and the outcomes of the process. We find that the quality of medical care is an extremely important determinant of defendants' medical malpractice liability. More generally, we find that the data are consistent with a model where 1) the plaintiff is not well informed ex ante about the likelihood of negligence and 2) the ex ante expected value to the plaintiff of a suit is high relative to the costs of filing a suit and getting more information.

TI An Experimental Comparison of Dispute Rates in Alternative Arbitration Systems. AU Ashenfelter, Orley; Currie, Janet; Farber, Henry S.; Spiegel, Matthew.

\section{Fassbender, Bert}

PD July 1989. TI A Sufficient Condition on Degree Sums of Independent Triples for Hamiltonian Cycles in 1 . Tough Graphs. AA University of Cologne. SR Universitat Bonn Sonderforschungsbereich 303 - Discussion Paper: 89.78; Sonderforschungsbereich 303 an der Universitat Bonn, Adenauerallee 24-42, D-5300 Bonn 1, DEUTSCHLAND. PG 6. PR no charge. JE C60. KW Graph Theory. AB We prove that if $G$ is a 1-tough graph with $n=|V(G)|$ greater than or equal to 13 such that the degree sum of any three independent vertices is at least $(3 n-14) / 2$, then $G$ is hamiltonian.

\section{Faust, Jon}

PD October 1988. TI The Variance Ratio Test: Statistical Properties and Implementation. AA Federal Reserve Bank of Kansas City. SR Federal Reserve Bank of Kansas City 
Research Working Paper: 88-08; Research Division, Federal Reserve Bank of Kansas City, 925 Grand Ave., Kansas City, MO 64198. PG 38. PR no charge. JE C22, C12, G12. KW Variance Ratio Tests. Stock Prices. Time Series Model.

AB The variance ratio test for mean reversion has received considerable attention in the debate about fads in asset prices and in the literature regarding the existence of business cycles. Despite the recent attention, very little has been known about the properties of this test. which is based on the ratio of the variance of a $k$-period to a one-period moving sum of a data series. In this paper, the test is shown in large samples to be a uniformly most powerful invariant test in distinguishing between white noise and a certain class of mean reverting alternative models. The exact small sample distribution of the test is given and a simple test based on an asymptotic approximation is evaluated. Finally, a joint test combining the information in several variance ratio tests is developed and appraised. Primarily as a demonstration, this joint test is implemented using stock price data.

PD November 1988. TI Supernovas in Monetary Theory: Does the Ultimate Sunspot Rule Out Money? AA Federal Reserve Bank of Kansas City. SR Federal Reserve Bank of Kansas City Research Working Paper: 88-09; Research Division, Federal Reserve Bank of Kansas City, 925 Grand Ave., Kansas City, MO 64198. PG 19. PR no charge. JE E41, E10. KW Monetary Theory. Duration Model. Money Demand.

AB This paper deals with a well-known problem in monetary modeling: in standard finite-duration models, the fact that some agent would be stuck with money when the world ends means there can never be a demand for money. A solution to this terminal problem is provided using variable holding periods in continuous time. Given these features, no matter when an agent accepts money, there is a prospect of passing it on before the world ends, and the terminal problem is short-circuited. Two intuitively appealing properties of the finite-duration equilibria are shown. First, at points in time distant from the end of the world, the fact that the world will end has almost no implications; second, the equilibrium path always ends with an unbounded inflation that leaves money valueless.

PD December 1989. TI Optimal Variance Ratio Tests for Serial Dependence and a Test for Mean Reversion. AA Federal Reserve Bank of Kansas City. SR Federal Reserve Bank of Kansas City Research Working Paper: 89-07; Research Division, Federal Reserve Bank of Kansas City, 925 Grand Ave. Kansas City, MO 64198. PG 21. PR no charge. JE C12, C22. KW Time Series. Random Walk. White Noise. Variance Ratio. Mean Reversion.

AB This paper considers a class of statistics that can be written as the ratio of the sample variance of a filtered time series to the sample variance of the original series. Any such statistic is shown to be optimal under normality for testing a null of white noise against some class of serially dependent alternatives. A simple characterization of the class of alternative models is provided in terms of the filter upon which the statistic is based. These results are applied to demonstrate that a variance ratio test for mean reversion is an optimal test for mean reversion and to illustrate the forms of mean reversion it is best at detecting.

\section{Fazzari, Steven}

TI Price Flexibility and Macroeconomic Stability: An
Empirical Simulation Analysis. AU Caskey, John P.; Fazzari, Steven.

\section{Fershtman, Chaim}

TI The Effect of Insider Trading on Insiders' Choice among Risky Investment Projects. AU Bebchuk, Lucian Arye; Fershtman, Chaim.

TI The Effect of Insider Trading on Insiders' Reaction to Opportunities to "Waste" Corporate Value. AU Bebchuk, Lucian Arye; Fershtman, Chaim.

PD October 1990. TI Delayed Agreements and NonExpected Utility. AU Fershtman, Chaim; Safra, Zvi; Vincent, Daniel. AA Fershtman: Tel Aviv University and Northwestern University. Safra: Tel Aviv University and University of Pennsylvania. Vincent: Northwestem University. SR Tel Aviv Foerder Institute for Economic Research Working Paper: 30-90; Department of Economics, Tel Aviv University, Ramat Aviv 69978, Tel Aviv, ISRAEL. PG 29. PR no charge. JE C71, C78. KW Non-Expected Utility. Negotiations. Cooperative Games.

AB The unexplained occurrence of inefficient delays in reaching agreement is known in the economics literature as the "Hicks paradox". This paper describes a strategic situation in which players may play a simultaneous move game either before or after a move of Nature. The structure is such that if the players are expected utility maximizers, they would be indifferent over the order of play. However, if at least one of the players is a non-expected utility maximizer, for example if player one has preferences over lotteries which exhibit betweenness and fanning out, such player may strictly prefer to wait before playing the game. If both players exhibit fanning out and betweenness, then there exist games in which both prefer to delay agreement.

PD January 1991. TI Cross Licensing of Complementary Technologies. AU Fershtman, Chaim; Kamien, Morton I. AA Fershtman: Tel Aviv University and Northwestern University. Kamien: Northwestern University. SR Tel Aviv Foerder Institute for Economic Research Working Paper: 1-91; Department of Economics, Tel Aviv University, Ramat Aviv 69978, Tel Aviv, ISRAEL. PG 32. PR no charge. JE C71, D45, O31. KW Cooperative Games. Licensing. Innovation.

AB Assuming that two complementary technologies are needed for the development of a certain good and cross licensing is feasible the paper discusses the interdependence between the licensing game and the innovation game. The continuation of the innovation game is a threat point in the cooperative licensing game while the possibility of licensing affects the firm's incentives to innovate.

\section{Finegan, T. Aldrich}

TI The Decline in Black Teenage Labor Force Participation in the South, 1900-1970: The Role of Schooling. AU Margo, Robert A.; Finegan, T. Aldrich.

\section{Fischer, Stanley}

TI Issues in Socialist Economy Reform. AU Gelb, Alan; Fischer, Stanley.

PD May 1991. TI Growth, Macroeconomics, and Development. AA Massachusetts Institute of Technology. SR National Bureau of Economic Research Working Paper: 
3702; National Bureau of Economic Research, 1050 Massachusetts Avenue, Cambridge, MA 02138. PG not $\begin{array}{llllll}\text { available. } & \text { PR } \$ 2.00 . \quad J E & \text { O41, } & \text { 047, } & 057 .\end{array}$ KW Macrocconomic Policy. Economic Growth. Growth Theory.

AB The 1980s were both the lost decade of growth for much of Latin America and Africa, and the period in which -- through the new growth theory - macroeconomists returned to the study of growth and development. The new growth theory is production function driven and concerned primarily with steady states, and has paid little attention to the role of macroeconomic policy -- as reflected for instance in the rate of inflation and the budget deficit .. in determining growth. This paper presents a variety of evidence that macroeconomic policies matter for long-run growth.

\section{Fishelson, Gideon}

PD October 1990. TI On the Stability of the Interstates Income Inequality Function: The U.S. 1950-1980. AA Tel Aviv University. SR Tel Aviv Foerder Institute for Economic Research Working Paper: 28-90; Department of Economics, Tel Aviv University, Ramat Aviv 69978, Tel Aviv, ISRAEL. PG 24. PR no charge. JE R13, C43, E25. KW Gini Index. Human Capital. Income Distribution.

AB In this study we explain the cross-section variability of intrastates income inequality which is measured by the Gini Index. The explanatory variables are the conventional ones which represent sociodemographic factors and the variance of human capital. The latter is measured by the Gini Index of years of school completed by the population 25 years and older. We estimate the model for four cross-sections 1950, 1960, 1970 and 1980. We found that correcting for heteroskedasticity which is generated by the state and year effects on the variance of the random error improves the results significantly.

\section{Fisher, Franklin M.}

PD October 1990. TI Organizing Industrial Organization: Reflections on Parts 2 and 3 of the "Handbook of Industrial Organization". AA Massachusetts Institute of Technology. SR Massachusetts Institute of Technology Department of Economics Working Paper: 566; Department of Economics, Massachusetts Institute of Technology, Cambridge, MA 02139. PG 28. PR $\$ 6.00$ Domestic, $\$ 8.00$ Overseas, $\$ 2.00$ Student. JE L16, D40. KW Industrial Organization. Oligopoly. Markets.

AB Parts 2 and 3 of the "Handbook of Industrial Organization" concern the theoretical and empirical analysis of markets. They reveal a field in exciting but disorganized ferment. The principal result of theory is that nearly anything can happen. This is confirmed by the inconclusive results of empirical studies. Theoretical models are over-simplified and provide questionable guidance in real situations. Empirical work is not informed by theory and is often without a sound analytic foundation. The field needs to study the ways in which the rich context of real situations affects behavior and results. Without this, the structure-conduct-performance paradigm is dead, and the field will make no real progress.

Fitoussi, J. P.

PD October 1990. TI Macroeconomic Perspectives. AU Fitoussi, J. P.; Velupillai, K. AA University of California, Los Angeles. SR University of California at Los Angeles Department of Economics Working Paper: 609;
Department of Economics, University of California, Los Angeles, 2263 Bunche, Los Angeles, CA 90024. PG 52. PR \$2.50. JE B22, D46, E10. KW Economic Thought. AB "Money, Interest and Prices" (henceforth MIP) has just been made available in a new, albeit truncated, version. We, relics of another age, applaud this. That it may suffer the fate of all classics and be quoted but seldom read is, perhaps, inevitable. It is, surely, no exaggeration to say that the MIP research agenda laid the groundwork for a crystallized macroeconomics. Macroeconomics, as an independent discipline, was forged out of the older subdisciplines monetary theory, public finance, trade theory, capital theory and business cycle theory. The many fundamental attempts to integrate value theory with these subdisciplines mark the various stepping stones towards an independent macroeconomics.

\section{Fogel, Robert W.}

PD May 1991. TI New Sources and New Techniques for the Study of Secular Trends in Nutritional Status, Health, Mortality, and the Process of Aging. AA University of Chicago and National Bureau of Economic Research. SR National Bureau of Economic Research Working Paper Series on Historical Factors and Long-Run Growth: 26; National Bureau of Economic Research, 1050 Massachusetts Avenue, Cambridge, MA 02138. PG not available. PR \$2.00. JE I12, J11, J14. KW Nutrition. Mortality. Elderly. Aging.

AB The aim of this paper is to describe the full dimensions of a new and rapidly growing research program that uses new data sources on food consumption, anthropometric measures, genealogies, and life cycle histories to shed light on secular trends in nutritional status, health, mortality, and the process of aging. The exploitation of these types of data involves integration of analytical procedures in medicine and economics with those of demography. The discussion is divided into four parts. Part one deals with sources on food consumption and with methods of exploiting these sources that involve the integration of energy cost accounting with techniques for the analysis of income distributions. The second part is concerned with sources of anthropometric information and with techniques that may be utilized to relate such information to the assessment of health and mortality. Part three involves the more complex problem of relating socioeconomic and biomedical stress suffered by individuals early in life to their work levels, health and mortality rates at middle and late ages. The final section discusses the uses of genealogies by themselves and in combination with the preceding data sources.

\section{Foresi, Silverio}

PD May 1990. TI Valuation of Nominal Securities. AA University of California, Los Angeles and New York University. SR New York University Salomon Brothers Center Working Paper: S-90-20; Salomon Brothers Center for the Study of Financial Institutions, Graduate School of Business Administration, New York University, 90 Trinity Place, New York, NY 10006. PG 54. PR \$5.00. JE G11, D58, E40, E50. KW Money. Securities. Portfolio Choice. Monetary Policy. Risk Premium. Interest Rates.

AB This paper introduces money in a general equilibrium model of security valuation, and provides several pricing formulas for nominally denominated securities. Since money is explicitly considered in this framework, the distinction between real and nominal quantities is non-empty. Money is one of the 
assets that compose the optimal portfolio and the pricing formulas are in nominal terms. The inflation process is not assumed, but is the result of monetary policy and liquidity preferences; risk premia for nominal value uncertainty are also endogenous. The optimal portfolio problem is reconsidered. The valuation formula for nominally denominated claims extends the fundamental valuation equation of Cox, Ingersoll and Ross (1985) to a monetary economy. Explicit solutions for the nominal interest rate are provided under alternative monetary and fiscal policies.

TI Asset Prices in Monetary Economies. AU Balduzzi, Pierluigi; Foresi, Silverio.

\section{Frank, Andras}

PD March 1990. TI Augmenting Graphs to Meet EdgeConnectivity Requirements. AA Eotvos University, Budapest. SR Universitat Bonn Sonderforschungsbereich 303 - Discussion Paper: 90634-OR; Sonderforschungsbereich 303 an der Universitat Bonn, Adenauerallee 24-42, D-5300 Bonn 1, DEUTSCHLAND. PG 42. PR no charge. JE C63, C60. KW Graph Theory. Augmenting Graphs. Polynomial Time Algorithm.

AB What is the minimum number gamma of edges to be added to a given graph $G$ so that in the resulting graph the edge-connectivity between every pair $[u, v]$ of nodes is at least a prescribed value $r(u, v)$ ? Generalizing earlier results of $S$. Sridhar and R. Chandrasekaran (when $\mathbf{G}$ is the empty graph), of K. P. Eswaran and R. E. Tarjan (when $r(u, v)=2$ ), and of G-R. Cai and Y.-G. i Sun (when $r(u, v)=k$ is greater than or equal to 2) we derive a min-max formula for gamma and describe a polynomial time algorithm to compute gamma. The directed counterpart of the problem is also solved for the case when $r(u, v)=k$ is greater than or equal to 1 . A fundamental tool in the proof is the splitting theorems of W. Mader and L. Lovasz. We also rely extensively on techniques concerning submodular functions. The method makes it possible to solve a degreeconstrained version of the problem.

PD August 1990. TI Submodular Functions in Graph Theory. AA University of Bonn. SR Universitat Bonn Sonderforschungsbereich 303 - Discussion Paper: 90660-OR; Sonderforschungsbereich 303 an der Universitat Bonn, Adenauerallee 24-42, D-5300 Bonn 1, DEUTSCHLAND. PG 16. PR no charge. JE C61, C60. KW Graph Theory. Submodular Functions. Combinatorial Optimization. Digraph.

AB We describe various aspects of the use of submodular functions in graph theory. New proofs of theorems of Mader and of Tutte are provided as well as a new application on making a digraph k-edge-connected by adding a minimum number of edges.

\section{Frank, Richard G.}

PD May 1991, TI Incentives, Optimality, and Publicly Provided Goods: The Case of Mental Health Services. AU Frank, Richard G.; Gaynor, Martin. AA Johns Hopkins University and National Bureau of Economic Research. SR National Bureau of Economic Research Working Paper: 3700; National Bureau of Economic Research, 1050 Massachusetts Avenue, Cambridge, MA 02138. PG not available. PR \$2.00. JE H51, I18, I11, H42. KW Health Care. Government Spending. Public Goods.

AB In this paper we investigate the incentives present in intergovernmental transfers for public mental health care. This represents an important issue due to the large portion of mental health care that is provided by local governments, the central role of states in financing care via intergovernmental transfers, and recent innovations adopted by some states altering the traditional terms of these transfers. Using a relatively simple model we show that when a state government provides both financing and a free input into local government production there will be excessive use of that input. If the preferences of society and those of the local provider of service are identical, this problem can be remedied by simply changing the provider a price equal to marginal cost for use of the input. If however, the provider and society differ in their preferences, setting the price of the input at marginal cost will not induce optimal behavior, nor will the imposition of capacity constraints.

\section{Frankl, P.}

TI Sharpening the Lym Inequality. AU Erdos, Peter L.; Frankl, P.; Kleitman, D. J.; Saks, M. E.; Szekely, L. A.

\section{French, Kenneth R.}

PD February 1990. TI Are Japanese Stock Prices too High? AU French, Kenneth R.; Poterba, James M. AA French: University of Chicago and National Bureau of Economic Research. Poterba: Massachusetts Institute of Technology and National Bureau of Economic Research. SR Massachusetts Institute of Technology Department of Economics Working Paper: 547; Department of Economics, Massachusetts Institute of Technology, Cambridge, MA 02139. PG not available. PR $\$ 6.00$ Domestic, $\$ 8.00$ Overseas, $\$ 2.00$ Student. JE G12, G14, M41. KW Stock Market. Capital Market. Integration. Market Efficiency. Accounting. Stock Prices.

AB The difference between reported price-earnings ratios in the United States and Japan is not as puzzling as it appears at first glance. Nearly half the disparity is caused by differences in accounting practices with respect to consolidation of earnings from subsidiaries and depreciation of fixed assets. If Japanese firms used U.S. accounting rules, we estimate that the $P / E$ ratio for the Tokyo Stock Exchange would have been 32.1, not the reported 54.3, at the end of 1988 . Accounting differences are unable, however, to explain the sharp rise in the Japanese stock market during the mid-1980s. Changes in required returns on equities, or in investor expectations of future growth for Japanese firms, must be invoked to explain this phenomenon.

\section{Frenkel, Jacob A.}

TI From Centrally-Planned to Market Economies: The Road from CPE to PCPE. AU Calvo, Guillermo A.; Frenkel, Jacob A.

\section{Froot, Kenneth A}

PD March 1991. TI Shareholder Trading Practices and Corporate Investment Horizons. AU Froot, Kenneth A; Perold, Andre F.: Stein, Jeremy C. AA Stein and Froot: Massachusetts Institute of Technology. Perold: Harvard University. SR National Bureau of Economic Research Working Paper: 3638; National Bureau of Economic Research, 1050 Massachusetts Avenue, Cambridge, MA 02138. PG not available. PR \$2.00. JE G31, G12, G14, M21. KW Stock Market. Asset Prices. Business Investment.

AB We investigate how shareholder trading practices might be linked to corporate investment horizons. We examine two 
possible linkages and analyze a range of data relevant to them. The first is excess volatility, which occurs when stock prices react not only to news about economic fundamentals, but also to trades based on non-fundamental factors. Excess volatility could lead to a higher cost of capital, and thereby reduce longterm corporate investment. The second linkage derives from an information gap between management and outside shareholders. In the presence of such a gap, maximizing shortrun and long-run stock prices are not the same thing. Management may be able to raise current stock prices by undertaking certain actions that will reduce long-run value. In such a case, management faces the dilemma of which shareholders to please: Those who do not plan to hold the stock for the long-run versus those who do. As shareholder horizons shorten, it can become more difficult to focus exclusively on maximizing long-run value.

\section{Fukao, Kyoji}

PD August 1989. TI The Fisherian Time Preference and the Evolution of Capital Ownership Patterns in a Global Economy. AU Fukao, Kyoji; Hamada, Koichi. AA Yale University. SR Yale Economic Growth Center Discussion Paper: 579; Economic Growth Center, Yale University, 27 Hillhouse Avenue, New Haven, CT 06520. PG 35. PR \$2.00 + Postage. JE O47, O19, F43. KW Growth Theory. Time Preference. Income Distribution. World Economy.

AB Conventionally economic growth theory was based on the assumption of a constant rate of time preference. Uzawa (1968) and Obstfeld (QJE, 1981) introduced the rate of time preference that increases with the utility level. Irving Fisher ("The Theory of Interest") has a different opinion, however, that people are more time impatient at the lower level of income. This paper assumes a non-monotonic time preference schedule such that people are more patient at the middle income levels and are less patient when they are either very poor or rich. Based on a nonlinear savings function out of wealth implied by such a time-preference schedule, this paper develops a singlegood, multi-country growth model of a global economy with free capital mobility. The long-run property of this system is characterized by three kinds of long-run equilibrium: the starvation (fatal attractor) equilibrium, the imperialism equilibria dominated by a nation or by a group of nations, and the co-prosperity equilibrium where the wealth and the income of countries in the system grow proportionately.

\section{Galor, Oded}

PD April 1990. TI Dynamic Efficiency of Equilibrium Paths in an Overlapping-Generations Model. AA Brown University. SR Brown University Department of Economics Working Paper: 90-14; Department of Economics, Brown University, Providence, RI 02912. PG 15. PR no charge. JE D61, D58, E13. KW Equilibrium Allocation. Production. Efficiency.

AB This paper analyzes the compatibility and dynamic efficiency with perfect foresight equilibrium paths experienced by an overlapping generations economy with productive capital. The study establishes sufficient conditions on the nature of the neoclassical production technology and the structure of individual preferences under which, every feasible path of equilibrium allocations is dynamically efficient.

PD August 1990. TI A Two-Sector OverlappingGenerations Model: A Characterization of the Dynamical
System. AA Brown University. SR Brown University Department of Economics Working Paper: 90-23; Department of Economics, Brown University, Providence, RI 02912. PG 49. PR no charge. JE O41, E13, E51. KW Growth Model. Overlapping Generations. Dynamic Model.

AB This paper attempts to establish an analytically tractable framework for the analysis of dynamic economic phenomena whose modeling necessitates a multi-dimensional commodity space. The paper develops a two-sector overlappinggenerations model along the lines of the two-sector optimal growth model. The study characterizes the dynamical system and establishes sufficient conditions for the existence of a unique perfect-foresight equilibrium path and for the indeterminacy of perfect-foresight equilibrium paths. The analysis demonstrates that the dynamical system may be characterized by multiple (i.e., path dependent) steady-state equilibria. The paper provides sufficient conditions for the existence of a unique and stable nontrivial steady-state equilibrium.

\section{Gambardella, Alfonso}

PD November 1989. TI Innovation and Profitability in the U.S. Pharmaceutical Industry. AA Stanford University. SR Stanford Center for Economic Policy Research Discussion Paper Series: 180; 100 Encina Commons, Stanford University, Stanford CA 94305. PG 42. PR no charge for members of non-profit institutions, $\$ 3.00$ otherwise. JE L65, E22, O32. KW Pharmaceutical Industry. R\&D. Innovation. Technological Change.

AB This paper develops a model based upon the characteristics of the drug development process. It explores the relations among sales, R\&D, physical capital, and market value of 14 large pharmaceutical firms during 1978-1985. Past R\&D expenditures are found to be an important determinant of sales. The empirical results emphasize the high mortality rate of drug development projects. Variables correlated with the competitors' performance have negative effects on sales. Shocks to sales explain $24 \%, 28 \%$, and $6 \%$ of the variance of the firms' $R \& D$, capital, and market value. Technological opportunity shocks, i.e. unexpected "successes" ("failures") during the drug development process, explain $7 \%$ of the market value.

\section{Garner, C. Alan}

PD November 1988. TI Commodity Prices: Policy Target or Information Variable? AA Federal Reserve Bank of Kansas City. SR Federal Reserve Bank of Kansas City Research Working Paper: 88-10; Research Division, Federal Reserve Bank of Kansas City, 925 Grand Ave., Kansas City, MO 64198. PG 34. PR no charge. JE E31, E52, E32, G10. KW Commodity Prices. Monetary Policy. Inflation. Price Index.

AB Monetary policy-makers have recently expressed interest in using a commodity price index as a policy guide. Although a commodity price index might give useful information about inflationary pressures, empirical evidence shows commodity prices would not be a good policy target. Granger tests and variance decompositions imply that commodity prices can improve forecasts of the CPI. However, stabilizing a commodity price index would not guarantee a stable general price level because commodity prices and consumer prices can drift apart over time. Moreover, the ability of the Federal 
Reserve to control commodity prices without direct commodity market intervention is open to doubt.

PD December 1989. TI Market Indicators for Monetary Policy. AA Federal Reserve Bank of Kansas City. SR Federal Reserve Bank of Kansas City Research Working Paper: 89-08; Research Division, Federal Reserve Bank of Kansas City, 925 Grand Ave, Kansas City, MO 64198. PG 26. PR no charge. JE F31, E52, E31, E32, E51. KW Exchange Rates. Interest Rates. Commodity Prices. Monetary Policy. Business Cycle. Inflation. Economic Growth. AB This paper provides empirical evidence on whether such market indicator variables as exchange rates, the slope of the yield curve, and commodity prices can be helpful in conducting monetary policy. Granger causality tests and variance decompositions are performed to examine the usefulness of these variables in predicting inflation and real economic growth. Out-of-sample forecasts with Bayesian vector autoregressions also shed light on the predictive value of the market indicator variables. In addition, the paper examines whether movements of the indicators are closely related to past changes in the money supply and reserve aggregates.

\section{Gatsios, Konstantine}

PD August 1989. TI Winners and Losers from AntiMerger Laws. AU Gatsios, Konstantine; Karp, Larry. AA Gatsios: Fitzwilliam College, Cambridge and Center for Economic Policy Research. Karp: University of California, Berkeley. SR Centre for Economic Policy Research Discussion Paper: 336; Centre for Economic Policy Research, 6 Duke of York Street. London SW1Y 6LA, UNITED KINGDOM. PG 33. PR 2.00 pounds (\$4.00). JE L11, L12, L22, L40. KW Mergers. Investment. Cartels. Monopoly. Industrial Organization.

AB We study a model in which, in the absence of anti-merger laws, a merger that includes all non-competitive firms always occurs. The merger, however, can only occur (in the absence of laws which prohibit it) after the firms are formed, which in the present context means after investment has occurred. The investment decision is always undertaken non-cooperatively but with the rational anticipation of whether or not a merger will subsequently occur. The anticipation of a merger alters the incentives for investment. The anticipated merger may increase the equilibrium level of investment to such an extent that net profits are lower than when a merger is prohibited. As a result the monopoly price may be less than the oligopoly price, and anti-merger laws may harm consumers and benefit producers.

\section{Gautschi, David A.}

TI The Outputs of Retail Activities: Concepts, Measurement, and Evidence. AU Betancourt, Roger R.; Gautschi, David A.

\section{Gaynor, Martin}

TI Incentives, Optimality, and Publicly Provided Goods: The Case of Mental Health Services. AU Frank, Richard G.; Gaynor, Martin.

\section{Gelb, Alan}

PD November 1990. TI Issues in Socialist Economy Reform. AU Gelb, Alan; Fischer, Stanley. AA Gelb: The World Bank. Fischer: Massachusetts Institute of Technology.
SR Massachusetts Institute of Technology Department of Economics Working Paper: 567; Department of Economics, Massachusetts Institute of Technology, Cambridge, MA 02139. PG 45. PR $\$ 6.00$ Domestic, $\$ 8.00$ Overseas, $\$ 2.00$ Student. JE P21, P23. KW Socialism. Economic Reform. AB We examine issues about the design and sequencing of economic reform in formerly socialist economies that have made the political decision to move to a private market economy. We also examine the potential role of foreign countries, in providing aid, technical assistance, and market access. In economies that start from a situation of actual or potential macroeconomic instability, macroeconomic stabilization and accompanying measures to harden budget constraints and create an emergency social safety net are the first priority. Price reform, implemented with the assistance of trade liberalization, and enterprises restructuring and privatization are then at the center of the reform process.

\section{Gerlach, Stefan}

TI Intertemporal Prices and the U.S. Trade Balance in Durable Goods. AU Burda, Michael C.; Gerlach, Stefan.

\section{Geronimus, Arline T.}

PD May 1991. TI The Socioeconomic Consequences of Teen Childbearing Reconsidered. AU Geronimus, Arline T.; Korenman, Sanders. AA Geronimus: University of Michigan. Korenman: Princeton University and National Bureau of Economic Research. SR National Bureau of Economic Research Working Paper: 3701; National Bureau of Economic Research, 1050 Massachusetts Avenue, Cambridge. MA 02138. PG not available. PR \$2.00. JE J13, J24, J11. KW Fertility. Children. Human Capital.

AB Teen childbearing is commonly viewed as an irrational behavior that leads to long-term socioeconomic disadvantage for mothers and their children. Cross-sectional studies that estimate relationships between maternal age at first birth and socioeconomic indicators measured later in life form the empirical basis for this view. However, these studies have failed to account adequately for differences in family background among women who time their births at different ages. We present new estimates of the consequences of teen childbearing that take into account observed and unobserved family background heterogeneity, comparing sisters who have timed their first births at different ages. Sister comparisons suggest that previous estimates are biased by failure to control adequately for family background heterogeneity, and, as a result, have overstated the consequences of early fertility.

\section{Gertler, Paul}

TI Household Production of Health: A Microeconomic Perspective on Health Transitions. AU DaVanzo, Julie; Gertler, Paul.

\section{Gertner, Robert}

PD May 1991. TI A Theory of Workouts and the Effects of Reorganization Law. AU Gertner, Robert; Scharfstein, David. AA Gertner: University of Chicago. Sharfstein: Massachusetts Institute of Technology and National Bureau of Economic Research. SR National Bureau of Economic Research Technical Paper: 103; National Bureau of Economic Research, 1050 Massachusetts Avenue, Cambridge, MA 02138. PG not available. PR \$2.00. JE G33, G34, M21, K20. KW Bankruptcy. Private Debt. Corporate Finance. 
AB We present a model of a financially distressed firm with outstanding bank debt and public debt. Coordination problems among public debtholders introduce investment inefficiencies in the workout process. In most cases, these inefficiencies are not mitigated by the ability of firms to buy back their public debt with cash and other securities -- the only feasible way that firms can restructure their public debt. We show that Chapter 11 reorganization law increases investment and we characterize the types of corporate financial structures for which this increased investment enhances efficiency.

\section{Giavazzi, Francesco}

TI The "New" EMS. AU Spaventa, Lugi; Giavazzi, Francesco.

\section{Gibbons, Robert}

PD August 1990. TI Optimal Incentive Contracts in the Presence of Career Concerns: Theory and Evidence. AU Gibbons, Robert; Murphy, Kevin J. AA Gibbons: Massachusetts Institute of Technology and National Bureau of Economic Research. Murphy: University of Rochester. SR Massachusetts Institute of Technology Department of Economics Working Paper: 563; Department of Economics, Massachusetts Institute of Technology, Cambridge, MA 02139. PG 48. PR $\$ 6.00$ Domestic, $\$ 8.00$ Overseas, $\$ 2.00$ Student. JE J31, J32, J41, KW Incentives. Business Career. Wage Contracts. CEOs.

AB This paper studies career concerns--concerns about the effects of current performance on future compensation--and describes how optimal incentive contracts are affected when career concerns are taken into account. Career concerns arise frequently: they occur whenever the market uses a worker's current output to update its belief about the worker's ability and competition then forces future wages (or wage contracts) to reflect these updated beliefs. Career concerns are stronger when a worker is further from retirement, because a longer prospective career increases the return to changing the market's belief. In the presence of career concerns, the optimal compensation contract optimizes total incentives--the combination of the implicit incentives from career concerns and the explicit incentives from the compensation contract.

\section{Gilboa, Itzhak}

PD April 1991. TI Absorbent Stable Sets. AU Gilboa, Itzhak; Samet, Dov. AA Gilboa: Northwestern University. Samet: Tel Aviv University. SR Northwestern Center for Mathematical Studies in Economics and Management Science Working Paper: 935; Northwestern University, 2001 Sheridan Road, 3-014 Leverone Hall, Evanston, IL 60208-2014. PG 36. PR $\$ 3.00$ in the U.S. or Canada; $\$ 5.00$ via international mail. Make check payable to Northwestern University. JE C73, D83, C70. KW Stable Sets. Learning. Evolution. Game Theory.

AB This paper suggests a general framework to deal with leaming, dynamics and evolution in games and economic environments. In this general set-up we define a (set-valued) solution concept and prove some properties, including existence. We then discuss more specific dynamical processes and show that the general solution concept provides quite intuitive results for various contexts.

\section{Glasner, David}

TI Debt, Deffation, the Great Depression, and the Gold
Standard. AU Batchelder, Ronald W.; Glasner, David.

\section{Goldberg, Linda S.}

PD January 1991. TI Internal Currency Markets and Production in the Soviet Union. AU Goldberg, Linda S.; Karimov, Il'dar. AA Goldberg: New York University and National Bureau of Economic Research. Karimov: CEMI, Moscow. SR New York University Economic Research Reports: 91-03; New York University, Faculty of Arts and Science, Department of Economics, Washington Square, New York, N.Y. 10003. PG 30. PR no charge. JE E42, E44, F31, O53. KW Exchange Rate. Soviet Union. Economic Reform. Money Supply. Currency. Auctions.

AB This paper considers the impact of macroeconomic and microeconomic policy tools on enterprise activities within an economy in the process of economic reform. Assuming a dual exchange rate regime and the type of increased enterprise autonomy introduced as components of partial economic reform as in the Soviet Union, policy changes induce shifts in production and hard currency allocation decisions. This paper considers the implications for: the supply of hard currency to internal auctions or interbank markets; the free internal price of foreign exchange; export volumes; the trade balance; the supply of goods available for internal consumption; and open and hidden inflation. The concentration of market power of producers in domestic industries and the design of currency auctions or interbank markets are key determinants, respectively, of the magnitude and direction of the enterprise responses to policy changes and external shocks.

\section{Goldstein, Heidi}

TI Spouse Selection and Marital Instability. AU Bennett, Neil G.; Goldstein, Heidi; Abzug, Rikki.

\section{Gordon, Louis}

TI An Experimental Study of Comparable Worth. AU Arnault, E. Jane; Gordon, Louis; Joines, Douglas H.; Phillips, G. Michael.

\section{Gorecki, Paul K.}

TI Market Structure and the Intensity of the Competitive Process in the Canadian Manufacturing Sector. AU Baldwin, John R.; Gorecki, Paul K.

\section{Gorman, Michael}

TI The Costs and Financing of Care for AIDS Patients: Results of a Cohort Study in Los Angeles. AU Pascal, Anthony; Bennett, Charles L.; Cvitanic, Marilyn; Gorman, Michael; Serrato, Carl.

TI The Costs and Financing of Care for AIDS Patients: Results of a Cohort Study in Los Angeles. AU Pascal, Anthony; Bennett, Charles L.; Cvitanic, Marilyn; Gorman, Michael; Serrato, Carl.

\section{Gorton, Gary}

PD May 1991. TI Security Baskets and Index-Linked Securities. AU Gorton, Gary; Pennacchi, George. AA Gorton: University of Pennsylvania and National Bureau of Economic Research. Pennacchi; University of Illinois. SR National Bureau of Economic Research Working Paper: 3711; National Bureau of Economic Research, 1050 Massachusetts Avenue, Cambridge, MA 02138. PG not 
available. PR \$2.00. JE G11. KW Portfolio Choice. Investment. Stock Market.

AB Security baskets and index-lined securities are securities whose values are functions of the cash flows or values of other assets. Creation of these "composite" securities would seem to be redundant since investors can costlessly replicate them. In this paper we study the existence and optimal design of composite securities. We first show that when some investors possess inside information, composite securities are not redundant. By holding composite securities, uninformed investors with unexpected needs to trade can reduce their expected losses to insiders. The existence of these securities will affect real investment decisions.

TI Rational Finite Bubbles. AU Allen, Franklin; Gorton, Gary.

\section{Goulder, Lawrence $\mathbf{H}$.}

TI Promoting Investment Under International Capital Mobility: An Intertemporal General Equilibrium Analysis. AU Bovenberg. A. Lans; Goulder, Lawrence H.

PD March 1990. TI Implications of Introducing U.S. Withholding Taxes on Foreigners' Interest Income. AA Stanford University and National Bureau of Economic Research. SR Stanford Center for Economic Policy Research Discussion Paper Series: 197; 100 Encina Commons, Stanford University, Stanford, CA 94305. PG 46. PR no charge for members of non-profit institutions, $\$ 3.00$ otherwise. JE H21, F21, G11, F41. KW Withholding Taxes. Taxation. Portfolio Choice. Trade Balance. International Investment. AB This paper explores efficiency and equity issues related to the introduction of a withholding tax on foreigners' interest income from their investments in the U.S. Because of existing treaty obligations and tax-avoidance options, the effective tax rate of any practicable withholding tax is likely to be considerably below its statutory rate. A statutory 30 percent U.S. withholding tax on portfolio interest, if not accompanied by similar (retaliatory) tax measures introduced by foreign governments, appears to yield aggregate domestic welfare gains. The gains are attributable to U.S. financial market power stemming from the large share represented by the U.S. of world financial transactions and from the imperfect substitutability between U.S. and foreign securities in portfolios. Gains also derive from effects on domestic saving. The withholding tax leads to only a temporary improvement in the U.S. trade balance and in aggregate exports. The ultimate deterioration of the trade balance is closely related to effects of the tax on international interest flows.

\section{Gourieroux, C.}

PD June 1990. TI Courbes de Performance et de Discrimination. AA CEPREMAP. SR Unite de Recherche Document de Travail ENSAE/INSEE: 9013; INSEE, Unite de Recherche, 18 Bd. Adolphe Pinard, 75675 Paris cedex 14, FRANCE. PG 32. PR no charge. JE C10. KW Scoring Functions. Logit Analysis. Discriminant Analysis.

AB We introduce an ordering on the scoring functions used in credit and insurance problems; this ordering corresponds to the idea of a more precise selection of the customers. It is naturally based on the comparison of some curves, called performance and discrimination curves. Various results are described concerning this ordering and the practical use of the associated curves. Paper in French.

\section{Grandmont, Jean-Michel}

PD January 1989. TI Keynesian Issues and Economic Theory. AA CEPREMAP. SR CEPREMAP Discussion Paper: 8907; CEPREMAP, 142 rue du Chevaleret, 75013 Paris, FRANCE. PG 47. PR 20 ff. JE E12, E13, E32. KW Unemployment. Business Cycle. Keynesian Model. Macroeconomic Model. Business Fluctuations.

AB Recent research helped in clarifying the nature of shortrun price and quantity adjustments in Keynesian macroeconomic models, and the possible causes of a persistent excess labor supply. It argues, however, that theories involving imperfect competition and real wage "rigidities" generate "Classical" unemployment, where multipliers act through supply side effects, while nominal inertia seems to be at the root of truly "Keynesian" multipliers. The appraisal contains also a nontechnical presentation of recent models of endogenous expectations-driven business fluctuations (cycles, "sunspots"). Under these conditions monetary policy can have persistent real effects under complete information ("money as sunspot").

\section{Granger, C. W. J.}

PD July 1988. TI Investigation of Production, Sales and Inventory Relationships. AU Granger, C. W. J.; Lee, TaeHwy. AA University of California; San Diego. SR University of California at San Diego Department of Economics Discussion Paper: 88-38; Department of Economics, 0508, University of California at San Diego, La Jolla, CA 92093. PG not available. PR \$2.00; checks payable to UC Regents. JE E22, E23, C22. KW Inventory. Error Correction Models. Co-integration. AB No abstract.

\section{Green, David}

TI Assessing Empirical Approaches for Analyzing Taxes and Labor Supply. AU MaCurdy, Thomas; Green, David; Paarsch, Harry J.

\section{Greenwood, Jeremy}

TI Tax Analysis in a Dynamic Stochastic Model: On Measuring Harberger Triangles and Okun Gaps. AU Huffman, Gregory W.; Greenwood, Jeremy.

\section{Grilli, Vittorio U.}

TI The "Gold Standard Paradox" and Its Resolution. AU Buiter, Willem H.; Grilli, Vittorio U.

PD May 1991. TI Financial Intermediation and Monetary Policies in the World Economy. AU Grilli, Vittorio U.; Roubini, Nouriel. AA Grilli: Birkbeck College and National Bureau of Economic Research. Roubini: Yale University and National Bureau of Economic Research. SR National Bureau of Economic Research Technical Paper: 104; National Bureau of Economic Research, 1050 Massachusetts Avenue, Cambridge, MA 02138. PG not available. PR \$2.00. JE E52, G21, E23. KW Banking. Credit. Monetary Policy. AB In this paper we investigate the role of credit institutions in transmitting monetary shocks to the domestic economy and to the rest of the world output. In modeling the monetary and financial sector of the economy we distinguish between monetary injections via lump-sum transfers to individuals and those via increased credit to the commercial banking sector in 
the form of discount window operations. Appropriately, we distinguish between the discount rate of the central bank and the lending and borrowing interest rates of commercial banks, which, we assume, are also subject to reserves requirements.

\section{Grossman, Gene $\mathbf{M}$.}

PD November 1989. TI Explaining Japan's Innovation and Trade: A Model of Quality Competition and Dynamic Comparative Advantage. AA Princeton University. SR Princeton Woodrow Wilson School Discussion Paper in Economics: 151; Woodrow Wilson School, Princeton University, Princeton, NJ 08544. PG 53. PR no charge. JE O31, F14, F13, O41. KW Endogenous Growth. Innovation. Technology. R\&D. Trade Policy.

AB In this paper, I develop a model of dynamic comparative advantage based on endogenous innovation. Firms in each of two countries devote resources to $R \& D$ in order to improve the quality of high-technology products. Research successes generate profit opportunities in the world market. The model predicts that a country such as Japan, with abundance of skilled labor and scarcity of natural resources, will specialize relatively in industrial innovation and in the production of high-technology goods. Data are provided to support this prediction. I use the model to explore the effects of R\&D subsidies, production subsidies and trade policies on the longrun rates of innovation in trade partner countries and on the long-run pattern of trade.

PD November 1989. TI Quality Ladders and Product Cycles. AU Grossman, Gene M.; Helpman, Elhanan. AA Grossman: Princeton University. Helpman: Tel Aviv University. SR Princeton Woodrow Wilson School Discussion Paper in Economics: 152; Woodrow Wilson School, Princeton University, Princeton, NJ 08544. PG 52. PR no charge. JE O31, O32, F11, O41, F14. KW Endogenous Growth. Innovation. R\&D. Product Cycles. Technology.

AB We develop a two-country model of endogenous innovation and imitation in order to study the interactions between these two processes. Firms in the North race to bring out the next generation of a set of technology-intensive products. Each product potentially can be improved a countably infinite number of times, but quality improvements require the investment of resources and entail uncertain prospects of success. In the South, entrepreneurs invest resources in order to leam the production processes that have been developed in the North. All R\&D investment decisions are made by forward looking, profit maximizing entrepreneurs. The steady-state equilibrium is characterized by constant aggregate rates of innovation and imitation. We study how these rates respond to changes in the sizes of the two regions and to policies in each region to promote learning.

PD December 1989. TI Trade, Innovation, and Growth. AU Grossman, Gene M.; Helpman, Elhanan. AA Grossman: Princeton University. Helpman: Tel Aviv University. SR Princeton Woodrow Wilson School Discussion Paper in Economics: 154; Woodrow Wilson School, Princeton University, Princeton, NJ 08544. PG 24. PR no charge. JE O11, O19, F13, O41. KW Long-Run Growth. Technological Change. Innovation. Commercial Policy. Growth Model. Trade Policy.

AB Casual observation and more systematic empirical research suggest that countries that have adopted an outward oriented development strategy have grown faster and achieved a higher level of economic well being than those that have chosen a more protectionist trade stance. The evidence on the efficacy of explicit policies to promote exports, including various forms of industrial targeting, is not yet conclusive. This paper proposes an approach to modeling endogenous innovation and endogenous human capital formation that may provide a means for improving our understanding of the connection between the international trade environment including the trade policy regime and long-run growth performance.

PD September 1990. TI Trade, Knowledge Spillovers and Growth. AU Grossman, Gene M.; Helpman, Elhanan. AA Grossman: Princeton University. Helpman: Tel Aviv University. SR Tel Aviv Foerder Institute for Economic Research Working Paper: 26-90; Department of Economics, Tel Aviv University, Ramat Aviv 69978, Tel Aviv, ISRAEL. PG 12. PR no charge. JE O34, O32, F13, F41. KW International Trade. Tariffs. Innovation. Trade. Trade Policy. Knowledge.

AB International spillovers of knowledge affect the rate of growth. The exact mechanisms through knowledge moves across countries may play an important role in the transmission of innovations and growth. We explore the effects of international trade as a direct carrier of knowledge spillovers. Despite the second best nature of our problem, we establish that in a small economy tariff reductions speed up innovation and growth and raise welfare.

PD November 1990. TI Hysteresis in the Trade Pattem. AU Grossman, Gene M.; Helpman, Elhanan. AA Grossman: Princeton University. Helpman: Tel Aviv University. SR Tel Aviv Foerder Institute for Economic Research Working Paper: 36-90; Department of Economics, Tel Aviv University, Ramat Aviv 69978, Tel Aviv, ISRAEL. PG 37. PR no charge. JE F11, F43, O31, 034. KW International Trade. Economic Growth. Innovation. R\&D. Technological Progress.

AB We study a world economy comprising two countries that may differ only in their prior experience in the research lab. Entrepreneurs in each country develop new technologies for varieties of a differentiated product whenever expected profits justify up-front research costs. Research productivity depends upon national stocks of knowledge capital, which accumulate in proportion to local research activity. The countries produce and trade their unique varieties of the differentiated good, as well as a homogeneous, "traditional" product. In this context, we ask whether a country can overcome a late start in research to develop a comparative advantage in the high-technology sector. We also examine the welfare properties of the equilibrium trajectory and of policies that might be used to reverse a country's fate.

\section{Grossman, Herschel I.}

PD July 1990. TI The Technology of Insurrection and the Allocative and Distributive Effects of Famine Relief. AA Brown University. SR Brown University Department of Economics Working Paper: 90-20; Department of Economics, Brown University, Providence, RI 02912. PG 21. PR no charge. JE F35, O15. KW Famine Relief. Insurrection. Resource Allocation. Income Distribution. Foreign Aid.

AB This paper analyzes the allocative and distributive effects of famine relief within a positive theory of insurrections. In this 
theory, famine relief causes a reallocation of resources from production to an intensified struggle over distributive shares. Moreover, although famine relief induces the ruler to lower taxes, and possibly even to subsidize production, the expected income of the general population of peasants increases by only a fraction of the amount of the famine relief. The analysis shows how these allocative and distributive effects depend on the technology of insurrection. For example, the reduction in production would be larger the more that famine relief would increase the expected return to time allocated to insurrection. Moreover, the expected income of the peasants would increase more the less effective is time allocated to soldiering in deterring insurrection and the more effective is time allocated to insurrection in increasing the probability that an insurrection will succeed.

\section{Gruber, Jonathan}

PD November 1990. TI The Incidence of Mandated Employer-Provided Insurance: Lessons from Workers' Compensation Insurance. AU Gruber, Jonathan; Krueger, Alan B. AA Gruber: Harvard University. Krueger: Princeton University and National Bureau of Economic Research. SR Princeton Industrial Relations Section Working Paper: 279; Industrial Relations Section, Department of Economics, Princeton University, Princeton, NJ 08544-2098. PG 47. PR \$1.50. JE J32, J33. KW Workers' Compensation. Fringe Benefits. Health Insurance.

AB Workers' compensation insurance provides cash payments and medical benefits to workers who incur a workrelated injury or illness. Many features of the workers' compensation program parallel features of proposed mandated employer-paid health insurance plans. This paper empirically examines the incidence of the workers' compensation program to infer the likely consequences of mandated health insurance proposals. In certain industries, such as trucking and carpentry, workers' compensation insurance costs are quite large, and vary tremendously within states over time, and across states at a moment in time. This variation is used to identify the incidence of the program. Empirical analysis of two data sets suggest that changes in employers' costs of workers' compensation insurance are largely shifted to employees in the form of lower wages.

\section{Guesnerie, Roger}

TI Noisy Observation in Adverse Selection Models. AU Caillaud, Bernard; Guesnerie, Roger; Rey, Patrick.

\section{Guidotti, Pablo E.}

TI Optimal Maturity of Nominal Govemment Debt: The First Tests. AU Calvo, Guillermo A.; Guidotti, Pablo E.; Leiderman, Leonardo.

\section{Gunderson, Morley}

PD September 1989. TI Provincial Public Sector Payrolls. AU Gunderson, Morley; Riddell, W. Craig. AA Gunderson: University of Toronto. Riddell: University of British Columbia. SR University of British Columbia Department of Economics Discussion Paper: 89-22; University of British Columbia, \#997-1873 East Mall, Vancouver, BC V6T IW5, CANADA. PG 54. PR $\$ .20$ per page Canadian to other than educational institutions. JE J45, J31, J51, L33. KW Public Sector. Labor Markets. Wage Differentials. Unions. Privatization.
AB This paper examines factors affecting provincial public sector payrolls in Canada, with particular attention on recent experience. Specific factors discussed include unionization, dispute settlement procedures (strikes versus arbitration), growth or retrenchment, wage controls, privatization, subcontracting, and pay and employment equity initiatives.

\section{Gustafson, Elizabeth}

TI An Empirical Examination of Government Expenditures and the Ex-Ante Crowding Out Effect for the British Economy. AU Chan, Anthony; Gustafson, Elizabeth.

\section{Gylfason, Thorvaldur}

PD February 1990. TI Exchange Rate Policy, Inflation, and Unemployment: The Experience of the Nordic EFTA Countries. AA University of Iceland. SR Centre for Economic Policy Research Discussion Paper: 377; Centre for Economic Policy Research, 6 Duke of York Street, London SWIY 6LA, UNITED KINGDOM. PG 32. PR 2.00 pounds (\$4.00). JE F31, O52, F41, F42, E42. KW Exchange Rates. Devaluation. Nordic Countries.

AB This paper reviews the exchange rate policy experience of the Nodic EFTA countries (Finland, Iceland, Norway and Sweden) since the early 1970 s. The paper briefly describes the main features of the national economies of the Nordic EFTA countries in an international perspective and their exchange rate arrangements in particular, and then attempts to weigh the principal pros and cons of these and alternative arrangements from the Nordic point of view. The paper also tries to evaluate macroeconomic performance in these countries since the early $1970 \mathrm{~s}$ in view of the exchange rate policies and other policies that have been followed, with special emphasis on their devaluation record during 1976-82 and the credibility of current policies.

PD February 1990. TI Inflation, Growth, and External Debt: A View of the Landscape. AA University of Iceland. SR Centre for Economic Policy Research Discussion Paper: 375; Centre for Economic Policy Research, 6 Duke of York Street, London SW1Y 6LA, UNITED KINGDOM. PG 30. PR 2.00 pounds $(\$ 4.00)$ JE E31, O41, F32. KW Inflation. Economic Growth. External Debt.

AB This paper reconsiders the relationship between inflation, economic growth and external debt, and discusses various channels through which (a) increased inflation tends to reduce growth and raise foreign indebtedness over time and (b) declining growth tends to amplify both inflation and debt. The observed growth differential indicates that the real costs of inflation over time may be quite high for individual countries as well as for the world economy as a whole.

Hahn, Robert W.

PD June 1990. TI Environmental Markets in the Year 2000. AU Hahn, Robert W.; Noll, Roger G. AA Hahn: American Enterprise Institute. Noll: Stanford University. SR Stanford Center for Economic Policy Research Discussion Paper Series: 205; 100 Encina Commons, Stanford University, Stanford CA 94305. PG 26. PR no charge for members of non-profit institutions, $\$ 3.00$ otherwise. JE Q25, Q28. KW Environmental Regulation. Regulation. Pollution.

AB This paper examines the prospects for marketable emission permits in the coming decade. We identify both the reasons that politicians are reluctant to embrace marketable 
emission permits as a solution to environmental problems as well as changes in the political landscape that could lead to the increased use of this approach. Over the next decade, we believe there is reason to be cautiously optimistic. Selective experimentation with market-based approaches is likely to continue; however, we are not optimistic about the prospects for widespread application of this tool. Moreover, applications of this tool will necessarily reflect important political constraints, thus rendering the tool substantially less effective than the textbook applications examined by economists. An important intellectual challenge is to work on the design of market-based approaches that address political concerns, enhance efficiency and promote innovation, so that it will be easier to meet the environmental challenges that lie ahead.

\section{Hakkio, Craig S.}

PD August 1989. TI Exchange Rates in the 1980s. AA Federal Reserve Bank of Kansas City. SR Federal Reserve Bank of Kansas City Research Working Paper: 89-04; Research Division, Federal Reserve Bank of Kansas City, 925 Grand Ave, Kansas City, MO 64198. PG 49. PR no charge. JE F31, F32. KW Exchange Rates. Devaluation. AB The exchange value of the dollar rose over 50 percent between 1980 and the first quarter of 1985 ; since then it has fallen about 50 percent. In addition, exchange rate volatility remained high in the $1980 \mathrm{~s}$. This article concludes that the dollar exchange rate in the 1980s was not unusual, given that we were in a flexible exchange rate regime; the dollar exchange rate was unusual when compared to fixed exchange rate regimes. Exchange rates in floating and fixed exchange rate regimes are different in at least four ways. First, swings are larger during floating regimes than during fixed regimes. Second, exchange rates are a random walk during floating regimes and not during fixed regimes. Third, real and nominal exchange rates are correlated during floating regimes but not during fixed regimes. And finally, exchange rates are more variable during floating regimes than during fixed regimes.

PD December 1989. TI Marginal Income Tax Rates and Real Economic Growth. AU Hakkio, Craig S.; Rush, Mark. AA Hakkio: Federal Reserve Bank of Kansas City. Rush: University of Florida. SR Federal Reserve Bank of Kansas City Research Working Paper: 89-09; Research Division, Federal Reserve Bank of Kansas City, 925 Grand Ave., Kansas City, MO 64198. PG 30. PR no charge. JE E62, H24, D31. KW Income Tax. Gross National Producl. Taxation. Fiscal Policy.

AB Virtually all economists agree that fiscal policy -changes in govemment spending and marginal tax rates .- can affect economic variables such as real GNP. As a result, many economists have studied the empirical effect of changes in government spending on real GNP. Fewer economists, though, have investigated the effects of changes in marginal tax rates. This is a significant oversight because marginal tax rates are a prominent feature in the nation's economy. There seem to be two reasons for this oversight. First, data on marginal tax rates have been harder to uncover than similar data for government spending. Second, even though the data are available, actual average marginal tax rates are endogenous in nature. In this paper we overcome these problems by constructing a "full employment marginal tax rate" for the 25,50 , and 80 percentile levels of household income.

PD August 1990. TI An Equilibrium Model of Spot and
Forward Exchange Rates. AU Hakkio, Craig S.; Sibert, Anne. AA Hakkio: Federal Reserve Bank of Kansas City. Sibert: Federal Reserve Bank of Kansas City and University of Kansas. SR Federal Reserve Bank of Kansas City Research Working Paper: 90-02; Research Division, Federal Reserve Bank of Kansas City, 925 Grand Ave, Kansas City, MO 64198. PG 37. PR no charge. JE F31, G15, D50. KW Exchange Rates. Risk Premium. Foreign Exchange.

AB This paper presents a numerical analysis of an optimizing, equilibrium model of the risk premium in the forward foreign exchange market. An overlapping-generations model with incomplete markets is employed. Because the equilibria are analytically intractable, the model must be solved numerically. We are able to show how changes in the distribution of the exogenous variables affect the distribution of the risk premium. Furthermore, several measures of the risk premium are investigated. We find that measures of "nominal" risk premia, typically found in empirical studies, can give different results from more theoretically appealing real measures.

PD September 1990. TI Real and Nominal Exchange Rates Since 1919. AU Hakkio, Craig S.; Joines, Douglas H. AA Hakkio: Federal Reserve Bank of Kansas City. Joines: University of Southem California. SR Federal Reserve Bank of Kansas City Research Working Paper: 90-03; Research Division, Federal Reserve Bank of Kansas City, 925 Grand Ave., Kansas City, MO 64198. PG 21. PR no charge. JE F31, F33, G15, E42. KW Exchange Rates. International Finance. International Markets.

AB This paper examines the long-run properties exchange rates -- real and nominal -- and how the exchange rate regime affects the behavior of exchange rates. To do this, monthly real and nominal exchange rates from 1919 to 1990 for the U.S. dollar against the U.K. pound, French Franc, Italian Lira, Canadian Dollar, and the German Mark were collected. The results are mixed. In the long-run, the real exchange rate sometimes does and sometimes does not have a unit root. Furthermore, the permanent component of most real exchange rates account for about half of the variance of the change in the real exchange rate. The permanent component of the nominal exchange rate, however, accounts for about all of the variance of the change in the nominal exchange rate.

\section{Haltiwanger, John}

TI The Aggregate Implications of Machine Replacement Theory and Evidence. AU Cooper, Russell; Haltiwanger, John.

TI Published Versus Sample Statistics from the ASM; Implications for the LRD. AU Davis, Steve J.; Haltiwanger, John; Schuh, Scott.

TI Published Versus Sample Statistics from the ASM: Implications for the LRD. AU Davis, Steve J.; Haltiwanger, John; Schuh, Scott.

TI Wage Dispersion Between and Within U.S. Manufacturing Plants, 1963-1986. AU Davis, Steve J.; Haltiwanger, John.

\section{Hamada, Koichi}

TI The Fisherian Time Preference and the Evolution of Capital Ownership Patterns in a Global Economy. AU Fukao, Kyoji; Hamada, Koichi. 


\section{Hancock, Diana}

PD December 1989. TI Bank Profitability, Deregulation, and the Production of Financial Services. AA Santa Clara University. SR Federal Reserve Bank of Kansas City Research Working Paper: 89-16; Research Division, Federal Reserve Bank of Kansas City, 925 Grand Ave., Kansas City, MO 64198. PG 23. PR no charge. JE G21, E52, E43, L16. KW Interest Rates. Monetary Policy. Commercial Banks.

AB The objective of the paper is to examine the effect of interest rates and other components of monetary policy on bank profitability, and the production of financial services, in a deregulated environment. An explicit model of financial production is developed including asset and liability holdings, and the demand and supply of financial services, for commercial banks. The bank maximizes variable profit or revenue less variable costs, given the quantity of financial and physical capital. Included in the production process are all items on the balance sheet, including cash, loans, demand deposits, time deposits, and capital. Prices are constructed per unit dollar of real balances for financial services. The production model includes other income statement items such as physical capital, materials and labor that effect profitability.

\section{Hansson, Ardo H.}

PD October 1989. TI International Barter as Disguised Dumping. AA University of British Columbia. SR University of British Columbia Department of Economics Discussion Paper: 89-21; University of British Columbia, \#997-1873 East Mall, Vancouver, BC V6T 1W5, CANADA. PG 15. PR $\$ .20$ per page Canadian to other than educational institutions. JE F11, F13. KW Dumping. International Trade. Barter. Monopoly.

AB This paper describes a simple formal model of international barter. It is based on a price discriminating monopolist prevented from dumping overtly by the law. Bartering for differentiated products, by introducing "opaqueness" into a transaction, provides a channel for disguised dumping. Conditions under which barter trade is privately rational, even when costly, are described.

PD March 1990. TI The 1948 West German Economic Reforms: A Model for Eastern Europe? AA University of British Columbia. SR University of British Columbia Department of Economics Discussion Paper: 90-05; University of British Columbia, \#997-1873 East Mall, Vancouver, BC V6T IW5. CANADA. PG not available. PR $\$ .20$ per page Canadian to other than educational institutions. JE P51, P52. KW Planned Economies. Economic Reform. Germany. Soviet Union. Liberalization.

AB The West German stabilization and liberalization of 1948 is evaluated as a potential model for Eastern European economic reform, using the Soviet Union as a concrete case for comparison. The pre-reform initial conditions and economic structure, and the menu of post-reform macroeconomic instruments are described and compared. It is argued that similarities are significant enough to make useful comparisons, and that the German experience holds important lessons for "socialist" reforms. These lessons, and steps which might precede a similar reform in Eastern Europe, are described.

\section{Hardle, Wolfgang}

PD September 1990. TI Bootstrap Confidence Bands. AU Hardle, Wolfgang; Nussbaum, Michael. AA Hardle:
CORE, Belgium. Nussbaum: Akademie der Wissenschaften, Berlin. SR Universitat Bonn Sonderforschungsbereich 303 Discussion Paper: A-314; Sonderforschungsbereich 303 an der Universitat Bonn, Adenauerallee 24-42, D-5300 Bonn 1, DEUTSCHLAND. PG 8. PR no charge. JE C14, C13, C63. KW Wild Bootstrap. Nonparametric Regression. Confidence Intervals.

AB Bootstrap confidence bands are constructed for nonparametric regression. Resampling is based on a suitably estimated residual distribution often called the Wild Bootstrap. The method is to construct first a fine grid of error bars with simultaneous coverage probability. Second the endpoints of these error bars are joined via polygon pieces or parabola using assumptions on the local curvature of the regression curve.

\section{Hargraves, Monica}

PD May 1990. TI Borrowing and Lending with Private Information and Collateral Constraints. AA Brown University. SR Brown University Department of Economics Working Paper: 90-19; Department of Economics, Brown University, Providence, RI 02912. PG 22. PR no charge. JE G21, D24, D21, E22. KW Collateral. Credit Rationing. Private Information. Investment.

AB This analysis considers a one-period economy with risky investment projects, where entrepreneurs have private information concerning project quality ex ante, and are the sole observers of project returns ex post. Loan contracts are an optimal combination of loan size, loan rate, and collateral level. Projects require two goods as inputs, only one of which is accepted by lenders as collateral. The need to overcome informational asymmetries may lead some entrepreneurs to produce with an inefficiently high proportion of the input that is accepted as collateral. This creates a link between the intermediation or financial sector of the economy and the real sector, with implications for aggregate output and welfare. The potential implications for economic growth are also discussed.

\section{Hart, Oliver}

PD July 1990. TI A Theory of Corporate Financial Structure Based on the Seniority of Claims. AU Hart, Oliver, Moore, John. AA Hart: Massachusetts Institute of Technology. Moore: London School of Economics. SR Massachusetts Institute of Technology Department of Economics Working Paper: 560; Department of Economics, Massachusetts Institute of Technology, Cambridge, MA 02139. PG 60. PR $\$ 6.00$ Domestic, $\$ 8.00$ Overseas, $\$ 2.00$ Student. JE G31, G32. KW Private Debt. Business Investment. Capital Structure.

AB We develop a theory of optimal capital structure based on the idea that debt and equity differ in their priority status relative to future corporate cash payments. A company with high (dispersed) debt will find it hard to raise new capital since new security-holders will have low priority relative to existing senior creditors. Conversely for a company with low debt. We show that there is an optimal debt-equity ratio and mix of senior and junior debt for a corporation whose management may undertake unprofitable as well as profitable investments. Among other things, our theory can explain the observation that profitable firms have low debt. In addition, it predicts that (long-term) debt will be high if new investment is risky and on average profitable, or if assets in place are risky and new investment is on average unprofitable. 


\begin{abstract}
Hart, Sergiu
PD November 1990. TI A Neo2 Bayesian Foundation of the Maxmin Value for Two-Person Zero-Sum Games. AU Hart, Sergiu; Modica, Salvatore; Schmeidler, David. AA Hart and Schmeidler: Tel Aviv University. Modica: University of Palermo. SR Tel Aviv Foerder Institute for Economic Research Working Paper: 38-90; Department of Economics, Tel Aviv University, Ramat Aviv 69978, Tel Aviv, ISRAEL. PG 19. PR no charge. JE C72, D10. KW Zero-Sum Games. Utility Theory. Noncooperative Games.

AB A joint derivation of utility and value for two-person zero-sum games is obtained using a decision theoretic approach. Acts map states to consequences. The latter are lotteries over prizes, and the set of states is a product of two finite sets ( $m$ rows and $n$ columns). Preferences over acts are complete, transitive, continuous, monotonic and certaintyindependent (Gilboa and Schmeidler (1989)), and satisfy a new axiom of strategic flexibility which we introduce. These axioms are shown to characterize preferences such that (i) the induced preferences on consequences are represented by a von Neumann-Morgenstern utility function, and (ii) each act is ranked according to the maxmin value of the corresponding $m$ $\mathrm{x} n$ utility matrix (a two-person zero-sum game). An alternative statement of the result deals simultaneously with all finite twoperson zero-sum games in the framework of conditional acts and preferences.
\end{abstract}

\section{Hayashi, Toshi}

PD March 1988. TI Competitiveness of Deregulated Bulk Power Markets. AA Rand Corporation. SR Rand Paper: P-7549; The Rand Corporation, 1700 Main Street, P.O. Box 2138, Santa Monica, CA 90406-2138. PG 161. PR not available. JE L43, L94, L10. KW Regulation. Electricity. Public Utilities.

AB This study examines whether deregulation in wholesale electricity markets (or bulk power markets) results in competitive bulk power trade. The study analyzes data from the Southwest Bulk Power Market Experiment, in which participating utilities were allowed flexibility in setting rates for specified sales. The author uses two approaches; (1) simulating bulk power trade under competitive, monopoly, and dominant-firm market assumptions, and (2) comparing actual bulk power prices in the base and experimental years. The simulation approach indicates that the volume and welfare gains of trade under market power assumptions do not appreciably differ from those under the competitive assumptions, providing no clues to the question of competitiveness.

\section{Head, Allen C.}

PD December 1990. TI Strategic Innovation and Economic Growth. AU Head, Allen C.; Lapham, Beverly J. AA Head: University of Minnesota. Lapham: Queen's University. SR Queen's Institute for Economic Research Discussion Paper: 801; Department of Economics, Queen's University, Kingston, Ontario, CANADA K7L 3N6. PG 48. PR \$3.00 Canada and U.S.; \$3.50 Foreign. JE O31, L13, E23, 041. KW Output. Growth Model. Oligopoly. Economic Growth. Innovations.

AB Strategic interaction among oligopolistic innovators and its implications for economic growth are examined in two dynamic computable general equilibrium models. In each environment, technologies for producing a final good are such that the profits of any intermediate good producer depend on the quality of all intermediate goods. This leads to strategic innovation choices which affect equilibrium growth rates. In the first economy, these spillovers lead to long-run output growth rates which fluctuate around a constant level. This level is affected by the degree of spillovers, the length of firms' planning horizons, the number of firms, and average innovation costs. In this economy a firm unequivocally benefits from innovation by other firms. A second economy is also considered in which innovation by other firms may harm intermediate goods producers. This results as innovation leads to rising factor costs. This second economy also exhibits continual output growth but at a decreasing rate.

\section{Helliwell, John F.}

PD March 1990. TI Globalization, Convergence, and the Prospects for Economic Growth. AU Helliwell, John F.; Chung, Alan H. AA University of British Columbia. SR University of British Columbia Department of Economics Discussion Paper: 90-06; University of British Columbia, \#997-1873 East Mall, Vancouver, BC V6T IW5, CANADA. PG 39. PR \$.20 per page Canadian to other than educational institutions. JE F01, O32, O57, D33. KW Globalization. Productivity. Economic Growth.

AB The paper uses historical data for the period 1963-85 to examine the economic growth record of the industrial economies and to establish a basis for assessing their economic prospects. The growth of real income per capita is decomposed into seven key ratios, including the contributions of normal output per employee and utilization rates, which together describe each country's productivity performance. A production function is used to define normal output and to assess the productivity implications of adopting alternative models of the international transmission of technical progress. Forecasts assuming normal levels of labor force participation, unemployment, and productivity at the end of the century show that for most countries the average growth of per capita real income will be higher than for 1973-1985, but lower than for 1963-1973.

\section{Helpman, Elhanan}

TI Quality Ladders and Product Cycles. AU Grossman, Gene M.; Helpman, Elhanan.

TI Trade, Innovation, and Growth. AU Grossman, Gene M.; Helpman, Elhanan.

TI Trade, Knowledge Spillovers and Growth. AU Grossman, Gene M.; Helpman, Elhanan.

PD September 1990. TI International Links of Innovation Rates. AA Tel Aviv University. SR Tel Aviv Foerder Institute for Economic Research Working Paper: 25-90; Department of Economics, Tel Aviv University, Ramat Aviv 69978, Tel Aviv, ISRAEL. PG 33. PR no charge. JE O19, O31, F34. KW Technology. Economic Growth. Innovation. International Trade.

AB Rates of innovation of trading countries depend on each other. I show that short-run comovements may differ significantly from long-run comovements. Consequently two trading countries may exhibit complicated time patterns of innovation rates in response to structural shifts, such as changes in the size of their resource base. 
TI Hysteresis in the Trade Pattern. AU Grossman, Gene M.; Helpman, Elhanan.

PD January 1991. TI Exchange Rate Systems: New Perspectives. AU Helpman, Elhanan; Leiderman, Leonardo. AA Tel Aviv University. SR Tel Aviv Foerder Institute for Economic Research Working Paper: 3-91; Department of Economics, Tel Aviv University, Ramat Aviv 69978, Tel Aviv, ISRAEL. PG 50. PR no charge. JE F31, EA2, E52. KW Monetary Policy. Exchange Rates. Central Bank.

AB This paper reviews recent theoretical and empirical work on exchange rate systems. We first review the literature that uses proper welfare criteria in comparisons of exchange rate systems and reach the conclusion that this approach is still underdeveloped. Then we turn to empirical evidence on simple performance measures under different regimes. We elaborate on the finding that real exchange rates are more volatile under flexible than under fixed exchange rates. Next, we address the viability of exchange rate pegs, with special emphasis on the implications of expectations of a change in regime. Finally, we discuss recent studies of exchange rate bonds.

\section{Henderson, J. Vernon}

PD September 1990. TI An Econometric Model of Industrial Location. AA Brown University. SR Brown University Department of Economics Working Paper: 90-26; Department of Economics, Brown University, Providence, RI 02912. PG 26. PR no charge. JE R11, R13, R32, O18. KW Economies of Scale. Manufacturing. Technology. Regional Economics.

AB The paper develops and estimates a model of industrial location. The data are for three-digit industries for the sample 126 urban areas in Brazil. The model estimates which cities will have an industry or not and what the scale of operation will be in each city. The parameters estimated describe the technology of a representative firm based on a profit function with external economies of scale and the parameters of the supply function of entrepreneurs. The estimation incorporates discrete choice, simultaneity, nonlinear equations, censoring and equilibrating error in a FIML specification. The results are used to simulate the impact of locational subsidies on the number of cities having a particular industry and the scale of operation in cities originally and newly containing the industry.

\section{Hermalin, Benjamin}

TI The Role of Outside Considerations in the Design of Compensation Schemes. AU Caillaud, Bernard; Hermalin, Benjamin.

\section{Hickok, Susan}

PD December 1990. TI Factors Behind the Shifting Composition of U.S. Manufactured Goods Trade. AA Federal Reserve Bank of New York. SR Federal Reserve Bank of New York Research Paper: 9036; Federal Reserve Bank of New York, 33 Liberty St., Rm. 901, New York City, New York 10045. PG 45. PR no charge. JE F14, L60. KW International Trade. Comparative Advantage. Trade Model. Manufacturing.

AB A divergent trend has developed over the last decade in the composition of U.S. manufactured goods imports compared 10 U.S. manufactured goods exports. Finished products have risen sharply as a percentage of U.S. purchases, with a corresponding fall in the import share of industrial supplies. On the U.S. export side no similar shift has occurred. This study examines the reasons why the composition of U.S. trade has evolved in this manner. The main finding is that changes in capital/labor ratios, were a prime factor in moving the observed U.S. comparative advantage away from finished goods and toward industrial supplies.

\section{Hiemstra, Craig}

PD November 1990. TI Applications to Weak-Form Market Efficiency of Recently Developed Tests for Nonlinear Dependence Based on the Correlation Integral. AA University of Maryland, College Park. SR University of Maryland Department of Economics Working Paper Series: 90-22; Department of Economics, University of Maryland, College Park, MD 20742. PG 39. PR no charge. JE G14, C22, C12. KW Market Efficiency. ARCH. Nonlinear Models. Time Series. Hypothesis Testing.

AB Recently developed tests for nonlinear dependence are applied to evaluate the practical importance of the possibility that standard tests of market efficiency accept the efficiency hypothesis simply because they are powerless in detecting nonlinear dependence. The practical importance of the possibility is evaluated by subjecting time series of forecast errors from a few models of asset prices to a variety of tests. The applications demonstrate that the low-power problem of standard tests is indeed important in practice, confirm the seeming ubiquity of ARCH dependence in financial data, and suggest that the recently developed tests have relatively little power against low-level AR and ARCH processes.

\section{Hirshleifer, Jack}

PD July 1989. TI The Dimensions of Power as Illustrated in a Steady-State Model of Conflict. AA Rand Corporation. SR Rand Note: N-2889; The Rand Corporation, 1700 Main Street, P.O. Box 2138, Santa Monica, CA 90406-2138. PG 32. PR not available. JE D74, D51. KW Conflict. Power. Cooperation. Cournot Equilibrium.

AB This note presents a theoretical analysis of the determinants of power, defined as the ability to achieve one's ends in the presence of rivals. The author analyzes two-sided interactions between contenders assumed to be rational and interested solely in maximizing income. Each contender strikes an optimal balance between productive activity (aimed at generating income through cooperation with the other side) and conflictual activity (aimed at appropriating the income produced by others or defending against others' efforts to do the same).

\section{Hirtle, Beverly}

PD May 1990. TI A Simple Model of Bank Loan Commitments and Monetary Policy. AA Federal Reserve Bank of New York. SR Federal Reserve Bank of New York Research Paper: 9010; Federal Reserve Bank of New York, 33 Liberty St., Rm. 901, New York City, New York 10045. PG 25. PR no charge. JE E44, E52, G21, E23. KW Monetary Policy. Private Debt. Commercial Banks.

AB This paper presents a simple model that explores the relationship between the market for bank loan commitments and the effectiveness of monetary policy. In the model, monetary policy is less effective -- in the sense that aggregate output is less sensitive to changes in interest rates -- when loan commitments are provided by the banking sector. The loan commitment contract specified in the model is very stylized, but it contains a number of elements that are typical of actual 
loan commitments. In particular, the contract is structured to capture the price hedge and liquidity insurance characteristics of loan commitments.

PD May 1990. TI Financial Market Evolution and the Interest Sensitivity of Output. AU Hirtle, Beverly: Kelleher, Jeanette. AA Federal Reserve Bank of New York. SR Federal Reserve Bank of New York Research Paper: 9013: Federal Reserve Bank of New York, 33 Liberty St., Rm. 901, New York City, New York 10045. PG 37. PR no charge. JE E44, E52, E32. KW Interest Rates. Financial Markets. Monetary Policy. Business Fluctuations.

AB The purpose of this paper is to examine one aspect of the transmission mechanism of monetary policy -- the relationship between interest rates and the growth of output .- and to quantify changes in that relationship over the period of recent financial market evolution. The basic goal of the analysis is to determine whether or not there have been any systematic changes in the interest sensitivity of the economy over the past three decades. The empirical approach taken is quite general in the sense that we estimate "unconditional" interest elasticities in simplified reduced form equations. Our primary finding is that the sensitivity of aggregate real GNP to both long-term and short-term interest rates appears to have decreased since the 1950s.

PD May 1990. TI Bank Loan Commitments and the Transmission of Monetary Policy. AA Federal Reserve Bank of New York. SR Federal Reserve Bank of New York Research Paper: 9009; Federal Reserve Bank of New York, 33 Liberty St., Rm. 901, New York City, New York 10045. PG 23. PR no charge. JE E44, E52, G21, E23. KW Monetary Policy. Private Debt. Credit Rationing. Banking.

AB This paper presents an empirical analysis of the effects of loan commitments on the transmission of monetary policy. Using loan commitment data from a survey of 113 large commercial banks, the results of this analysis suggest that the growth of the loan commitment market has been associated with a decline in the interest sensitivity of real output. This aggregate result is robust to a variety of specifications, lending initial support to the contention that loan commitments affect monetary policy by protecting borrowers from rationing. However, a more detailed analysis suggests that the impact of loan commitments on the interest sensitivity of output may be a consequence of their effect on the composition of the overall pool of commercial and industrial borrowers.

\section{Hoang, Chinh T.}

PD March 1990. TI Algorithms for Minimum Weighted Colouring of Perfectly Ordered, Comparability, Triangulated, and Clique Separable Graphs. AA University of Bonn. SR Universitat Bonn Sonderforschungsbereich 303 Discussion Paper: 90632-OR; Sonderforschungsbereich 303 an der Universitat Bonn, Adenauerallee 24-42, D-5300 Bonn 1, DEUTSCHLAND. PG 12. PR no charge. JE C60, C63. KW Graph Theory. Ordered Graph. Triangulated Graph. Clique Decomposition. Colouring Algorithm. Polynomial Algorithm.

AB We design an $O(\mathrm{~nm})$ algorithm to find a minimum weighted colouring and a maximum weighted clique of a perfectly ordered graph. We also present two $O$ (n squared) algorithms to find a minimum weighted colouring of a comparability graph and of a triangulated graph. Our colouring algorithms use an algorithm to find a stable set meeting all maximal (with respect to set inclusion) cliques of a perfectly ordered graphs. We show that the problem of finding such stable set in an arbitrary graph is NP-hard. We shall also describe a polynomial algorithm to find a minimum weighted colouring of a clique of separable graph.

PD June 1990. TI A Parallel Algorithm for Minimum Weighted Colouring of Trianagulated Graphs. AA University of Bonn. SR Universitat Bonn Sonderforschungsbereich 303 - Discussion Paper: 90645-OR; Sonderforschungsbereich 303 an der Universitat Bonn, Adenauerallee 24-42, D-5300 Bonn I, DEUTSCHLAND. PG 11. PR no charge. JE C63, C60. KW Graph Theory. Parallel Algorithm. Colouring Problem.

AB We present a parallel algorithm to find a minimum weighted colouring of a triangulated graph. This algorithm runs in $O((\log n)$ cubed $)$ time using $O((n$ squared times $m)$ divided by $(\log n))$ processors in the CRCW PRAM model.

PD June 1990. TI On the Sibling - Structure of Perfect Graphs. AA University of Bonn. SR Universitat Bonn Sonderforschungsbereich 303 - Discussion Paper: 90644-OR; Sonderforschungsbereich 303 an der Universitat Bonn, Adenauerallee 24-42, D-5300 Bonn 1, DEUTSCHLAND. PG 4. PR no charge. JE C60. KW Graph Theory. Perfect Graphs.

AB Two vertices $x, y$ are siblings with respect to a set $Q$ if both $Q$ union $\{x\}$ and $Q$ union $\{y\}$ induce a $P(4)$. Two graphs $G$ $=(V, E)$ and $G^{\prime}=\left(V^{\prime}, E^{\prime}\right)$ are said to have the same siblingstructure if there is a bijection $f: V$ to $V$ ' such that vertices $x, y$ are siblings with respect to a set $Q$ in $G$ if and only if $f(x), f(y)$ are siblings with respect to $f(Q)$ in $G$ '. We prove that if two graphs have the same sibling-structure then either both graphs are perfect or both graphs are imperfect.

\section{Hochstattler, Winfried}

PD December 1989. TI Shellability of Oriented Matroids. AA University of Cologne. SR Universitat Bonn Sonderforschungsbereich 303 - Discussion Paper: 89.80; Sonderforschungsbereich 303 an der Universitat Bonn, Adenauerallee 24-42, D-5300 Bonn 1, DEUTSCHLAND. PG 9. PR no charge. JE C60, C61, C67. KW Oriented Matroids. Simplex Algorithm.

AB A. Mandel (1982) proved that the maximal cells of an Oriented Matroid poset are B-shellable. Our result shows that the whole Oriented Matroid is shellable, 100.

PD January 1990. TI Vertex-Edge-Paths and a Forbidden Facet. AA University of Cologne. SR Universitat Bonn Sonderforschungsbereich 303 - Discussion Paper: 90.81; Sonderforschungsbereich 303 an der Universitat Bonn, Adenauerallee 24-42, D-5300 Bonn 1, DEUTSCHLAND. PG 6. PR no charge. JE C60. KW Oriented Matroid. Skeleton Graph.

AB We prove that the skeleton graph of a cell of an Oriented Matroid is still connected, if we delete all nodes adjacent to one facet.

PD March 1990. TI A Note on the Lattice of 2-MatroidIntersections. AU Hochstattler, Winfried; Rieder, J. AA University of Cologne. SR Universitat Bonn Sonderforschungsbereich 303 - Discussion Paper: 90.84; Sonderforschungsbereich 303 an der Universitat Bonn, Adenauerallee 24-42, D-5300 Bonn 1, DEUTSCHLAND. 
PG 5. PR no charge. JE C60. KW Matroid Intersection. Lattices.

AB In this note we present a class of examples, which show that the property of the lattice generated by the bases of a 2matroid-intersection to be the intersection of the two lattices associated with the bases of the two matroids does not hold in general, even if one of the involved matroids is a partition matroid with more than two classes.

\section{Hoff, Karla}

PD December 1990. TI Land Taxes, Output Taxes, and Sharecropping: Was Henry George Right? AA University of Maryland, College Park. SR University of Maryland Department of Economics Working Paper Series: 90-26; Department of Economics, University of Maryland, College Park, MD 20742. PG 37. PR no charge. JE N43, N53, H21. KW Land Tax. Output Tax. Economic History. Imperfect Markets.

AB Economists have long argued that if a land tax is administratively feasible, then to increase efficiency it should be used to the exclusion of output taxes. This article shows that underlying this policy prescription is the assumption that institutions for pooling and spreading production risks are perfect. When account is taken of the imperfections in those institutions, a mix of land and low output taxes will be Pareto superior to a pure land tax regime and may induce higher output, as well. Henry George was wrong! The Pareto superiority to a pure land tax of a portfolio of land and output taxes generally holds even when the land tax is indexed to regional output and when land is farmed under sharecropping. This result is an application of the theorem of the second best.

PD December 1990. TI Imperfect Information and Rural Credit Markets: Puzzles and Policy Perspectives. AU Hoff, Karla; Stiglitz, Joseph E. AA Hoff. University of Maryland, College Park. Stiglitz: Stanford University. SR University of Maryland Department of Economics Working Paper Series: 90-25; Department of Economics, University of Maryland, College Park, MD 20742. PG 32. PR no charge. JE O18, O16, O53, R58, R51. KW Credit Market. Rural Sector. Developing Countries. Government Intervention.

AB This paper explores the nature of contracts and institutions in the rural credit markets of developing countries, emphasizing the problems of imperfect information and imperfect enforcement. It provides a rich set of facts about rural credit markets based on newly published analyses of credit markets in Nigeria, Thailand, India, Pakistan, and China. Institutions pervasive in rural credit markets in developing countries are usufruct loans, trade-credit interlinkages, kinshipand village-based credit systems, trade-credit interlinkages, and rotating savings and credit associations. These institutions help to solve the information and enforcement problems in lending. This paper provides a framework for assessing the consequences of government interventions in rural credit markets.

\section{Hoffman, Philip T.}

PD April 1991. TI Land Rents and Agricultural Productivity: The Paris Basin 1450-1789. AA California Institute of Technology. SR Caltech Social Science Working Paper: 752; Division of Humanities and Social Sciences, 22877. California Institute of Technology, Pasadena, CA 91125. PG 50. PR no charge. JE N53, N13, O14, 047. KW Agriculture. Labor Productivity. France. Economic
Growth.

AB Using evidence from a sample of over 800 leases, this paper examines the productivity of farming in the Paris Basin between 1450 and 1789 . Existing evidence about productivity is unreliable, the paper argues, and the leases provide historians with a new and valuable source for the study of productivity and economic growth. Much of the paper is devoted to a defense of the method employed with the leases, which point to spurts of spectacular growth on local farms but also to stunning setbacks during times of war and increased taxation. The paper concludes with analysis of the causes of economic growth in pre-industrial agriculture.

\section{Hofmeister, $M$.}

TI On Coverings of the Complete Graph with 4 Vertices. AU Ewen, R.; Hofmeister, $M$.

PD August 1990. TI Non-Equivalent Cocycles of Graphs Over Finite Fields. AA University of Cologne. SR Universitat Bonn Sonderforschungsbereich 303 . Discussion Paper: 90.88; Sonderforschungsbereich 303 an der Universitat Bonn, Adenauerallee 24-42, D-5300 Bonn 1, DEUTSCHLAND. PG 7. PR no charge. JE C60. KW Graph Theory.

AB The automorphism group of a graph acts on its cocycle space over any field. The orbits of this group action will be counted in case of finite fields. In particular, we obtain an enumeration of non-equivalent edge cuts of the graph.

\section{Holzer, Harry J.}

TI Industrial Shifts, Skills Levels, and the Labor Market for White and Black Males. AU Bound, John; Holzer, Harry J.

\section{Hoover, Kevin D.}

PD January 1991. TI Calibration Versus Estimation: Standards of Empirical Assessment in the New Classical Macroeconomics. AA University of California at Davis. SR University of California at Davis Research Program in Applied Macro and Macro Policy: 72; Department of Economics, University of California at Davis, Davis, California 95616-8578. PG 34. PR not available. JE E13, B41, C50. KW Calibration. Estimation. New Classical Macroeconomics. Modeling. Business Cycle.

AB The new classical macroeconomics is split between those who believe that quantitative assessment of theoretical models requires conventional estimation and testing of implied restrictions and those (especially advocates of real business cycle models) who believe that models should be calibrated. This paper argues that calibration is not simply a strategy for immunizing models from empirical rejection, but can be understood in terms of the fundamental nature of idealization in science. There is, however, nothing in the calibration approach per se that recommends new classical real business cycle models over other models. Furthermore, adequate comparative standards for calibrated models have yet to be developed.

\section{Howe, Howard}

TI The Political and Institutional Independence of U.S. Monetary Policy. AU Akhtar, M. A.; Howe, Howard.

\section{Huang, Weihong}

PD September 1989. TI Chaotically Switching Bear and Bull Markets: The Derivation of Stock Price Distribution from 
Behavioral Rules. AU Huang, Weihong; Day, Richard $\mathrm{H}$. AA University of Southern California. SR University of Southern California Modelling Research Group Working Paper: M8922; Department of Economics, University of Southem California, University Park, Los Angeles, CA 90089-0152. PG 30. PR no charge. JE G12, G14. KW Stock Market. Asset Pricing.

AB A stock market model is developed to explain some observable characteristics of the stock market such as its tendency to generate alternating periods of generally rising or generally falling prices, so called "bull" and "bear" markets that seem suddenly to switch from one to the other at irregular intervals. The distributions of stock prices is derived from a representation of three stylized types of market participant market maker, investors and market sheep.

\section{Huffiman, Gregory W.}

PD September 1988. TI A Representative Agent Model of Asset Pricing and Transaction Volume. AA University of Western Ontario. SR Federal Reserve Bank of Kansas City Research Working Paper: 88-05; Research Division, Federal Reserve Bank of Kansas City, 925 Grand Ave., Kansas City, MO 64198. PG 36. PR no charge. JE G12, D51, D58. KW Asset Prices. Equilibrium Allocation. Representative Agent Model. General Equilibrium Model.

AB Two stochastic infinitely lived representative agent models are studied which have implications for the behavior of asset prices, rates of return, and the level of transaction volume. A natural measure of transaction volume is shown to be illbehaved when the equilibrium allocations solve an equal weight planning problem. An alternative measure of transaction volume for the same economy can be characterized. It is shown that under certain conditions the dynamic behavior of the endogenous variables, including the distribution of individual transaction volume, can be characterized as a function of the parameters which determine the structure of preferences and technology. A version of the model, in which the equilibrium allocations are not optimal is also shown to produce an endogenous transaction volume. This is important because it is generally stated that the representative agent paradigm is reticent on the issue of the behavior of transaction volume.

PD September 1988. TI The Accuracy of the Grid Approximation Method. AA University of Western Ontario. SR Federal Reserve Bank of Kansas City Research Working Paper: 88-06; Research Division, Federal Reserve Bank of Kansas City, 925 Grand Ave., Kansas City, MO 64198. PG 13. PR no charge. JE C61, C25, C51, C52. KW Dynamic Model. Approximation Theory.

AB A popular method applied to the analysis of certain dynamic stochastic economic models is to restrict certain state variables to lie in a specified grid. The stochastic features of the restricted model can then be analyzed using computational techniques such as those of dynamic programming. The restricted model can then be used to arrive at a probability distribution function for the endogenous variables. The present paper analyzes the accuracy of this approximation for a restricted class of economies, and investigates how the accuracy of the approximation depends upon various parameters which determine the structure of preferences and technology.

PD January 1989. TI Tax Analysis in a Dynamic Stochastic Model: On Measuring Harberger Triangles and
Okun Gaps. AU Huffman, Gregory W.; Greenwood, Jeremy. AA University of Western Ontario. SR Federal Reserve Bank of Kansas City Research Working Paper: 89-01; Research Division, Federal Reserve Bank of Kansas City, 925 Grand Ave, Kansas City, MO 64198. PG 33. PR no charge. JE H21, E32, D61, C61. KW Taxation. Government Policy. Subsidies. Business Fluctuations.

AB A stochastic representative agent model is analyzed in which the allocations are not necessarily Pareto optimal. It is shown that a variation on traditional dynamic programming techniques can be employed to obtain a solution of the model. The economy is then specialized to study the impact of various distortional government tax and subsidy schemes. The presence of these government policies makes the resulting allocations non-optimal. The dynamic impact of varying various tax or subsidy rates is analyzed. It is shown that the government can use its policy tools to stabilize the cyclical fluctuations, and this is done for the economy under study. The benefits of implementing such a policy are calculated and are compared with the size of the welfare gains realized by reducing various tax distortions.

\section{Hughes, Alan}

TI Predicting Success; Pre-Merger Characteristics and Post-Merger Performance. AU Cosh, Andy; Hughes, Alan; Lee, Kevin; Singh, Ajit.

PD August 1990. TI Industrial Concentration and the Small Business Sector in the U.K.: The 1980s in Historical Perspective. AA University of Cambridge. SR University of Cambridge Small Business Research Centre Working Paper: 5; Department of Applied Economics, University of Cambridge, Sidgwick Avenue, Cambridge CB3 9DE, UNITED KINGDOM. PG 14. PR $\$ 5.00$ (2.50 pounds); checks payable to University of Cambridge. JE L11, L16, L60, C82. KW Small Businesses. Firm Size. Market Concentration. Manufacturing.

AB This paper argues that the increases in the shares of small businesses in economic activity in the 1980s have their roots prior to 1979. A major part of officially reported changes in the numbers of small firms in the U.K. manufacturing sector in the 1980s are shown to be the result of a change in the way the data are collected. It is shown that stability in aggregate and market concentration since the early 1970 s has been associated with an apparently widening productivity gap between large and small firms.

TI Age, Size. Growth and Survival: U.K. Companies in the 1980s. AU Dunne, Paul; Hughes, Alan.

TI Small Businesses: An Analysis of Recent Trends in their Relative Importance and Growth Performance in the U.K. with Some European Comparisons. AU Dunne, Paul; Hughes, Alan.

\section{Hung, Juann $H$.}

PD March 1991. TI Noise Trading and the Effectiveness of Sterilized Foreign Exchange Intervention. AA Federal Reserve Bank of New York. SR Federal Reserve Bank of New York Research Paper: 9111; Federal Reserve Bank of New York, 33 Liberty St., Rm. 901, New York City, New York 10045. PG 31. PR no charge. JE F31. KW Foreign Exchange. Exchange Rates. Noise. Efficient Markets.

AB This paper argues that the noise trading approach is a more realistic approach than the efficient markets hypothesis to 
understanding the foreign exchange market and exchange rate dynamics. The exchange rate may be misaligned or excessively volatile when noise trading is active and uncovered arbitrage by fundamentalists is limited due to risk considerations or liquidity constraints. Under such conditions, sterilized intervention can be effective by manipulating the trading rules commonly used by noise traders.

\section{Ito, Takatoshi}

PD October 1988. TI Intraday Yen/Dollar Exchange Rate Movements: News or Noise? AU Ito, Takatoshi; Roley, V. Vance. AA Ito: University of Minnesota and National Bureau of Economic Research. Roley: Federal Reserve Bank of Kansas City and University of Washington. SR Federal Reserve Bank of Kansas City Research Working Paper: 88-07; Research Division, Federal Reserve Bank of Kansas City, 925 Grand Ave., Kansas City, MO 64198. PG 40. PR no charge. JE F31, G15, F32. KW Exchange Rates. Stock Markets.

AB Intraday movements in the yen/dollar rate are examined over the 1980-86 period using opening and closing quotes in the New York and Tokyo markets. The results indicate that random walk behavior is violated about half of the time in various subsamples. However, the economic significance of departures from the random walk model diminishes over time. Large jumps in the exchange rate also are examined, and some evidence on subsequent mean reversion is presented. Finally, the response of Japanese and U.S. stock prices suggests that intraday yen/dollar rate movements do contain at least some relevant information.

TI Bequest Taxes and Accumulation of Household Wealth: U.S. - Japan Comparison. AU Barthold. Thomas A.: Ito, Takatoshi.

\section{Jack, Bryan}

PD August 1990. TI The Cournot-Nash Alliance Public Good Model: An Integrated, Diagrammatic, Approach to the Free-Riding, Multilateral-Contribution, and Neutrality Results. AA University of Maryland, College Park. SR University of Maryland Department of Economics Working Paper Series: 90-16: Department of Economics, University of Maryland, College Park, MD 20742. PG 43. PR no charge. JE H41, F01, D50, D62. KW Public Goods. Nash Equilibrium. Free Riding.

AB This paper introduces the endowment-consumption diagram as an alternative to the algebra-calculus method of analyzing the Cournot-Nash alliance public good model, defined by Samuelson (1954) and Olson and Zeckhauser (1966). The endowment-consumption technique fixes a total (global) endowment, so that each country's (isolation) expenditure on public and private goods can be expressed as a function of others' endowments. The diagram correlates this information from all countries, and directly yields the combinations of relative endowment that yield "free-riding" vice universal provision of the public good. The "neutrality" result, announced by Warr (1983), is also clearly illustrated by the diagram. The endowment-consumption technique can be used to analyze groups of more than two countries. It can also be extended to "impure" public goods, and to non-traded public goods that have different marginal costs in different countries.

\section{Jackson, Matthew 0.}

PD November 1990.

Implementation in Bounded Mechanisms. AU Jackson, Matthew O.; Palfrey, Thomas R.; Srivastava, Sanjay. AA Jackson: Northwestern University. Palfrey: California Institute of Technology. Srivastava: Carnegie Mellon University. SR Caltech Social Science Working Paper: 754; Division of Humanities and Social Sciences, 228-77. California Institute of Technology, Pasadena, CA 91125. PG 38. PR no charge. JE D71, C72, C71. KW Mechanism Design. Game Theory. Social Choice. Nash Equilibrium.

AB We characterize social choice correspondences which can be implemented in undominated Nash equilibrium by bounded mechanisms (An undominated Nash equilibrium is a Nash equilibrium in which no agent uses a weakly dominated strategy. A mechanism is bounded if every dominated strategy is dominated by an undominated strategy). We provide necessary conditions and sufficient conditions for such implementation. Our conditions are satisfied in virtually all "economic" settings, and are also satisfied by many interesting correspondences identified in the social choice literature. For economic settings, we provide a particularly simple implementing mechanism in which the undominated Nash equilibrium outcomes coincide with those obtained by iterated elimination of weakly dominated strategies.

\section{Jeong, Jinook}

TI On the Exact Small Sample Distribution of the Instrumental Variable Estimator. AU Maddala, G. S.; Jeong, Jinook.

PD July 1990. TI A Nonparametric Test for Rationality of Survey Data Using the Bootstrap Method. AU Jeong, Jinook; Maddala, G. S. AA University of Florida. SR University of Florida Working Paper in Economics: 90-7; Department of Economics, University of Florida, Gainesville, FL 32611. PG 18. PR no charge. JE C12, D84, C51. KW Measurement Error. Rationality. Bootstrap Method. Surveys. Expectations.

AB Conventional tests for rationality of survey data on expectations are not valid in the presence of measurement errors. However, if two or more survey measures of expectations are available on the true unobserved expectational variables, we can devise the appropriate tests for rationality. This paper utilizes this method for survey data on expectations for 90-day T-bill rates, S\&P indexes, and foreign exchange rates (D-mark, Swiss Franc, British Pound and Japanese Yen). Since the maximum likelihood estimation and tests for rationality are based on the normality assumption for the errors, the bootstrap method is used as an alternative. The results and the conclusions, however, do not change much with the bootstrap method, thus suggesting that the assumption of normality is not crucial to the conclusions. The rationality hypotheses is rejected in all cases.

PD July 1990. TI Measurement Errors and Tests for Rationality. AU Jeong, Jinook; Maddala, G. S. AA University of Florida. SR University of Florida Working Paper in Economics: 90-8; Department of Economics, University of Florida, Gainesville, FL 32611. PG 39. PR no charge. JE D84, C12, C51. KW Rational Expectations. Measurement Errors. Latent Variables Model. Surveys. Unit Root.

AB The rationality of survey data on expectations has received considerable attention in recent years. The traditional tests for rationality - the regression and volatility tests have 
often rejected the hypothesis of rationality. It has been argued that these tests are not valid in the presence of unit roots in the survey data and the actual observed series. Hence some cointegration tests have been suggested. These co-integration tests have often failed to reject the hypothesis of rationality. The present paper considers an alternative reason for the failure of the traditional regression and volatility tests. Since survey data are proxies for the true expectational variables, the traditional tests would suffer from the errors in variables bias.

TI An Evaluation of Incentive Regulations for Electric Utilities. AU Berg. Sanford V.; Jeong, Jinook.

\section{Joines, Douglas H.}

PD December 1989. TI Money Supply Announcements and Real Economic Activity. AA University of Southem Califomia. SR Federal Reserve Bank of Kansas City Research Working Paper: 89-10; Research Division, Federal Reserve Bank of Kansas City, 925 Grand Ave., Kansas City, MO 64198. PG 25. PR no charge. JE E51, E52, E43. KW Money Supply. Interest Rates.

AB This paper derives testable implications of a model due to Siegel (1985) in which interest rates react to announced innovations in the money supply solely because money announcements reveal information about real economic activity. Tests of these implications yield results inconsistent with the model. In addition, the results contradict the finding of Huizinga and Leiderman (1987) that interest rates tended to rise in response to unexpected increases in the monetary base from October 1979 to February 1984.

TI An Experimental Study of Comparable Worth. AU Arnault, E. Jane; Gordon, Louis; Joines, Douglas H.; Phillips, G. Michael.

PD December 1989. TI How Bad is the Federal Budget Deficit? AA University of Southern California. SR Federal Reserve Bank of Kansas City Research Working Paper: 89-12; Research Division, Federal Reserve Bank of Kansas City, 925 Grand Ave., Kansas City, MO 64198. PG 42. PR no charge. JE H62, H63. KW Government Spending. Budget Deficits. Deficit Financing. Public Debt.

AB Although it is infeasible for the government to run arbitrarily large budget deficits forever, deficits may be sustained indefinitely if they are not too large. This paper shows how large the deficit can be if the ratio of government debt to GNP is held at various target levels. It concludes that the debtGNP ratio can be held at or below its current level as long as the budget deficit, as conventionally measured, does not greatly exceed $\$ 70$ billion in the near term. Since GNP will be larger in the future than it is now, the economy can sustain deficits larger than $\$ 70$ billion in the future without requiring an eventual tax increase. The paper also surveys the debate over the economic consequences of government budget deficits.

TI Real and Nominal Exchange Rates Since 1919. AU Hakkio, Craig S.; Joines, Douglas H.

\section{Joyce, Theodore J.}

PD May 1991. TI Unemployment and Infant Health: Time-Series Evidence from the State of Tennessee. AU Joyce, Theodore J.; Mocan, H. Naci. AA Joyce: City University of New York and National Bureau of Economic Research. Mocan: National Bureau of Economic Research and
University of Colorado. SR National Bureau of Economic Research Working Paper: 3694; National Bureau of Economic Research, 1050 Massachusetts Avenue, Cambridge, MA 02138. PG not available. PR $\$ 2.00$. JE I12, E24, E32, J13. KW Unemployment. Health. Fertility.

AB The relationship between unemployment and health continues to absorb social scientists. The primary reason is the potential significance of an association. If a substantial deterioration in aggregate health is related to economic downturns, then the cost of a recession may be much greater than the foregone output. This paper investigates the aggregate time series relationship between unemployment and low birth weight with monthly data from the state of Tennessee from 1970 through 1989. The study differs from previous work in that we decompose the unemployment rate into its structural and cyclical components. Moreover, we use vector autoregressions to test the reduced form relationship between unemployment and low birth weight.

\section{Kahn, George A.}

PD September 1989. TI The Output and Inflation Effects of Dollar Depreciation. AA Federal Reserve Bank of Kansas City. SR Federal Reserve Bank of Kansas City Research Working Paper: 89-05; Research Division, Federal Reserve Bank of Kansas City, 925 Grand Ave, Kansas City, MO 64198. PG 40. PR no charge. JE E31, E32, F31. KW Exchange Rates. Output. Business Cycle. Inflation.

AB This paper examines the effects of fuctuations in the real foreign exchange rate on inflation and real output. Theoretically, a lower dollar increases aggregate demand but, by raising expected prices and the cost of imported inputs, it reduces aggregate supply. Prices unambiguously rise, but output may rise or fall, depending on the relative importance of demand versus supply effects. Moreover, while the demand effect increases real output only temporarily, the supply effect is potentially permanent. Looking specifically for evidence of adverse long-run supply effects, the paper provides estimates of the net effect of a lower dollar on inflation and output.

\section{Kahn, James A.}

PD April 1991. TI Why is Production More Volatile than Sales? Theory and Evidence on The Stockout-Avoidance Motive for Inventory-Holding. AA Hoover Institution and University of Rochester. SR Stanford Hoover Institute Working Paper in Economics: E-91-7; Domestic Studies Program Working Paper Series, Hoover Institution, Stanford University, Stanford, CA 94305. PG 42. PR not available. JE E22, E23, E32, L62. KW Inventories. Production Smoothing. Automobile Industry. Manufacturing. Business Cycle.

AB This paper argues that the macroeconomically interesting features of inventory behavior are well captured by a model in which firms face only demand uncertainty with a nonnegativity constraint on inventories. Empirical implications of the "stockout-avoidance" model of inventory behavior are derived and then tested on disaggregated automobile industry data. The results largely support the model, though they suggest a small role for production-smoothing as well. Subsidiary evidence on the relative variance of demand and cost shocks suggests that demand shocks are indeed more important.

PD April 1991. TI Debt, Asymmetric Information and Bankruptcy. AA Hoover Institution and University of Rochester. SR Stanford Hoover Institute Working Paper in 
Economics: E-91-8; Domestic Studies Program Working Paper Series, Hoover Institution, Stanford University, Stanford, CA 94305. PG 30. PR not available. JE G33, D21, D92. KW Debt. Bankruptcy. Liquidity Constraints.

AB This paper provides a model of credit in an optimal contract setting in which a simple debt contract with a default clause is optimal even when randomization is allowed. An observable liquidation value for projects is the crucial feature that gives rise to debt. The model provides an explicit economic distinction between illiquidity and insolvency, and also emphasizes the role of ongoing monitoring of borrowers rather than ex post monitoring. The social costs of bankruptcies are due to inefficient liquidations, as the optimal contract generally involves some liquidation of projects whose value exceeds the liquidation value.

\section{Kamecke, Ulrich}

PD October 1990. TI A Strategic Interpretation of the Gale Shapley Algorithm in a Multi-Item Oral Auction. AA University of Bonn. SR Universitat Bonn Sonderforschungsbereich 303 - Discussion Paper: A-321; Sonderforschungsbereich 303 an der Universitat Bonn, Adenauerallee 24-42, D-5300 Bonn 1, DEUTSCHLAND. PG 19. PR no charge. JE C78, D44. KW Algorithm. Matching Problem. Oral Auction.

AB This paper presents a model in which the Gale-Shapley algorithm is used by rational agents to construct the outcome of a one-to-one matching problem in a multi-item oral auction. The sellers' evaluations of the items are common knowledge while the buyers' evaluations are private information. If the buyers bid for the items and an auctioneer rejects the insufficient offers then the GS-algorithm is the only outcome which survives the iterated elimination of dominated strategies. If the sellers keep or reject the bids then the GS-algorithm is the unique strictly perfect equilibrium. An example shows that the conditions of a perfect equilibrium are not sufficient to exclude all the unreasonable outcomes.

\section{Kamien, Morton I.}

TI Cross Licensing of Complementary Technologies. AU Fershtman, Chaim; Kamien, Morton I.

\section{Kandori, Michihiro}

PD January 1991. TI Learning, Mutation, and Long Run Equilibria in Games. AU Kandori, Michihiro; Mailath, George J.; Rob, Rafael. AA Kandori: University of Pennsylvania and Princeton University. Mailath and Rob: University of Pennsylvania. SR University of Pennsylvania Center for Analytic Research in Economics and the Social Sciences (CARESS) Working Paper: 91-01; University of Pennsylvania, Center for Analytic Research in Economics and the Social Sciences, McNeil Building, 3718 Locust Walk, Philadelphia, PA 19104-6297. PG 32. PR no charge. JE C71, C73, C62. KW Evolution Model. Mutations. Nash Equilibrium. Symmetric Game.

AB We analyze an evolutionary model with a finite number of players and with noise or mutations. The expansion and contraction of strategies is linked .- as usual .. to their current relative success, but mutations -- which perturb the system away from its deterministic evolution -- are present as well. Mutations can occur in every period, so that the focus is on the implications of ongoing mutation, not a one-shot mutation. The effect of these mutation is to drastically reduce the set of equilibria to what we term "long-run equilibria." For $2 \times 2$ symmetric games with two symmetric strict Nash equilibria the equilibrium selected satisfies (for large populations) Harsanyi and Selten's (1988) criterion of risk-dominance.

\section{Kannan, Ravi}

PD August 1990. TI Solution of the Frobenius Problem and its Generalization. AA Carnegie Mellon University. SR Universitat Bonn Sonderforschungsbereich 303 Discussion Paper: 90657-OR; Sonderforschungsbereich 303 an der Universitat Bonn, Adenauerallee 24-42, D-5300 Bonn 1, DEUTSCHLAND. PG 36. PR no charge. JE C60, C63. KW Frobenius Problem. Covering Radius. Polynomial Time Algorithm.

AB This paper considers the "Frobenius problem": Given n natural numbers $a(1), a(2), \ldots, a(n)$ such that their greatest common divisor is 1 , find the largest natural number that is not expressible as a nonnegative integer combination of them. This problem can be seen to be NP-hard. For the cases $n=2,3$ polynomial time algorithms are known to solve it. Here a polynomial time algorithm is given for every fixed $n$. This is done by first proving an exact relation between the Frobenius problem and a geometric concept called the "covering radius". Then a polynomial time algorithm is developed for finding the covering radius of any polytope in a fixed number of dimensions.

PD August 1990. TI A Circuit-Based Proof of Toda's Theorem. AU Kannan, Ravi; Venkateswaran, H.; Vinay, V. AA Kannan: Carnegie Mellon University. Venkateswaran: Georgia Institute of Technology. Vinay: Indian Institute of Science. SR Universitat Bonn Sonderforschungsbereich 303 - Discussion Paper: 90651-OR; Sonderforschungsbereich 303 an der Universitat Bonn, Adenauerallee 24-42, D-5300 Bonn 1, DEUTSCHLAND. PG 4. PR no charge. JE C60, C88. KW Toda's Result. Polynomial Hierarchy. Computer Science. AB In this paper we give a simple proof of Toda's result. Our approach is different because we start with uniform circuit definitions of PH and apply the Valiant-Vazirani lemma on these circuits. Recently, Allender and Hertrampf have obtained similar results for polynomial size circuits. The result also shows that unboundedness does not help over semiunboundedness for certain uniform families of circuits. Our result highlights the usefulness of uniform circuit definitions of complexity classes in proving non-trivial results. We believe that the combinatorial nature of the circuits makes these proofs simpler and more elegant.

\section{Kaplow, Louis}

PD May 1991. TI The Income Tax as Insurance: The Casualty Loss and Medical Expense Deductions and the Exclusion of Medical Insurance Premiums. AA Harvard University and National Bureau of Economic Research. SR National Bureau of Economic Research Working Paper: 3723; National Bureau of Economic Research, 1050 Massachusetts Avenue, Cambridge, MA 02138. PG not available. PR \$2.00. JE H24, I18. KW Income Tax. Taxes. Medical Insurance. Health Care.

AB Whether personal income tax deductions are appropriate refinements to the concept of income or unwarranted tax expenditures continues to be the subject of debate. The casualty loss and medical expense deductions are frequently justified on the grounds that ability to pay is reduced by largely unavoidable expenditures or losses. This article reconsiders the 
question taking account of the availability of private insurance, which is in fact widespread for relevant losses in both areas. When individuals can insure, the second level of insurance implicit in the casualty loss and medical expense deductions distorts consumption choices and insurance decisions.

PD May 1991. TI Taxation and Risk Taking: A General Equilibrium Perspective. AA Harvard University and National Bureau of Economic Research. SR National Bureau of Economic Research Working Paper: 3709; National Bureau of Economic Research, 1050 Massachusetts Avenue, Cambridge, MA 02138. PG not available. PR $\$ 2.00$. JE H21, D58, E62, D81. KW Taxation. Government Spending. Fiscal Policy.

AB Taxation and risk taking are examined in a general equilibrium model that incorporates uncertain government revenue in a nonrestrictive manner and allows the government to influence its revenue through portfolio investments as well as through tax policy. It is demonstrated that each of a wide range of taxes can be decomposed into some combination of a wage tax, and ex ante wealth tax, and a modification of the government's investment portfolio. For example, a tax on investment returns (from risky and riskless assets) is equivalent, with an adjustment in the government's portfolio, to a tax on the riskless component of investment returns or to an ex ante wealth tax -- both of which absorb no private risk and yield certain revenue.

PD May 1991. TI A Note on Taxation as Social Insurance for Uncertain Labor Income. AA Harvard University and National Bureau of Economic Research. SR National Bureau of Economic Research Working Paper: 3708; National Bureau of Economic Research, 1050 Massachusetts Avenue, Cambridge, MA 02138. PG not available. PR \$2.00. JE H24, H23, H21, D31, D81. KW Income Taxes. Taxation. Social Insurance.

AB Various authors, notably Eaton and Rosen (1980a) and Varian (1980), have proposed that income taxation may be justified to some extent on the grounds that it serves as social insurance against uncertainties in labor income. They assume that private insurance is unavailable, primarily because of moral hazard, and demonstrate that some taxation is efficient because the benefits of mitigating risk exceed incentive costs. This note suggests that private insurance should be considered explicitly in examining this question. Moral hazard problems limiting private insurance coverage are not alleviated by government insurance. Moreover, in the presence of moral hazard, government insurance, through labor income taxation or otherwise, may be an inefficient policy because private insurance decisions are distorted. More traditional justifications for redistributive taxation are unaffected by this argument.

\section{Karimov, Il'dar}

TI Internal Currency Markets and Production in the Soviet Union. AU Goldberg, Linda S.; Karimov, Il'dar.

\section{Karni, Edi}

PD December 1990. TI Atemporal Dynamic Consistency and Expected Utility Theory. AU Kami, Edi; Schmeidler, David. AA Kami: Johns Hopkins University. Schmeidler: Tel Aviv University. SR Tel Aviv Foerder Institute for Economic Research Working Paper: 39-90; Department of Economics, Tel Aviv University, Ramat Aviv 69978, Tel Aviv, ISRAEL. PG 10. PR no charge. JE C70.
KW Dynamic Consistency. Compound Lotteries. Utility Theory.

AB In this paper we represent atemporal sequential decisions as compound lotteries. We show that a preference relation defined on the set of conditional lotteries, (i.e., sublotteries conditioned on the lotteries to which they belong,) that satisfies consequentialism and the axiom of reduction of compound lotteries, satisfies the independence axiom of expected utility theory if and only if it satisfies dynamic consistency.

\section{Karp, Larry}

TI Winners and Losers from Anti-Merger Laws. AU Gatsios, Konstantine; Karp, Larry.

\section{Katseli, Louka T.}

PD February 1990. TI Structural Adjustment of the Greek Economy. AA Institute for Intemational Economic Studies, Stockholm. SR Centre for Economic Policy Research Discussion Paper: 374; Centre for Economic Policy Research, 6 Duke of York Street, London SW1Y 6LA, UNITED KINGDOM. PG 126. PR 2.00 pounds (\$4.00). JE O52, F15, O11. KW Greece. Economic Integration.

AB This study analyzes the likely pattern of structural adjustment of the Greek economy as economic integration proceeds, in light of the structural rigidities present in the commodity, capital and labor markets. The presence of such rigidities is attributed to "state corporatism", identified as the prevalent mode of economic and social organization characterized by an interlocking set of interests and entitlements across the state, financial institutions and traditional industry. The state-corporatist environment has condoned and fostered the development of dual markets and has given rise to allocative inefficiencies in their operations. Integration challenges the fundamentals of state corporatism through trade and capital market liberalization, through exposure of the official sector to external competition and through the requirements imposed by macroeconomic policy coordination.

\section{Katz, Lawrence F.}

TI The Company You Keep: The Effects of Family and Neighborhood on Disadvantaged Youths. AU Case, Anne C.; Katz, Lawrence F.

\section{Keeble, David}

PD September 1990. TI Small Firms, Business Services Growth and Regional Development in the U.K.: Some Empirical Findings. AU Keeble, David; Bryson, John; Wood, Peter. AA Keeble and Bryson: University of Cambridge. Wood: University College London. SR University of Cambridge Small Business Research Centre Working Paper: 7; Department of Applied Economics, University of Cambridge, Sidgwick Avenue, Cambridge CB3 9DE, UNITED KINGDOM. PG 46. PR $\$ 5.00$ (2.50 pounds); checks payable to University of Cambridge. JE L86, L84, M31. KW Business Services. Market Research. Consultants. Small Businesses. Marketing.

AB Since 1980, the United Kingdom has experienced very rapid growth in firms and employment in information-intensive business services. This paper documents the nature and extent of this growth, with particular reference to small and new firms in management consultancy and market research, and reviews its locational impact. Numbers of business service firms, most 
of which are small, independent companies, have grown much faster than consumer service firms. Despite a significant death rate, many small businesses in these sectors have grown rapidly, as have very large firms. Business service growth has contributed powerfully to the U.K.'s north-south divide, being focussed on London and the outer South East. Possible causes of these trends and key future research issues are reviewed.

PD September 1990. TI Small Firms, New Firms and Uneven Regional Development in the U.K. AA University of Cambridge. SR University of Cambridge Small Business Research Centre Working Paper: 2; Department of Applied Economics, University of Cambridge, Sidgwick Avenue, Cambridge CB3 9DE, UNITED KINGDOM. PG 22. PR $\$ 5.00$ (2.50 pounds); checks payable to University of Cambridge. JE 018, R11, R32, L11. KW Small Businesses. Regional Economics.

AB The causes, impacts and geographies of recent small business development in the U.K. are varied and complex. New firm formation and small firm growth are important influences on contemporary local and regional development in Britain, particularly with regard to the North/South divide and urban rural shift. This paper argues that any attempt at theorizing small firm growth must incorporate several, rather than one, major causal influences. A flexible accumulation or specialization approach may well offer the best prospect of successful theorizing incorporating demand and other influences identified in this paper.

\section{Keeler, Emmett B.}

TI Adjusting Capitation Rates Using Objective Health Measures and Prior Utilization. AU Newhouse, Joseph P.; Manning. Willard G.; Keeler, Emmett B.; Sloss, Elizabeth M.

\section{Keeton, William R.}

PD July 1988. TI Loan Losses and Bank Risk-Taking: Is There a Connection? AU Keeton, William R.; Morris, Charles S. AA Federal Reserve Bank of Kansas City. SR Federal Reserve Bank of Kansas City Research Working Paper: 88-04; Research Division, Federal Reserve Bank of Kansas City, 925 Grand Ave., Kansas City, MO 64198. PG 45. PR no charge. JE G21, G11, G24. KW Debt Default. Commercial Banks. Bank Loans. Portfolio Choice.

AB This paper presents a simple theoretical model of the relationship between loan losses and bank risk-taking and then uses a sample of 2,400 banks in Tenth Federal Reserve District states to test the hypothesis that differences in loan losses are partly due to differences in risk-taking. According to the model, banks that deliberately took greater risk by adopting low credit standards should have charged higher loan rates than other banks in the same market. Furthermore, banks that adopted low credit standards because they had a low aversion to risk should have taken other forms of portfolio risk at the same time they made high-risk loans. Although the various risk-taking measures used in this study explain only a small part of the total variation in loan losses, the empirical results confirm that the banks that charged the highest loan rates and took the greatest amount of other portfolio risk in 1979-81 tended to end up with the highest loan losses in 1984-85.

\section{Kehagias, Athanasios}

TI Efficiency and Optimality in Stochastic Models with Production. AU Bertocchi, Graziella; Kehagias, Athanasios.

\section{Kelejian, Harry $\mathrm{H}$.}

PD January 1991. TI Spatial Autocorrelation: A New Computationally Simple Test with an Application to Per Capita County Police Expenditures. AU Kelejian, Harry H.; Robinson, Dennis P. AA Kelejian: University of Maryland, College Park. Robinson: U.S. Army Corps of Engineers, Fort Belvoir. SR University of Maryland Department of Economics Working Paper Series: 91-1; Department of Economics, University of Maryland, College Park, MD 20742. PG 19. PR no charge. JE H72, R12, R11. KW Police Expenditures. Spatial Theory. Government Spending. Local Governments.

AB A large sample moments test for spatial autocorrelation is proposed. The test is computationally simple; it also does not require the model to be linear, the pattern of autocorrelation to be known, or panel data.

\section{Kelleher, Jeanette}

TI Financial Market Evolution and the Interest Sensitivity of Output. AU Hirtle, Beverly; Kelleher, Jeanette.

Kern, W.

TI Some Convergence Results for Probabilistic Tabu Search. AU Faigle, Ulrich; Kem, W.

TI Minimum Loss Scheduling. AU Nawijn, W. M.; Kem, W.; Baas, S. M.

TI Scheduling Jobs on Parallel Machines, Each with a UnitCapacity Buffer. AU Baas, S. M.; Kem, W.; Nawijn, W. M.

TI Some Order Dimension Bounds for Communication Complexity Problems. AU Faigle, Ulrich; Kem, W.

\section{Kesselman, Jonathan R.}

PD November 1989. TI Rate Structure and Personal Taxation: Flat Rate or Dual Rate? AA Universily of British Columbia. SR University of British Columbia Department of Economics Discussion Paper: 89-26; University of British Columbia, \#997-1873 East Mall, Vancouver, BC V6T IW5, CANADA. PG 80. PR $\$ .20$ per page Canadian to other than educational institutions. JE H24, H21. KW Taxes. Tax System. Income Tax. Tax Burden.

AB Proposals for flat rate income taxes have offered substantial benefits in increased economic efficiency, horizontal equity, and simplicity of administration and compliance. However, even with provisions for tax relief at lower incomes, flat taxes would shift the distribution of the tax burden away from those at high incomes and onto persons at middle incomes. This study explores the possibilities for exploiting most of the benefits of a flat rate tax while retaining a distributional pattern closer to that of existing tax systems. A dual rate tax structure is proposed to confine the upper-bracket rate to a minority of the taxpaying population. The dual tax has to deal with the problem of tax relief for persons at lower incomes with out complicating the marginal rate structure at the bottom of the scale. Most flat tax proposals have failed to address this problem, and the analysis provided for tax relief in this study is equally applicable to flat and dual rate systems.

\section{Kim, Chulsoo}

PD January 1990. TI Measuring Deviations from the Permanent Income Hypothesis. AA Stanford University. SR Stanford Center for Economic Policy Research 
Discussion Paper Series: 189; 100 Encina Commons, Stanford University, Stanford CA 94305. PG 35. PR no charge for members of non-profit institutions, $\$ 3.00$ otherwise. JE D11, D12, D91, E21. KW Permanent Income Hypothesis. Keynesian Theory. Liquidity Constraint. Consumption.

AB This paper examines the permanent income hypothesis (PIH) by computing all the testable implications of the hypothesis and characterizing its failure by the extent to which consumption deviates from the PIH. By measuring deviations from the PIH, the empirical results can be interpreted in terms of economic significance as opposed to statistical significance. In other words, we examine whether the PIH is a reasonable model rather than whether the PIH is exactly correctly specified. This paper finds that consumption deviates from the PIH by $26-34 \%$ for the postwar U.S. data, which indicates substantial utility loss when viewed in a representative agent framework.

PD February 1990. TI Characterizing the Failure of the Permanent Income Hypothesis. AA Stanford University. SR Stanford Center for Economic Policy Research Discussion Paper Series: 188; 100 Encina Commons, Stanford University, Stanford CA 94305. PG 26. PR no charge for members of non-profit institutions, $\$ 3.00$ otherwise. JE D11, D12, D91, E21. KW Permanent Income Hypothesis. Keynesian Theory. Liquidity Constraints. Consumption.

AB This paper characterizes the failure of the permanent income hypothesis (PIH) in terms of excess sensitivity and excess smoothness. First, this paper examines a model explaining the excess sensitivity of consumption by computing all the testable implications of the model and characterizing its failure in terms of the extent to which consumption deviates from the excess sensitivity of consumption. The model has the smallest deviation when the fraction of agents who consume their current income rather than permanent income is 1 . Second, this paper develops the excess smoothness test which is independent of the presence of unit roots in the labor income process. Consumption is shown to be too smooth to be justified by the PIH. Both results suggest that the postwar U.S. consumption is more consistent with the Keynesian consumption hypothesis rather than the PIH.

PD March 1990. TI Liquidity Constraints or Myopia?: An Empirical Investigation. AA Stanford University. SR Stanford Center for Economic Policy Research Discussion Paper Series: 190; 100 Encina Commons, Stanford University, Stanford CA 94305. PG 11. PR no charge for members of non-profit institutions, $\$ 3.00$ otherwise. JE D11, D12, D91, E21. KW Permanent Income Hypothesis. Keynesian Theory. Liquidity Constraint. Consumption.

AB We test whether agents are liquidity constrained or myopic to examine why consumption is too sensitive to current income. If agents are liquidity constrained, more agents are likely to be liquidity constrained during recession than boom. Thus, we should observe negative correlations between the fraction of agents who consume current income and output fluctuations. If agents are myopic, on the other hand, the fraction should be independent of output fluctuations. We find that a higher fraction of agents consume their current income in recession. We therefore conclude that consumption is too sensitive to current income because agents are liquidity constrained not because agents are myopic.

\section{Kipnis, Victor}

PD August 1989. TI Relevancy Criterion for Discriminating Among Alternative Model Specifications. AA University of Southern California. SR University of Southem California Modelling Research Group Working Paper: M8917; Department of Economics, University of Southem California, University Park, Los Angeles, CA 90089-0152. PG 17. PR no charge. JE C52, C51, C15. KW NonNested Models. Pseudosamples. Linear Regression. Model Specification.

AB A methodology is developed for comparing different model specifications in the framework of the linear regression analysis. The suggested approach is based on the two main principles. The first one states that assessment of the goodnessof-fit of the rival models should rest on the evaluation of the procedures by which these models have actually been fitted to the observed data. The relevancy of a model building procedure is evaluated by generating pseudosamples that a priori contain no relationship between a response and explanatory variables. The procedure whose performance for the original data differs most from that for the pseudosamples is considered the best, and the corresponding model is suggested for representing the data. The presented nonparametric relevancy criterion can be used to discriminate among different model specifications, including non-nested families. Its strength is evaluated using Monte-Carlo simulations.

\section{Kiyotaki, Nobuhiro}

TI Toward a Theory of International Currency. AU Matsuyama, Kiminori; Kiyotaki, Nobuhiro; Matsui, Akihiko.

\section{Klein, Martin}

PD October 1990. TI ECU Bond Prices: Private Markets and Political Constraints. AA University of Bonn. SR Universitat Bonn Sonderforschungsbereich 303 Discussion Paper: B-169; Sonderforschungsbereich 303 an der Universitat Bonn, Adenauerallee 24-42, D-5300 Bonn 1, DEUTSCHLAND. PG 20. PR no charge. JE F33, F36, F31, F32. KW European Monetary System. Currency Basket. Interest Rates. Bond Prices. Exchange Rates.

AB Under the existing statutes of the European Monetary System (EMS) the European Currency Unit (ECU) is a "mixed bag" of economic and political elements. On the one hand it is simply a portfolio of EMS member currencies, on the other hand it is supposed to reflect the relative economic strength of the ECU member countries. The implicit conflict between these two aspects gives rise to periodic readjustments of the ECU basket. The present paper analyzes the behavior of ECU bond prices under state-contingent basket readjustments, i.e. those that could be triggered by the evolution of the member currencies' cross exchange rates. We discuss the problems that arise and develop a non-linear pricing formula that can be applied in this context.

\section{Kleit, Andrew N.}

TI Exclusion, Collusion and Confusion: The Limits of Raising Rival's Costs. AU Coate, Malcolm B.; Kleit, Andrew N.

\section{Kleitman, D. J.}

TI Sharpening the Lym Inequality. AU Erdos, Peter L.; Frankl, P.; Kleiıman, D. J.; Saks, M. E.; Szekely, L. A. 
Kletzer, Kenneth $M$.

PD December 1989. TI Inefficient Private Renegotiation of Sovereign Debt. AA Yale University. SR Centre for Economic Policy Research Discussion Paper: 357; Centre for Economic Policy Research, 6 Duke of York Street, London SWIY 6LA, UNITED KINGDOM. PG 55. PR 2.00 pounds (\$4.00). JE F34, H63, F33. KW Debt Renegotiation. Asymmetric Information. International Lending. Public Debt.

AB The literature on sovereign debt emphasizes that international financial transactions are impeded because the fulfiliment of contractual obligations by a government is timeinconsistent. The process of renegotiation between private creditors and debtor governments can create further inefficiencies in the world allocation of capital. In this paper, two potential sources of social cost in the private renegotiation of debt repayments and new loans are discussed. First, legal privileges accorded to existing creditors by their collective governments can render the efficient allocation of capital constrained by sovereign immunity time-consistent when there is ex post bargaining over net transfers. Second, the use of offers in a renegotiation to elicit private information about debtor characteristics is socially costly.

PD January 1991. TI Persistent Differences in National Productivity Growth Rates with a Common Technology and Free Capital Mobility. AU Kletzer, Kenneth M.; Buiter, Willem H. AA Yale University. SR Yale Economic Growth Center Discussion Paper: 627; Economic Growth Center, Yale University, Box 1987 Yale Station, New Haven, Connecticut 06520. PG 53. PR $\$ 2.00$ plus postage. JE F41, F43, F12, KW Endogenous Growth. Capital Mobility. Growth Model. Productivity.

AB The paper develops a two-country endogenous growth model to investigate possible causes for the existence and persistence of productivity growth differentials between nations despite a common technology, constant returns to scale and perfect international capital mobility. Private consumption is derived from a three-period overlapping generations specification. The source of productivity (growth) differentials in our model is the existence of a non-traded capital good ("human capital") whose augmentation requires a non-traded current input (time spent by the young in education rather than leisure). We consider the influence on productivity growth differentials of private thrift, public debt, the taxation of capital and savings and of policy towards human capital formation.

\section{Koot, Ronald S.}

TI A Measure of Federal Reserve Credibility. AU Croushore, Dean D.; Koot, Ronald S.

\section{Koray, Semih}

PD November 1989. TI A Welfaristic Characterization of Revelation Equilibria Under Imputational Government. AU Koray, Semih; Sertel, Murat R. AA Koray: Middle East Technical University. Sertel: University of Pennsylvania and Bogazici University. SR University of Pennsylvania Center for Analytic Research in Economics and the Social Sciences (CARESS) Working Paper: 90-19; University of Pennsylvania, Center for Analytic Research in Economics and the Social Sciences, McNeil Building, 3718 Locust Walk, Philadelphia, PA 19104-6297. PG 7. PR no charge. JE C72. KW Revelation Game. Nash Equilibrium. Preferences.
AB When players' declarations about their private preferences are to be used in enforcing imputations, i.e. individually rational Pareto optima according to the declared preference profile, the Nash equilibria of the revelation game so defined always induce individually rational outcomes according to the true preferences, and for all such outcomes there is (and we construct) a Nash equilibrium declaration of preferences which induces precisely that outcome.

\section{Korenman, Sanders}

TI The Socioeconomic Consequences of Teen Childbearing Reconsidered. AU Geronimus, Arline T.; Korenman, Sanders.

\section{Koujianou, Penny}

TI Consumer Expenditure Survey Database. AU Attanasio, Orazio P.; Koujianou, Penny; Weber, Guglielmo.

\section{Kratochvil, Jan}

PD August 1990. TI On the Computational Complexity of Seidel's Switching. AU Kratochvil, Jan; Nesetril, Jaroslav; Zyka, Ondrej. AA Kratochvil and Zyka: Charles University. Nesetril: University of Bonn. SR Universitat Bonn Sonderforschungsbereich 303 - Discussion Paper: 90656-OR; Sonderforschungsbereich 303 an der Universitat Bonn, Adenauerallee 24-42, D-5300 Bonn 1 . DEUTSCHLAND. PG 7. PR no charge. JE C63, C60. KW Graph Theory. Isomorphism.

AB Given a graph $G$ and a vertex $v$ of $G$, Seidel's switching of $v$ in $G$ results in making $v$ adjacent to exactly those vertices it was nonadjacent to in $G$, while the rest of $G$ remains unchanged. Graphs $\mathrm{G}$ and $\mathrm{H}$ are called switching equivalent if $\mathrm{G}$ can be made isomorphic to $\mathrm{H}$ by a sequential application of Seidel's switching. When $P$ is a graph property, we consider the following problem for $S(P)$ : Instance: A graph G. Question: Is $G$ switching equivalent to a graph possessing the property $P$ ? The purpose of this extended abstract is to present examples showing that in general, the complexity of $S(P)$ is independent of the complexity of $\mathrm{P}$. On the other hand, we prove that deciding whether two given graphs are switching equivalent is isomorphism-complete.

\section{Krueger, Alan B.}

TI The Effect of Age at School Entry on Educational Attainment: An Application of Instrumental Variables with Moments from Two Samples. AU Angrist, Joshua D.; Krueger, Alan B.

TI The Incidence of Mandated Employer-Provided Insurance: Lessons from Workers' Compensation Insurance. AU Gruber, Jonathan; Krueger, Alan B.

TI School Quality and Black-White Relative Earnings: A Direct Assessment. AU Card, David; Krueger, Alan B.

\section{Krugman, Paul R.}

PD January 1990. TI Integration and the Competitiveness of Peripheral Industry. AU Krugman, Paul R.; Venables, Anthony J. AA Krugman: Massachusetts Institute of Technology. Venables: University of Southampton. SR Centre for Economic Policy Research Discussion Paper: 363; Centre for Economic Policy Research, 6 Duke of York Street, London SWIY 6LA, UNITED KINGDOM. PG 29. 
PR 2.00 pounds (\$4.00). JE F15, F13, F11. KW Trade Liberalization. Industrial Location. Factor Markets. Economic Integration. Trade Policy. Trade Model.

AB This paper analyzes economic integration between two economies; one central, with a large local market, and the other peripheral, with a small local market. Each economy has an imperfectly competitive manufacturing sector. Trade liberalization creates a strong incentive for the imperfectly competitive industry to concentrate in the central region, near the large market. This may cause the direction of net trade to be the opposite of that predicted by factor endowments. This effect may be offset by a lower wage in the periphery than in the center; we find that in the early stages of integration relative wages in the center and periphery diverge, with convergence occurring only in the later stages.

\section{Krupnick, Alan J.}

TI Ethanol Fuel and Non-Market Benefits: Is a Subsidy Justified? AU Walls, Margaret A.; Krupnick, Alan J.; Toman, Michael A.

\section{Lam, David}

PD November 1990. TI Declining Inequality in Schooling in Brazil and Its Effects on Inequality in Eamings. AU Lam, David; Levison, Deborah. AA Lam: University of Michigan, Ann Arbor. Levison: Population Studies Center, Michigan. SR Yale Economic Growth Center Discussion Paper: 618; Economic Growth Center, Yale University, Box 1987 Yale Station, New Haven, Connecticut 06520. PG 28. PR \$2.00 plus postage. JE J24. J41, J31. KW Brazil. Education. Income Distribution. Human Capital. Wages.

AB Household survey data demonstrate that Brazilian males born between 1925 and 1963 experienced steady increases in mean schooling and significant declines in schooling inequality. The variance in years of schooling increased for cohorts born up until 1950, with steady declines for more recent cohorts. Decomposition of a standard human capital earnings equation indicates that trends in schooling tended to reduce earnings inequality from 1976 to 1985 , due to reductions in both the variance of schooling and in returns to schooling. These improvements were more than offset, however, by increases in other sources of inequality. Although the net increase in earnings inequality from 1976 to 1985 is disturbing, the reduction in schooling inequality represents a fundamental improvement in the determinants of earnings inequality in Brazil that will have beneficial effects for decades.

\section{Lancaster, Tony}

PD May 1990. TI A Paradox in Choice-Based Sampling. AA Brown University. SR Brown University Department of Economics Working Paper: 90-17; Department of Economics, Brown University, Providence, RI 02912. PG 10. PR no charge. JE C13, C25. KW Asymptotic Distribution. Asymptotic Theory. Discrete Choice Models. Estimation. Maximum Likelihood.

AB This paper deals with the asymptotic distribution theory of parameter estimates in discrete choice models for which the data have been gathered by choice-based sampling. It is argued that the relevant distribution theory is that conditional on the realized fraction of the sample making each choice, since these are ancillary statistics with known marginal distribution. We give the conditional and unconditional asymptotic distributions of Manski and McFadden's conditional maximum likelihood estimator and its modification due to Cosslett. We show that by considering the distribution of estimators conditional on the ancillary we can resolve the paradox in this literature to the effect that replacing known incidental parameters by estimates reduces the variance of estimators. This replacement does not reduce variance; it eliminates bias.

\section{Lang, Gunther}

PD November 1990. TI Dynamic Efficiency and Capital Accumulation. AA University of Bonn. SR Universitat Bonn Sonderforschungsbereich 303 - Discussion Paper: A-325; Sonderforschungsbereich 303 an der Universitat Bonn, Adenauerallee 24-42, D-5300 Bonn 1, DEUTSCHLAND. PG 17. PR no charge. JE H55, D91, D50. KW Capital Accumulation. Diamond Model. Pensions. Retirement. Production Technology.

AB This paper answers the question of dynamic efficiency in the framework of the well-known Diamond model, additionally allowing for arbitrary population dynamics and a changing production technology. Arbitrary equilibrium paths, not only steady-states, can be characterized with respect to their efficiency. Furthermore, it will be shown under general assumptions that a Pareto-improving transition from a pay-asyou-go financed state pension scheme to a capital-funded system is impossible, in contrast to opposite claims in the literature. Finally, some light will be shed on the role of capital accumulation in gaining dynamic efficiency.

\section{Langenfeld, James A.}

PD November 1990. TI Rent Increasing Costs: The Antitrust Implications from a Paradox in Value Theory. AU Langenfeld, James A.; Morris, John R. AA Federal Trade Commission. SR Federal Trade Commission Bureau of Economics Working Paper: 182; Bureau of Economics, Federal Trade Commission, 6th and Pennsylvania Ave. NW, Washington, D.C. 20580. PG 32. PR no charge. JE L13, L16, L41, M37. KW Antitrust. Collusion. Advertising. Oligopoly. Competition.

AB This paper explains the anticompetitive consequences of horizontal restraints by analyzing how restrictions affect the cost conditions faced by individual members of the group. Our analysis assumes that the firms cannot collude to directly restrict output or raise price. A group of firms, however, may agree on restrictions that affect the costs of individual firms. By accepting restraints which raise the incremental costs of each firm, competitors can raise their profits. If the group has the ability to force entrants to join, then entry drives profits to zero but price is not reduced. If the group cannot force entrants to join the group, then entry forces price to minimum average cost for nonmembers.

\section{Lapham, Beverly J.}

TI Strategic Innovation and Economic Growth. AU Head, Allen C.; Lapham, Beverly J.

\section{Larent, Monique}

TI The Cut Cone III: On the Role of Triangle Facets. AU Deza, Michel; Larent, Monique; Poljak, Svatopluk.

\section{Laurent, Monique}

TI Bouquets of Matroids and F-Squashed Geometries. AU Deza, Michel; Laurent, Monique; Pasini, Antonio. 


\section{Lazear, Edward P.}

PD February 1991. TI List Price Policies and Bait-andSwitch Strategies. AA University of Chicago and Hoover Institution. SR Stanford Hoover Institute Working Paper in Economics: E-91-5; Domestic Studies Program Working Paper Series, Hoover Institution, Stanford University, Stanford, CA 94305. PG 37. PR not available. JE M31, M37. KW Prices. Marketing. Advertising.

AB Pricing and pricing strategies follow some consistent patterns. Most goods carry a list price, which frequently deviates from the price paid. Goods are formally "put on the market," even though all goods are for sale at some price. Firms also use marketing strategies, like bait-and-switch, to sell their goods. Bait-and-switch results when the market is sufficiently dense at one end so that it pays a seller to lie about the quality of the product that is available. The cost of lying is that the buyers attracted will not necessarily value the good the most. When the market is dense at the low end, firms will advertise low quality, low price goods and attempt to switch customers to higher priced items. When the market is dense at the upper end, firms will advertise high quality goods and attempt to switch buyers to lower quality items.

\section{Leborgne, Daniele}

TI Avoiding Two-Tiers: Europe. AU Lipietz, Alain; Leborgne, Daniele.

PD 1989. TI Two Social Strategies in the Production of New Economic Spaces. AU Leborgne, Daniele; Lipietz, Alain. AA CEPREMAP. SR CEPREMAP Discussion Paper: 8911; CEPREMAP, 142 rue du Chevaleret, 75013 Paris, FRANCE. PG 32. PR 20 ff. JE L51, O11, R11. KW Regulation. Economic Policy. Economic Development. AB While examining the developments in the crisis of fordism, it appears that problems in international regulation are far from being solved, but various solutions, of different efficiency, are developing on the "demand" side. A topology of these solutions is presented, as far as professional relations, industrial organization, and spatial unfolding are concerned. It seems that their implementation on territories is the result of two contrasted social strategies: offensive flexibility and defensive flexibility.

\section{Lee, Cheng $F$.}

TI A Cross-Sectional Analysis of Mutual Funds' Market Timing and Security Selection Skill. AU Chan, Anthony; Chen, Carl R.; Lee, Cheng F.; Rahman, Shafigur.

\section{Lee, Kevin}

T1 Predicting Success; Pre-Merger Characteristics and Post-Merger Performance. AU Cosh, Andy; Hughes, Alan; Lee, Kevin; Singh, Ajit.

\section{Lee, Tae-Hwy}

TI Investigation of Production, Sales and Inventory Relationships. AU Granger, C. W. J.; Lee, Tae-Hwy.

\section{Lehr, William}

PD July 1989. TI ISDN and the Small User: Regulatory Policy Issues. AU Lehr, William; Noll, Roger G. AA Stanford University. SR Stanford Center for Economic Policy Research Discussion Paper Series: 175; 100 Encina Commons, Stanford University, Stanford CA 94305.
PG 56. PR no charge for members of non-profit institutions, $\$ 3.00$ otherwise. JE L96, L51, L52. KW Telecommunications. Digital Networks. Price Regulation. Regulations.

AB Worldwide local telephone companies are planning to implement ISDN -- a new technology for ubiquitous national telecommunications systems. To be worthwhile, these investments must make possible new services that will vastly increase expenditures on telecommunications. This paper examines one element of the issue of whether telephone companies should be permitted to proceed with these investments. It is the likely effects of ISDN on small users -residential and small business customers who are unlikely to make much use of the new capabilities provided by ISDN. The paper identifies several ways in which ISDN may make the public network less valuable for small users, and proposes a two-step policy to reduce the chance of injuring them. One is slow deployment of the first ISDN standards, with extensive monitoring and experimentation to determine its costs and benefits. The other is procompetitive policies that might provide a reasonable form of alternative access for small users should ISDN threaten them.

PD January 1990. TI Incremental Costs and the Efficient Pricing of Local Exchange Services: A Synopsis of the Incremental Cost Conference. AA Stanford University. SR Stanford Center for Economic Policy Research Discussion Paper Series: 202; 100 Encina Commons, Stanford University, Stanford, CA 94305. PG 30. PR no charge for members of non-profit institutions, $\$ 3.00$ otherwise. JE L96, L51. KW Telecommunications. Regulation. Communications Industry.

AB The following report summarizes the prepared comments and open discussion which occurred at the Incremental Cost Conference which was held December 5-6, 1989, in Stanford, CA. The Incremental Cost Task Force was a joint effort by the California Public Utilities Commission, the RAND Corporation, Pacific Bell, and GTE in order to provide a methodology and estimates for determining incremental costs for local exchange services in California. This conference was convened so as to get critical comments from key stakeholders before preparing the ICTF's final report for public distribution.

\section{Leiderman, Leonardo}

TI Optimal Maturity of Nominal Government Debt: The First Tests. AU Calvo, Guillermo A.; Guidotti, Pablo E.; Leiderman, Leonardo.

TI Exchange Rate Systems: New Perspectives. AU Helpman, Elhanan; Leiderman, Leonardo.

\section{Levine, Phillip B.}

PD October 1990. TI Contemporaneous vs. Retrospective Unemployment: Through the Filter of Memory or the Muddle of the Current Population Survey? AA Princeton University. SR Princeton Industrial Relations Section Working Paper: 276; Industrial Relations Section, Department of Economics, Princeton University, Princeton, NJ 08544-2098. PG 46. PR \$1.50. JE C81, C82. KW Unemployment Rates. Current Population Survey. Panel Data. Unemployment. Measurement Error.

AB This paper documents and attempts to explain the observed disparities between unemployment rates computed from contemporaneous and retrospective CPS data. The 
maintained hypothesis is that the discrepancies are consistent with different definitions of unemployment between the two measures. The longitudinal nature of the CPS, which allows a respondent's answers to be matched between one year and the next, is exploited to examine two commonly expressed shortcomings in the contemporaneous definition. I find that relative to the retrospective measure, more workers with weak labor force attachment are considered unemployed in the contemporaneous rate. In addition, discouraged workers, who are classified as out of the labor force according to the contemporaneous definition, may be counted as unemployed in the retrospective.

\section{Levison, Deborah}

TI Declining Inequality in Schooling in Brazil and Its Effects on Inequality in Earnings. AU Lam, David; Levison, Deborah.

\section{Lewis, Karen $\mathrm{K}$.}

TI Do Risk Premia Explain It All? Evidence from the Term Structure. AU Evans, Martin D. D.; Lewis, Karen K.

\section{Lewis, Tracy $\mathbf{R}$.}

PD August 1990. TI Selecting an Agent's Ability. AU Lewis, Tracy R.; Sappington, David E. M. AA Lewis: University of California, Davis. Sappington: University of Florida. SR University of Florida Working Paper in Economics: 90-6; Department of Economics, University of Florida, Gainesville, FL 32611. PG 29. PR no charge. JE D82, D81. KW Incentives. Ability. Adverse Selection. Principal-Agent Model. Asymmetric Information.

AB We extend standard adverse selection models by making the agent's ability level endogenous. Higher levels of ability make lower realizations of the agent's privately observed cost more likely. We show that when she is able to commit to an incentive scheme before the agent chooses his ability, the principal will induce more (less) ability from the agent when the agent's primary ex post incentive is to exaggerate (understate) his private information. Thus, the principal may prefer agents of either higher or lower ability. A class of examples is also presented in which both the principal and agent prefer that the principal moves first.

PD November 1990. TI Conservation and Incentive Regulation. AU Lewis, Tracy R.; Sappington, David E. M. AA Lewis: University of California, Davis. Sappington: University of Florida. SR University of Florida Working Paper in Economics: 90-11; Department of Economics, University of Florida, Gainesville, FL 32611. PG not available. PR no charge. JE Q41, Q48. KW Conservation. Incentives. Regulation. Energy.

AB We examine the design of regulatory policy to foster energy conservation by an energy producer. The producer has private information about the net benefits of its conservation efforts. The ideal outcome for consumers can be ensured if the firm's conservation efforts are observable, even if the effects of these efforts cannot be monitored accurately. More generally, the ideal outcome is not feasible. Prices below marginal production costs may be optimal to induce the firm to increase conservation efforts.

\section{Lim, Guay C.}

PD October 1990. TI Testing for the Fundamental
Determinants of the Long-Run Real Exchange Rate. AA University of Melbourne. SR Brown University Department of Economics Working Paper: 90-28; Department of Economics, Brown University, Providence, RI 02912. PG 34. PR no charge. JE F31, F32. KW Exchange Rates. Trade Balance. Current Account. Interest Rates.

AB The method of co-integration is used to test for the fundamental determinants of the long-run real exchange rate between the U.S. and other G-10 countries. The results show that an increase in productivity leads, in the long-run, to a depreciation of the real rate, while real appreciations are associated with improvements in the terms of trade, with increases in world interest rates and with increases in U.S. interest rates relative to foreign rates.

\section{Lin, Justin Yifu}

PD October 1990. TI Education and Innovation Adoption in Agriculture: Evidence from Hybrid Rice in China. AA University of California at Los Angeles. SR University of California at Los Angeles Department of Economics Working Paper: 603; Department of Economics, University of California, Los Angeles, 2263 Bunche, Los Angeles, CA 90024. PG 33. PR \$2.50. JE Q16, Q13, Q11. KW Socialist Economy. China. Technological Change. Human Capital. Agriculture.

AB This paper uses the diffusion of hybrid rice as a case for examining the effects of education on the adoption of new technology in China. A simple behavioral model that treats the adoption of hybrid rice as a portfolio selection problem is presented. The implications of the model are tested with farm level data collected from a sample of 500 households in Hunan Province. The results from a dichotomous probit model and a two-limit tobit model are consistent with the hypothesis that education has a positive impact on the adoption of new technology.

PD October 1990. TI Hybrid Rice Innovation in China: A Study of Market-Demand Induced Technological Innovation in a Centrally-Planned Economy. AA University of California, Los Angeles. SR University of California at Los Angeles Department of Economics Working Paper: 604; Department of Economics, University of California, Los Angeles, 2263 Bunche, Los Angeles, CA 90024. PG 20. PR \$2.50. JE P23, P21, Q16, Q13. KW Agriculture. Socialist Economy. China. Innovation.

AB The work presented in this paper is an attempt to analyze the innovation and diffusion of hybrid rice in China as a case study in the mechanism of agricultural technology innovation in a centrally-planned economy. The empirical evidence indicates that the size of rice acreage in a province is the major factor in determining resource allocation for rice research in that province's academy of agricultural sciences and the aggregated adoption rate of hybrid rice in the province. This is consistent with the implications of the Griliches-Schmookler hypothesis. The empirical evidence also indicates that the adoption of hybrid rice in a province is affected by the profitability of hybrid rice and the labor-land ratio in that province.

\section{Lindsey, Phoebe A.}

PD July 1989. TI Medicaid Second Surgical Opinion Programs and Inpatient Hospital Review Programs: Results of a 1987 Survey. AA Rand Corporation. SR Rand Note: N. 2790; The Rand Corporation, 1700 Main Street, P.O. Box 2138, 
Santa Monica, CA 90406-2138. PG 45. PR not available. JE I11, I18. KW Health Care. Medical Costs. Medicaid Program. Hospitals.

AB In 1986, concerned about stemming the steady increase in health care costs, Congress mandated a study of state Medicaid utilization review programs that would identify high-volume and high-cost procedures, the payment rates for such procedures. the rates at which such procedures are performed, and the number of board certified or board eligible physicians who perform such procedures. In addition, for states that have mandatory second surgical opinion programs (SSOPs) or inpatient hospital preadmission review programs, the study was required to determine the extent to which such programs impede access to care for Medicaid patients. This note reports the results of the 1987 survey of all state Medicaid agencies, including the District of Columbia, regarding Medicaid SSOPS and programs of inpatient hospital preadmission review.

\section{Lipietz, Alain}

PD 1989. TI The Debt Problem, European Integration and the New Phase of World Crisis. AA CEPREMAP. SR CEPREMAP Discussion Paper: 8924; CEPREMAP, 142 rue du Chevaleret, 75013 Paris, FRANCE. PG 25. PR 20 ff. JE F32, F34, F33. KW Current Account. European Community. Debt Crisis.

AB This paper focuses on the problems of the world economy after the crash of October 1987 which was the end of a third phase of the crisis of fordism. The solution to the supply-side of this crisis, based on "negotiated involvement" of the workers. seems to overcome the solution based on "liberal flexibility". As a result, heavy international unbalances appeared U.S. deficits compound themselves compared to Third World Debt. A non-recessionist adjustment of world demand implies a large cancellation of this debt and a reform of the main world market, the European Community.

PD 1989. TI Avoiding Two-Tiers: Europe. AU Lipietz, Alain; Leborgne, Daniele. AA CEPREMAP. SR CEPREMAP Discussion Paper: 8923; CEPREMAP, 142 rue du Chevaleret, 75013 Paris, FRANCE. PG 31. PR 20 ff. JE O52, J50, O14, O15. KW Capital-Labor Ratio. Labor Contracts. Europe. Labor Relations.

AB On the basis of the "regulation approach", the paper will present prospectively the possibilities of new capital-labor relations in Europe at the end of the "crisis of fordism". Strong tendencies are developing for an unequal distribution of these relations, mainly across regions and genders. Hence the risk of a "Two-Tiers" Europe. Advanced compromises with negotiated involvement of workers in the labor process, skilled jobs; welfare benefits and strong labor contracts is a first strategy out of crisis, but may be excluding women and ethnic minorities. Some firms and regions try to compete through low wages (direct and indirect) and precarious status. There is strong evidence that the regions Europe is made of are already diverging along these two ("offensive" and "defensive") strategies. This may be noted through the measure of their growth in volume and in international value.

TI Two Social Strategies in the Production of New Economic Spaces. AU Leborgne, Daniele; Lipietz, Alain.

PD 1989. TI Basis for a Democratic Alternative. AA CEPREMAP. SR CEPREMAP Discussion Paper: 8910; CEPREMAP, 142 rue du Chevaleret, 75013 Paris, FRANCE. PG 20. PR 20 ff. JE L51.
KW Democracy. Political Science. Regulation.

AB First we sum-up some recent developments of "regulation approach" in the field of political science. Two types of "democracy" appear: a form of regulation within a societal paradigm corresponding to a model of development, and a criteria of value between paradigms. As such, "fordism" implied a "hierarchical organicist" paradigm, and the "liberalproductivism" of the eighties just gave up the "organicist" aspect. We then explore the economic basis for an alternative paradigm, non hierarchical yet organicist. Democracy is extended to organization of labor and implementation of the Welfare State. Local face-to-face procedures appear as a major form of democratic regulation.

\section{Lipschultz, Marc}

PD June 1990. TI The Stability of Beta for Nuclear Electric Utilities, 1976-1986: A Note. AU Lipschultz, Marc; Maggioncalda, Jeff, Rothwell, Geoffrey S. AA Stanford University. SR Stanford Center for Economic Policy Research Discussion Paper Series: 203; 100 Encina Commons, Stanford University, Stanford, CA 94305. PG 16. PR no charge for members of non-profit institutions, $\$ 3.00$ otherwise. JE L94. KW Asset Pricing Model. Utilities. Nuclear Power. Regulation.

AB When using the Capital Asset Pricing Model, researchers often assume that the coefficient of risk, measured by beta, is stable over time. In this paper, we challenge this assumption by analyzing data for fifteen American nuclear-electric utilities from 1976-1986. We utilize an instrumental variables estimation technique along with instability detection and isolation procedures to detect and isolate the points of instability in the beta coefficients. We find pronounced instability in 1984 for 13 of the 15 equities considered. The apparent instability of investors' perceptions of risk makes regulators' dealings with allowed rates of return extremely difficult. Further, instability of beta violates the assumptions of the commonly used technique of cumulative average residual (CAR) analyses. Therefore, any CAR based event-study conducted on nuclear utilities in the post-1984 era is invalid. The framework for instability analysis developed in this note should precede any CAR analysis.

\section{Loebl, Martin}

PD 1988. TI Unprovability of Set Union Problem Strategies. AU Loebl, Martin; Nesetril, Jaroslav. AA Charles University, Prague. SR Universitat Bonn Sonderforschungsbereich 303 - Discussion Paper: 88528-OR; Sonderforschungsbereich 303 an der Universitat Bonn, Adenauerallee 24-42, D-5300 Bonn 1, DEUTSCHLAND. PG 63. PR no charge. JE C60. KW Set Union Problem. Algorithms. Finite Set Theory.

AB We consider the set union problem (SUP) which consists in designing data for manipulation of a family of disjoint sets which partition a given universe of $\mathbf{n}$ elements. We provide a data structure and axioms for an on line strategy-LOCAL POSTORDER-for SUP which fails to be linear but it has a very slow-indeed in the theory of finite sets unprovable-growth. This complements a result of Tarjan who showed an Ackermann type growth for a related problem. Our results may be summarized by saying that (in finite set theory) we may assume that our algorithms are linear (although we know that in fact they fail to be linear). Perhaps this is the first occurrence of unprovability in the complexity analysis of algorithms. 
PD September 1990. TI Postorder Strategy for Tree Compressions. AA Charles University, Prague. SR Universitat Bonn Sonderforschungsbereich 303 Discussion Paper: 90648-OR; Sonderforschungsbereich 303 an der Universitat Bonn, Adenauerallee 24-42, D-5300 Bonn 1, DEUTSCHLAND. PG 40. PR no charge. JE C60. KW Compression Systems. Network Algorithm.

AB In this paper we prove (in a more general setting) that postorder compression systems have linear total length. This solves a conjecture of Hart and Sharir open for several years.

PD September 1990. TI Greedy Compression Systems. AA University of Bonn. SR Universitat Bonn Sonderforschungsbereich 303 - Discussion Paper: 90659-OR; Sonderforschungsbereich 303 an der Universitat Bonn, Adenauerallee 24-42, D-5300 Bonn 1, DEUTSCHLAND. PG 6. PR no charge. JE C63, C60. KW Compression Systems. Ackermann Function. Skeleton Technique. Balanced Trees.

AB We present a theorem concerning the length of compression systems on trees. Let us call a strategy of compressing trees greedy if each compression goes from an end-vertex with maximum distance to the root. We prove a lower bound for maximum total length of greedy compression systems of form $n($ alpha(n)) where $I T I=n$ and alpha(n) is a functional inverse to Ackermann function. This bound is optimum for balanced trees.

PD October 1990. TI Postorder Compression Systems. AA Charles University. SR Universitat Bonn Sonderforschungsbereich 303 - Discussion Paper: 90662-OR; Sonderforschungsbereich 303 an der Universitat Bonn, Adenauerallee 24-42, D-5300 Bonn 1, DEUTSCHLAND. PG 12. PR no charge. JE C63, C60. KW Postorder System. Compression Systems. Set Union Problem.

AB In this paper we prove (in a more general setting) that postorder compression systems have linear total length. This solves a conjecture of Hart and Sharir open for several years.

\section{Lyon, Andrew B.}

PD December 1990. TI Capital Gains Tax Rate Differentials and Tax Trading Strategies. AA University of Maryland, College Park. SR University of Maryland Department of Economics Working Paper Series: 90-27; Department of Economics, University of Maryland, College Park, MD 20742. PG 30. PR no charge. JE H21, G14, G11. KW Capital Gains. Taxation. Stock Market. Securities. AB This paper examines the potential benefits from trading strategies which exploit the difference in the rate at which short-term and long-term capital gains and losses are taxed. The paper extends simulation results of Constantinides (1984) to examine the potential value of tax trading strategies using actual stock price data over the period 1963 to 1989 . The results of the simulation suggest that in the absence of transaction costs, trading strategies could have yielded profits beyond those attained from following a buy-and-hold trading rule for securities with above average volatility. However, with moderate transaction costs these trading strategies offer only modest gains beyond those of a buy-and-hold strategy.

\section{Ma, Ching-to Albert}

PD August 1990. TI Bargaining with Deadlines and Random Delays. AU Ma, Ching-to Alber;; Manove, Michael. AA Boston University. SR Universitat Bonn
Sonderforschungsbereich 303 - Discussion Paper: A-315; Sonderforschungsbereich 303 an der Universitat Bonn, Adenauerallee 24-42, D-5300 Bonn 1, DEUTSCHLAND. PG 36. PR no charge. JE C78, C71. KW Bargaining Model. Perfect Equilibrium. Cheap Talk.

AB Bargaining often occurs under the pressure of a deadline. The deadline may be externally imposed, or one of the parties to the negotiation may have adopted the deadline and made a credible commitment to it. Collective bargaining, contract negotiations and international negotiations are often subject to such deadlines. Anecdotal evidence suggests that bargaining sessions subject to deadlines often begin with cheap talk and rejected proposals; agreements, if they are reached at all, tend to be concluded near the deadline. Furthermore, experimental studies provide strong evidence for the existence of such deadline effects. We attempt to capture and explain these phenomena in a strategic bargaining model. This model incorporates a bargaining deadline along with exogenous random delays in the transmission and consideration of offers.

\section{Machina, Mark J.}

PD August 1988. TI Comparative Statics and NonExpected Utility Preferences. AA University of Califomia, San Diego. SR University of California at San Diego Department of Economics Discussion Paper: 88-44; Department of Economics, 0508, University of California at San Diego, La Jolla, CA 92093. PG 15. PR \$2.00; checks payable to UC Regents. JE D81, D11. KW Risk. Uncertainty. Non-Expected Utility. Utility Theory.

AB Researchers have shown that many, though not all, of the basic results of expected utility analysis can be more or less directly generalized to non-expected utility preferences. This paper describes the essential difference between those results which can be extended in this manner and those which cannot, and shows that an important family of comparative statics theorems falls into the former class.

PD July 1990. TI A More Robust Definition of Subjective Probability. AU Machina, Mark J.; Schmeidler, David. AA Machina: University of Califormia, San Diego. Schmeidler: Tel Aviv University and Ohio State University. SR Universitat Bonn Sonderforschungsbereich 303 Discussion Paper: A-306; Sonderforschungsbereich 303 an der Universitat Bonn, Adenauerallee 24-42, D-5300 Bonn I, DEUTSCHLAND. PG 66. PR no charge. JE D81. KW Subjective Probability. Decision Theory. Expected Utility Hypothesis.

AB Although their goal is to separate a decision maker's underlying beliefs (their subjective probabilities of events) from their preferences (their attitudes toward risk), classic choice-theoretic derivations of subjective probability all rely upon some form of the Marschak-Samuelson "Independence Axiom" or the Savage "Sure-Thing Principle," which is equivalent to requiring that the decision maker's preferences over lotteries conform to the expected utility hypothesis. This paper presents a choice-theoretic derivation of subjective probability which satisfies the axioms of classical probability theory, but which neither assumes nor implies that the decision maker's preferences over lotteries necessarily conform to the expected utility hypothesis.

\section{MacKinnon, James G.}

TI Regression-Based Methods for Using Control and Antithetic Variates in Monte Carlo Experiments. 


\section{AU Davidson, Russell; MacKinnon, James G.}

\section{MaCurdy, Thomas}

PD December 1989. TI Assessing Empirical Approaches for Analyzing Taxes and Labor Supply. AU MaCurdy, Thomas; Green, David; Paarsch, Harry J. AA MaCurdy: Stanford University. Green and Paarsch: University of British Columbia. SR Stanford Center for Economic Policy Research Discussion Paper Series: 204; 100 Encina Commons, Stanford University, Stanford CA 94305. PG 94. PR no charge for members of non-profit institutions, $\$ 3.00$ otherwise. JE J22, H24. KW Labor Supply. Taxes. Linear Constraints. Nonlinear Budget Sets. Income Effect.

AB Recent surveys on the labor supply responses of men document a divergence in the estimates of substitution and income effects obtained using various estimation approaches. Generally, studies accounting for nonlinear tax schedules in a static selting via a piecewise-linear approach produce estimates that typically imply higher substitution and lower income responses than are suggested by empirical work applying other approaches. This paper demonstrates that maximum likelihood estimation of a consumer choice problem with nonlinear budget sets implicitly relies on the satisfaction of inequality constraints that translate into behaviorally meaningful restrictions. These constraints arise not as a consequence of economic theory, but instead as a requirement to create a properly defined statistical model.

\section{Maddala, G. S.}

PD June 1990. TI On the Exact Small Sample Distribution of the Instrumental Variable Estimator. AU Maddala. G. S.: Jeong, Jinook. AA University of Florida. SR University of Florida Working Paper in Economics: 90-5; Department of Economics, University of Florida, Gainesville, FL 32611. PG 11. PR no charge. JE C13, C21, C22. KW Small Sample Properties. Instrumental Variables.

AB This note examines the small sample properties of the IV estimator. Recently, it has been argued that the small sample distribution of the IV estimator is bi-model when the instruments are bad. This note shows that the anomalous results are a consequence of some seemingly innocuous assumptions on the instruments and that the distribution of the IV estimators is not bi-model even when the instruments are bad.

TI A Nonparametric Test for Rationality of Survey Data Using the Bootstrap Method. AU Jeong, Jinook; Maddala, G. S.

TI Measurement Errors and Tests for Rationality. AU Jeong, Jinook; Maddala, G.S.

\section{Maggioncalda, Jeff}

TI The Stability of Beta for Nuclear Electric Utilities, 1976-1986: A Note. AU Lipschultz, Marc: Maggioncalda, Jeff; Rothwell, Geoffrey S.

\section{Magill, Michael}

PD September 1989. TI The Non-Neutrality of Money in a Production Economy with Nominal Assets. AU Magill, Michael; Quinzii, Martine. AA University of Southem California. SR University of Southern California Modelling Research Group Working Paper: M8921; Department of Economics, University of Southern California, University Park,
Los Angeles, CA 90089-0152. PG 36. PR no charge. JE E52, E44, D52. KW Monetary Equilibrium. Monetary Policy. Incomplete Markets.

AB In a general equilibrium model with money we show that anticipated changes in monetary policy have real effects if markets are incomplete and have no real effects if markets are complete. Unanticipated changes in monetary policy always have real effects.

\section{Mailath, George J.}

PD December 1990. TI Signaling Games: An Introduction. AA University of Pennsylvania. SR University of Pennsylvania Center for Analytic Research in Economics and the Social Sciences (CARESS) Working Paper: 90-22; University of Pennsylvania, Center for Analytic Research in Economics and the Social Sciences, McNeil Building, 3718 Locust Walk, Philadelphia, PA 19104-6297. PG 43. PR no charge. JE C72, C62, D82. KW Cooperative Games. Sequential Equilibrium. Asymmetric Information. Signaling Games.

AB This paper surveys some recent work on signaling games. The questions of interest are: When can actions taken by an informed agent serve as an effective signal of that agent's private information? When actions taken by an informed agent do serve as a signal of that agent's private information, does the fact that other agents are using the action choice as a signal affect the informed agent's choice? If there are several possible consistent ways in which action choice can serve as a signal (i.e., if there are multiple equilibria), are there compelling ways to select a unique one? A particular example that I will use often is Spence's job market signaling model.

TI Learning, Mutation, and Long Run Equilibria in Games. AU Kandori, Michihiro; Mailath, George J.; Rob, Rafael.

\section{Maimon, Oded}

TI An Impulse Control Method for Investment Decisions in Dynamic Technology. AU Bar-Ilan, Avner; Maimon, Oded.

\section{Malathy, $\mathbf{R}$.}

PD October 1989. TI Labor Supply Behavior of Married Women in Urban India. AA Yale University. SR Yale Economic Growth Center Discussion Paper: 585; Economic Growth Center, Yale University, 27 Hillhouse Avenue, New Haven, CT 06520. PG 27. PR $\$ 2.00+$ Postage. JE J22, J21. KW India. Labor Supply. Women.

AB The labor market participation of urban women in India, though not impressive, has been increasing since the seventies of this century. Despite the many similarities that urban areas of India share with the advanced industrialized countries, no attempt has been made to apply the available labor supply models to study the labor market behavior of urban women. The purpose of this paper is to fill this gap by investigating married women's labor supply in a metropolitan area of India. Using the recent developments in econometric techniques wage and labor supply functions are estimated under alternative specifications. This paper also examines some methodological issues such as the specification of the wage equation, the importance of sample selection bias in wage and labor supply equations, the exogeneity assumptions on experience and children variables, and the consequences of using standard Tobit and generalized Tobit formulations of the labor supply model. 


\section{Mandler, Michael}

PD November 1989. TI A Theorem of Sraffa. AA University of Pennsylvania. SR University of Pennsylvania Center for Analytic Research in Economics and the Social Sciences (CARESS) Working Paper: 89-23; University of Pennsylvania, Center for Analytic Research in Economics and the Social Sciences, McNeil Building, 3718 Locust Walk, Philadelphia, PA 19104-6297. PG 25. PR no charge. JE E11, E23, D58. KW Pricing. Production. Commodities. General Equilibrium Model.

AB Near the beginning of his controversial book "The Production of Commodities by Means of Commodities", Sraffa writes down a simple system of equations that describe the relationship that a price system must obey for there to be an equal rate of profit across different sectors of production. Only referring to this system of equations, Sraffa concludes that there is an indeterminacy in the price system. Part of the contention that the book aroused was due to the fact that Sraffa's approach is in accord with the emphasis of neoclassical economics on optimization and competitive markets. This paper examines this question by considering a general equilibrium model that encompasses the details of Sraffa's model.

\section{Mankiw, N. Gregory}

PD November 1990. TI A Contribution to the Empirics of Economic Growth. AU Mankiw, N. Gregory; Romer, David; Weil. David N. AA Mankiw: Harvard University. Romer: University of California at Berkeley. Weil: Brown University. SR Brown University Department of Economics Working Paper: 90-29; Department of Economics, Brown University, Providence, RI 02912. PG 45. PR no charge. JE 057, 041, 047. KW Human Capital. Education. Saving. Growth Model. Standard of Living. Income Distribution.

AB This paper examines whether the Solow growth model is consistent with the international variation in the standard of living. It shows that an augmented Solow model that includes accumulation of human as well as physical capital provides an excellent description of the cross-country data. The model explains about 80 percent of the international variation in income per capita, and the estimated influences of physical capital accumulation, human capital accumulation, and population growth confirm the model's predictions. The paper also examines the implications of the Solow model for convergence in standards of living - that is, for whether poor countries tend to grow faster than rich countries. The evidence indicates that, holding population growth and capital accumulation constant, countries converge at about the rate the augmented Solow model predicts.

\section{Manning, Willard G.}

TI Adjusting Capitation Rates Using Objective Health Measures and Prior Utilization. AU Newhouse, Joseph P.; Manning, Willard G.; Keeler, Emmett B.; Sloss, Elizabeth M.

\section{Manove, Michael}

TI Bargaining with Deadlines and Random Delays. AU Ma, Ching-to Albert; Manove, Michael.

\section{Mansoorian, Arman}

PD August 1990. TI Attachment to Home and Efficient Purchases of Population in a Fiscal Externality Economy. AU Mansoorian, Arman; Myers, Gordon $M$.
AA University of Western Ontario. SR University of Western Ontario Department of Economics Research Report: 9010; Department of Economics, Social Sciences Center, University of Westem Ontario, London, Ontario, CANADA N6A 5C2. PG 24. PR \$5.00 Canada; $\$ 7.00$ Elsewhere. JE R13, R58, H77. KW Regional Economics. Intergovernmental Relations. Equilibrium Allocations. Externalities.

AB This paper examines the efficiency properties of an economy characterized by strategically competing regions and individuals with varying degrees of attachment to home, in an otherwise standard fiscal externality setting. Regional authorities may make interregional transfers in purchasing preferred populations. However, there is a range of distributions of resources over which neither region makes transfers. Nevertheless, all equilibrium allocations resulting from the Nash behavior of regional authorities, including those that involve no transfers, are efficient. Therefore, in contrast to the standard conclusions of the fiscal externality literature, there is no efficiency role for a central authority.

PD September 1990. TI Habit Persistence and the Harberger-Laursen-Metzler Effect in an Infinite Horizon Model. AA University of Western Ontario. SR University of Westem Ontario Department of Economics Research Report: 9011; Department of Economics, Social Sciences Center, University of Western Ontario, London, Ontario, CANADA N6A 5C2. PG 14. PR \$5.00 Canada; \$7.00 Elsewhere. JE F31, F32, F34, E21. KW Terms of Trade. Savings. Current Account. Exchange Rate. Infinite Horizon Model. Consumption.

AB The habit persistence model of Ryder and Heal is used to examine the Harberger-Laursen-Metzler (H-L-M) effect. The model captures Keynes's "fundamental psychological law", which underlied the original intuition for the H-L-M effect. Our results are in contrast to the general view in the literature that the stability requirements preclude the H-L-M effect in an infinite horizon model. We show that if the habitual standard of living adjusts fast enough to changes in real consumption then the H-L-M effect holds, and a terms of trade deterioration reduces saving. However, if the habitual standard of living adjusts slowly to changes in real consumption, then the stability requirements dominate the intuition for the H-L-M effect, and the opposite result is obtained.

\section{Margo, Robert A.}

PD May 1991. TI The Decline in Black Teenage Labor Force Participation in the South, 1900-1970: The Role of Schooling. AU Margo, Robert A.; Finegan, T. Aldrich. AA Vanderbilt University. SR National Bureau of Economic Research Working Paper: 3704; National Bureau of Economic Research, 1050 Massachusetts Avenue, Cambridge, MA 02138. PG not available. PR \$2.00. JE J22, J21, J15. KW Labor Force. Minorities. Education. Labor Supply. AB Between 1950 and 1970 the labor force participation rate of southern black males aged 16-19 declined by 27 percentage points. This decline has been attributed to two demand side shocks; the mechanization of cotton agriculture in the 1950s and extensions in the coverage of the federal minimum wage in the 1960s. We show, however, that participation rates of southem black teens fell continuously between 1900 and 1950 . The proximate causes of the pre-1950 decline in black teen participation were increases in school enrollment rates and decreases in labor force participation by teens enrolled in 
school. Because the underlying causes of both effects had not run their course by mid-century, we conclude that about half of the post-1950 decline in black teen participation in the South would have occurred even without the two demand side shocks.

\section{Matsui, Akihiko}

PD November 1990. TI Best Response Dynamics and Socially Stable Strategy. AA University of Pennsylvania. SR University of Pennsylvania Center for Analytic Research in Economics and the Social Sciences (CARESS) Working Paper: 90-21; University of Pennsylvania, Center for Analytic Research in Economics and the Social Sciences, McNeil Building. 3718 Locust Walk, Philadelphia, PA 19104-6297. PG 34. PR no charge. JE C73, C62. KW Dynamic Model. Stability. Cheap Talk.

AB Best response dynamics is a dynamic process in which a strategy increases its frequency only if it is a best response to the present strategy distribution. Gilboa and Matsui (1990) proposed a stability concept directly derived from the dynamic process. We face a difficulty in its application since it is hard to verify the stability condition of a dynamic process in general. Changing the process slightly, the present paper proposes a static equivalence of the stability of the process. We also present some examples which are related to the questions of forward induction and cheap talk.

TI Toward a Theory of Intemational Currency. AU Matsuyama, Kiminori; Kiyotaki, Nobuhiro; Matsui, Akihiko.

\section{Matsuyama, Kiminori}

PD April 1991. TI Toward a Theory of International Currency. AU Matsuyama, Kiminori; Kiyotaki, Nobuhiro; Matsui, Akihiko. AA Matsuyama: Northwestern University. Kiyotaki: London School of Economics and University of Wisconsin. Matsui: University of Pennsylvania. SR Northwestern Center for Mathematical Studies in Economics and Management Science Working Paper: 931; Northwestern University, 2001 Sheridan Road, 3-014 Leverone Hall, Evanston, IL 60208-2014. PG 47. PR \$3.00 in the U.S. or Canada; $\$ 5.00$ via international mail. Make check payable to Northwestern University. JE E42, F10, F33. KW International Currency. Matching Game.

AB Our goal is to provide a theoretical framework in which both positive and normative aspects of international currency can be addressed in a systematic way. To this end, we use the framework of random matching games and develop a two country model of the world economy, in which two national fiat currencies compete and may be circulated as media of exchange. There are multiple equilibria, which differ in the areas of circulation of the two currencies. In one equilibrium, the two national currencies are circulated only locally. In another, one of the national currencies is circulated as an international currency. There is also an equilibrium in which both currencies are accepted internationally. We also find an equilibrium in which the two currencies are directly exchanged. The existence conditions of these equilibria are characterized, using the relative country size and the degree of economic integration as the key parameters.

PD May 1991. TI Agricultural Productivity, Comparative Advantage, and Economic Growth. AA Northwestern University. SR Northwestern Center for Mathematical Studies in Economics and Management Science Working
Paper: 934; Northwestern University, 2001 Sheridan Road, 3-014 Leverone Hall, Evanston, IL 60208-2014. PG 28. PR $\$ 3.00$ in the U.S. or Canada; $\$ 5.00$ via international mail. Make check payable to Northwestern University. JE F43, 011, 041. KW Agriculture. Endogenous Growth. Industrial Revolution. Economic Development.

AB The role of agricultural productivity in economic development is addressed in a two-sector model of endogenous growth in which a) preferences are non-homothetic and the income elasticity of demand for the agricultural good is less than unitary, and b) the engine of growth is learning-by-doing in the manufacturing sector. For the closed economy case, the model predicts a positive link between agricultural productivity and economic growth, while, for the small open economy case, it predicts a negative link. This suggests that the openness of an economy should be an important factor when planning development strategy and predicting growth performance.

\section{McCall, John J.}

PD July 1990. TI The "Smithian" Self and the "Bayesian" Brain. AA University of California at Los Angeles. SR University of California at Los Angeles Department of Economics Working Paper: 596; Department of Economics, University of California, Los Angeles, 2263 Bunche, Los Angeles, CA 90024. PG 111. PR \$2.50. JE A12, B41. KW Economics. Natural Sciences. Tastes. Technology.

AB The purpose of our research is to demonstrate that economic science is a process with its foundations in the natural sciences (technology) and neuroscience (tastes). Much of the current economic research is static with respect to tastes and technology and ignores these fundamental processes. We propose and are showing how economics can be reconstituted as a process based on the recent advances in neuroscience, computer science, psychology and biophysics. The economic insights which should flow naturally from a process-oriented economic science will edify economics and may provide guidance for computer and biological neural science.

\section{McDiarmid, C.}

TI Small Transversals in Hypergraphs. AU Chvatal, Vasek; McDiarmid, C.

\section{McKelvey, Richard D.}

TI A Bayesian Sequential Experimental Study of Learning in Games. AU El-Gamal, Mahmoud A.; McKelvey, Richard D.; Palfrey, Thomas R.

\section{McMillan, John}

PD February 1990. TI The Analytics of Industrial Restructuring. AA Rand Corporation. SR Rand Note: N3080; The Rand Corporation, 1700 Main Street, P.O. Box 2138, Santa Monica, CA 90406-2138. PG 22. PR not available. JE L11, L16, L21, L22. KW Industrial Organization. Industry Structure. Market Structure.

AB This note surveys theoretical research on troubled industries -- on how interindustry adjustments take place, and on the rationales for government intervention to ease the transition. The author considers incentives in the decision to leave an industry. For example, in an industry with excess capacity and declining demand, theory shows that larger firms tend to bear a disproportionately large share of the burden of adjustment. Much of the adjustment that actually takes place in any market economy is successfully mediated by the market. 
Low prices are in themselves a signal to firms to cut back on their capacities. The author also presents possible reasons that the price systems may not produce fully optimal adjustment. These reasons include market frictions, especially in the labor market.

\section{McQueen, Grant}

PD December 1990. TI Stock Prices, News, and Business Conditions. AU McQueen, Grant; Roley, V. Vance. AA McQueen: Brigham Young University. Roley: University of Washington and National Bureau of Economic Research. SR Federal Reserve Bank of Kansas City Research Working Paper: 90-04; Research Division, Federal Reserve Bank of Kansas City, 925 Grand Ave., Kansas City, MO 64198. PG 15. PR no charge. JE E32, G12. KW Stock Prices. Business Fluctuations. Business Cycle. Stock Market.

AB Previous research finds that fundamental macroeconomic news has little effect on stock prices. This study shows that after allowing for different stages of the business cycle, a stronger relationship between stock prices and news is evident. In particular, the empirical results suggest that the effect of news about real economic activity depends on the varying responses of expected cash flows relative to equity discount rates. When the economy is strong, for example, the stock market responds negatively to good news about real economic activity, reflecting the larger effect on discount rates relative to expected cash flows.

\section{Melitz, J.}

PD December 1990. TI Monetary Policy in France. AA INSEE. SR Unite de Recherche Document de Travail ENSAE/INSEE: 9018; INSEE, Unite de Recherche, 18 Bd. Adolphe Pinard, 75675 Paris cedex 14, FRANCE. PG 47. PR no charge. JE E52, N44. KW France. Financial Reform. Monetary History.

AB This discussion of monetary policy in France, which is intended for a chapter in a general handbook on monetary policy (in English) that will cover a number of other countries as well, begins with the early postwar period and carries the story up to the present. A separate section analyzes the new framework for monetary policy that dates from the recent wave of reforms starting in 1984.

\section{Melnick, Glenn A.}

TI The Effects of Hospital Competition and the Medicare PPS Program on Hospital Cost Behavior in California. AU Zwanziger, Jack; Melnick, Glenn A.

\section{Melton, William C.}

PD May 1988. TI Federal Reserve Behavior Since 1980: A Financial Markets Perspective. AU Melton, William C.; Roley, V. Vance. AA Melton: IDS Financial Services, Inc. Roley: University of Washington. SR Federal Reserve Bank of Kansas City Research Working Paper: 88-02; Research Division, Federal Reserve Bank of Kansas City, 925 Grand Ave., Kansas City, MO 64198. PG 21. PR no charge. JE E52, E58, E42, E43. KW Federal Reserve. Monetary Policy. Interest Rates. Money Supply.

AB The financial market's understanding of Federal Reserve behavior is used to examine recent changes in monetary policy. Changes in the level of interest rates in response to specific types of economic information are primarily considered. Differences in the volatility of interest rates across periods provide additional evidence on changes in monetary policy regimes. The results indicate that monetary policy changed several times since 1980 with respect to either the Federal Reserve's targets, its desire to achieve its targets, or its operating procedures. The different regimes correspond to Federal Reserve statements about changes in policy. In this context, then, the evidence suggests that policy was credible.

\section{Mester, Loretta J.}

TI Debt Covenants and Renegotiations. AU Berlin, Mitchell; Mester, Loretta J.

\section{Metcalf, Gilbert E.}

PD December 1989. TI Federal Taxation and the Supply of State Debt. AA Princeton University. SR John M. Olin Program for the Study of Economic Organization and Public Policy: 40; Department of Economics, Woodrow Wilson School of Public \& International Affairs, Princeton University, Princeton, NJ 08544. PG 36. PR no charge. JE H74, H77, H71. KW Tax Policy. Municipal Bonds. Public Finance. State Government.

AB This paper presents a model of debt finance at the subnational level from which municipal bond supply equations are derived. Federal tax considerations are shown to be important determinants of the price entering the bond supply equation. Using data on $\mathbf{4 0}$ state governments over a seven year period in the 1980s, I show that federal tax rates have an important effect on the supply of municipal bonds - independent of the demand side effect that is usually considered in the literature. Furthermore, the effect persists after controlling for capital expenditure, thereby suggesting that municipal bond proceeds are fundable at the margin. This has implications for the measurement of the tax expenditure associated with tax exempt debt.

\section{Miller, Paul W.}

TI Language in the Labor Market: The Immigrant Experience in Canada and the United States. AU Chiswick, Barry R.; Miller, Paul W.

\section{Mitzkewitz, Michael}

PD July 1990. TI Signaling and Equilibrium Selection Part I: Preliminaries and Generic Games. AA University of Bonn. SR Universitat Bonn Sonderforschungsbereich 303 Discussion Paper: B-158; Sonderforschungsbereich 303 an der Universitat Bonn, Adenauerallee 24-42, D-5300 Bonn 1, DEUTSCHLAND. PG 66. PR no charge. JE C71, C70. KW Game Theory. Signaling Games. Cooperative Games.

AB This paper is the first part of a study that works out the Harsanyi-Selten solution for a complete class of simple signaling games, applies this solution to different economic models and compares the solution with the results of refinement concepts. In this first part we motivate our project, give an introduction into Harsanyi and Selten's general theory of equilibrium selection and compute the solution for the generic signaling games of the class we will consider.

\section{Mocan, H. Naci}

TI Unemployment and Infant Health: Time-Series Evidence from the State of Tennessee. AU Joyce, Theodore J.; Mocan, H. Naci. 


\section{Modica, Salvatore}

TI A Neo2 Bayesian Foundation of the Maxmin Value for Two-Person Zero-Sum Games. AU Hart, Sergiu; Modica, Salvatore; Schmeidler, David.

\section{Monfort, Alain}

PD September 1990. TI Les Axes de Developpements des Methodes Macroeconometriques. AA INSEE. SR Unite de Recherche Document de Travail ENSAE/INSEE: 9014; INSEE, Unite de Recherche, $18 \mathrm{Bd}$. Adolphe Pinard, 75675 Paris cedex 14, FRANCE. PG 28. PR no charge. JE C22, E10, C53, C52. KW VAR Models. Nonstationarity. ARCH Models. Disequilibrium Models. Macroeconomics.

AB In this note we briefly describe four recent developments of the macroeconometric methods; the VAR models, the nonstationary models, the ARCH model and the disequilibrium models. Paper in French.

\section{Moore, John}

TI A Theory of Corporate Financial Structure Based on the Seniority of Claims. AU Hart, Oliver, Moore, John.

\section{Morgan, Donald}

PD October 1989. TI Bank Credit Commitments and Credit Rationing. AA Federal Reserve Bank of Kansas City. SR Federal Reserve Bank of Kansas City Research Working Paper: 89-06; Research Division, Federal Reserve Bank of Kansas City, 925 Grand Ave, Kansas City, MO 64198. PG 21. PR no charge. JE G21. KW Investment. Debt. Borrowing. Credit Rationing. Debt Contracts.

AB We consider the optimal financing of investment projects with random costs and privately observed returns. We show that ordinary debt contracts price default risk in a manner that increases default risk. This pricing is inefficient when default is costly and may lead to quantity credit rationing. In contrast, the pricing of bank credit commitments reduces default risk and eliminates the type of quantity rationing that may occur under ordinary debt contracts. We find that under ordinary debt contracts, a rise in banks' costs of funds reduces project values through distinct interest and rationing channels. Under commitments, only the interest channel is operative, the rationing channel is blocked. Nevertheless, project value may still decline more under a commitment. These results illuminate recent empirical research on commitments.

\section{Morris, Charles S.}

TI Loan Losses and Bank Risk-Taking: Is There a Connection? AU Keeton, William R.; Morris, Charles S.

TI The Prepayment Experience of FNMA Mortgage-Backed Securities. AU Becketti, Sean; Morris, Charles S.

\section{Morris, John R.}

TI Rent Increasing Costs: The Antitrust Implications from a Paradox in Value Theory. AU Langenfeld, James A.; Morris, John R.

\section{Mortenson, Dale T.}

PD May 1991. TI Equilibrium Unemployment Cycles. AA Northwestern University. SR Northwestern Center for Mathematical Studies in Economics and Management Science Working Paper: 939; Northwestern University, 2001 Sheridan
Road, 3-014 Leverone Hall, Evanston, IL 60208-2014. PG 50. PR $\$ 3.00$ in the U.S. or Canada; $\$ 5.00$ via international mail. Make check payable to Northwestern University. JE E24, J64. KW Unemployment. Wage Contracts.

AB The global dynamics of an equilibrium model of aggregate unemployment that focuses on the job/worker matching process is studied for the case of increasing returns to scale in production and constant returns to scale in the matching process. In anticipation of a particular solution to the wage bargaining problem, unmatched expected present value maximizing workers and employers respectively invest in search and recruiting effort that collectively determines the aggregate matching rate. An equilibrium is a dynamic path for the aggregate number of matches generated by best response investment decisions under rational expectations. There are no periodic solutions if the wage bargain is efficient and the future is discounted.

\section{Mowery, David C.}

PD January 1990. TI The Growth of U.S. Industrial Research. AA University of California, Berkeley. SR Stanford Center for Economic Policy Research Discussion Paper Series: 182; 100 Encina Commons, Stanford University, Stanford CA 94305. PG 31. PR no charge for members of non-profit institutions, $\$ 3.00$ otherwise. JE O31, O32, O33. KW R\&D. Innovation. Technology.

AB Historical analysis of the development of industrial research in the U.S. economy raises important issues for economic historians, theorists and scholars of industrial organization. For neoclassical theory, the conditions governing the appropriability of the returns to $R \& D$ investment are a critical factor in determining the level and effects of R\&D investment. Theoretical analyses of technological change rarely consider the utilization and transfer of R\&D results (an exception is Cohen and Levinthal, 1989). Yet this aspect of the innovation process is essential to understanding the historical development of industrial research in the U.S. economy.

PD January 1990. TI Government Policy and Industry Evolution in the U.S. Integrated Circuit Industry: What Lessons for Newly Industrializing Economies? AU Mowery, David C.: Steinmueller, W. Edward. AA Mowery: University of California, Berkeley. Steinmueller: Stanford University. SR Stanford Center for Economic Policy Research Discussion Paper Series: 192; 100 Encina Commons, Stanford University, Stanford CA 94305. PG 77. PR no charge for members of non-profit institutions, $\$ 3.00$ otherwise. JE L63, L11, L16, O33. KW Integrated Circuit Industry. Industrial Organization. Technological Change. Intellectual Property. Trade Policy. Industry Policy.

AB This paper has three main goals: (1) to present an overview and analysis of the development of the U.S. microelectronics industry as a basis for an assessment of the nature and effects of U.S. government policies; (2) to describe and speculate about the structure and effects of proposed policy changes that may emerge from the current debate; and (3) to examine the implications for Newly Industrialized Economies of the conclusions to the first two exercises.

\section{Mueller, Dennis C.}

PD November 1990. TI Constitutional Rights. AA University of Maryland, College Park. SR University of Maryland Department of Economics Working Paper Series: 
90-21: Department of Economics, University of Maryland, College Park, MD 20742. PG 50. PR no charge. JE H11, D72, D71. KW Constitutions. Public Choice. Externalities.

AB The question of what rights would or should be protected by a constitution has not been examined in the public choice literature. Nor has the more general question been addressed of the criteria by which constitutional rights are determined. The closest the literature has come to these questions is in the debate over liberal rights initiated by Amartya Sen (1970a, b; 1976). But here the existence of a right and its nature was assumed from the start, and the debate hinged around the conflict between this right and the Pareto postulate. A systematic examination from a public choice perspective of the origin of constitutional rights and their inherent characteristics has yet to appear. This paper begins to fill this void.

\section{Mukhopadhyay, Sudhin K.}

PD November 1989. TI Technological Change and Labor Use in Rice Agriculture: Analysis of Village Level Data in West Bengal, India. AA Yale University. SR Yale Economic Growth Center Discussion Paper: 590; Economic Growth Center, Yale University, 27 Hillhouse Avenue, New Haven, CT 06520. PG 23. PR \$2.00 + Postage. JE O13, Q12, Q13, O53. KW India. Technology. Agriculture. Environment.

AB This paper attempts to examine the factors behind the relatively slow rate of technological progress in the rice-based agriculture of West Bengal, India. The basic argument is that technical progress is determined by environmental and market factors specific to given locations. Results of the analysis show that physical environmental factors and relative profitability are strong determinants of technology adoption. Modern technology induces increases in cropping intensity which in turn helps higher labor use in agriculture. Labor use also depends positively upon the ratio of crop price to wages and negatively upon the level of unionization of laborers. Policy implications highlight environment-specific physical factors (e.g., irrigation, water control and other infrastructural facilities), economic factors (e.g., input and output prices), and technological factors (e.g., generation and diffusion of modem varieties suited to location-specific conditions) that can ensure higher relative yield and profitability. These are critical elements for the sustained progress of agricultural technology in West Bengal.

\section{Muller, Sigrid}

PD September 1990. TI ECU-Finanztitel: Bewertung und Hedge-Eigenschaften. AA University of Bonn. SR Universitat Bonn Sonderforschungsbereich 303 Discussion Paper: B-163; Sonderforschungsbereich 303 an der Universitat Bonn, Adenauerallee 24-42, D-5300 Bonn 1, DEUTSCHLAND. PG 15. PR no charge. JE F31, F33, F36, O19. KW European Community. European Monetary System. Exchange Rates. International Finance.

AB Paper in German.

\section{Mumford, Karen}

PD November 1990. TI Wage Bargaining with Endogenous Profits, Overtime Working and Heterogeneous Labor. AU Mumford, Karen; Dowrick, Steve. AA Mumford: Princeton University. Dowrick: Warwick University. SR Princeton Industrial Relations Section
Working Paper: 277; Industrial Relations Section, Department of Economics, Princeton University, Princeton, NJ 08544-2098. PG 32. PR \$1.50. JE J31, J51, J53. KW Bargaining. Wage Determination. Insider Power. Unions.

AB This paper estimates the role of insider power in wage determination in a unionized industry, examining the direction and magnitude of biases which may arise through failure to control for variation in both hours of work and the composition of the labor force and through failure to control for the endogeneity of measured profits. Furthermore, by examining the extent to which rent sharing is related to exogenous demand shocks rather than to potentially endogenous productivity, we provide a test of the bargaining and "pure" efficiency wage models, finding that the majority of the insider weighting can be explained by the bargaining model. Our data set covers earnings and profitability in the New South Wales coal industry form 1952 to 1987. We estimate a partial adjustment model and test for co-integration of the time series in order to establish whether or not a long-run stable equilibrium exists.

\section{Murphy, Kevin J.}

TI Optimal Incentive Contracts in the Presence of Career Concerns: Theory and Evidence. AU Gibbons, Robert; Murphy, Kevin J.

\section{Myers, Gordon M.}

TI Attachment to Home and Efficient Purchases of Population in a Fiscal Externality Economy. AU Mansoorian, Arman; Myers, Gordon M.

\section{Nachbar, John $\mathrm{H}$.}

PD September 1989. TI The Evolution of Cooperation in the Finitely Repeated Prisoner's Dilemma. AA Rand Corporation. SR Rand Paper: P-7591; The Rand Corporation, 1700 Main Street, P.O. Box 2138, Santa Monica, CA 90406-2138. PG 25. PR not available. JE C71. KW Repeated Games. Cooperative Games.

AB This paper examines "evolutionary" dynamic behavior in the finitely repeated prisoner's dilemma. It is first noted that the "fitness" of cooperation found in the best known simulation of this type, that by Robert Axelrod, stems from strategy-set restrictions that altered Nash Equilibrium behavior: Axelrod's restricted game has a continuum of pure cooperation equilibria and no pure defection equilibrium. New simulations, maintaining the finite game's equilibrium structure, are presented here. It is found that although cooperation is ultimately exploited and extinguished, dynamic paths can "pseudo converge" in ways that allow partial cooperation to flourish for extended periods of time.

\section{Nadiri, M. Ishaq}

TI Endogenous Capital Utilization and Productivity Measurement in Dynamic Factor Demand Models: Theory and an Application to the U.S. Electrical Machinery Industry. AU Prucha, Ingmar R.; Nadiri, M. Ishaq.

TI A Dynamic Model of Product Demand, Cost of Production and Interindustry R\&D Spillovers. AU Bernstein, Jeffrey I.; Nadiri, M. Ishaq.

\section{Nawijn, W. M.}

PD February 1990. TI Minimum Loss Scheduling. AU Nawijn, W. M.; Kem, W.; Baas, S. M. AA Kem: 
University of Cologne. Nawijn and Baas: University of Twente. SR Universitat Bonn Sonderforschungsbereich 303 Discussion Paper: 90.82; Sonderforschungsbereich 303 an der Universitat Bonn, Adenauerallee 24-42, D-5300 Bonn 1, DEUTSCHLAND. PG 15. PR no charge. JE C61, C60, C67. KW Dynamic Programming. Scheduling Problem. Polynomial Algorithm.

AB Consider a single machine with a buffer of capacity one for waiting jobs. Given the arrival epochs, the weights and the processing times of $\mathbf{n}$ consecutive future jobs, a maximum weight subset of jobs is to be found that is schedulable without violating the buffer's capacity constraint. A polynomial algorithm for the unweighted loss-delay problem is presented. For the weighted one-machine case, shown to be NP-hard, a dynamic programming formulation is given.

TI Scheduling Jobs on Parallel Machines, Each with a UnitCapacity Buffer. AU Baas, S. M.; Kem, W.; Nawijn, W. M.

\section{Nerlove, Marc}

PD August 1990. TI Income Distribution and Efficiency: The Role of Social Security. AU Nerlove, Marc; Razin, Assaf; Sadka, Efraim; von Weizsacker, Robert K. AA Nerlove: University of Pennsylvania. Razin and Sadka: Tel Aviv University. von Weizsacker: University of Bonn. SR Universitat Bonn Sonderforschungsbereich 303 Discussion Paper: A-308; Sonderforschungsbereich 303 an der Universitat Bonn, Adenauerallee 24-42, D-5300 Bonn 1, DEUTSCHLAND. PG 29. PR no charge. JE H55, D31, D61. KW Social Security System. Social Welfare. Intergenerational Transfers. Pensions. Income Distribution.

AB The redistributive role of a Social Security system is widely recognized. Current discussions in the U.S. regarding treatment of the so-called Social Security trust fund as an offset to the federal deficit, is a reflection of this view. To confine the Social Security system to a purely redistributive role, however, ignores the possibility that the system may also mitigate inefficiencies arising from institutional constraints to individual intergenerational transfers. This paper is concerned with the way in which a Social Security system of taxes and transfers acts to redistribute income within and between generations. Such redistributions improve the social welfare both by reducing income inequality and by mitigating the effects of bequest constraints.

PD October 1990. TI Tax Policy, Investments in Human and Physical Capital, and Productivity. AU Nerlove, Marc; Razin, Assaf; Sadka, Efraim; von Weizsacker, Robert K. AA Nerlove: University of Pennsylvania. Sadka and Razin: Tel Aviv University and National Bureau of Economic Research. Weizsacker: University of Bonn. SR Universitat Bonn Sonderforschungsbereich 303 - Discussion Paper: A-322; Sonderforschungsbereich 303 an der Universitat Bonn, Adenauerallee 24-42, D-5300 Bonn 1, DEUTSCHLAND. PG 25. PR no charge. JE E21, E22, J41, H24, 041. KW Tax Policy. Income Tax. Resource Allocation. Human Capital.

AB In a world with only unskilled labor and physical capital, a comprehensive income tax generates two distortionary effects on resource allocations. It distorts the intratemporal leisureconsumption trade-offs and the intertemporal savingconsumption trade-offs. In this paper we analyze the effects of these distortions on overall savings, the composition of savings between investments in human capital and physical capital, and the pattern of economic growth.

\section{Nesetril, Jaroslav \\ TI Unprovability of Set Union Problem Strategies. \\ AU Loebl, Martin; Nesetril, Jaroslav. \\ TI On the Computational Complexity of Seidel's Switching. \\ AU Kratochvil, Jan; Nesetril, Jaroslav; Zyka, Ondrej.}

\section{Neumann, Manfred M. J.}

PD October 1990. TI Internationale Wirtschaftspolitik: Koordination, Kooperation oder Wettbewerb? AA University of Bonn. SR Universitat Bonn Sonderforschungsbereich 303 - Discussion Paper: B-168; Sonderforschungsbereich 303 an der Universitat Bonn, Adenauerallee 24-42, D-5300 Bonn 1, DEUTSCHLAND. PG 26. PR no charge. JE F33, F42, F36, O19. KW International Policy. EMS. Policy Coordination. Economic Policy.

AB Paper in German.

\section{Newhouse, Joseph P.}

PD July 1989. TI Adjusting Capitation Rates Using Objective Health Measures and Prior Utilization. AU Newhouse, Joseph P.; Manning, Willand G.; Keeler, Emmett B.; Sloss, Elizabeth M. AA Rand Corporation. SR Rand Note: N-2986; The Rand Corporation, 1700 Main Street, P.O. Box 2138, Santa Monica, CA 90406-2138. PG 14. PR not available. JE I11. KW Medical Costs. Health Care. Medical Expenditures.

AB Several analysts have proposed adding adjusters based on health status and prior utilization to the adjusted average per capita cost formula. This note, reprinted from [Health Care Financing Review], Vol. 10, No. 3, Spring 1989, estimates how well such adjusters predict annual medical expenditures among non-elderly adults. Both measures substantially improve on the variables currently used. If only health measures are added, 20-30 percent of the predictable variance is explained; if only prior use is added, more than 40 percent is explained. The results support including some measure of use in the formula until better health measures are developed.

\section{Nolan, Peter}

PD October 1990. TI Markets, Institutions and Technical Change: The Production and Utilization of Machine Tools in China. AU Nolan, Peter, Wang, Hong. AA University of Cambridge. SR University of Cambridge Small Business Research Centre Working Paper: 8; Department of Applied Economics, University of Cambridge, Sidgwick Avenue, Cambridge CB3 9DE, UNITED KINGDOM. PG 31. PR $\$ 5.00$ (2.50 pounds); checks payable to University of Cambridge. JE O53, O14, L60. KW Machinery Tools. Technical Progress. Economic Development. Industrialization. China.

AB This paper has three objectives. First, it provides a critical appraisal of the literature on the role of machine tools in economic development. Second, it outlines the main characteristics of the production and use of machine tools in China pre-1978 including the relative roles of large and small enterprises. Third, it examines the processes through which Chinese economic reforms after 1978 affected China's machine tool industry, and their possible implication for the future organization of its enterprises. 


\section{Noldeke, Georg}

PD July 1990. TI Switching Away from Probability One Beliefs. AU Noldeke, Georg; van Damme, Eric. AA Noldeke: University of Bonn. van Damme: Tilburg University. SR Universitat Bonn Sonderforschungsbereich 303 - Discussion Paper: A-304; Sonderforschungsbereich 303 an der Universitat Bonn, Adenauerallee 24-42, D-5300 Bonn 1, DEUTSCHLAND. PG 40. PR no charge. JE C71, C73, D83. KW Signaling Games. Dynamic Games. Incomplete Information. Sequential Equilibrium. Repeated Games.

AB This paper considers a class of repeated signaling games to gain some intuitive insights into the effects and the desirability of modeling players in a dynamic game of incomplete information as being obstinate in the sense that their beliefs satisfy a support restriction. We demonstrate that such a restriction is rather dubious on a-priori grounds and in general imposes "too much" pooling on sequential equilibrium outcomes. Equilibria violating a suppont restriction should therefore not be dismissed in dynamic models of incomplete information and may actually reflect the possibility of reputation effects present in such a setting.

\section{Noll, Roger G.}

TI ISDN and the Small User: Regulatory Policy Issues. AU Lehr, William; Noll, Roger G.

PD September 1989. TI The Political Economics of State Responses to Divestiture and Federal Deregulation in Telecommunications. AU Noll, Roger G.; Smart, Susan R. AA Stanford University. SR Stanford Center for Economic Policy Research Discussion Paper Series: 176; 100 Encina Commons, Stanford University, Stanford CA 94305. PG 41. PR no charge for members of non-profit institutions, \$3.00 otherwise. JE L96, L51, L52. KW Telecommunications. Regulation. Telephones. Prices.

AB During the 1980s customers of basic local exchange service experienced rate shock -- substantial increases in the monthly flat rate of local access. The purpose of this paper is to examine the magnitude and pattern of these price changes for the purposes of determining their consistency with two potential explanations. The first is the efficiency hypothesis: federal procompetitive policies in telecommunications forced local exchange carriers to set prices more in line with cost of service, abandoning historical pattems of cross-subsidization in the price structure. The second explanation is derived from an application of the economic theory of regulatory policy: that price increases would be spread across users in a predictable fashion so as to minimize their political backlash.

TI Environmental Markets in the Year 2000. AU Hahn, Robert W.; Noll, Roger G.

\section{Nussbaum, Michael}

TI Bootstrap Confidence Bands. AU Hardle, Wolfgang; Nussbaum, Michael.

\section{Nyarko, Yaw}

PD January 1991. TI Optimal Growth with Unobservable Resources and Learning. AU Nyarko, Yaw; Olson, Lars J. AA Nyarko: New York University. Olson: University of California, Riverside. SR New York University Economic Research Reports: 91-01; New York University, Faculty of Arts and Science, Department of Economics, Washington Square,
New York, N.Y. 10003. PG 62. PR no charge. JE D83, D33, D81, D84. KW Bayesian Learning. Learning. Consumption. Wealth.

AB This paper examines the problem of choosing optimal resource consumption from an imperfectly observable aggregate capital, wealth or resource stock which the decisionmaker learns about over time. Learning is complicated by the fact that the planner receives information about an object (the true resource stock) which is a moving target. Under the assumption that the utility of zero consumption is negative infinity we show that the optimal policy follows a completely deterministic "cautious" or minimax policy that assumes the worst in each period and optimizes against that. The following conclusions are obtained when this model is compared to a model with completely observable wealth level: (1) there is "over-saving," (2) investment and output processes are more volatile than consumption, and (3) regressions underestimate the risk aversion of agents. We also show that information about the wealth or stock level is only valuable if it alters the support of the agent's beliefs. Thus, information may be statistically informative yet economically valueless. If information changes the support of the agent's beliefs then the optimal solution features an endogenous resource "discovery" process.

\section{Oates, Wallace E.}

PD October 1990. TI Public Finance with Several Levels of Government: Theories and Reflections. AA University of Maryland, College Park. SR University of Maryland Department of Economics Working Paper Series: 90-20; Department of Economics, University of Maryland, College Park, MD 20742. PG 40. PR no charge. JE H77, H72, H11, H21. KW Local Finance. Government Finance. Local Governments. Fiscal Policy.

AB This paper provides a selective survey and assessment of research in "fiscal federalism." It explores the assignment of fiscal functions and of forms of taxation to different levels of government, intergovernmental grants, local finance, regulatory federalism, and the effect of fiscal centralization on the overall size of the public sector. The paper attempts to set forth both what we know about these matters and what remains on our research agenda.

\section{Ogaki, Masao}

TI Engel's Law and Saving. AU Atkeson, Andrew; Ogaki, Masao.

PD September 1990. TI Aggregation of Intratemporal Preferences under Complete Markets. AA University of Rochester. SR University of Rochester Center for Economic Research Working Paper: 249; Department of Economics, University of Rochester, Rochester, NY 14627. PG 15. PR no charge. JE D11, C43. KW Aggregation. Utility Theory. Consumer Economics. Consumption.

AB By extending and applying an aggregation result in financial economics under complete markets to intratemporal demand, the present paper shows that all concave intratemporal utility functions can be aggregated. A fictitious representative consumer is constructed in an economy with heterogeneous consumers whose preferences can be represented by timeadditive, von Neumann-Morgenstern utility functions. The distribution of total consumption expenditures does not affect the utility function of the representative consumer. This aggregation result for preferences is valid even when aggregate 
demand functions do not satisfy usual properties of individual demand functions and depend on the distribution of total consumption expenditures.

\section{Oh, Kong Dan}

TI The Development and Structure of Consumer Credit in Japan. AU Alexander, Arthur J.; Oh, Kong Dan.

Okojie, Christiana E. E.

PD November 1989. TI Fertility Response to Child Survival in Nigeria: An Analysis of Microdata from Bendel State. AA Yale University. SR Yale Economic Growth Center Discussion Paper: 592; Economic Growth Center, Yale University, 27 Hillhouse Avenue, New Haven, CT 06520. PG 23. PR $\$ 2.00+$ Postage. JE J13, I32, 112. KW Fertility. Children. Mortality. Poverty.

AB The paper analyzes the response of fertility to own child survival respondents in Bendel State of Nigeria. The microeconomic theory of fertility behavior provides the theoretical framework for the analysis. Fertility is specified as a function of price and income variables and the survival ratio -- two equations were estimated. Actual survival ratio is used as a regressor in the first equation. A preferred two-stage procedure is also used in which the survival ratio is estimated by the method of instrumental variables, because of its endogeneity. The survival ratio has a negative and statistically significant association with fertility for all subgroups with the response elasticity varying between 0.3 and 0.8 . The response elasticity is highest among rural women who had experienced the highest incidence of child mortality in the sample. Results suggest the need to reduce mortality levels significantly and fertility will respond rapidly to changes in mortality levels.

\section{Okuno-Fujiwara, Masahiro}

PD October 1990. TI Social Norms and Random Matching Games. AU Okuno-Fujiwara, Masahiro; Postlewaite, Andrew. AA Okuno-Fujiwara: University of Tokyo. Postlewaite: University of Pennsylvania. SR University of Pennsylvania Center for Analytic Research in Economics and the Social Sciences (CARESS) Working Paper: 90-18; University of Pennsylvania, Center for Analytic Research in Economics and the Social Sciences, McNeil Building, 3718 Locust Walk, Philadelphia, PA 19104-6297. PG 28. PR no charge. JE C71, C78. KW Nash Equilibrium. Common Knowledge. Folk Theorem.

AB Nash equilibrium has been tremendously useful in understanding economic problems in which strategic behavior is important. The theoretical foundations of the solution concept often include the assumption that the game to be played is common knowledge, an assumption that often seems not realistic, particularly in games involving large numbers of players. In this paper we introduce the concept of norm equilibrium for random matching games. A norm equilibrium essentially a Nash equilibrium that implicitly relies on substantially less information than the traditional common knowledge of the game. We use norm equilibria to provide a type of folk theorem for random matching games and to analyze the effect of increasing the numbers of players in a random matching game.

\section{Olivella, Pau}

TI Bonuses and Penalties as Equilibrium Incentive Devices, with Application to Manufacturing Systems. AU Aron,
Debra J.; Olivella, Pau.

\section{Olson, Lars J.}

TI Optimal Growth with Unobservable Resources and Learning. AU Nyarko, Yaw; Olson, Lars J.

\section{Orr, James}

PD September 1990. TI Foreign Direct Investment in U.S. Manufacturing: Effects on the Trade Balance. AA Federal Reserve Bank of New York. SR Federal Reserve Bank of New York Research Paper: 9032; Federal Reserve Bank of New York, 33 Liberty St., Rm. 901, New York City, New York 10045. PG 32. PR no charge. JE F14, F23, F32, L60. KW Trade Balance. Multinational Firms. Foreign Investment. Manufacturing.

AB This paper analyzes the extent to which the recent growth of foreign direct investment in U.S. manufacturing industries can significantly reduce U.S. trade deficit over the mediumterm. Trade balance effects are estimated for four industries which are important for U.S. trade performance and which have had sizable inflows of foreign investment: automobiles, steel, chemicals and electronics. The findings suggest that any improvement in the trade balance arising from foreign direct investment will be relatively small. Apart from the automobile industry, direct investment has not represented a large-scale shift of new productive capacity from major import supplying countries to the United States. Rather, foreign investors have acquired existing firms, particularly in electronics and chemicals, and the change of ownership has not been associated with either a significant decline in imports or an expansion of exports.

\section{Ouellette, P.}

TI The Producer and the Real Balance Effect. AU Bronsard, C.; Ouellette, P.; Salvas-Bronsard, L.

\section{Paarsch, Harry J.}

PD September 1989. TI Deciding Between the Common and Private Value Paradigms in Empirical Models of Auctions. AA University of British Columbia. SR University of British Columbia Department of Economics Discussion Paper: 89-20; University of British Columbia, \#997-1873 East Mall, Vancouver, BC V6T 1W5, CANADA. PG 29. PR $\$ .20$ per page Canadian to other than educational institutions. JE D44, L80. KW Auctions. Common Value.

AB Within both the common and private value paradigms, I construct two simple theoretical models of rational bidding at sealed-bid auctions. Each model is then mapped into an empirical specification. Neither specification nests the other but one can, in principle although not always in practice, use the methods of Cox $(1961,1962)$ and others to decide between the two competing models. I then apply this empirical framework to data from a sample of tree planting contract auctions held in the province of British Columbia, Canada.

TI Assessing Empirical Approaches for Analyzing Taxes and Labor Supply. AU MaCurdy, Thomas; Green, David; Paarsch, Harry J.

Pakes, Ariel

PD February 1990. TI Empirical Implications of Alternative Models of Firm Dynamics. AU Pakes, Ariel; Ericson, Richard. AA Yale University. SR Yale Economic 
Growth Center Discussion Paper: 594; Economic Growth Center, Yale University, 27 Hillhouse Avenue, New Haven, CT 06520. PG 75. PR $\$ 2.00+$ Postage. JE D21, L11, G33. KW Uncertainty. Firm Behavior. Market Structure. Retail Trade. Manufacturing.

AB This paper considers two models for analyzing the dynamics of firm behavior that allow for heterogeneity among firms, idiosyncratic (or firm specific) sources of uncertainty, and discrete events (exit and entry). Models with these characteristics are needed for empirical analysis of the causes and effects of the dispersion in the distribution of outcome paths among firms, and for correcting for the self-selection induced by liquidation in the empirical analysis of firm's responses to alternative policy and environmental changes. It is shown that the two models have different nonparametric implications, and that these are rich enough to enable the construction of both testing, and selection correction, procedures that are both, fully consistent with the theoretical model, and easy to implement. The paper concludes by checking for the implications of the two models on an eight year panel of Wisconsin firms. We find one model to be consistent with the data on manufacturing, and the other to be consistent with the data for retail trade.

\section{Palanigounder, Duraisamy}

PD July 1989. TI Human Capital and Adoption of Innovations in Agricultural Production: Indian Evidence. AA Yale University. SR Yale Economic Growth Center Discussion Paper: 577; Economic Growth Center, Yale University, 27 Hillhouse Avenue, New Haven, CT 06520. PG 25. PR $\$ 2.00+$ Postage. JE Q16, Q13, Q12. KW Education. Agriculture.

AB This paper examines the impact of farmers' education and extension contacts on the adoption of High Yielding Varieties (HYV) in single crop (paddy) and multi crop production using a dichotomous logit model. The empirical results based on farm level data from one Indian state, namely Tamil Nadu, demonstrate that education of the farm head and extension contacts have strong positive effects on the probability of adoption of HYV and its intensity of use. The influence of other explanatory variables such as price of variable inputs and quantity of fixed inputs confirm the a priori expectations. The results provide a case for increased spending on rural education and intensifying extension services.

\section{Palfrey, Thomas R.}

TI Undominated Nash Implementation in Bounded Mechanisms. AU Jackson, Matthew O.; Palfrey, Thomas R.; Srivastava, Sanjay.

PD December 1990. TI Implementation in Bayesian Equilibrium: The Multiple Equilibrium Problem in Mechanism Design. AA California Institute of Technology. SR Caltech Social Science Working Paper: 760; Division of Humanities and Social Sciences, 228-77, Caiifornia Institute of Technology, Pasadena, CA 91125. PG 43. PR no charge. JE C70, D71, C62. KW Mechanism Design. Game Theory. Social Choice. Bayesian Equilibrium.

AB This paper surveys the literature on implementation in Bayesian Equilibrium.

TI A Bayesian Sequential Experimental Study of Learning in Games. AU El-Gamal, Mahmoud A;; McKelvey, Richard D.; Palfrey, Thomas R.

\section{Parikh, Kirit}

PD December 1989. TI Poverty Alleviation Policies in India: Food Consumption Subsidy, Food Production Subsidy and Employment Generation. AU Parikh, Kirit; Srinivasan, T. N. AA Yale University, SR Yale Economic Growth Center Discussion Paper: 591; Economic Growth Center, Yale University, 27 Hillhouse Avenue, New Haven, CT 06520. PG 28. PR $\$ 2.00+$ Postage. JE I32, I38, O11, 053. KW Poverty. India. Government Policy.

AB Poverty alleviation has been the overarching objective of the development strategy of India since independence, although achievements have fallen far short of expectations. Over time a number of targeted and non-targeted poverty alleviation policies of varying extent of coverage and efficiency have been tried. The paper compares the effectiveness of some of these policy interventions in alleviating poverty using counterfactual policy simulations with a sequential applied general equilibrium model of the Indian economy for the period 19802000.

\section{Park, Sangkyun}

PD February 1991. TI Bank Failure Contagion in Historical Perspective. AA Federal Reserve Bank of New York. SR Federal Reserve Bank of New York Research Paper: 9103; Federal Reserve Bank of New York, 33 Liberty St., Rm. 901, New York City, New York 10045. PG 49. PR no charge. JE G21, N21, N22. KW Bank Failures. Financial Crisis. Banking. Commercial Banks.

AB Bank failures are contagious due to the lack of bankspecific information. Depositors who lack financial information on individual banks make withdrawal decisions based on the condition of the banking system as a whole. A high ratio of bank failures then signals an adverse condition within the banking sector and triggers system-wide bank runs. Examination of the U.S. banking history presents two major empirical findings: Bank failures were less contagious when the public was better informed of the financial structure specific to individual banks; the government or banks stopped bank panics mainly by providing financial information on banks.

PD February 1991. TI A Triggering Mechanism of Economy-Wide Bank Runs. AA Federal Reserve Bank of New York. SR Federal Reserve Bank of New York Research Paper: 9102; Federal Reserve Bank of New York, 33 Liberty St., Rm. 901, New York City, New York 10045. PG 31. PR no charge. JE G21. KW Financial Crisis. Bank Failures. Banking. Commercial Banks.

AB This paper models an economy in which individuals maximize utility using a Bayesian inference rule. The model shows that bank failures are contagious due to the lack of bank-specific information. Depositors, lacking financial information specific to each bank, estimate the return from deposits based on the condition of the banking system as a whole. A high ratio of bank failures signals an adverse condition within the banking sector and a high risk of deposits. Depositors run on banks in general when the expected return from deposits falls below that from currency holding due to a high failure ratio.

\section{Pascal, Anthony}

PD February 1990. TI The Costs and Financing of Care for AIDS Patients: Results of a Cohort Study in Los Angeles. AU Pascal, Anthony; Bennett, Charles L.; Cvitanic, Marilyn; Gorman, Michael; Serrato, Carl. AA Rand Corporation. 
SR Rand Note: N-3060; The Rand Corporation, 1700 Main Street, P.O. Box 2138, Santa Monica, CA 90406-2138. PG 24. PR not available. JE I11, I18. KW Health Care. Medical Costs. Medical Expenditures.

AB The economic burden of the acquired immune deficiency syndrome (AIDS) epidemic and its distribution across payers impose major stresses on individual patients and on the health care system. These have been the subject of much concern; however, no standard methodology has been developed that specifically addresses these issues. This pilot study develops a systematic approach to assigning costs to inpatient and outpatient care for AIDS patients and to estimating shares accounted for by the various payers in the system. It demonstrates that a much broader spectrum of care expenses can be estimated by a combination of patient interviews and collection of data on charges from care providers.

\section{Pasini, Antonio}

TI Bouquets of Matroids and F-Squashed Geometries. AU Deza, Michel; Laurent, Monique; Pasini, Antonio.

\section{Patel, Urjit R.}

TI Debt, Deficits and Inflation: An Application to the Public Finances of India. AU Buiter, Willem H.; Patel, Urjit R.

\section{Pearce, Douglas K.}

TI Firm Characteristics, Unanticipated Inflation, and Stock Returns. AU Roley, V. Vance; Pearce, Douglas K.

\section{Peled, Dan}

TI Competitive Banking with Confidence Crisis and International Borrowing. AU Bental, Benjamin; Eckstein, Zvi; Peled, Dan.

\section{Pencavel, John}

PD January 1990. TI The Contribution of Higher Education to Economic Growth and Productivity: A Review. AA Stanford University. SR Stanford Center for Economic Policy Research Discussion Paper Series: 191; 100 Encina Commons, Stanford University, Stanford CA 94305. PG 48. PR no charge for members of non-profit institutions, $\$ 3.00$ otherwise. JE J24, J22, J31, I21. KW Labor Productivity. Education. Wages. Labor Supply.

AB This paper provides for non-specialists a review of the economics literature on the role of higher education in the efficient allocation of resources. Three areas of empirical research are described. The first concerns the contribution of schooling to economic growth and produclivity as measured both in aggregate data and in microeconomic studies. The second examines the association between schooling and earnings and, in particular, the gap between the earnings of college graduates and those of high school graduates. The third discusses the supply of professional labor and the role of earnings, tuition costs, and other factors in affecting this supply.

\section{Pennacchi, George}

TI Security Baskets and Index-Linked Securities. AU Gorton, Gary; Pennacchi, George.

\section{Perold, Andre F.}

TI Shareholder Trading Practices and Corporate Investment Horizons. AU Froot, Kenneth A; Perold, Andre F.; Stein,
Jeremy C.

\section{Pesenti, Paolo A.}

PD November 1990. TI Perforate and Imperforate Currency Bands: Exchange Rate Management and the Term Structure of Interest Rate Differentials. AA not available. SR Yale Economic Growth Center Discussion Paper: 626; Economic Growth Center, Yale University, Box 1987 Yale Station, New Haven, Connecticut 06520. PG 39. PR $\$ 2.00$ plus postage. JE E42, F31, E43. KW Exchange Rates. Interest Rates. Monetary Regime.

AB This paper provides a simple analytical characterization of an exchange rate regime which is consistent with the main stylized facts of current currency band institutional schemes, namely the reduction of exchange rate volatility the concentration of the exchange rate around its central parity and the coexistence of marginal and intramarginal interventions. For particular policy rules, even an informal (so called perforate) target zone which allows the exchange rate to be above (below) any upper (lower) limit with non zero probability can make the exchange rate less responsive to shocks in fundamentals than a formal band defended by interventions at the boundaries. The implications for the dynamic behavior of interest rates, including a closed form solution for the term structure of interest rate differentials as a function of the current spot exchange rate, are derived and analyzed in detail.

\section{Phillips, G. Michael}

TI An Experimental Study of Comparable Worth. AU Arnault, E. Jane; Gordon, Louis; Joines, Douglas H.; Phillips, G. Michael.

\section{Polinsky, A. Mitchell}

PD November 1989. TI A Note on Optimal Fines When Wealth Varies Among Individuals. AU Polinsky, A. Mitchell; Shavell, Steven. AA Polinsky: Stanford University and National Bureau of Economic Research. Shavell: Harvard University and National Bureau of Economic Research. SR Stanford Center for Economic Policy Research Discussion Paper Series: 184; 100 Encina Commons, Stanford University, Stanford CA 94305. PG 7. PR no charge for members of non-profit institutions, $\$ 3.00$ otherwise. JE K42. KW Fines. Deterrences. Crime. Enforcement. Law.

AB An important result in the economic theory of enforcement is that, under certain circumstances, it is optimal for a fine to be as high as possible -- to equal the entire wealth of individuals. Such a fine allows the probability of detection to be as low as possible, thereby saving enforcement costs. This note shows that when the level of wealth varies among individuals, the optimal fine generally is less than the wealth varies among individuals, the optimal fine generally is less than the wealth of the highest wealth individuals, and may well be less than the wealth of most individuals.

\section{Poljak, Svatopluk}

TI The Cut Cone III: On the Role of Triangle Facets.

AU Deza, Michel; Larent, Monique; Poljak, Svatopluk.

\section{Postlewaite, Andrew}

TI Social Norms and Random Matching Games. AU Okuno-Fujiwara, Masahiro; Postlewaite, Andrew. 


\section{Poterba, James M.}

TI Speculative Dynamics and the Role of Feedback Traders. AU Cutler, David M.; Poterba, James M.; Summers, Lawrence $\mathrm{H}$.

TI Speculative Dynamics. AU Cutler, David M.; Poterba, James M.; Summers, Lawrence H.

TI Are Japanese Stock Prices too High? AU French, Kenneth R.; Poterba, James M.

PD November 1990. TI Is the Gasoline Tax Regressive? AA Massachusetts Institute of Technology and National Bureau of Economic Research. SR Massachusetts Institute of Technology Department of Economics Working Paper: 568; Department of Economics, Massachusetts Institute of Technology, Cambridge, MA 02139. PG 31. PR $\$ 6.00$ Domestic, \$8.00 Overseas, $\$ 2.00$ Student. JE H24, H23, D12, E21. KW Life-Cycle Models. Excise Taxes. Gasoline Demand. Energy Taxes. Oil. Regressive Taxes.

AB Claims of the regressivity of gasoline taxes typically rely on annual surveys of consumer income and expenditures which show that gasoline expenditures are a larger fraction of income for very low income households than for middle or highincome households. This paper argues that annual expenditure provides a more reliable indicator of household well-being than annual income. It uses data from the Consumer Expenditure Survey to re-assess expenditures which high-spending and low-spending households devote to retail gasoline purchases. This altemative approach shows that low-expenditure households devote a smaller share of their budget to gasoline than do their counterparts in the middle of the expenditure distribution.

\section{Potscher, B. M.}

PD September 1990. TI Optional Skipping of Martingale Differences and Related Sequences. AA University of Maryland, College Park. SR University of Maryland Department of Economics Working Paper Series: 90-18; Department of Economics, University of Maryland, College Park, MD 20742. PG 8. PR no charge. JE C13. KW Martingale. Optional Skipping Theorem.

AB We establish relationships between conditional expectations of an optionally skipped sequence and conditional expectations of the original sequence. These results are used to show that (under moment conditions) an optionally skipped martingale difference sequence is again a martingale difference sequence. Doob's (1936) optional skipping theorem for i.i.d. sequences can also be obtained from these results.

\section{Promel, Hans Jurgen}

PD June 1990. TI Excluding Induced Subgraphs II: Extremal Graphs. AU Promel, Hans Jurgen; Steger, Angelika. AA University of Bonn. SR Universitat Bonn Sonderforschungsbereich 303 - Discussion Paper: 90642-OR; Sonderforschungsbereich 303 an der Universitat Bonn, Adenauerallee 24-42, D-5300 Bonn 1, DEUTSCHLAND. PG 13. PR no charge. JE C60. KW Graph Theory. Subgraphs. Extremal Graphs. Random Graphs.

AB In this paper we study properties of the classes of graphs not containing a fixed subgraph $\mathrm{H}$ as an induced subgraph. In particular, we introduce a new parameter tau $(\mathrm{H})$ and show that fundamental results of extremal graph theory for weak subgraphs carry over to induced subgraphs, if one replaces in the corresponding theorems the chromatic number by tau $(\mathrm{H})$.
PD July 1990. TI Excluding Induced Subgraphs III: A General Asymptotic. AU Promel, Hans Jurgen; Steger, Angelika. AA University of Bonn. SR Universitat Bonn Sonderforschungsbereich 303 - Discussion Paper: 90650-OR; Sonderforschungsbereich 303 an der Universitat Bonn, Adenauerallee 24-42, D-5300 Bonn 1, DEUTSCHLAND. PG 20. PR no charge. JE C60. KW Graph Theory. Subgraphs. Hypergraphs.

AB In this paper we study asymptotic properties of the class of graphs not containing a fixed graph $\mathrm{H}$ as an induced subgraph. In particular we show that the number Forb* $(n)$ of such graphs on $n$ vertices is essentially determined by the number of subgraphs of a single graph.

\section{Prucha, Ingmar $\mathbf{R}$.}

PD October 1990. TI Endogenous Capital Utilization and Productivity Measurement in Dynamic Factor Demand Models: Theory and an Application to the U.S. Electrical Machinery Industry. AU Prucha, Ingmar R.; Nadiri, M. Ishaq. AA Prucha: University of Maryland, College Park and National Bureau of Economic Research. Nadiri: New York University and National Bureau of Economic Research. SR University of Maryland Department of Economics Working Paper Series: 90-19; Department of Economics, University of Maryland, College Park, MD 20742. PG 61. PR no charge. JE 024, E23, E27. KW Dynamic Model. Technical Change. Capacity Utilization. Productivity. Factor Demand. Investment.

AB Studies of the firm's demand for factor inputs often assume a constant rate of utilization of the inputs and ignore the fact that the firm can simultaneously choose the level and the rate of utilization of its inputs. In particular, the literature on dynamic factor demand models has, until recently, largely overlooked the issue of capital utilization and/or did not distinguish carefully between the distinct concepts of capital and capacity utilization. In this paper we allow for variations in the rate of capital utilization within the context of a dynamic factor demand model by adopting a modeling framework within which the firm combines its beginning-of-period stocks with other inputs to produce its outputs as well as its end-ofperiod stocks.

\section{Quijano, Alicia M.}

TI Growth in Japanese Lending and Direct Investment in the United States: Are They Related? AU Seth, Rama; Quijano, Alicia M.

\section{Quinzii, Martine}

TI The Non-Neutrality of Money in a Production Economy with Nominal Assets. AU Magill, Michael; Quinzii, Martine.

\section{Quirmbach, Herman C.}

PD August 1989. TI Opportunism, Relationship-Specific Assets, and Contract Length. AA University of Southern California. SR University of Southern California Modelling Research Group Working Paper: M8918; Department of Economics, University of Southem California, University Park, Los Angeles, CA 90089-0152. PG 39. PR no charge. JE L14, D23, C78. KW Vertical Integration. Contracts. Negotiation. Transaction Costs.

AB The level of relationship-specific assets (RSA) in a relationship affects the degree of opportunism in contract renegotiation and the choice of contract length. In many 
circumstances, higher RSA may actually lead to less opportunism in renewing short-term contracts. Thus, while short-term contracts are preferable for very low RSA and longterm contracts tend to be preferable for very high RSA, higher levels of RSA need not favor long-term contracts "monotonically." These results also help in analyzing contracts with nonrenewal penalties. I show that such contracts reduce opportunism only if there are transaction costs associated with collecting the penalty.

\section{Radecki, Lawrence J.}

PD November 1990. TI A Survey of the Origins and Purposes of Deposit Protection Programs. AA Federal Reserve Bank of New York. SR Federal Reserve Bank of New York Research Paper: 9034; Federal Reserve Bank of New York, 33 Liberty St., Rm. 901, New York City, New York 10045. PG 73. PR no charge. JE G28, G21. KW Deposit Insurance. Banking. Commercial Banks.

AB This paper conducts a selective survey of deposit guarantee programs. First, the establishment of programs guaranteeing bank accounts in several countries are reviewed and put into a historical context. Deposit protection programs have become common only during the past 15 years. Second, the intended purposes of a deposit protection program are analyzed. The usefulness of a protection program and its role in the safety net for the banking system becomes clearer when it is recognized that the reorganization of a failing bank is preferred to ceasing its operations, and that a deposit insurance fund may provide the resources needed to expedite an assisted merger or a recapitalization. Third, a deposit protection program, while intended primarily to maintain order and safety, has secondary effects on the banking sector. These subsidiary and sometimes subtle effects are specified and examined.

\section{Radicke, Ulf-Dietmar}

PD August 1990. TI The Complexity of Multi-Spindle Drilling Problems. AA University of Cologne. SR Universitat Bonn Sonderforschungsbereich 303 . Discussion Paper: 90.89; Sonderforschungsbereich 303 an der Universitat Bonn, Adenauerallee 24-42, D-5300 Bonn 1, DEUTSCHLAND. PG 10 . PR no charge. JE C44, C60. KW NP-Completeness. Set Covering. Circuit Boards.

AB To save time drilling the holes of printed circuit boards, multi-spindle machines were introduced. They are equipped with up to 7 spindles in a row and may drill several holes in one "lift". The distances between these spindles can be changed to reduce the number of "lifts" needed, but this change is costly. So two problems arise: Finding a good distance pattern to drill a certain set of printed circuit boards with the minimal number of "lifts" and, apparently the easier problem, how to drill with the minimal number of "lifts" once the distance pattem has been installed. We show that both problems are NP-complete for 3 spindles or more.

\section{Rahman, Shafigur}

TI A Cross-Sectional Analysis of Mutual Funds' Market Timing and Security Selection Skill. AU Chan, Anthony; Chen, Carl R.; Lee, Cheng F.; Rahman, Shafigur.

\section{Rappoport, Peter}

TI Money Versus Credit Rationing: Evidence for the National Banking Era, 1880-1914. AU Bordo, Michael D.; Rappoport, Peter, Schwartz, Anna J.

\section{Razin, Assaf}

TI Income Distribution and Efficiency: The Role of Social Security. AU Nerlove, Marc; Razin, Assaf; Sadka, Efraim; von Weizsacker, Robert K.

TI Tax Policy, Investments in Human and Physical Capital, and Productivity. AU Nerlove, Marc; Razin, Assaf; Sadka, Efraim; von Weizsacker, Robert K.

\section{Rey, Patrick \\ TI Noisy Observation in Adverse Selection Models. AU Caillaud, Bernard; Guesnerie, Roger; Rey, Patrick.}

\section{Ricardo-Campbell, Rita}

PD February 1991. TI Business, Health Care Costs and Competition. AA Stanford University. SR Stanford Hoover Institute Working Paper in Economics: E-91-6; Domestic Studies Program Working Paper Series, Hoover Institution, Stanford University, Stanford, CA 94305. PG 38. PR not available. JE I11, I18, I31. KW Health Care. Medical Costs. Medical Insurance.

AB The United States has had a public/private system of financing and delivering health care since 1965. Today, government pays about $30 \%$; business, $28 \%$; individuals, $41.5 \%$ and charity less than $1 \%$. Physicians are increasing their prices ahead of the change in their Medicare reimbursement, legislated for 1992. U.S. business has not really tested whether requiring today's much better informed employee/consumer to pay more out-of-pocket would have restrained the health care cost increases over the last two decades. It would be ironic if the continuing surge in costs of our medical care and increasing numbers without health insurance coverage now drive the United States to adopt a national health insurance when East European socialist countries are seeking ways to reduce government in economic activity and the U.K. is trying to introduce competitive markets within the British National Health Service.

\section{Richter, Rudolf}

PD February 1991. TI A Socialist Market Economy - Can It Work? AA University of Saarbracken Germany and the Hoover Institution. SR Stanford Hoover Institute Working Paper in Economics: E-91-4; Domestic Studies Program Working Paper Series, Hoover Institution, Stanford University, Stanford, CA 94305. PG 32. PR not available. JE P21, P27. KW Socialism. Planning. Socialist Economy. AB We review the debate on whether a socialist economy can function. We evaluate the von Mises-Lange debate in light of recent theory and discuss newly proposed socialist mechanisms.

\section{Riddell, W. Craig}

TI Provincial Public Sector Payrolls. AU Gunderson, Morley; Riddell, W. Craig.

\section{Rieder, J.}

TI A Note on the Lattice of 2-Matroid-Intersections. AU Hochstattler, Winfried; Rieder, J.

\section{Rizzo, John A.}

PD November 1989. TI Advertising and the Price, Quantity and Quality of Primary Care Physician Services. AU Rizzo, John A.; Zeckhauser, Richard J. AA Harvard 
University. SR Harvard John F. Kennedy School of Government Discussion Paper: 180D; J.F.K. School of Government, 79 J.F.K. Street, Cambridge, MA 02138. PG 46. PR no charge. JE M37, I11. KW Advertising. Physician. Health Economics. Medical Care. AB Physician advertising has increased dramatically during the past decade, and available evidence suggests that this trend will continue. This paper examines the impact of such advertising on the price, quantity, and quality of physician services. Unlike earlier research on the effects of advertising in the professions, our study attempts to control for possible selection effects. The results indicate that, while advertising and quality (the latter measured as time spent per patient office visit) appear to be complements, advertising does not lower price (perhaps because physician ads typically do not mention fees) or raise patient volume. Had we not controlled for selection effects, the relationships between advertising and the outcomes of interest would appear to be much stronger. Overall, the effects of physician advertising appear to have been modest.

\section{Rob, Rafael}

TI Learning, Mutation, and Long Run Equilibria in Games. AU Kandori, Michihiro; Mailath, George J.; Rob, Rafael.

\section{Robinson, Dennis $\mathbf{P}$.}

TI Spatial Autocorrelation: A New Computationally Simple Test with an Application to Per Capita County Police Expenditures. AU Kelejian, Harry H.; Robinson, Dennis P.

\section{Rogerson, Richard}

TI Risk Sharing, Indivisible Labor and Aggregate Fluctuations. AU Cho, Jang-Ok; Rogerson, Richard.

\section{Roley, V. Vance}

PD April 1988. TI Firm Characteristics, Unanticipated Inflation, and Stock Returns. AU Roley, V. Vance; Pearce, Douglas K. AA Roley: Federal Reserve Bank of Kansas City and University of Washington. Pearce: North Carolina State University. SR Federal Reserve Bank of Kansas City Research Working Paper: 88-01; Research Division, Federal Reserve Bank of Kansas City, 925 Grand Ave., Kansas City, MO 64198. PG 25. PR no charge. JE E31, E32, G13, G14. KW Inflation. Stock Market. Stock Prices.

AB This paper re-examines the effects of nominal contracts on the relationship between unanticipated inflation and an individual stock's rate of return. This study differs in three main ways from previous research. First, announced inflation data are used to examine the effects of unanticipated inflation. Second, a different specification is used to obtain more efficient estimates. Third, additional nominal contracts are considered. The empirical results indicate that time-varying firm characteristics related to inflation predominately determine the effect of unanticipated inflation on a stock's rate of return. A firm's debt-equity ratio appears to be particularly important in determining the response.

TI Federal Reserve Behavior Since 1980: A Financial Markets Perspective. AU Melton, William C.; Roley, V. Vance.

TI Intraday Yen/Dollar Exchange Rate Movements: News or Noise? AU Ito, Takatoshi; Roley, V. Vance.
TI Stock Prices, News, and Business Conditions. AU McQueen, Grant; Roley, V. Vance.

\section{Romer, David}

TI A Contribution to the Empirics of Economic Growth. AU Mankiw, N. Gregory; Romer, David; Weil, David N.

\section{Rosenberg, Norman J.}

PD March 1989. TI Policy Options for Adaptation to Climate Change. AU Rosenberg. Norman J.; Crosson, Pierre; Easterling, William E., III; Frederick, Kenneth; Sedjo, Roger. AA Resources for the Future. SR Resources for the Future Energy and Natural Resources Division Discussion Paper: ENR89-05; Energy and Natural Resources Division, Resources for the Future, 1616 P Street, NW., Washington, DC 20036, USA. PG 45. PR $\$ 5.00$ prepaid (U.S. funds only). JE Q28, Q20. KW Climate Change. Natural Resources. Greenhouse Effect.

AB As part of a report to the Governing Board of UNOP, the Climate Resources Program of Resources for the Future undertook to review a wide range of policy options for their potential to ease adjustment and adaptation of natural resource industries to climate change of the kinds anticipated to follow greenhouse warming in the coming decades.

\section{Rothschild, Michael}

PD August 1990. TI Economic Theory Teaches Us That Economic Theory Teaches Us Nothing: The Case of Asset Prices. AA University of California, San Diego and National Bureau of Economic Research. SR Universitat Bonn Sonderforschungsbereich 303 - Discussion Paper: A-316; Sonderforschungsbereich 303 an der Universitat Bonn, Adenauerallee 24-42, D-5300 Bonn 1, DEUTSCHLAND. PG 9. PR no charge. JE G12, D11, D81. KW Asset Prices. Asset Market. Finance Theory.

AB The purpose of this note is to put in the public domain, a result which is so simple and obvious that "everyone knows it," but which some find surprising and interesting when it is presented to them. The question we address is the following: "What restrictions does economic theory (the assumption that rational agents maximize) place on asset prices?" The answer we give: "almost none," is similar to the one which Sonnenschein (1973) gave when he asked the same question about (excess) demand functions.

\section{Rothwell, Gèoffrey S.}

PD February 1990. TI Utilization and Service: Decomposing Nuclear Reactor Capacity Factors. AA Stanford University. SR Stanford Center for Economic Policy Research Discussion Paper Series: 187; 100 Encina Commons, Stanford University, Stanford CA 94305. PG 17. PR no charge for members of non-profit institutions, $\$ 3.00$ otherwise. JE L94, Q41, Q42. KW Nuclear Power. Productivity. Electricity.

AB Statistical analyses of electricity generation productivity have focused on the capacity factor, i.e., the ratio of realized to potential output. Here, the capacity factor is decomposed into the capacity utilization rate (output when the reactor is operating) and the service factor (the percent of operating time). Elasticities of capacity factor, utilization rate, service factor, and the forced outage rate with respect to reactor size and age are estimated for fuel cycles of four reactor manufacturers, controlling for changes in the industry after the 
accident at Three Mile Island in 1979. While the service factor decreases with size for all reactor makes, the increase in the capacity utilization rate yields a positive relationship between size and the capacity factor for boiling water reactors. Age has no consistent influence. Only Babcock \& Wilcox (the manufacturer of TMI) reactors experienced a significant decrease in productivity after 1979.

TI Subsidy to the Commercial Nuclear Power Industry Through the Price-Anderson Liability Limit. AU Dubin, Jeffrey A.; Rothwell, Geoffrey S.

PD April 1990. TI Coal-Electric Scale Economies and Construction Lead Times. AA Stanford University. SR Stanford Center for Economic Policy Research Discussion Paper Series: 198; 100 Encina Commons, Stanford University, Stanford, CA 94305. PG 34. PR no charge for members of non-profit institutions, $\$ 3.00$ otherwise. JE L94, L11. KW Scale Economies. Electricity. Coal. Utilities.

AB Empirical studies of coal-fired power plant construction costs have found positive economies of scale. However these studies did not consider the relationships among cost, plant size, and the length of the building period; nor did they examine changes in scale economics over the range of plant size. This paper derives an econometric model based on the electric utility's attempt to maximize the present value of a power plant. A translog cost function and a non-linear lead time equation are simultaneously estimated. Specification tests show that because larger plants take longer to build, scale economies are reduced by one-third from previous estimates. Also, the minimum average cost is found to be between $550-700$ megawatts of generating capacity.

TI The Stability of Beta for Nuclear Electric Utilities, 1976-1986: A Note. AU Lipschultz, Marc; Maggioncalda, Jeff, Rothwell, Geoffrey S.

\section{Roubini, Nouriel}

TI Financial Intermediation and Monetary Policies in the World Economy. AU Grilli, Vittorio U.; Roubini, Nouriel.

\section{Rubinstein, Ariel}

PD June 1990. TI Renegotiation-Proof Implementation and Time Preferences. AU Rubinstein, Ariel; Wolinsky, Asher. AA Rubinstein: Tel Aviv University. Wolinsky: Northwestern University. SR Tel Aviv Foerder Institute for Economic Research Working Paper: 14-90; Department of Economics, Tel Aviv University, Ramat Aviv 69978, Tel Aviv, ISRAEL. PG 38. PR no charge. JE C78, D74. KW Contracts. Extensive Games. Time Preferences.

AB This paper explores how the requirement that the implementation of contracts be renegotiation proof affects the set of contracts which can be implemented in a seller-buyer scenario in which the information regarding the agent's valuations is non-verifiable. This paper explicitly adds a time dimension to an implementation problem, and introduces a natural criterion of renegotiation proofness for the case of time consuming renegotiation. Consequently, the results regarding the set of implementable contracts are different from those in the related literature.

PD September 1990. TI On the Interpretation of the Nash Bargaining Solution and its Extension to Non-Expected Utility Preferences. AU Rubinstein, Ariel; Safra, Zvi; Thomson, William. AA Rubinstein and Safra: Tel Aviv University.
Thomson: Rochester University, SR Tel Aviv Foerder Institute for Economic Research Working Paper: 24-90; Department of Economics, Tel Aviv University, Ramat Aviv 69978. Tel Aviv, ISRAEL. PG 25. PR no charge. JE C78. KW Nash Bargaining. Bargaining. Non-Expected Utility. Utility Theory.

AB The paper reexamines the foundations of the axiomatic Nash bargaining theory. More specifically it questions the interpretation of the Nash bargaining solution and extends it to a family of non-expected utility preferences.

PD May 1991. TI Rationalizable Conjectural Equilibria: Between Nash and Rationalizability. AU Rubinstein, Ariel; Wolinsky, Asher. AA Rubinstein: Tel Aviv University. Wolinsky: Northwestern University. SR Northwestern Center for Mathematical Studies in Economics and Management Science Working Paper: 933; Northwestern University, 2001 Sheridan Road, 3-014 Leverone Hall, Evanston, IL 60208-2014. PG not available. PR $\$ 3.00$ in the U.S. or Canada; $\$ 5.00$ via international mail. Make check payable to Northwestern University. JE C72. KW Rationalizability. Conjectures. Noncooperative Games. Nash Equilibrium. Common Knowledge.

AB For a steady state to be a Nash equilibrium the agents have to perfectly observe the actions of others. This paper suggests a solution concept for cases where players observe only an imperfect signal of what the others' actions are. The model is enriched by specifying the signal that each player has about the actions taken by the others. The solution, which we call rationalizable conjectural equilibrium (RCE), is a profile of actions such that each player's action is optimal, given the assumption that it is common knowledge that all players maximize their expected utility given their knowledge. The RCE occupies an intermediary position between Nash equilibrium on the one hand and Rationalizability style Bernheim-Pearce on the other hand. The concept is demonstrated by several examples in which it refines the rationalizability concept and still is not equivalent to Nash equilibrium.

\section{Rudin, Jeremy R.}

PD January 1990. TI Out-of-Sample Evidence on the Persistence of Innovations in Real Output. AA University of British Columbia. SR University of British Columbia Department of Economics Discussion Paper: 90-02; University of British Columbia, \#997-1873 East Mall, Vancouver, BC V6T IW5, CANADA. PG not available. PR $\$ .20$ per page Canadian to other than educational institutions. JE E23, E32, E37. KW Forecasting. Output. Random Walk.

AB There is no consensus about which, of many, suggested univariate models for real output is "correct". This suggests that no single model is most appropriate in every circumstance, that is, that no model encompasses all others. In this situation. useful tests of competing models will be those designed to identify which model is most suitable for each particular purpose. This paper presents and implements such a test: a long-horizon forecast encompassing (or forecast pooling) test. Using U.S. and Canadian data, the hypothesis that the (logarithmic) random walk with drift model produces the most accurate long horizon forecasts of real output cannot be rejected.

\section{Rush, Mark}

TI Marginal Income Tax Rates and Real Economic Growth. 


\section{AU Hakkio, Craig S.; Rush, Mark.}

\section{Rustichini, Aldo}

TI Social Conflict, Growth and Income Distribution. AU Benhabib, Jess; Rustichini, Aldo.

\section{Ruys, Pieter H. M.}

PD January 1990. TI Signaling Devices for the Supply of Semi-Public Goods. AU Ruys, Pieter H. M.; van der Laan, Gerard; Talman, Dolf J. J. AA Ruys and Talman: Tilburg University. van der Laan: Free University, Amsterdam. SR Universitat Bonn Sonderforschungsbereich 303 Discussion Paper: A-326; Sonderforschungsbereich 303 an der Universitat Bonn, Adenauerallee 24-42, D-5300 Bonn 1, DEUTSCHLAND. PG 18. PR no charge. JE H41, D62, D43, D21. KW Public Goods. Consumption. Price Discrimination. Central Planner.

AB This paper deals with the concept of a semi-public good. These semi-public goods are characterized by the fact that their use is being supplemented by specific private goods. The consumption of this complementary private good is constrained by an individual quantity constraint for each individual agent. The quantity constraints depend on the level of the semi-public good. For instance, car driving is limited by the level of the road system. This approach allows us to design economic institutions which carry out price discrimination among users of a semi-public good. People who are seriously hampered by too small a provision of a public good, because it constrains their use of the private commodity, are willing to pay a mark-up on the price for the latter one if this mark-up is spent for expanding the provision of the public good.

\section{Ryding, John}

PD May 1990. TI Housing Finance and the Transmission Mechanism of Monetary Policy. AA Federal Reserve Bank of New York. SR Federal Reserve Bank of New York Research Paper: 9008; Federal Reserve Bank of New York, 33 Liberty St., Rm. 901, New York City, New York 10045. PG 43. PR no charge. JE R21, E44, G21. KW Monetary Policy. Mortgages. Housing Market.

AB This paper evaluates the impact of changes in housing finance on the effect of monetary policy on residential investment. Surveying developments, the paper discusses the consequences of financial innovations like deposit rate deregulation, the growth of mortgages backed securities, adjustable rate mortgages, and increased competition among lenders. A theoretical model of the housing loan market is developed that implies that deposit rate deregulation is likely to have reduced the impact of monetary policy changes on housing investment.

\section{Sacher, Seth B.}

PD January 1991. TI Housing Demand and Property Tax Incidence in a Life-Cycle Framework. AA Federal Trade Commission. SR Federal Trade Commission Bureau of Economics Working Paper: 184; Bureau of Economics, Federal Trade Commission, 6th and Pennsylvania Ave. NW, Washington, D.C. 20580. PG 25. PR no charge. JE H71, R21, D12. KW Housing Demand. Taxes. Property Tax. Consumer Economics.

AB Studies of tax incidence usually present estimates based on annual data and then simply note that estimates based on lifetime information would be preferable, but are precluded by data limitations. This paper presents estimates of property tax incidence in both an annual and life cycle framework. If full forward shifting is assumed, the property tax appears much less regressive in a lifetime sense than an annual one. If less than full forward shifting is assumed, the property tax appears to be a flat tax in lifetime terms, which is quite distinct from the annual results.

\section{Sadka, Efraim}

TI Income Distribution and Efficiency: The Role of Social Security. AU Nerlove, Marc; Razin, Assaf; Sadka, Efraim; von Weizsacker, Robert K.

TI Tax Policy, Investments in Human and Physical Capital, and Productivity. AU Nerlove, Marc; Razin, Assaf; Sadka, Efraim; von Weizsacker, Robert K.

\section{Safra, Zvi}

TI On the Interpretation of the Nash Bargaining Solution and its Extension to Non-Expected Utility Preferences. AU Rubinstein, Ariel; Safra, Zvi; Thomson, William.

TI Delayed Agreements and Non-Expected Utility. AU Fershtman, Chaim; Safra, Zvi; Vincent, Daniel.

PD November 1990. TI Bargaining Solutions without the Expected Utility Hypothesis. AU Safra, Zvi; Zilcha, Itzhak. AA Tel Aviv University. SR Tel Aviv Foerder Institute for Economic Research Working Paper: 33-90; Department of Economics, Tel Aviv University, Ramat Aviv 69978, Tel Aviv, ISRAEL. PG 28. PR no charge. JE C78, D10, D81. KW Nash Equilibrium. Utility Theory. Bargaining. NonExpected Utility.

AB In this paper we first study the possible extensions of the Nash bargaining solution to the case where decision makers are not necessarily expected utility (EU) maximizers. We suggest two different approaches to the issue and it is shown that the two extensions coincide when the preferences are of the EU and the rank dependent utility types. The extensions differ in the case of weighted utility preferences. We also show that the first extension is applicable 10 the Kalai-Smorodinski (KS) solution while the second is not. In the second part of the paper we investigate the sensitivity of the extensions to changes in the degree of risk aversion of one of the bargainers. It is shown that, when the first extension is considered, the existing results crucially depend on the assumption that the bargainers are of the EU type. For more general preferences there is no relation between the Nash (and the KS) solution and the degree of risk aversion.

\section{Sah, Raaj K.}

PD December 1989. TI An Explicit Closed-Forum Formula for Profit Maximizing k-out-of-n Systems to Two Kinds of Failures. AA Yale University. SR Yale Economic Growth Center Discussion Paper: 623; Economic Growth Center, Yale University, 27 Hillhouse Avenue, New Haven, CT 06520. PG 11. PR $\$ 2.00$ + Postage. JE C61. KW Profit. Optimization.

AB This paper derives and analyzes an explicit closed-form formula for the optimal $k$ in $k$-out-of-n systems consisting of i.i.d. components. The system can be in one of two possible modes with a pre-specified probability. The components are subject to failure in each of the two modes. The costs of the two kinds of system failures are generally not identical. Since the formula is explicit, it permits a calculation of the optimal $k$ 
directly in terms of the parameters of the system. In addition, it yields many results concerning both the bounds of the optimal $k$ and the effects of a change in parameters on the optimal $k$ and on the optimized value of the system's expected profit.

PD April 1990. TI The Quality of Mangers in Centralized Versus Decentralized Organizations. AU Sah, Raaj K.; Stiglitz, Joseph E. AA Sah: Yale University. Stiglitz: Stanford University. SR Yale Economic Growth Center Discussion Paper: 624; Economic Growth Center, Yale University, Box 1987 Yale Station, New Haven, Connecticut 06520. PG 9. PR $\$ 2.00$ plus postage. JE M12, M21. KW Management. Managers. Promotion.

AB This paper examines the dynamic consequences of a greater centralization or decentralization of the decisionmaking authority to appoint successor managers on the quality of managers actually appointed. Our main result is that a greater centralization results in a greater variability over time in the quality of managers. An intuitive reason for this is that though a highly capable manager may have large beneficial effects on the managerial choices within a centralized system, because this manager has greater authority in such a system, a highly incapable manager placed in the same position has correspondingly large deleterious effects.

PD February 1991. TI Fallibility in Human Organization and Political Systems. AA Yale University. SR Yale Economic Growth Center Discussion Paper: 625; Economic Growth Center, Yale University, 27 Hillhouse Avenue, New Haven, CT 06520. PG 29. PR \$2.00 + Postage. JE D81, M12, D72, D71. KW Decision Theory. Committees. Mangement.

AB This paper presents a perspective on some of the organizational and economic consequences of the fallibility in human judgments and decisions. The effects of fallibility are explored in several different contexts. For instance, the paper shows that a diversification of political authority in the hands of many individuals has some desirable consequences, previously not adequately identified, vis a vis its concentration in the hands of a few. It examines the consequences of fallibility in choosing the successors to the current set of managers in organizations, and how these consequences might differ between centralized and decentralized organizations. It illustrates some trade-offs that arise from individuals' fallibility in the choice of projects and ideas within settings such as committees, hierarchies and polyarchies. It compares the performances of hierarchies and polyarchies, focusing on how they might accept or reject innovation-oriented projects, such as R\&D investments, and ideas for new products and technologies.

Saks, M. E.

TI Sharpening the Lym Inequality. AU Erdos, Peter L.; Frankl, P.; Kleitman, D. J.; Saks, M. E.; Szekely, L. A.

\section{Sala-i-Martin, Xavier}

PD December 1990. TI Lecture Notes on Economic Growth (II): Five Prototype Models of Endogenous Growth. AA Yale University. SR Yale Economic Growth Center Discussion Paper: 622; Economic Growth Center, Yale University, Box 1987 Yale Station, New Haven, Connecticut 06520. PG 47. PR $\$ 2.00$ plus postage. JE O41, E13. KW Economic Growth. Externality. Endogenous Growth. Returns to Scale. Growth Model.
AB This paper explores the five simplest models of endogenous growth. We start with the AK model (Rebelo (1990)) and argue that all endogenous growth models can be viewed as variations or microfoundations of it. We then examine the Barro (1990) model of government spending and growth. Next we look at the Arrow-Sheshinski-Romer model of learning by doing and externalities. The Lucas (1988) model of human capital accumulation is then considered. Finally, we present a simple model of R\&D and growth.

PD December 1990. TI Lecture Notes on Economic Growth (I): Introduction to the Literature and Neoclassical Models. AA Yale University. SR Yale Economic Growth Center Discussion Paper: 621; Economic Growth Center, Yale University, Box 1987 Yale Station, New Haven, Connecticut 06520. PG 44. PR $\$ 2.00$ plus postage. JE O41, E13. KW Economic Growth. Externalities. Endogenous Growth. Returns to Scale. Growth Model.

AB This is a survey of the literature on Economic Growth. In the introduction we analyze the main differences between exogenous and endogenous growth models using fixed savings rate analysis. We argue that in order to have endogenous growth there must be constant returns to the factors that can be accumulated. A graphical tool is then developed to show that changes in the savings rate have different effects on long-run growth in the two kinds of models. We show that only endogenous growth models are affected by shifts in the savings rate. We then explore two versions of the Ramsey-CassKoopmans neoclassical model where savings are determined optimally: one with exogenous productivity growth and one without.

\section{Salvas-Bronsard, L.}

TI From a Hicks-Grandmont Temporary Equilibrium to a Rational Expectation Equilibrium and Conversely. AU Bronsard, C.; Salvas-Bronsard, L.; Trognon, A.

TI The Producer and the Real Balance Effect. AU Bronsard, C.; Ouellette, P.; Salvas-Bronsard, L.

\section{Samet, Dov}

TI Absorbent Stable Sets. AU Gilboa, Itzhak; Samet, Dov.

\section{Santiago, Carlos E.}

PD July 1989. TI Family Composition and Wage Employment in Small-Scale Economic Activities in Malawi. AA Yale University. SR Yale Economic Growth Center Discussion Paper: 578: Economic Growth Center, Yale University, 27 Hillhouse Avenue, New Haven, CT 06520. PG 44. PR $\$ 2.00$ + Postage. JE 015, 011, 017. KW Developing Countries. Labor Force. Employment.

AB Despite rapid growth of formal sector employment, LDCs are often hard pressed to absorb their growing labor force. This paper finds that the small-scale non-farm sector can contribute significantly to employment generation. Moreover, because of the nature of non-farm household production, the disemployment effects of wage hikes are smaller than in the more conventional enterprise. The implication is that a smallscale non-farm focused development strategy can provide employment at above subsistence wages. These results are substantiated by the experience of Malawi. 


\section{Sappington, David E. M.}

TI Resolving Double Moral Hazard Problems with Buyout Agreements. AU Demski, Joel S.; Sappington, David E. M.

TI Selecting an Agent's Ability. AU Lewis, Tracy R.; Sappington, David E. M.

TI Conservation and Incentive Regulation. AU Lewis, Tracy R.; Sappington, David E. M.

\section{Sarris, Alexander $\mathbf{H}$.}

PD January 1990. TI Rigidities and Macroeconomic Adjustment Under Market Opening: Greece and 1992. AA University of Athens. SR Centre for Economic Policy Research Discussion Paper: 364; Centre for Economic Policy Research, 6 Duke of York Street, London SW1Y 6LA, UNITED KINGDOM. PG 42. PR 2.00 pounds (\$4.00). JE O52, F15, F36, F41. KW Greece. Capital Mobility. Economic Integration.

AB The completion of the European Market envisaged after 1991 will change rapidly the external conditions faced by the Greek economy through liberalization of the current and capital accounts. It is not expected, however, to alter as fast the duality inherent in Greek productive structure between a large scale fixed price sector and a small scale flexible price sector, or the behavior of the State vis-a-vis financing of its deficit through crowding out the private sector. The theoretical model developed integrates real and financial adjustment behavior of the Greek economy under the assumptions that the overall level of investment is determined by available savings, and that the economy operates with excess capacity and unemployment. The model is shown to reproduce recent patterns of development in Greece. The developments envisaged after 1992 are shown to imply in the short-run a real exchange rate depreciation and an indeterminate GDP change.

\section{Satchell, Stephen E.}

PD July 1990. TI Futures, Forward and Option Prices in a No-Arbitrage Economy. AU Satchell, Stephen E.; Stapleton, Richard C.; Subrahmanyam, Marti G. AA Satchell: Trinity College, Cambridge. Stapleton: University of Lancaster. Subrahmanyam: New York University. SR New York University Salomon Brothers Center Working Paper: S-90-24; Salomon Brothers Center for the Study of Financial Institutions, Graduate School of Business Administration, New York University, 90 Trinity Place, New York, NY 10006. PG 30. PR \$5.00. JE G12, G13. KW Futures Market. Interest Rates. Asset Pricing. Arbitrage.

AB The difference between a futures contract and a forward contract has been analyzed in some detail by Cox, Ingersoll, and Ross (1981) (CIR), Richard and Sundaresen (1981), and Jarrow and Oldfield (1981). When interest rates are stochastic, the futures price of an asset may differ significantly from its forward price. In this paper we assume a no-arbitrage economy and extend the CIR characterization of futures and forward prices. First, we show that the futures price follows a martingale with respect to an equivalent martingale measure as it does in the non-stochastic interest rate economy of Harrison and Kreps (1979) and Ross (1989). The second part of the paper applies a similar methodology to evaluate the futures price and the forward price of a European style contingent claim.

\section{Scharfstein, David}

TI A Theory of Workouts and the Effects of Reorganization
Law. AU Gertner, Robert; Scharfstein, David.

\section{Schmeidler, David}

TI A More Robust Definition of Subjective Probability. AU Machina, Mark J.; Schmeidler, David.

TI A Neo2 Bayesian Foundation of the Maxmin Value for Two-Person Zero-Sum Games. AU Hart, Sergiu; Modica, Salvatore; Schmeidler, David.

TI Atemporal Dynamic Consistency and Expected Utility Theory. AU Kami, Edi; Schmeidler, David.

\section{Schmidt, Roland}

PD September 1990. TI Graphical Interpretation of Price Indices and the Impact of Rebasings on Measured Inflation. AA University of Bonn. SR Universitat Bonn Sonderforschungsbereich 303 - Discussion Paper: B-162; Sonderforschungsbereich 303 an der Universitat Bonn, Adenauerallee 24-42, D-5300 Bonn 1, DEUTSCHLAND. PG 14. PR no charge. JE E31, C81, C43. KW Inflation. Price Index. Cost of Living.

AB We show a graphical depiction of the Laspeyres, Paasche, Fisher and the two "True Cost of Living" indices and explain within the Figures why rebasing the Laspeyres index does not necessarily lead to less measured inflation.

PD September 1990. TI Inflation Expectations if the Target Rate of the Central Bank is Uncertain. AA University of Bonn. SR Universitat Bonn Sonderforschungsbereich 303 - Discussion Paper: B-161; Sonderforschungsbereich 303 an der Universitat Bonn, Adenauerallee 24-42, D-5300 Bonn 1, DEUTSCHLAND. PG 34. PR no charge. JE E31, E42, E52, E58. KW Inflation. Central Bank. Monetary Policy. Expectations.

AB This paper shows how inflation expectations have to be formed if the monetary regime shifts with some probability. The inflation target of the central bank is described by a Markov process and individuals use actual inflation rates to conjecture about the target rates. As it turns out, expectations follow a distributed lag model. In the empirical part this expectation model is estimated within the Fisher equation and the theoretical restrictions are tested. We find that the inflation volatility was not caused by target rate shifts of the Deutsche Bundesbank but mainly by control errors and other nonsystematic disturbances. The high autocorrelation of inflation rates has to be attributed to a steady monetary policy and is not due to price stickiness.

\section{Schrader, Rainer}

TI A Greedy Pre-Processing Algorithm for Setup Optimization. AU Faigle, Ulrich; Schrader, Rainer.

\section{Schuh, Scott}

TI Published Versus Sample Statistics from the ASM; Implications for the LRD. AU Davis, Steve J.; Haltiwanger, John; Schuh, Scott.

TI Published Versus Sample Statistics from the ASM: Implications for the LRD. AU Davis, Steve J.; Haltiwanger, John; Schuh, Scott.

Schultz, T. Paul

PD October 1990. TI Assessing Family Planning Cost Effectiveness: Applicability of Individual Demand-Program 
Supply Framework. AA Yale University. SR Yale Economic Growth Center Discussion Paper: 615; Economic Growth Center, Yale University, Box 1987 Yale Station, New Haven, Connecticut 06520. PG 33. PR $\$ 2.00$ plus postage. JE J13, J18. KW Fertility. Family Planning.

AB This paper considers the distinction between two sets of factors that affect fertility -- community supply of family planning services, and constraints on parent demand for births -- and assesses how it guides the empirical design of evaluation of family planning programs. Evaluating the effect of program activities on fertility requires that certain determinants of parent demand for births be held constant. Increases in supply are associated with reductions in "cost" of birth control. The supply-demand framework can clarify the segments of the population for which the program is likely to be more or less cost-effective, and how the effectiveness of various program activities may change with the scale of the program and interact with other program elements and population characteristics. Evidence from Thailand demonstrates that family planning expenditures are subject to diminishing returns and that marginal returns differ across elements of the program and segments of the population. To improve the efficiency and equity of family planning programs, policy-makers need estimates of the cost-effectiveness of family planning programs at the "margin" of various "mixes" of program activities, within distinguishable segments of the reproductive-aged population.

\section{Schwartz, Anna J.}

TI Money Versus Credit Rationing: Evidence for the National Banking Era, 1880-1914. AU Bordo, Michael D.; Rappoport, Peter, Schwartz, Anna J.

\section{Schwarzler, Werner}

PD December 1989. TI A Generalized Cut-Condition for Multiflows in Matroids. AU Schwarzler, Werner; Sebo, Andras. AA Schwarzler: University of Bonn. Sebo: Universite Fourier Grenoble 1. SR Universitat Bonn Sonderforschungsbereich 303 - Discussion Paper: 89619-OR; Sonderforschungsbereich 303 an der Universitat Bonn, Adenauerallee 24-42, D-5300 Bonn 1, DEUTSCHLAND. PG 16. PR no charge. JE C60, C62. KW Binary Matroids. Multiflows.

AB The class of binary matroids for which the so called "cul-condition" is not only necessary but also sufficient for the existence of a multiflow was characterized by P. Seymour. We formulate a natural generalization of the cut-condition and give a characterization of the corresponding larger class of matroids in terms of forbidden minors.

\section{Schweizer, Urs}

PD September 1990. TI Liberty of Contract Versus Coercion through Rules. AA University of Bonn. SR Universitat Bonn Sonderforschungsbereich 303 Discussion Paper: A-313; Sonderforschungsbereich 303 an der Universitat Bonn, Adenauerallee 24-42, D-5300 Bonn 1, DEUTSCHLAND. PG 27. PR no charge. JE D74, D75, D62. KW Externalities. Market Failure. Social Choice.

AB External effects are traditionally claimed to give rise to a discrepancy between private and social benefits which, in turn, prevents the involved parties from achieving a first best solution. The government is then called to provide the proper remedies. The traditional argument does not stand firm under scrutiny as it relies on noncooperative behavior of, in essence, the Prisoners' Dilemma type without however giving much thought to the implicit assumption of the paradigm which has parties sitting in separate cells. The paradigm need not fit. Moreover, even if it does, the government may face similar difficulties in penetrating the walls while administering the corrective measure. The present paper advocates the view to specify the assumption of the paradigm in contractual terms. The approach allows us to explore the trade-off between market and policy failure in a framework which is well balanced in that it has all institutional arrangements operating in the same environment as far as the setting of the transaction costs is concerned.

\section{Sebo, Andras \\ TI A Generalized Cut-Condition for Multiflows in Matroids. AU Schwarzler, Werner; Sebo, Andras.}

\section{Seike, Atsushi}

PD June 1989. TI The Effect of the Employee Pension on the Labor Supply of the Japanese Elderly. AA Rand Corporation. SR Rand Note: N-2862; The Rand Corporation, 1700 Main Street, P.O. Box 2138, Santa Monica, CA 90406-2138. PG 49. PR not available. JE J22, J14, J32, O53. KW Japan. Retirement. Pension System. Labor Supply.

AB In Japan today, the ratio of elderly to nonelderly in the general population is increasing at a rate nearly twice that of other developed nations. This rapidly aging population has given rise to two important policy issues in Japan: (1) the need to maintain the fiscal health of the pension system as the demand for retirement benefits increases, and (2) the need to create employment opportunities for older people who are able and willing to continue working. Both issues are related to, and affected by, the effects of public pensions on the labor supply, but little is known about the way these factors interrelate in Japan. To begin to fill this information gap, this note formulates labor supply models, with corrections for selectivity bias, based on an estimate of the effects of the employee pension on both the decision to remain in the labor force and the number of hours worked per week.

\section{Selten, Reinhard}

PD November 1990. TI Some Remarks on Bounded Rationality. AA University of Bonn. SR Universitat Bonn Sonderforschungsbereich 303 - Discussion Paper: B-172; Sonderforschungsbereich 303 an der Universitat Bonn, Adenauerallee 24-42, D-5300 Bonn 1, DEUTSCHLAND. PG 13. PR no charge. JE D21, D11, D80, C61. KW Rationality. Optimization Problem. Utility Theory.

AB Herbert A. Simon (1957) introduced the concept of bounded rationality more than thirty years ago. He proposed to replace the idea of utility maximization by a more realistic view of economic behavior involving satisfying and the adaptation of aspiration levels to success and failure. He pointed out that in view of the enormous complexity of the decision tasks confronting firms and consumers optimization transcends human cognitive capabilities. Some people like my teacher Heinz Sauermann and myself were immediately convinced by Simon's arguments.

\section{Sertel, Murat R.}

TI A Welfaristic Characterization of Revelation Equilibria Under Imputational Government. AU Koray, Semih; Sertel, 
Murat R.

\section{Seth, Rama}

PD September 1990. TI Leverage and Cyclicality. AA Federal Reserve Bank of New York. SR Federal Reserve Bank of New York Research Paper: 9027; Federal Reserve Bank of New York, 33 Liberty St., Rm. 901, New York City, New York 10045. PG not available. PR no charge. JE G31, G32, O50, E32. KW Corporate Debl. Interest Rates.

AB The United States is the only major industrialized country in which firms have experienced increases in both leverage and interest burden over the 1980s. While firms in some other countries have also leveraged up, only in smaller economies such as Norway and Belgium did they also experience an increase in the interest burden. This paper outlines recent leverage patterns in 24 countries for which we have the relevant data, examines 6 major industrialized countries in greater detail, and studies whether leveraging by firms is taking place in the more cyclical (and hence vulnerable) industries.

PD September 1990. TI Explaining LBOs and Acquisitions. AA Federal Reserve Bank of New York. SR Federal Reserve Bank of New York Research Paper: 9020; Federal Reserve Bank of New York, 33 Liberty St., Rm. 901, New York City, New York 10045. PG 29. PR no charge. JE D21, G34, L60, L12. KW Leveraged BuyOuts. Corporate Control. Takeovers.

AB This paper attempts to identify some key factors that determine the distribution of leveraged buy-outs (LBOs) and acquisitions across industries. Previous research has concentrated on the effects of changes in corporate control. There has been little work, however, in identifying factors that determine changes in corporate control across industries. Our aim is to arrive at and estimate an appropriate reduced form equation that explains the observed distribution of LBOs and acquisitions across industries. Our results indicate that industry size, concentration, leverage, and conglomeration have been important in determining the incidence of LBOs.

PD January 1991. TI Growth in Japanese Lending and Direct Investment in the United States: Are They Related? AU Seth, Rama; Quijano, Alicia M. AA Federal Reserve Bank of New York. SR Federal Reserve Bank of New York Research Paper: 9101; Federal Reserve Bank of New York, 33 Liberty St., Rm. 901. New York City, New York 10045. PG 17. PR no charge. JE F21, F23, F34, G15, G21. KW Foreign Banks. Foreign Investment. Multinational Firms. Private Debt. Banking.

AB This study juxtaposes the data on liabilities of U.S. nonbank affiliates of Japanese companies and those on loans by U.S. branches and agencies of Japanese banks to infer the share of Japanese bank lending to affiliates. Studies on the growth of foreign banks in the United States ascribe foreign banks' operations, in particular those of Japanese banks, to growth in foreign trade and direct investment in this country. We find, however, that data on U.S. nonbank affiliates of Japanese firms from the Commerce Department and data on U.S. branches and agencies of Japanese banks from the Federal Financial Institutions Examination Council do not support this hypothesis. Local borrowing by affiliates of Japanese firms do not account for the majority of Japanese lending in the United States. The increased scope of Japanese bank lending to U.S.- owned corporations means that any credit tightening by Japanese banks, due to the difficulty they may have in meeting capital requirements, could have a broader impact than often thought. Namely, these firms may find themselves particularly vulnerable to a tightening of credit by Japanese Banks.

PD February 1991. TI Patterns of Corporate Leverage in Selected Industrialized Countries. AA Federal Reserve Bank of New York. SR Federal Reserve Bank of New York Research Paper: 9107; Federal Reserve Bank of New York, 33 Liberty St., Rm. 901, New York City, New York 10045. PG 17. PR no charge. JE E32, G15, G32, 057. KW Private Debt. Business Cycle.

AB This paper examines the pattern of leveraging by firms across different sectors in selected industrialized countries. In particular, it examines the extent of and the change in leverage of firms in sectors sensitive to economic fluctuations. Earlier studies of the United States have concluded that, to the extent a pattern is discernible, highly indebted firms are concentrated in non-cyclical sectors. This study confirms the earlier finding but also establishes that U.S. firms that have been increasing their leverage most rapidly have been concentrated in cyclical sectors. In addition, the paper reports findings for five other countries most of which de-leveraged in the $1980 \mathrm{~s}$. The pattern of de-leveraging has not been homogeneous across the countries studied.

\section{Shachar, Roni}

PD January 1991. TI Forgetfulness and Political Cycle. AA Tel Aviv University. SR Tel Aviv Foerder Institute for Economic Research Working Paper: 2-91; Department of Economics, Tel Aviv Universily, Ramat Aviv 69978, Tel Aviv, ISRAEL. PG 21. PR no charge. JE D72, H41. KW Voting. Government Spending. Political Cycles. Incumbent. Public Good.

AB This paper presents a mechanism which stands behind both the political business cycle and the political ideological cycle (a cycle in the non-economic policies executed by politicians). It shows that if the rational voters suffer from forgetfulness (a noise in their memory), the government expenditure on the production of public good increases as elections approach. Hence, the model provides a description of a cycle in the government expenditures and budget deficit. This model does not require any government information superiority over the rational voter with respect to its competency. The resources in this model are transferred from the beginning of the incumbent's term of service and used near the end of this period. We also find that the less concave the production function, the wider the cycle.

\section{Shaffer, Sherrill}

PD April 1990. TI Aggregate Deposit Insurance Funding and Taxpayer Bailouts. AA Federal Reserve Bank of Philadelphia. SR Federal Reserve Bank of Philadelphia Research Working Paper: 90-14; Working Papers, Department of Research, Federal Reserve Bank of Philadelphia, 10 Independence Mall, Philadelphia, PA 19106. PG 43. PR no charge (except overseas airmail, $\$ 2.00$; checks/money orders in U.S. funds payable to Federal Reserve Bank of Philadelphia.). JE G21, G28. KW Deposit Insurance. Commercial Banks. Banking. Government Policy.

AB Recent events have focussed attention on the fragility of the federal deposit insurance funds and made redesign of the insurance system an active policy issue. This paper explores the 
implications of different rate structures for the long-term solvency of the fund, using two simulation techniques based on historical loss distributions. Two findings stand out: even under the higher premium rate mandated by FIRREA, the probability that the fund could become insolvent over a given 55-year period is higher than previously recognized; and modifying or eliminating the rebating of "excess" premiums can substantially reduce the probability of insolvency without further increasing the nominal premium rate.

PD July 1990. TI A Test of Competition in Canadian Banking. AA Federal Reserve Bank of Philadelphia. SR Federal Reserve Bank of Philadelphia Research Working Paper: 90-18; Working Papers, Department of Research, Federal Reserve Bank of Philadelphia, 10 Independence Mall, Philadelphia. PA 19106. PG 36. PR no charge (except overseas airmail, \$2.00; checks/money orders in U.S. funds payable to Federal Reserve Bank of Philadelphia.). JE G21, L11, G28, L84. KW Competition. Banking. Canada. Regulation.

AB This paper applies a nonstructural test of competitive conduct to aggregate Canadian banking data for the period 1965-1989. The results are consistent with perfect competition and strongly reject monopolization. Further, the degree of competition was found not to be lessened following the regulatory changes of 1980 and subsequent structural changes; indeed, the best specifications indicated a slight but significant shift to an unexpected "supercompetitive" mode characterized by aggregate bank assets several billion dollars greater than the competitive equilibrium level. A Goldfeld-Quandt test confirmed the timing of this shift.

PD November 1990. TI Regulation and Endogenous Contestability. AA Federal Reserve Bank of Philadelphia. SR Federal Reserve Bank of Philadelphia Research Working Paper: 90-28; Working Papers, Department of Research, Federal Reserve Bank of Philadelphia, 10 Independence Mall, Philadelphia, PA 19106. PG 21. PR no charge (except overseas airmail, \$2.00; checks/money orders in U.S. funds payable to Federal Reserve Bank of Philadelphia.). JE D43, L51, L13, L93. KW Regulation. Contestability. Technology. Monopoly.

AB This paper establishes three main results. First, when firms face alternative technologies, the degree of contestability may change endogenously depending on whether an industry is regulated; the airline industry is discussed as a possible example. Second, when sunk costs are zero, the contestable outcome is obtained if the cost of a price adjustment by an incumbent exceeds that of a quantity adjustment over the relevant time frame. Third, simple regulatory policies such as a mandatory lag on price changes can be designed to promote contestability with minimally informed regulators. When applied to a natural monopoly, such policies have certain advantages over alternate approaches such as a Demsetz auction, especially when demand is inelastic.

PD November 1990. TI Stable Cartels with a Cournot Fringe. AA Federal Reserve Bank of Philadelphia. SR Federal Reserve Bank of Philadelphia Research Working Paper: 90-24; Working Papers, Department of Research, Federal Reserve Bank of Philadelphia, 10 Independence Mall, Philadelphia, PA 19106. PG 24. PR no charge (except overseas airmail, $\$ 2.00$; checks/money orders in U.S. funds payable to Federal Reserve Bank of Philadelphia.). JE D43, D61, D63. KW Cartels. Cournot Equilibrium. Oligopoly.
Welfare Analysis.

AB A stable cartel of just over half the firms is derived in a simple linear model when the cartel behaves as a Stackelberg leader and behavior in the fringe is Cournot. Conditions are shown under which the Cournot behavior and Stackelberg sequence emerge endogenously. The criterion of cooperative stability is introduced where the cartel can exclude unwanted members, and is shown not to alter the size of the stable cartel. Welfare properties are also examined.

PD December 1990. TI The Lerner Index, Welfare, and the Structure-Conduct-Performance Linkage. AA Federal Reserve Bank of Philadelphia. SR Federal Reserve Bank of Philadelphia Research Working Paper: 90-27; Working Papers, Department of Research, Federal Reserve Bank of Philadelphia, 10 Independence Mall, Philadelphia, PA 19106. PG 23. PR no charge (except overseas airmail, \$2.00; checks/money orders in U.S. funds payable to Federal Reserve Bank of Philadelphia.). JE D43, D61, D63. KW Oligopoly. Complementarity. Welfare Analysis.

AB This paper explores some previously unrecognized weaknesses of the Lerner index as a measure of performance. In the context of a homogeneous Cournot oligopoly, is shown that a change in structure can cause the Lerner index to move in either the same or opposite directions as consumer welfare, producer surplus, or total welfare. For a differentiated duopoly, the Lerner index and total welfare both respond to changes in the conjectural variation in a direction that depends on parameter values when the goods are complements, with the two measures indicating conflicting directions of benefit within each of two parameter ranges corresponding to weak complements and strong complements, respectively.

\section{Shapiro, Carl}

PD January 1990. TI Economic Rationales for the Scope of Privatization. AU Shapiro, Carl; Willig, Robert D. AA Princeton University. SR John M. Olin Program for the Study of Economic Organization and Public Policy: 41; Department of Economics, Woodrow Wilson School of Public \& International Affairs, Princeton University, Princeton, NJ 08544. PG 46. PR no charge. JE L33. KW Privatization. Public Sector. Public Enterprises.

AB We develop an information-theoretic model to evaluate the effects of privatization. We first establish a neutrality result: Privatization will have no effect unless private information about the profitability of operating the enterprise is present prior to investment and unless there is an efficiency cost of transferring funds out of the public sector. Under these conditions, we identify the factors that tend to favor one form of ownership over the other, from a public-interest perspective. Privatization necessarily raises the cost to public sector officials of redirecting resources, whether such redirection is publicspirited or not. If the political system is ineffective at compelling public officials to act in the long-run public interest, privatization can improve performance by serving as a government commitment to limit the interventions of these officials.

\section{Shavell, Steven}

TI A Note on Optimal Fines When Wealth Varies Among Individuals. AU Polinsky, A. Mitchell; Shavell, Steven.

\section{Sheshinski, Eytan}

PD November 1990. TI Staggered and Synchronized 
Price Policies under Inflation: The Multi-Product Monopoly Case. AU Sheshinski, Eytan; Weiss, Yoram. AA Sheshinski: Hebrew University of Jerusalem. Weiss: Tel Aviv University. SR Tel Aviv Foerder Institute for Economic Research Working Paper: 35-90; Department of Economics, Tel Aviv University, Ramat Aviv 69978, Tel Aviv, ISRAEL. PG 66. PR no charge. JE D42. KW Inflation. Price Adjustment. Adjustment Costs. Monopoly.

AB The paper examines pricing policy of a multiproduct monopoly in an inflationary environment. Assuming costs of adjustment for nominal price changes of each of the two goods we enquire whether the monopoly will synchronize or stagger the price adjustments of the two goods. Depending on initial conditions both patterns can arise. However, if the two goods are substitutes then the synchronized policy is more likely. Prices are analyzed more often under a staggered than under a synchronized pricing policy. Increase in the inflation rate, reduction in the costs of adjustment and a stronger positive interaction increases the frequency of price changes.

\section{Shoven, John B.}

TI Comparison of the Cost of Capital in the U.S. and Japan: The Roles of Risk and Taxes. AU Bernheim, B. Douglas; Shoven, John B.

\section{Shy, Oz}

TI Partially Compatible Brands and Consumer Welfare. AU Chou, Chien-Fu; Shy, Oz.

TI Do Consumers Always Gain When More People Buy the Same Brand? AU Chou, Chien-Fu; Shy, $\mathrm{Oz}$.

\section{Siandra, Eduardo}

PD November 1990. TI Money and Specialization in Production. AA University of California, Los Angeles. SR University of California at Los Angeles Department of Economics Working Paper: 610; Department of Economics, University of California, Los Angeles, 2263 Bunche, Los Angeles, CA 90024. PG 39. PR \$2.50. JE O42, D51, D58, 012. KW Barter. Autarky. Monetary Exchange. Economic Development. Production. General Equilibrium Model.

AB This paper investigates the connection between specialization and the institution of money in a search general equilibrium model with a continuum of differentiated commodities. In a model with agents of different productivity, we provide a condition for monetary exchange to enlarge the extent of the market and to enhance specialization. It is shown how individuals sort themselves out among autarkic, pure barter and money types. Specifically, the most productive individuals will produce for the market and engage in monetary exchange. Implications for economic development and economic history are highlighted. A similar analysis is carried out in a model with homogeneous types.

\section{Sibert, Anne}

PD December 1988. TI Taxing Capital in an Open Economy. AA University of Kansas. SR Federal Reserve Bank of Kansas City Research Working Paper: 88-11; Research Division, Federal Reserve Bank of Kansas City, 925 Grand Ave., Kansas City, MO 64198. PG 32. PR no charge. JE H25, H21, G31, F41, F32. KW Capital Taxation.
Taxation. Open Economy. Current Account.

AB In closed economy models it is typically found that capital taxation is inefficient. It has also been suggested that investment incentives may worsen an open economy's current account. This paper analyzes capital taxation in a dynamic, optimizing, general equilibrium model of a large, open economy. It is shown that the existence of current account imbalances may alter conventional results. For example, a country with a current account deficit may find that labor is much less adversely affected by capital taxation than a surplus country and investment incentives improve to its current account in all but the short-run.

TI An Equilibrium Model of Spot and Forward Exchange Rates. AU Hakkio, Craig S.; Sibert, Anne.

\section{Singh, Ajit}

TI Predicting Success; Pre-Merger Characteristics and Post-Merger Performance. AU Cosh, Andy; Hughes, Alan; Lee, Kevin; Singh, Ajit.

\section{Sloss,}

TI Adjusting Capitation Rates Using Objective Health Measures and Prior Utilization. AU Newhouse, Joseph P.; Manning, Willard G.; Keeler, Emmett B.; Sloss, Elizabeth M.

\section{Smart, Susan R.}

TI The Political Economics of State Responses to Divestiture and Federal Deregulation in Telecommunications. AU Noll, Roger G.; Smart, Susan R.

\section{Sobel, Joel}

TI On the Effectiveness of Liability Rules When Agents are Not Identical. AU Emons, Winand; Sobel, Joel.

\section{Spaventa, Lugi}

PD January 1990. TI The "New" EMS. AU Spaventa, Lugi; Giavazzi, Francesco. AA Dipartimento de Scienze Economiche. SR Centre for Economic Policy Research Discussion Paper: 369; Centre for Economic Policy Research, 6 Duke of York Street, London SWIY 6LA, UNITED KINGDOM. PG 29. PR 2.00 pounds $(\$ 4.00)$. JE F33, F36, F31, F42, F47. KW European Monetary System. Capital Controls. Economic Integration. Financial Integration. Exchange Rates. Capital Mobility.

AB This paper attempts to provide an interpretation of recent developments in EMS. The System has evolved from a regime of adjustable, frequently adjusted parities, where capital controls provided a shelter to weaker currencies, to one where this shelter is being removed, in advance of stage two of the Delors Report. An understanding seems to have been reached that exchange rate realignments would be made only in exceptional circumstances. The paper sheds some light on the reasons why financial liberalization seems to have strengthened, rather than weakened the EMS, but it also explains why many in Europe today argue that the EMS with fixed exchange rates and free capital mobility may be unstable. Our findings are at odds with the expected consequences of a shift to more fixed exchange rates when inflation differentials persist and there are no capital controls.

Spiegel, Matthew

TI An Experimental Comparison of Dispute Rates in 
Alternative Arbitration Systems. AU Ashenfelter, Orley; Currie. Janet; Farber, Henry S.; Spiegel, Matthew.

\section{Spulber, Daniel F.}

PD April 1991. TI Monopoly Pricing Strategies. AA Northwestern University. SR Northwestern Center for Mathematical Studies in Economics and Management Science Working Paper: 936; Northwestern University, 2001 Sheridan Road, 3-014 Leverone Hall, Evanston, IL 60208-2014. PG 17. PR $\$ 3.00$ in the U.S. or Canada; $\$ 5.00$ via international mail. Make check payable to Northwestern University. JE D42, L12. KW Monopoly. Prices.

AB The design of monopoly pricing strategies is examined in a general framework with an unknown population distribution of consumer characteristics, downward-sloping, multi-unit consumer demand, and increasing marginal cost. Reference point pricing is introduced and is shown to implement the profit-maximizing allocation. The design of generalized priority service is extended to the unknown demand setting. Nonlinear pricing is shown to be approximately optimal for the monopolist as the number of consumers gets large.

\section{Srinivasan, T. N.}

TI Poverty Alleviation Policies in India: Food Consumption Subsidy, Food Production Subsidy and Employment Generation. AU Parikh, Kirit; Srinivasan, T. N.

\section{Srivastava, Sanjay}

TI Undominated Nash Implementation in Bounded Mechanisms. AU Jackson, Matthew O.; Palfrey, Thomas R.; Srivastava, Sanjay.

\section{Stapleton, Richard C.}

TI Futures, Forward and Option Prices in a No-Arbitrage Economy. AU Satchell, Stephen E.; Stapleton, Richard C.; Subrahmanyam, Marti G.

\section{Steger, Angelika}

TI Excluding Induced Subgraphs II: Extremal Graphs.

AU Promel, Hans Jurgen; Steger, Angelika.

TI Excluding Induced Subgraphs III: A General Asymptotic. AU Promet, Hans Jurgen; Steger, Angelika.

\section{Stein, Jeremy C.}

TI Shareholder Trading Practices and Corporate Investment Horizons. AU Froot, Kenneth A; Perold, Andre F.; Stein, Jeremy C.

\section{Stein, Jerome L.}

TI The Dynamics of the Real Exchange Rate, Foreign Debt and Capital Intensity. AU Allen, Polly Reynolds; Stein, Jerome L.

\section{Steindel, Charles}

PD November 1990. TI Recent Trends in Capital Formation. AA Federal Reserve Bank of New York. SR Federal Reserve Bank of New York Research Paper: 9033; Federal Reserve Bank of New York, 33 Liberty St., Rm. 901, New York City, New York 10045. PG 25. PR no charge. JE E22, L60. KW Capital Stock. Investment. Capital Formation. Manufacturing.

AB The economic expansion of the 1980s saw a sharp contrast between high gross investment levels and slow growth of the gross and net capital stocks. Theory suggests that neither investment nor the capital stock series provide exact measures of the aggregate productivity of capital. Empirically, though, the capital stock series appear to be better proxies than investment to the underlying productivity of capital, despite arguments that aggregate investment is a less deceptive measure when the investment mix changes. The capital stock slowdown is most evident in basic industrial goods and structures, while virtually all industries have seen rapid growth in information-processing equipment.

\section{Steinmueller, W. Edward}

TI Government Policy and Industry Evolution in the U.S. Integrated Circuit Industry: What Lessons for Newly Industrializing Economies? AU Mowery, David C.; Steinmueller, W. Edward.

\section{Stengos, Thanasis}

TI Semiparametric Specification Testing of Nonlinear Models. AU Delgado, Miguel A.; Stengos, Thanasis.

\section{Stiglitz, Joseph E.}

TI The Quality of Mangers in Centralized Versus Decentralized Organizations. AU Sah, Raaj K.; Stiglitz, Joseph E.

TI Imperfect Information and Rural Credit Markets: Puzzles and Policy Perspectives. AU Hoff, Karla; Stiglitz, Joseph E.

TI Price Equilibrium, Efficiency, and Decentralizability in Insurance Markets. AU Arnott, Richard; Stiglitz, Joseph E.

\section{Stock, James H.}

PD May 1991. TI Confidence Intervals for the Largest Autoregressive Root in U.S. Macroeconomic Times Series. AA University of California, Berkeley. SR National Bureau of Economic Research Technical Paper: 105; National Bureau of Economic Research, 1050 Massachusetts Avenue, Cambridge, MA 02138. PG not available. PR $\$ 2.00$. JE C22, C12. KW Time Series. Unit Roots. Confidence Intervals. Asymptotic Theory. Hypothesis Testing.

AB This paper provides asymptotic confidence intervals for the largest autoregressive root of a time series when this root is close to one. The intervals are readily constructed either graphically or using tables in the Appendix. When applied to the Nelson-Plosser (1982) data set, the main conclusion is that the confidence intervals typically are wide. The conventional emphasis on testing for whether the largest root equals one fails to convey the substantial sampling variability associated with this measure of persistence.

\section{Strauss, John}

PD October 1989. TI Modelling the Use and Adoption of Technologies by Upland Rice and Soybean Farmers in CentralWest Brazil. AU Strauss, John; Barbosa, Mariza M. T. I.; Teixeira, Sonia M.; Thomas, Duncan; Gomes, Raimundo A. Q., Jr. AA Yale University, SR Yale Economic Growth Center Discussion Paper: 587; Economic Growth Center, Yale University, 27 Hillhouse Avenue, New Haven, CT 06520. PG 23. PR $\$ 2.00+$ Postage. JE Q16, O13, O32, 054 . KW Agriculture. Technology. Brazil. Human Capital.

AB This paper explores reduced form determinants of the adoption of certain technologies by upland rice and soybean 
farmers in the central-west region of Brazil. We merge community level data on the availability and quality of publicly provided infrastructure, principally extension, to farm level data containing information on farmer human capital as well as land quantity and quality. By using community level measures of availability and quality of extension we avoid problems of endogeneity of farm level measures of extension use. We find positive impacts of farmer education on the diffusion process, in accordance with other studies. We also isolate effects of the quality of regional extension investment as measured by the average experience of technical extension staff. These results, which are relatively new in the agricultural diffusion literature, indicate that investments in human capital of extension workers does have a payoff in terms of farmer adoption of better cultivation practices.

TI Estimating the Impact of Income and Price Changes on Consumption in Brazil. AU Thomas, Duncan; Strauss, John; Barbosa, Mariza M. T. I.

PD March 1990. TI The Shape of the CalorieExpenditure Curve. AU Strauss, John; Thomas, Duncan. AA Yale University. SR Yale Economic Growth Center Discussion Paper: 595; Economic Growth Center, Yale University, 27 Hillhouse Avenue, New Haven, CT 06520. PG 41. PR $\$ 2.00+$ Postage. JE D12, I12, I31, E21. KW Consumption. Nutrition. Households. Calories.

AB It is generally agreed that as income (or expenditure) rises, households switch to higher valued foods not necessarily with higher nutrient content. Some recent work has suggested that, even among the very poor, as income rises households purchase only additional taste and non-calorie nutrients: the calorie-income curve is very flat. In this paper the effect of expenditure on calorie and protein demand is estimated with data from a large scale Brazilian expenditure survey. Nonparametric estimates, which impose very little structure on the relationship between nutrient intake and expenditure, demonstrate that the calorie-expenditure curve is positively sloped for households in the bottom three quartiles of the per capita expenditure distribution; it is kinked when per capita calorie intake is between 2,500 and 3,000 calories per day and is flat at higher expenditure levels. The protein-expenditure curve is also positively sloped although it does not flatten out as much as the calorie curve, reflecting a switch into higher valued foods, richer in protein.

\section{Subrahmanyam, Marti G.}

TI Futures, Forward and Option Prices in a No-Arbitrage Economy. AU Satchell, Stephen E.; Stapleton, Richard C.; Subrahmanyam, Marti G.

\section{Sulganik, Eyal}

PD August 1990. TI Some New Ordering in Economics of Information. AA Tel Aviv University. SR Tel Aviv Foerder Institute for Economic Research Working Paper: 21 90; Department of Economics, Tel Aviv University, Ramat Aviv 69978, Tel Aviv, ISRAEL, PG 49. PR no charge. JE D83, D82. KW Information. Blackwell's Theorem. Stochastic Dominance. Orderings. Representation Theorem.

AB Blackwell's theorem is a major tool in information economics. In this paper we define a new relation by restricting Blackwell's relation of informativeness using stochastic dominance theory and Birkhoff's extreme points representation theorem. We also show how to use dynamic setting to complete this new order.

\section{Summers, Lawrence $\mathbf{H}$.}

TI Speculative Dynamics and the Role of Feedback Traders. AU Cutler, David M.; Poterba, James M.; Summers, Lawrence $\mathrm{H}$.

TI Speculative Dynamics. AU Cutler, David M.; Poterba, James M.; Summers, Lawrence $H$.

\section{Svensson, Lars E. $\mathbf{O}$.}

PD December 1989. TI Target Zones and Interest Rate Variability. AA University of Stockholm. SR Centre for Economic Policy Research Discussion Paper: 372; Centre for Economic Policy Research, 6 Duke of York Street, London SWIY 6LA, UNTTED KINGDOM. PG 34. PR 2.00 pounds (\$4.00). JE F31, E42, E43, F37. KW Target Zones. Interest Rates. Risk Premium. Exchange Rates.

AB The trade-off between interest rate variability and the width of an exchange rate target zone is examined, using the regulated Brownian motion model of target zones. It is shown that for narrow exchange rate bands, and for reasonable parameter values, the interest rate differential's asymptotic variability is increasing in the width of the exchange rate band; whereas for wide exchange rate bands it is slowly decreasing in the exchange rate band. The interest rate differential's instantaneous variability is decreasing in the width of the exchange rate band. A narrow target zone differs from a completely fixed exchange rate regime in that the interest rate differential's instantaneous standard deviation is high and even increases when the zone narrows.

\section{Szekely, L. A.}

TI Sharpening the Lym Inequality. AU Erdos, Peter L.; Frankl, P.; Kleitman, D. J.; Saks, M. E.; Szekely, L. A.

TI Counting Bichromatic Evolutionary Trees. AU Erdos, Peter L.; Szekely, L. A.

\section{Tabellini, Guido}

TI Political Instability, Political Weakness and Inflation: An Empirical Analysis. AU Edwards, Sebastian; Tabellini, Guido.

\section{Takacs, Wendy E.}

PD February 1990. TI Labour Adjustment Costs and British Footwear Protection. AU Takacs, Wendy E.; Winters, L. Alan. AA Takacs: University of Maryland. Winters: University of Wales. SR Centre for Economic Policy Research Discussion Paper: 376; Centre for Economic Policy Research, 6 Duke of York Street, London SWIY 6LA, UNITED KINGDOM. PG 41. PR 2.00 pounds (\$4.00). JE F13, F41, F47, L67. KW Imports. Commercial Policy. Output. Employment. Protectionism.

AB Import protection is frequently advocated as a means of preserving jobs and avoiding labor adjustment costs. Defining adjustment costs in terms of output foregone during the process of adjustment and ignoring any general equilibrium repercussions, we estimate that quantitative restriction on British footwear imports during 1979 protected about 1,000 jobs and avoided once-and-for-all adjustment costs of only around 1 million pounds. The result is based on new data which reveal high rates of labor turnover in the footwear sector and so imply that displaced labor is readily re-employed. We 
use a model of output and employment derived from a multiinput-multi-output profit function, which shows that trade restrictions have relatively small effects on U.K. output and employment.

\section{Talman, Dolf J. J.}

TI Signaling Devices for the Supply of Semi-Public Goods. AU Ruys, Pieter H. M.; van der Laan, Gerard; Talman, Dolf J. J.

Tan, Hong W.

PD August 1989. TI Technical Change and Human Capital Acquisition in Japanese and U.S. Labor Markets. AA Rand Corporation. SR Rand Paper: P-7588; The Rand Corporation, 1700 Main Street, P.O. Box 2138. Santa Monica, CA 90406-2138. PG 34. PR not available. JE O14, 032, 047, O57. KW Productivity. Growth. Technological Change.

AB This paper analyzes cross-national similarities and differences in order to determine how labor markets react to and affect technical change and productivity growth. Long-term employment, high investment in training, compensation for firm-specific skills, and larger firm size are factors that lead to greater productivity in technologically advanced economies. The author concludes that proper rewards to both workers and employers will create an environment that enhances productivity derived from technological advance.

\section{Teixeira, Sonia M.}

TI Modelling the Use and Adoption of Technologies by Upland Rice and Soybean Farmers in Central-West Brazil. AU Strauss, John; Barbosa, Mariza M. T. I.; Teixeira, Sonia M.; Thomas, Duncan; Gomes, Raimundo A. Q., Jr.

TI Modelling the Use and Adoption of Technologies by Upland Rice and Soybean Farmers in Central-West Brazil. AU Strauss, John; Barbosa, Mariza M. T. I.; Teixeira, Sonia M.; Thomas, Duncan; Gomes, Raimundo A. Q., Jr.

\section{Thomas, Duncan}

PD October 1989. TI Intra-Household Resource Allocation; An Inferential Approach. AA Yale University. SR Yale Economic Growth Center Discussion Paper: 586; Economic Growth Center, Yale University, 27 Hillhouse Avenue, New Haven, CT 06520. PG 29. PR $\$ 2.00+$ Postage. JE I12, I31, D12, E21. KW Nutrition. Consumption. Households.

AB If household income is pooled and then allocated to maximize welfare, then income under the control of mothers and fathers should have the same impact on demand. With survey data on family health and nutrition in Brazil, the equality of parental income effects is rejected. Unearned income in the hands of mothers has a bigger effect on her family's health than income under the control of fathers; for child survival probabilities the effect is almost twenty times bigger. The common preference (or neoclassical) model of the household is rejected. If unearned income is measured with error and income is pooled then the ratio of maternal to paternal income effects should be the same; equality of the ratios cannot be rejected. There is also evidence for gender preference; mothers prefer to devote resources to improving the nutritional status of their daughters, fathers to sons. and Price Changes on Consumption in Brazil. AU Thomas, Duncan; Strauss, John; Barbosa, Mariza M. T. I. AA Yale University. SR Yale Economic Growth Center Discussion Paper: 589; Economic Growth Center, Yale University, 27 Hillhouse Avenue, New Haven, CT 06520. PG 45. PR $\$ 2.00+$ Postage. JE D12, E21, 054 . KW Consumption. Brazil. Households. Demand Functions.

AB A set of commodity demand functions are estimated with a very rich, multi-purpose Brazilian budget survey, "Estudo Nacional da Despesa Familiar" (ENDEF), which covered over 53,000 households. Particular attention is paid to demand for foods. Since income responses are not linear, a generalized form of the Almost Ideal Demand System is adopted; household per capita expenditure is used as a measure of resource availability and we take account of both endogeneity and measurement error. All expenditure elasticities are significantly different from zero and greater than unity for meat, dairy products and most non-foods. Since the survey reports both expenditures and quantities, regional price indices are constructed, paying special attention to problems of measurement error and quality variation within price aggregates.

TI The Shape of the Calorie-Expenditure Curve. AU Strauss, John; Thomas, Duncan.

PD January 1991. TI Like Father, Like Son: Gender Differences in Household Resource Allocations. AA Yale University. SR Yale Economic Growth Center Discussion Paper: 619; Economic Growth Center, Yale University, 27 Hillhouse Avenue, New Haven, CT 06520. PG 32. PR $\$ 2.00+$ Postage. JE J13, I12. KW Gender. Household. Children. Health.

AB Using household survey data from the United States, Brazil and Ghana, we examine the relationship between parental education and child height, an indicator of health and nutritional status. In all three countries, the education of the mother has a bigger effect on her daughter's height; paternal education, in contrast, has a bigger impact on his sons's height. There are, apparently, differences in the allocation of household resources depending on the gender of the child and these differences vary with the gender of the parent. In Ghana, relative to other women, the education of a woman who is better educated than her husband has a bigger impact on the height of her daughter than her son. In Brazil, women's nonlabor income has a positive impact on the health of her daughter than her son. If relative education of parents and nonlabor income are indicators of power in a household bargaining game, then these results suggest that gender differences in resource allocations reflect both technological differences in child rearing and differences in the preferences of parents.

\section{Thomson, William}

TI On the Interpretation of the Nash Bargaining Solution and its Extension to Non-Expected Utility Preferences. AU Rubinstein, Ariel; Safra, Zvi; Thomson, William.

\section{Toman, Michael A.}

TI Ethanol Fuel and Non-Market Benefits: Is a Subsidy Justified? AU Walls, Margaret A.; Krupnick, Alan J.; Toman, Michael A. 


\section{Trautman, William B.}

PD October 1989. TI Regulating Communication Technology: The Case of Automated Teller Machine Networks. AA Rand Corporation. SR Rand Note: N-2867; The Rand Corporation, 1700 Main Street, P.O. Box 2138, Santa Monica, CA 90406-2138. PG 82. PR not available. JE G21, G28, L63, O32. KW Communication. Automated Tellers. Regulation. ATMs.

AB This research establishes a framework for analyzing the regulation of evolving communication technologies with a case study of automated teller machines (ATMs). The high fixed cost of communication technology may provide a basis for regulatory intervention, because it may enable large firms to gain a competitive advantage over small firms; it may also lead to efficiency. The regulatory issue is whether laws should be enacted that give competing firms access to existing technology, thus protecting the market share of small firms and enabling them to compete more equitably with large firms. Mandatory access laws can impose cost on society, however, by slowing the diffusion of technology and postponing the benefits associated with new communication services.

Trick, Michael A.

PD April 1990. TI A Tutorial on Network Flows and Matchings. AA Carnegie Mellon University. SR Universitat Bonn Sonderforschungsbereich 303 . Discussion Paper: 89621-OR; Sonderforschungsbereich 303 an der Universitat Bonn, Adenauerallee 24-42, D-5300 Bonn 1, DEUTSCHLAND. PG 101. PR no charge. JE C44, C67, C63. KW Maximum Flow. Minimum Cost Flow. Matching Algorithms. Simplex Method.

AB In these notes, we examine algorithms for network flow and matching problems. Networks flows and matchings hold a special place in Operations Research. They have been used to model countless practical situations. Researchers have developed techniques to solve even very large real-world problems. These notes examine the development of a variety of solution techniques. There are four main sections to these notes, covering maximum flow, minimum cost flow, matchings, and the network simplex method. In each section we examine a variety of solution techniques. These notes do not say much about applications.

\section{Trognon, A.}

TI From a Hicks-Grandmont Temporary Equilibrium to a Rational Expectation Equilibrium and Conversely. AU Bronsard, C.; Salvas-Bronsard, L.; Trognon, A.

\section{Uctum, Merih}

PD February 1991. TI Foreign Interest Rate Disturbance, Financial Flows and Physical Capital Accumulation in a Small Open Economy. AA Federal Reserve Bank of New York. SR Federal Reserve Bank of New York Research Paper: 9106; Federal Reserve Bank of New York, 33 Liberty St., Rm. 901, New York City, New York 10045. PG 21. PR no charge. JE F21, F34, F41, F31. KW Foreign Investment. Capital Mobility. Open Economy.

AB The purpose of this paper is to analyze the interaction of financial capital movements and accumulation of physical capital in a small open economy faced with a foreign interest disturbance under flexible exchange rates. Tobin's q theory of investment plays a central role not only in linking the financial and real sides of the economy but also in the determination of financial capital movements across boundaries. It is shown that endogenizing physical capital has important implications for the exchange rate dynamics not captured by the models which assume a fixed capital stock.

\section{Usher, Dan}

PD July 1990. TI The Significance of the Probabilistic Voting Theorem. AA Queen's University. SR Queen's Institute for Economic Research Discussion Paper: 785; Department of Economics, Queen's University, Kingston, Ontario, CANADA K7L 3N6. PG 22. PR \$3.00 Canada and U.S.; \$3.50 Foreign. JE D72, D71, D63. KW Majority Rule. Social Choice. Democracy. Political Parties.

AB Public decision making by majority rule is open to the danger of exploitation of minorities by majorities. Since any majority can employ the vote to expropriate the corresponding minority, it would seem that there can be no electoral equilibrium allocation of income or transfers in a democratic society and that democracy itself might be unstable. Much of democratic theory is devoted to the study of how this danger can be averted. The probabilistic voting theorem establishes that a degree of voter insensitivity to offers of rival political parties imparts an electoral equilibrium where it would not otherwise exist. The theorem is valid on its assumptions, but those assumptions are considerably stronger, and the theorem is less comforting about the prospects for the stability of democratic government, than one might at first suppose.

\section{Valdez, R. Burciaga}

PD October 1989. TI The Effect of a Prepaid Group Practice on Children's Medical Care Use and Health Outcomes Compared to Fee-for-Service Care. AA Rand Corporation. SR Rand Note: N-2618; The Rand Corporation, 1700 Main Street, P.O. Box 2138, Santa Monica, CA 90406-2138. PG 57. PR not available. JE I11. KW Medical Costs. Health Care.

AB To evaluate differences in medical expenditures and child health outcomes in a prepaid group practice compared with the fee-for-service (FFS) system when both serve comparable populations with the same service benefits, this note uses data from Seattle participants in the Health Insurance Experiment. No differences in imputed total expenditures were observed for children randomly assigned to a health maintenance organization (HMO) or to FFS plans. Children on cost-sharing FFS plans, however, had fewer medical contacts and received fewer preventive services than those assigned to the HMO. No significant differences in physiologic outcomes (e.g., visual acuity, hemoglobin level) were results of the experiment neither strongly support nor indict fee-for-service or prepaid care for children.

\section{van Damme, Eric}

TI Switching Away from Probability One Beliefs. AU Noldeke, Georg; van Damme, Eric.

\section{van der Laan, Gerard}

TI Signaling Devices for the Supply of Semi-Public Goods.

AU Ruys, Pieter H. M.; van der Laan, Gerard; Talman, Dolf J. J.

\section{van der Ploeg, Frederick}

PD November 1989. TI Monetary Interdependence Under Alternative Exchange Rate Regimes: A European 
Perspective. AA Tilburg University University and Center for Economic Policy Research. SR Centre for Economic Policy Research Discussion Paper: 358; Centre for Economic Policy Research, 6 Duke of York Street, London SW1Y 6LA, UNITED KINGDOM. PG 23. PR 2.00 pounds $(\$ 4.00)$. JE F33, F36, E42. KW Policy Coordination. Monetary Policy. Financial Integration. European Monetary System.

AB This paper analyzes and compares the effects of common demand and supply shocks on the setting of optimal monetary policies under a clean float, a managed exchange rate system (such as the EMS) and a monetary union, when welfare depends on unemployment and the cost of living. The results suggest that monetary union yields the smallest welfare loss and a float the greatest, and that the EMS gives France and Italy the opportunity to appreciate their currencies and reduce their welfare loss at the expense of Germany. The robustness of the results with respect to rational expectations and wage-price dynamics is verified with the aid of differential game theory and numerical simulation.

PD January 1990. TI Monetary Disinflation, Fiscal Expansion and the Current Account in an Interdependent World. AA Tilburg University and Center for Economic Policy Research. SR Centre for Economic Policy Research Discussion Paper: 366; Centre for Economic Policy Research, 6 Duke of York Street, London SWIY 6LA, UNITED KINGDOM. PG 42. PR 2.00 pounds (\$4.00). JE F11, F41, F47. KW Monetary Policy. Economic Integration. Open Economy. Trade Model. International Macroeconomics.

AB A two-country, intertemporal, perfect-foresight model with micro foundations, Cobb-Douglas preferences and technologies, floating exchange rates, uncovered interest parity, and nominal wage rigidities is formulated. The transient and steady-state effects of a joint and unilateral monetary disinflation and a fiscal expansion are analyzed. The foreign repercussions of monetary and fiscal policy do not affect the home economy, so that the multipliers are the same as for a small open economy. Since Ricardian debt neutrality holds, the nominal interest rate is equal to the rate of time preference plus the discounted average of future, expected monetary growth rates and is independent of fiscal policy and foreign policies.

\section{VanHoose, David D.}

PD August 1989. TI Discretion, Wage Indexation, and Inflation. AU VanHoose, David D.; Waller, Christopher J. AA Indiana University. SR Federal Reserve Bank of Kansas City Research Working Paper: 89-03; Research Division, Federal Reserve Bank of Kansas City, 925 Grand Ave, Kansas City, MO 64198. PG 27. PR no charge. JE E31, E52, J41. KW Inflation. Monetary Policy. Wage Contracts. Wages.

AB This paper explores the implications of differential informational assumptions for the macroeconomic effects of wage indexation in a regime of time-consistent discretionary monetary policy. It is demonstrated that changes in the degree of indexation of nominal wages to unanticipated inflation can have very different effects upon the mean level of and variability of inflation and upon the relative variability of real output as the amount of information available to and used by a discretionary monetary authority is altered. As a result, the manner in which exogenous demand- or supply-side disturbances influence these variables in a discretionary equilibrium depends significantly upon the relative information sets of wage setters and of the monetary policy-maker.
PD December 1989. TI Discretionary Monetary Policy and Socially Efficient Wage Indexation. AU VanHoose, David D.; Waller, Christopher J. AA Indiana University. SR Federal Reserve Bank of Kansas City Research Working Paper: 89-13; Research Division, Federal Reserve Bank of Kansas City, 925 Grand Ave., Kansas City, MO 64198. PG 16. PR no charge. JE E52, J31, J41, E24. KW Monetary Policy. Wages. Wage Contracts.

AB This paper examines equilibrium and socially efficient wage indexation in a time-consistent discretionary monetary policy equilibrium. In the context of a simple model of wage indexation and discretionary monetary policy, it is demonstrated that the socially efficient degree of indexation of nominal wages to unanticipated price changes generally deviates from the equilibrium indexation choice of wage setters. The fundamental reasons for this result are that wage indexation choices influence both the behavior of a discretionary monetary authority and aggregate inflation variability and that atomistic wage setters generally do not have an incentive to take into account these externalities in their individual indexation decisions.

TI Optimal Monetary Policy in a Multisector Economy with an Economy-Wide Money Market. AU Duca, John V.; VanHoose, David D.

PD December 1989. TI Borrowed Reserves Targeting and Nominal Income Smoothing. AA Indiana University. SR Federal Reserve Bank of Kansas City Research Working Paper: 89-15; Research Division, Federal Reserve Bank of Kansas City, 925 Grand Ave., Kansas City, MO 64198. PG 24. PR no charge. JE E52, E58. KW Reserve Requirements. Borrowing. Central Bank. Federal Reserve.

AB This paper provides a theoretical analysis of the Federal Reserve's borrowed reserves targeting procedure. In the context of a model in which nonborrowed reserves are varied to achieve, on average, an intraperiod target level of borrowing that is consistent with an objective involving interperiod variability of nominal income it is demonstrated that periodic adjustments of the borrowings target generally are optimal. In turn, the amount and direction of the target adjustment is conditioned to the deviation of actual borrowings from the borrowings target set in the previous period and depends upon the values of structural parameters and the sources and magnitudes of exogenous disturbances. It is argued that actual Federal Reserve behavior is not inconsistent with these implications of the model.

\section{Vansanten, Kris}

TI Deterministic Chaos in the Foreign Exchange Market. AU De Grauwe, Paul; Vansanten, Kris.

\section{Velupillai, $\mathbf{K}$.}

TI Macroeconomic Perspectives. AU Fitoussi, J. P.; Velupillai, $\mathrm{K}$.

\section{Venables, Anthony J.}

TI Integration and the Competitiveness of Peripheral Industry. AU Krugman, Paul R.; Venables, Anthony J.

\section{Venkateswaran, $\mathbf{H}$.}

TI A Circuit-Based Proof of Toda's Theorem. AU Kannan, Ravi; Venkateswaran, H.; Vinay, V. 
Vinay, $\mathrm{V}$.

TI A Circuit-Based Proof of Toda's Theorem. AU Kannan, Ravi; Venkateswaran, H.; Vinay, V.

\section{Vincent, Daniel}

TI Delayed Agreements and Non-Expected Utility. AU Fershtman, Chaim; Safra, Zvi; Vincent, Daniel.

\section{Vives, Xavier}

PD April 1990. TI Banking Competition and European Integration. AA Universitat Autonoma de Barcelona. SR Centre for Economic Policy Research Discussion Paper: 373; Centre for Economic Policy Research, 6 Duke of York Street, London SW1Y 6LA, UNITED KINGDOM. PG 25. PR 2.00 pounds $(\$ 4.00)$. JE F36, G21, L11, L51. KW Banking. European Integration. Deregulation. Financial Integration.

AB We assess how banking competition will be affected by the process of deregulation and integration in European financial markets, drawing on the lessons of recent research in finance, banking and industrial organization. Our central thesis contends that the main effect of integration will be to change the focus of banks' strategic behavior from collusion and regulatory capture to competition. Nevertheless, competition will be imperfect due to the presence of significant economic barriers to entry, and this means that the upper bound for the benefits of integration is lower than the competitive benchmark.

\section{Vohra, Rajiv}

PD April 1990. TI Efficient Resource Allocation Under Increasing Returns. AA Brown University. SR Brown University Department of Economics Working Paper: 90-15; Department of Economics, Brown University, Providence, RI 02912. PG 33. PR no charge. JE D42, D61, D63. KW Production. Economies of Scale. Monopoly. Efficiency. Public Sector. Regulation. Resource Allocation.

AB This paper will be concerned with a theoretical analysis of the static resource allocation problem in a mixed economy of a particularly simple kind - one in which government intervention is restricted to operating an increasing returns technology in the interests of economic efficiency. It will be possible to view government intervention either as the operation of a public sector or as the regulation of a firm. In particular, we shall be concerned with the theoretical justification for regulation and an attempt to characterize the nature of regulation which is consistent with an efficient allocation of resources.

PD September 1990. TI Equity and Efficiency in NonConvex Economies. AA Brown University. SR Brown University Department of Economics Working Paper: 90-27; Department of Economics, Brown University, Providence, RI 02912. PG 24. PR no charge. JE D63, D61, E13, E23. KW Economics of Scale. Efficiency.

AB The objective of this paper is to consider the following question. Does the presence of increasing returns introduce a fundamental trade-off between equity and efficiency objectives? We show that if the envy-free notion of Foley (1967) is taken as the equity criterion and Pareto optimality as the efficiency criterion, then the answer is yes; there exist well-behaved economies with increasing returns (and no agent-specific inputs) in which there do not exist any envy-free and Pareto optimal allocations. We also propose a weakening of the envy- free criterion and prove that this weaker equity notion is compatible with Pareto optimality in general non-convex economies.

von Weizsacker, Robert $\mathrm{K}$.

TI Income Distribution and Efficiency: The Role of Social Security. AU Nerlove, Marc; Razin, Assaf; Sadka, Efraim; von Weizsacker, Robert K.

PD August 1990. TI Alterssicherung und Demographische Inzidenz: Verteilungstheoretische Konsequenzen der Rentenreform 1992. AA University of Bonn. SR Universitat Bonn Sonderforschungsbereich 303 Discussion Paper: A-307; Sonderforschungsbereich 303 an der Universitat Bonn, Adenauerallee 24-42, D-5300 Bonn 1, DEUTSCHLAND. PG 17. PR no charge. JE J14, J11, D31. KW Pensions. Demographics. Income Distribution.

AB Paper in German.

TI Tax Policy, Investments in Human and Physical Capital, and Productivity. AU Nerlove, Marc; Razin, Assaf; Sadka, Efraim; von Weizsacker, Robert K.

\section{Vuong, Quang $\mathrm{H}$.}

PD September 1989. TI Model Selection, Classical Tests, and the Comprehensive Method. AA University of Southern California. SR University of Southern California Modelling Research Group Working Paper: M8920; Department of Economics, University of Southern California, University Park, Los Angeles, CA 90089-0152. PG 45. PR no charge. JE C12, C51, C52. KW Model Selection. Non-Nested Hypotheses. Misspecification.

AB This is the first of a series of two papers that relates the model selection tests proposed in Vuong (1989) to some classical tests of a suitably defined parametric null hypothesis in the comprehensive model that nests the competing models. Using the geometry of information divergence, we show that the null hypothesis of model selection can be reformulated in terms of the I-projection of the true probability distribution generating the data on the comprehensive model. This allows us to contrast our model selection approach to that advocated by Atkinson (1970). When each competing model reduces to one distribution, we show that the test statistics proposed in our earlier paper are numerically equal to some robust Wald and LM statistics of this reformulated null hypothesis.

\section{Wales, T. J.}

TI Quadratic Spline Models for Producer Supply and Demand Functions. AU Diewert, W. E.; Wales, T. J.

\section{Waller, Christopher J.}

TI Discretion, Wage Indexation, and Inflation. AU VanHoose, David D.; Waller, Christopher J.

TI Discretionary Monetary Policy and Socially Efficient Wage Indexation. AU VanHoose, David D.; Waller, Christopher J.

\section{Walls, Margaret A.}

PD August 1989. TI Ethanol Fuel and Non-Market Benefits: Is a Subsidy Justified? AU Walls, Margaret A.; Krupnick, Alan J.; Toman, Michael A. AA Resources for the Future. SR Resources for the Future Energy and Natural Resources Division Discussion Paper: ENR89-07; Energy and 
Natural Resources Division, Resources for the Future, $1616 \mathrm{P}$ Street, NW., Washington, DC 20036, USA. PG 28. PR $\$ 5.00$ prepaid (U.S. funds only). JE H24, Q42, Q41, Q48. KW Price Supports. Energy. Subsidies. Oil. Fuel.

AB Crop-based ethanol fuel that consists of 10 percent pure ethanol and 90 percent gasoline is currently exempt from a portion of the federal gasoline excise tax. In this paper, we address two questions related to this implicit subsidization. (1) Can ethanol compete with gasoline without the subsidy? (2) Are external benefits from ethanol fuel use sufficient to justify the current federal subsidy, and even if they are, do less costly means of achieving those benefits exist? Our answer to question (1) is a clear "no" given petroleum and corn prices in today's markets. Even allowing for a possible upward distortion in corn prices due to U.S. farm support policies, ethanol is not cost competitive with gasoline. With respect to (2), it appears that any environmental or energy security benefits generated thus far from ethanol's use have been small. Moreover, less costly means of achieving these benefits are likely to exist.

\section{Wang, Hong}

TI Markets, Institutions and Technical Change: The Production and Utilization of Machine Tools in China. AU Nolan, Peter, Wang, Hong.

\section{Waterman, David}

PD August 1989. TI Diversity, Quality, and "Homogenization" of Information Products in a Monopolistically Competitive Industry. AA University of Southern California. SR University of Southern California Modelling Research Group Working Paper: M8919; Department of Economics. University of Southem California, University Park, Los Angeles, CA 90089-0152. PG 19. PR no charge. JE M37, L13, L15. KW Product Variety. Product Quality. Monopolistic Competition. Advertising.

AB In addition to price, producers of information products face two important decisions: how much to invest in the "first copy" (i.e., the production quality of a television program or computer program) and the degree to which product content should be "homogenized" to appeal to a broad vs. a narrow range of potential buyers. This paper investigates equilibrium trade-offs between these factors and product variety by introducing two new decision variables, product quality and product "content," into the framework of Salop's (1979) circular product space model of monopolistic competition. We further investigate non-price vs. price competition regimes to represent the trade-offs between advertiser supported "free" media (e.g., broadcast television) and "pay" media (e.g., cable television").

\section{Watson, Mark W.}

PD May 1991. TI Measures of Fit for Calibrated Models. AA Northwestern Universily, Federal Reserve Bank of Chicago, and National Bureau of Economic Research. SR National Bureau of Economic Research Technical Paper: 102; National Bureau of Economic Research, 1050 Massachusetts Avenue, Cambridge, MA 02138. PG not available. PR \$2.00. JE C22, C52. KW Time Series. Dynamic Model.

AB This paper develops a new procedure for assessing how well a given dynamic economic model describes a set of economic time series. To answer the question, the variables in the model are augmented with just enough error so that the model can exactly mimic the second moment properties of the actual data. The properties of this error provide a useful diagnostic for the economic model, since they show the dimensions in which the model fits the data relatively well and the dimensions in which it fits the data relatively poorly.

\section{Weber, Guglielmo}

TI Consumer Expenditure Survey Database. AU Attanasio, Orazio P.; Koujianou, Penny; Weber, Guglielmo.

\section{Weber, Robert J.}

PD March 1991. TI Equilibrium in Non-Partitioning Strategies. AA Northwestern University. SR Northwestern Center for Mathematical Studies in Economics and Management Science Working Paper: 929; Northwestern University, 2001 Sheridan Road, 3-014 Leverone Hall, Evanston, IL 60208-2014. PG 10. PR $\$ 3.00$ in the U.S. or Canada; $\$ 5.00$ via international mail. Make check payable to Northwestern University. JE D82, D44, C78. KW Incomplete Information. Auctions.

AB Herein we present a single example with three purposes: (1) to show the existence of equilibria in a game which violates the assumptions of currently-available general existence theorems, (2) to illustrate the importance of the "affiliation" assumption in economic games of incomplete information, by showing how even a slight relaxation can lead to the nonexistence of equilibria in monotone strategies, and, most importantly, (3) to exhibit an equilibrium point in strategies which partially reveal information without inducing posterior partitionings of the players' type spaces.

\section{Weber, Shlomo}

PD February 1990. TI An Equivalence Result for the Core of an Economy with a Public Good. AU Weber, Shlomo; Wiesmeth, Hans. AA Weber: York University. Wiesmeth: University of Bonn. SR Universitat Bonn Sonderforschungsbereich 303 - Discussion Paper: A-282; Sonderforschungsbereich 303 an der Universitat Bonn, Adenauerallee 24-42, D-5300 Bonn 1, DEUTSCHLAND. PG 26. PR no charge. JE D51, H41, D61. KW Core. Public Good. Finite Economy.

AB The central result of this paper is a refinement of an equivalence theorem in Mas-Colell (1980) for the core of a finite economy with a public good. It is shown that an allocation belongs to the core if and only if it is a cost share equilibrium. A further characterization of core elements which can be supported by a strictly monotonic cost sharing method is also provided. An application of these results allows a complete characterization of core allocations which can be supported by a linear cost share system. The set of linear cost share equilibria, which are in one-to-one correspondence with the Lindahl-Foley equilibria, is determined by uniform upper and lower bounds on the elasticity of substitution for the public good. In contrast to cost share equilibria, Lindahl-Foley equilibria are based on profit maximization.

\section{Weil, David N.}

TI A Contribution to the Empirics of Economic Growth. AU Mankiw, N. Gregory; Romer, David; Weil, David N.

\section{Weiss, Yoram}

TI Staggered and Synchronized Price Policies under Inflation: The Multi-Product Monopoly Case. 
AU Sheshinski, Eytan; Weiss, Yoram.

Welsh, D. J. A.

PD October 1990. TI Colouring and Knot Polynomials. AA University of Oxford and University of Bonn. SR Universitat Bonn Sonderforschungsbereich 303. Discussion Paper: 90664-OR; Sonderforschungsbereich 303 an der Universitat Bonn, Adenauerallee 24-42, D-5300 Bonn 1, DEUTSCHLAND. PG 20. PR no charge. JE C61, C63, C60. KW Graph Theory. Knot Theory. Statistical Physics. Combinatorics. Tutte Polynomial.

AB These lectures will attempt to explain a connection between the recent advances in knot theory using the Jones and related knot polynomials with classical problems in combinatorics and statistical mechanics. The difficulty of some of these problems will be analyzed in the context of their computational complexity. In particular, we shall discuss: (i) colourings and group valued flows in graphs, (ii) knots and the Jones and Kauffman polynomials, (iii) the Ising, Potts and percolation problems of statistical physics, and the (iv) computational complexity of the above problems.

\section{Weymark, John A.}

PD January 1990. TI A Reconsideration of the Harsanyi-Sen Debate on Utilitarianism. AA University of British Columbia. SR University of British Columbia Department of Economics Discussion Paper: 90-03; University of British Columbia, \#997-1873 East Mall, Vancouver, BC V6T IW5, CANADA. PG 80. PR $\$ .20$ per page Canadian to other than educational institutions. JE D71, D60. KW Expected Utility Hypothesis. Social Choice.

AB The first part of this article reviews John Harsanyi's expected utility based defences of utilitarianism. The second part of this article considers Amartya Sen's argument that Harsanyi's theorems are merely social representation theorems, and not theorems about utilitariansim. It is argued that Sen is correct in his criticism of Harsanyi if utility only has meaning as a representation of preference. However, it is shown that it is possible to provide a utilitarian interpretation to Harsanyi's theorems if utility does not simply measure preference.

\section{White, Betsy Buttrill}

TI The U.S. Financial System: A Status Report and a Structural Perspective. AU Akhtar, M. A.; White, Betsy Buttrill.

\section{White, Halbert}

PD August 1988. TI The Encompassing Principle for Non-Nested Dynamic Model Specification. AA University of California, San Diego. SR University of California at San Diego Department of Economics Discussion Paper: 88-41; Department of Economics, 0508, University of California at San Diego, La Jolla, CA 92093. PG 32. PR \$2.00; Checks payable to UC Regents. JE C51, C12, C13. KW NonNested Models. Specification Testing. M-Tests. Model Selection. Encompassing Tests. Hypothesis Testing.

AB We show that encompassing tests can be conveniently viewed as $\mathrm{m}$-tests, and we investigate their use for specification testing and model selection in dynamic contexts. This permits straightforward derivation of the asymptotic distribution of encompassing tests under null and locally alternative hypotheses, regardless of whether or not the asymptotic covariance matrix is consistently estimated. Estimation of the asymptotic covariance matrix is a particular challenge in dynamic contexts, as it generally must be autocorrelationconsistent. We also briefly discuss the use of encompassing tests (e.g., the Cox test of non-nested hypotheses) for model selection, and argue that while such tests cannot be used by themselves, they have an important role to play in conjunction with other specification tests.

\section{White, Kenneth J.}

PD February 1990. TI The Durbin-Watson Test for Autocorrelation in Nonlinear Models. AA University of British Columbia. SR University of British Columbia Department of Economics Discussion Paper: 90-04; University of British Columbia, \#997-1873 East Mall, Vancouver, BC V6T 1W5. CANADA. PG 11. PR \$.20 per page Canadian to other than educational institutions. JE C22, C12, C52. KW Nonlinear Model. Hypothesis Testing. Autocorrelation.

AB This paper shows a simple method for approximating the exact distribution of the Durbin-Watson test statistic for firstorder autocorrelation in a nonlinear model. The proposed Approximate Nonlinear Durbin-Watson (AND) test has good size and power when compared to alternatives.

\section{White, Lawrence J.}

PD 1990. TI The Debacle of the S\&Ls in the United States: Some Cautionary Lessons for the Regulation of Financial Institutions. AA New York University. SR New York University Salomon Brothers Center Working Paper: S90-25; Salomon Brothers Center for the Study of Financial Institutions, Graduate School of Business Administration, New York University, 90 Trinity Place, New York, NY 10006. PG 25. PR $\$ 5.00$. JE G21, G28. KW Banking. Regulation. Banking Crisis. Thrifts.

AB The insolvencies of hundreds of savings and loan associations (S\&Ls or thrifts) in the United States in the late 1980s has been a searing event for regulators, politicians, and owners and managers of thrifts. The costs of these insolvencies will be huge and will largely be borne by the U.S. taxpayers. The complete story of this debacle -- what happened, why it happened, how it happened, and what must be done to ensure that it never happens again -- is still not well understood. This paper will attempt to provide a brief review of the story of the S\&L debacle and extract the important lessons from it.

\section{White, Michelle J.}

TI Medical Malpractice: An Empirical Examination of the Litigation Process. AU Farber, Henry S.; White, Michelle J.

\section{Wiesmeth, Hans}

TI An Equivalence Result for the Core of an Economy with a Public Good. AU Weber, Shlomo; Wiesmeth, Hans.

\section{Willig, Robert D.}

TI Economic Rationales for the Scope of Privatization. AU Shapiro, Carl; Willig, Robert D.

\section{Winters, L. Alan}

TI Labour Adjustment Costs and British Footwear Protection. AU Takacs, Wendy E; Winters, L. Alan.

Winters, P. A.

PD January 1990. TI Non-Tariff Barriers and Rationing: 
U.K. Footwear Imports. AU Winters, P. A.; Brenton, L. Alan. AA University College of North Wales. SR Centre for Economic Policy Research Discussion Paper: 365; Centre for Economic Policy Research, 6 Duke of York Street, London SWIY 6LA, UNITED KINGDOM. PG 58. PR 2.00 pounds (\$4.00). JE D12, F13, F17, L67. KW Trade Policy. Quantity Restraints. Imports. Consumer Demand.

AB The imposition of a quantitative restriction on imports implies that someone somewhere is quantity-rationed. If prices rise to cut demand back to the constraint level, suppliers are rationed; if not, demanders are. In this paper we developed a means of identifying if and when consumers are rationed and of allowing for this in the estimation of demand equations and in the calculation of welfare effects. By way of example we consider the effects of the various non-tariff barriers that have affected imports of different types of footwear from certain suppliers into the U.K.

\section{Wolinsky, Asher}

TI Renegotiation-Proof Implementation and Time Preferences. AU Rubinstein, Ariel; Wolinsky, Asher.

TI Rationalizable Conjectural Equilibria: Between Nash and Rationalizability. AU Rubinstein, Ariel; Wolinsky, Asher.

\section{Wood, Peter}

PD May 1990. TI Small Firms, Business Services and Flexibility. AA University College London. SR University of Cambridge Small Business Research Centre Working Paper: 3; Department of Applied Economics, University of Cambridge, Sidgwick Avenue, Cambridge CB3 9DE, UNITED KINGDOM. PG 36. PR $\$ 5.00 \quad(2.50$ pounds); checks payable to University of Cambridge. JE L86, L11, L16. KW Business Services. Information Services. Firm Size. Market Concentration.

AB Reviews the economic role of information-based business services, which offer expertise in close integration with the in-house service and production functions of customer organizations. Like all services this role should be assessed through the productive contribution they make to clients' activities. Specialization of expertise often favors small firms, frequently operating in competition with a client's own inhouse service functions, as well as with other service firms. Services are also distinct from goods in their relationship to technological change. They are defined by the manner of their use, rather than production, and therefore possess no core technology. Pressures towards more capital intensive service production also generate new needs for specialized services and encourages firms to adapt towards more protected "niche" markets.

TI Small Firms, Business Services Growth and Regional Development in the U.K.: Some Empirical Findings. AU Keeble, David; Bryson, John; Wood, Peter.

\section{Wooldridge, Jeffrey $M$.}

PD September 1990. TI Distribution-Free Estimation of Some Nonlinear Panel Data Models. AA Massachusetts Institute of Technology. SR Massachusetts Institute of Technology Department of Economics Working Paper: 564; Department of Economics, Massachusetts Institute of Technology, Cambridge, MA 02139. PG 37. PR $\$ 6.00$ Domestic, $\$ 8.00$ Overseas, $\$ 2.00$ Student. JE C23, C13, C51. KW Panel Data. Unobserved Effects. Nonlinear Model.
AB The notion of a conditional linear predictor is used as a distribution-free method for eliminating the individual-specific effects in a class of nonlinear, unobserved components panel data models. The methodology is applied to a general count model, which allows for individual dispersion in addition to an individual mean effect. As a corollary of the general results, the multinomial quasi-conditional maximum likelihood estimator is shown to be consistent and asymptotically normal when only the first two moments in the unobserved effects model have been correctly specified. This has important implications for analyzing count data in panel contexts. Simple, robust specification tests for this class of count models are also developed.

\section{Worthington, Paula R.}

PD June 1990. TI Investment and Market Power: Evidence from the United States Manufacturing Sector. AA Federal Reserve Bank of New York. SR Federal Reserve Bank of New York Research Paper: 9015; Federal Reserve Bank of New York, 33 Liberty St., Rm. 901, New York City, New York 10045. PG 28. PR no charge. JE L11, L20, L52, L60. KW Manufacturing. Market Power. Investment. Adjustment Costs.

AB This paper presents theoretical and empirical evidence of a relationship between market power and investment. An adjustment cost model is used to show that non-price-taking behavior within an industry affects the industry's optimal capital stock choices. Annual data from the U.S. manufacturing sector at the four-digit SIC level are used to estimate relationships between investment variability and seller concentration within an industry. The empirical results suggest that seller concentration is weakly and positively related to investment variability, and that demand, financial, and capital cost factors are important determinants of investment variability.

\section{Xiaoli, Li}

TI The Trend and the Model Schedule of Leaving the Parental Home After Marriage in China. AU Yi, Zeng; Xiaoli, Li; Zhongdong, Ma.

\section{Yang, Jeong-Ae}

TI An N-Person Pure Bargaining Solution. AU Chae, Suchan; Yang, Jeong-Ae.

\section{Yi, Jong Goo}

TI The Role of Precedent in Repeated Litigations. AU Che, Yeon Koo; Yi, Jong Goo.

TI Litigations with Multiple Plaintiffs: The Case of Effort Externality. AU Che, Yeon Koo; Yi, Jong Goo.

\section{Yi, Zeng}

PD September 1990. TI The Trend and the Model Schedule of Leaving the Parental Home After Marriage in China. AU Yi, Zeng; Xiaoli, Li; Zhongdong, Ma. AA not available. SR Yale Economic Growth Center Discussion Paper: 616; Economic Growth Center, Yale University, Box 1987 Yale Station, New Haven, Connecticut 06520. PG 31. PR $\$ 2.00$ plus postage. JE J11, J12, O53. KW Marriage. Households. Children. Labor Force. China.

AB The changes in the pattern of leaving the parental home are directly linked to changes in the patterns of marriage, 
childbearing, labor force participation and the number, size and structure of the family/household. Thus, it is linked to the social/economic planning of the welfare system as well as the demand/supply of housing and goods for household consumption. This paper tries to investigate this important issue to the Chinese context. Based on the relevant survey data from the twelve Chinese provinces/municipalities and following a life table analysis approach, this study found that the percentage of the couples living with either the husband's parents or the wife's parents at the time of the marriage has been significantly increasing in almost all of the surveyed mainland provinces.

\section{Young, Alwyn}

PD May 1991. TI Invention and Bounded Learning by Doing. AA Massachusetts Institute of Technology. SR National Bureau of Economic Research Working Paper: 3712; National Bureau of Economic Research, 1050 Massachusetts Avenue, Cambridge, MA 02138. PG not available. PR \$2.00. JE O31, O41. KW Technology. Innovation. Growth Model. Industrialization.

AB This paper presents a model of the interaction between invention and learning by doing. Learning depends upon invention in that learning by doing is viewed as the serendipitous exploration of the finite productive potential of invented technologies. At the same time, the profitability of costly invention is dependent upon learning in that costs of production depend upon the society's aggregate historical leaming experience. The resulting model is a true hybrid. With small markets, the profitability of invention is low, and hence the rate of invention becomes the constraining factor in growth. With large markets, invention is very profitable and tends to pull ahead of the society's learning experience.

\section{Yuengert, Andrew M.}

PD August 1989. TI Estimating Immigrant Assimilation Rates with Synthetic Panel Data. AA Yale University. SR Yale Economic Growth Center Discussion Paper: 580; Economic Growth Center, Yale University, 27 Hillhouse Avenue, New Haven, CT 06520. PG 38. PR $\$ 2.00+$ Postage. JE F22, J31, E24. KW Immigration. Migration. Wages.

AB Biases on OLS estimates of the return to education can also affect estimates of relative earnings. This paper explores the extent of bias in the OLS measurements of immigrant relative earnings, using a synthetic panel of immigrants from the 1970 and 1980 Censuses. Synthetic panel estimates imply that OLS underestimates relative immigrant earnings in both 1970 and 1980. Rates of relative earnings growth for newly arrived immigrants are often large and significantly positive. Assimilation rates for immigrant groups who have been in the country longer are smaller and often insignificant, but these are mostly groups who had already surpassed native earnings in 1970.

PD August 1989. TI Self-Employment and the Eamings of Male Immigrants in the U.S. AA Yale University. SR Yale Economic Growth Center Discussion Paper: 581; Economic Growth Center, Yale University, 27 Hillhouse Avenue, New Haven, CT 06520. PG 48. PR $\$ 2.00+$ Postage. JE F22, J31, E24, J21. KW Immigration. Migration. Wages. Self-Employment.

AB Immigrants enter self-employment more often than native workers; comparisons of immigrant and native earnings must somehow incorporate the self-employed. A two-sector model is used to test several theories of immigrant selfemployment; the model provides no evidence of selection into either sector, but rejects the equality of wage and selfemployment earnings functions. Incorporating these results, estimates of immigrant earnings growth are calculated. They suggest that self-employed immigrant assimilation rates are higher than wage-employed rates. When an immigrant groups contains lots of self-employed workers, excluding them will bias downwards estimates of immigrant assimilation.

PD February 1991. TI Self-Employment and the Earnings of Male Immigrants in the U.S.. AA Federal Reserve Bank of New York. SR Federal Reserve Bank of New York Research Paper: 9105; Federal Reserve Bank of New York, 33 Liberty St., Rm. 901, New York City, New York 10045. PG 50. PR no charge. JE J24, J31, C34. KW Wages. Immigrants.

AB Previous estimates of immigrant assimilation rates have either excluded self-employed workers, or have included them without concern for the economic processes generating sector choice and earnings. This paper argues that, in order to understand more fully the labor market adjustments of U.S. immigrants, one must better understand why they choose selfemployment more often than the native-borm. In the framework of a switching regression model of sectoral choice and earnings, three hypotheses of immigrant self employment are tested. In light of these estimates, measures of immigrant earnings growth which incorporate the self-employed sector are calculated.

PD February 1991. TI Estimating Immigrant Assimilation Rates with Synthetic Panel Data. AA Federal Reserve Bank of New York. SR Federal Reserve Bank of New York Research Paper: 9104; Federal Reserve Bank of New York, 33 Liberty St., Rm. 901, New York City, New York 10045. PG 36. PR no charge. JE F22, J61, J31, C23. KW Immigrants. Wages.

AB Much of the recent literature on U.S. immigrant assimilation rates is based on an OLS methodology which is vulnerable to biases from left-out variables. A synthetic panel, created from the 1970 and 1980 U.S. Census, is used to generate unbiased estimates of relative earnings and earnings growth rates during the 1970's for a number of different U.S. immigrant groups. OLS estimates of immigrant relative earnings, calculated from the same Census data, generally underestimate relative immigrant earnings in both 1970 and 1980, and relative earnings growth. The largest rates of relative earnings growth are found among newly arrived immigrants.

\section{Zeckhauser, Richard J.}

TI Advertising and the Price, Quantity and Quality of Primary Care Physician Services. AU Rizzo, John A.; Zeckhauser, Richard J.

\section{Zeng, Langche}

PD June 1990. TI A Heteroskedastic Logit Model. AA California Institute of Technology. SR Caltech Social Science Working Paper: 756; Division of Humanities and Social Sciences, 228-77, California Institute of Technology, Pasadena, CA 91125. PG 14. PR no charge. JE C13, C25, C12, C51. KW Heteroskedasticity. Logit Model.

AB This paper extends the Generalized Extreme Value model to allow heteroskedasticity across alternatives as well as across 
individuals. The nested multinomial logit model is further generalized to relax the restriction that the similarity parameters are constant across the population. Estimation techniques are discussed and statistical tests for violation of the standard assumptions of the existing models are developed.

TI The Heterogeneous Logit Model. AU Dubin, Jeffrey A.: Zeng, Langche.

\section{Zhongdong, Ma}

TI The Trend and the Model Schedule of Leaving the Parental Home After Marriage in China. AU Yi, Zeng; Xiaoli, Li; Zhongdong, Ma.

\section{Zilcha, Itzhak}

TI Two-Country Firm: Exchange Rate Uncertainty and Futures Markets. AU Broll, Udo; Zilcha, Itzhak.

PD August 1990. TI Characterizing Efficiency in Stochastic Overlapping Generations Models. AA Tel Aviv University, SR Tel Aviv Foerder Institute for Economic Research Working Paper: 16-90; Department of Economics, Tel Aviv University, Ramat Aviv 69978, Tel Aviv, ISRAEL. PG 26. PR no charge. JE D61, D81, D90, D58. KW Uncertainty. Production. Efficient Allocations. Stochastic Model.

AB We introduce uncertainty about production in Diamond's OLG model. We compare any two feasible consumptionproduction allocations using stochastic ordering and define two types of efficient allocations (given initial capital stock). For stationary allocations it is shown that efficiency (type-I) is equivalent to $E[\log r(w)]$ greater than or equal to 0 where $r(w)$ generates the stationary interest factors corresponding to this allocation ( 0 is the population growth rate). We also derive a complete characterization of type-II efficient allocations. Later we generalize this characterization of efficiency results to nonstationary allocations.

TI Bargaining Solutions without the Expected Utility Hypothesis. AU Safra, Zvi; Zilcha, Itzhak.

\section{Zwanziger, Jack}

PD October 1988. TI The Effects of Hospital Competition and the Medicare PPS Program on Hospital Cost Behavior in California. AU Zwanziger, Jack; Melnick, Glenn A. AA Rand Corporation. SR Rand Note: N-3049; The Rand Corporation, 1700 Main Street, P.O. Box 2138, Santa Monica, CA 90406-2138. PG 20. PR not available. JE I11. KW Health Care. Hospitals. Medical Costs.

AB Previous studies of hospital competition have found that greater competition leads to higher hospital costs. In this note the authors report how the behavior of California's hospitals has changed since the introduction of programs intended to contain the rate of increase of hospital costs. Using data that cover the period preceding and following the introduction of these programs, they found that hospitals in more competitive markets have lowered their costs significantly.

\section{Zyka, Ondrej}

TI On the Computational Complexity of Seidel's Switching.

AU Kratochvil, Jan; Nesetril, Jaroslav; Zyka, Ondrej. 